

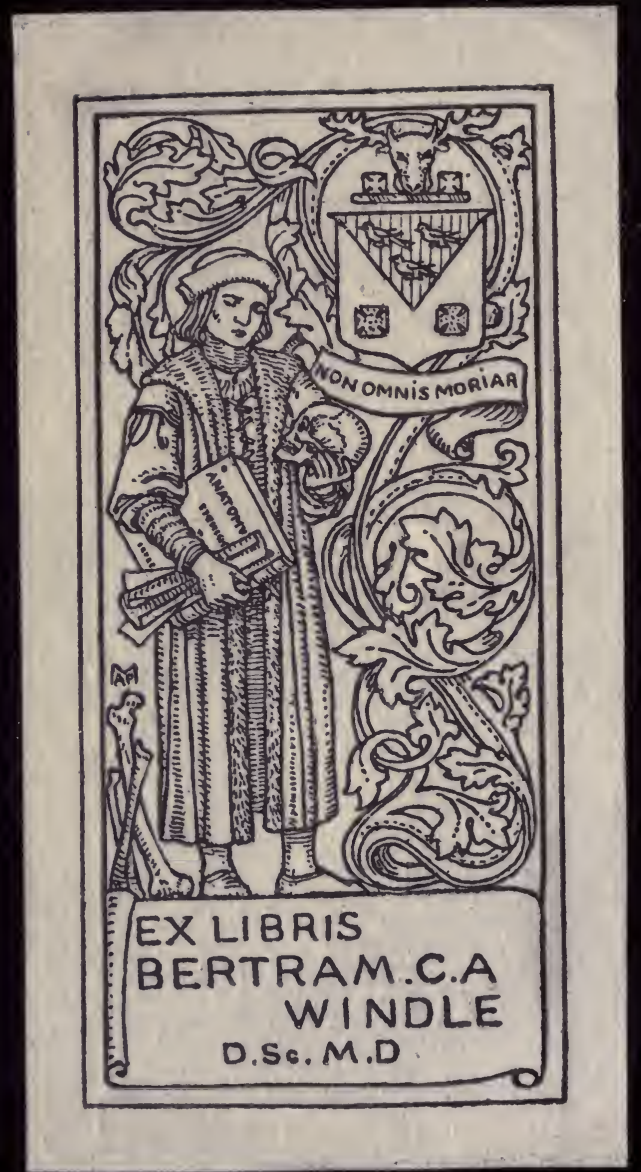





\section{STUDIES IN THE THEORY}

\section{OF DESCENT}

BY

DR. AUGUST WEISMANN

PROFESSOR IN THE UNIVERSITY OF FREIBURG

WITH NOTES AND ADDITIONS BY THE AUTHOR

TRANSLATED AND EDITED, WITH NOTES, BY

RAPHAEL MELDOLA, F.C.S.

LATE VICE-PRESIDENT OF THE ENTOMOLOGICAL SOCIETY OF LONDON

WI'H A PREFATORY NOTICE BY

C H A R L E S A R W I N, LL.D., F.R S. Author of "The Origin of Species," Eoc.

IN TWO VOLUMES

VOL. I.

WITH EIGHT COLOUREI PLATES

בnondon:

SAMPSON LOW, MARSTON, SEARLE, \& RIVINGTON CROWN BUILDINGS, I88, FLEET STREET

I 882

[All rights reserved.] 
Digitized by the Internet Archive in 2007 with funding from Microsoft Corporation 


\section{PREFATORY NOTICE.}

THE present work by Professor Weismann, well known for his profound embryological investigations on the Diptera, will appear, I believe, to every naturalist extremely interesting and well deserving of careful study. Any one looking at the longitudinal and oblique stripes, often of various and bright colours, on the caterpillars of Sphinxmoths, would naturally be inclined to doubt whether these could be of the least use to the insect; in the olden time they would have been called freaks of Nature. But the present book shows that in most cases the colouring can hardly fail to be of high importance as a protection. This indeed was proved experimentally in one of the most curious instances described, in which the thickened anterior end of the caterpillar bears two large ocelli or eye-like spots, which give to the creature so formidable an appearance that birds were frightened away. But the mere explanation of the colouring of these caterpillars is but a very small part of the merit of the work. This mainly consists in the light thrown on the 
laws of variation and of inheritance by the facts given and discussed. There is also a valuable discussion on classification, as founded on characters displayed at different ages by animals belonging to the same group. Several distinguished naturalists maintain with much confidence that organic beings tend to vary and to rise in the scale, independently of the conditions to which they and their progenitors have been exposed; whilst others maintain that all variation is due to such exposure, though the manner in which the environment acts is as yet quite unknown. At the present time there is hardly any question in biology of more importance than this of the nature and causes of variability, and the reader will find in the present work an able discussion on the whole subject, which will probably lead him to pause before he admits the existence of an innate tendency to perfectibility. Finally, whoever compares the discussions in this volume with those published twenty years ago on any branch of Natural History, will see how wide and rich a field for study has been opened up through the principle of Evolution; and such fields, without the light shed on them by this principle, 'would for long or for ever have remained barren.

Charles Darivin. 


\section{TRANSLATOR'S PREFACE.}

IN offering to English readers this translation of Professor Weismann's well-known "Studies in the Theory of Descent," the main part of which is devoted to entomological subjects, I have been actuated by the desire of placing in the hands of English naturalists one of the most complete of recent contributions to the theory of Evolution as applied to the elucidation of certain interesting groups of facts offered by the insect world. Although many, if not most, working naturalists are already familiar with the results of Dr. Weismann's researches, of which abstracts have from time to time appeared in English and American scientific journals, I nevertheless believe that a study of the complete work, by enabling the reader to follow closely the detailed lines of reasoning *and methods of experiment employed by the author, will be found to be of considerable value to those biologists who have not been able to follow the somewhat difficult phraseology of the original. It is not my intention, nor would it be becoming in me to discuss here the merits of 
the results arrived at by the minute and laborious investigations with which Dr. Weismann has for many years occupied himself. I may however point out that before the appearance of the present work the author, in addition to his wellknown papers on the embryology and develop. ment of insects, had published two valuable contributions to the theory of descent, viz. one entitled "Über die Berechtigung der Darwin'schen Theorie" (I 868), and another "Über den Einfluss der Isolirung auf die Artbildung" (1872). These works, which are perhaps not so well known in this country as could be desired, might be advantageously studied in connection with the present volume wherein they are frequently referred to.

Since every new contribution to science is a fresh starting-point for future work, I may venture without any great breach of propriety to dwell briefly upon one or two of the main points which appear to me to be suggested by Prof. Weismann's investigations.

Although the causes of Glacial Epochs is a subject which has much occupied the attention of geologists and physiographers, the question is one of such great complexity that it cannot yet be regarded as finally settled. But apart from the question of causes-a most able discussion of which is given by the author of "Island Life"there is not the least doubt that at no very distant geological period there occurred such an 
epoch, which, although intermittent, was of considerable duration. The last great geological event which our globe experienced was in fact this Ice Age, and the pure naturalist has not hitherto attributed in my opinion sufficient importance to the direct modifying effects of this prolonged period of cold. It is scarcely possible that such a vast climatic change as that which came on at the close of the Pliocene Period should have left no permanent effect upon our present fauna and flora, all the species of which have survived from the glacial age. The great principle of Natural Selection leads us to see how pre-glacial forms may have become adapted to the new climatic conditions (which came on gradually) by the "survival of the fittest" or "indirect equilibration." The influence of the last Glacial Epoch as a factor in determining the present geographical distribution of animals and plants has already been amply treated of by many writers since the broad paths were traced out by Darwin, Lyell, and Wallace. The last named author has indeed quite recently discussed this branch of the subject most exhaustively in his work on "Island Life" above mentioned. The reference of a particular group of phenomenathe seasonal dimorphism of butterflies-to the direct action of the Glacial Period and the subsequent influence of the ameliorating climate, was however the first step taken in this neglected 
field by the author of the present work in 1875 . It is possible, and indeed probable, that future researches will show that other characters among existing species can be traced to the same causes.

The great generalizations of embryology, which science owes so largely to the researches of Karl Ernst von Baer, bear to the theory of descent the same relations that Kepler's laws bear to the theory of gravitation. These last-named laws are nothing more than generalized statements of the motions of the planets, which were devoid of meaning till the enunciation of the theory of gravitation. Similarly the generalized facts of embryology are meaningless except in the light of the theory of descent. It has now become a recognized principle in biology that animals in the course of their development from the ovum recapitulate more or less completely the phases through which their ancestors have passed. The practical application of this principle to the determination of the line of descent of any species or group of species is surrounded by difficulties, but attempts have been made of late years-as by Haeckel in his Gastrula theory-to push the law to its legitimate consequences. In this country Sir John Lubbock, in 1874, appealed to the embryonic characters of larvæ in support of his views on the origin of insects. To the author of this work $(1876)$ is due the first application of the principle of Ontogeny as revealing 
the origin of the markings of caterpillars. A most valuable method of research is thus opened up, and entomologists should not be long in availing themselves of it. Our knowledge of the subject of larval development in Lepidoptera is still most imperfect, and it cannot as yet be foreseen to what extent the existing notions of classification in this much-studied order may have to be modified when a minute study of the Comparative Ontogeny of larval characters, worked out as completely as possible for each family, has enabled a true genealogical system to be drawn up. The extent to which such a larval genealogy would coincide with our present classification cannot now be decided, but he who approaches this fruitful line of inquiry in the true spirit of an investigator, will derive much instruction from Prof. Weismann's remarks on "Phyletic Parallelism in Metamorphic Species." The affinities of the larger groups among Lepidoptera would most probably be made out once and. for ever if systematists would devote more time to observation in this field, and to the co-ordination and working up of the numerous data scattered throughout the vast number of entomological publications.

The doctrine of development by no means implies, as has sometimes been maintained, a continuous advancement in organization. Although the scale of organic nature has continued 
to rise as a whole, cases may occasionally occur where a lower grade of organization is better adapted to certain conditions of life. This principle of "degeneration" was recognized by Darwin as early as in the first edition of the "Origin of Species ;" it was soon perceived to be applicable to the phenomenon of parasitism, and was first definitely formulated by Dr. Anton Dohrn in 1875 . In a lecture delivered before the British Association at Sheffield in 1879, Prof. E. Ray Lankester ascribed to "degeneration" a distinct and well-defined function in the theory of descent. Dr. Weismann's explanation of the transformation of Axolotl given in the fourth essay of this work, may be regarded as a special contributiom to this phase of Darwinism. Whilst refuting the idea held by certain naturalists, that such cases are arguments against the origin of species by the accumulation of minute variations, and prove the possibility of development per saltum, the theory here advanced (that Siredon at a former period existed at a higher stage of development as Amblystoma, and that the observed cases of metamorphosis are but reversions to this lost higher stage) suggests the question whether there may not still be in existence many other degenerated forms quite unsuspected by naturalists.

Many of the opponents of Evolution have from time to time denounced this doctrine as leading 
to "pure materialism," a denunciation which may appear somewhat alarming to the uninitiated, but which may not seem fraught with any serious consequences to those who have followed the course of philosophical speculation during the last few years. Those who attack the doctrine on this ground will however do well to consider Prof. Weismann's views set forth in the last essay in this volume, before hastily assuming that the much dreaded "materialism" is incompatible with any other conception of Nature.

The small amount of leisure time which I have been able to devote to the translation of this volume has delayed its completion considerably beyond the anticipated time, and it was with a view to meeting this difficulty that I departed from the original form of the German edition and issued it in parts. Owing to the extremely idiomatic character of the German text, I have throughout endeavoured to preserve only the author's meaning, regardless of literal translation or of the construction of the original. In some few cases, however, I have intentionally adopted literal translations of certain technical expressions which might, I think, be advantageously introduced into our biological vocabularies. Some alterations have been made in the original text by the author for the present edition, and many new notes have been added. For those bearing my initials I am alone responsible. 
It gives me much pleasure in conclusion to express my thanks to Dr. Weismann, not only for the readily given permission to publish an English translation of his work, but also for much valuable assistance during the execution of the task. The author has been good enough to superintend the drawing of the plates for this edition, and he has also read through the greater part of the manuscript. From Mr. Darwin also I have received much kindly encouragement, and among entomologists I am especially indebted to Mr. W. H. Edwards of West Virginia, for his valuable additions to the first part. To my friends Mr. A. G. Butler, Mr. Roland Trimen, and Mr. F. Moore, I owe acknowledgments for much useful information concerning the caterpillars of exotic Sphingida, which I have incorporated in the notes and appendices, and Mr. W. S. Simpson has given me occasional advice in the translation of some of the more difficult passages.

R. M.

London, November, i 88 I. 


\section{PREFACE TO THE ENGLISH EDITION.}

With the appearance of Charles Darwin's work "On the Origin of Species," in the year I858, there commenced a new era in biology. Weary of the philosophical speculations which, at the beginning of this century, had at first been started wiit moderation but had afterwards been pushed to excess, biologists had entirely let drop all general questions and confined themselves to special investigations. The consideration even of general questions had quite fallen into disuse, and the investigation of mere details had led to a state of intellectual shortsightedness, interest being shown only for that which was immediately in view. Immense numbers of detailed facts were thus accumulated, but they could not possibly be mastered; the intellectual bond which should have bound them together was wanting.

But all this was changed in a short time. At first only single and mostly the younger naturalists fell in with the new theory of development proclaimed by Darwin, but the conviction soon became general that this was the only scientifi- 
cally justifiable hypothesis of the origin of the organic world.

The materials accumulated in all the provinces of biology now for the first time acquired a deeper meaning and significance; unexpected inter-relations revealed themselves as though spontaneously, and what formerly appeared as unanswerable enigmas now became clear and comprehensible. Since that time what a vast modification has the subject of animal embryology undergone; how full of meaning appear the youngest developmental stages, how important the larvæ; how significant are rudimentary organs; what department of biology has not in some measure become affected by the modifying influence of the new ideas!

But the doctrine of development not only enabled us to understand the facts already existing; it gave at the same time an impetus to the acquisition of unforeseen new ones. If at the present day we glance back at the development of the biological sciences within the last twenty years, we must be astonished both at the enormous array of new facts which have been evoked by the theory of development, and by the immense series of special investigations which have been called forth by this doctrine.

But while the development theory for by far the greater majority of these investigations served as a light which more and more illuminated the 
darkness of ignorance, there appeared at the same time some other researches in which this doctrine itself became the object of investigation, and which were undertaken with a view to establish it more securely.

To this latter class of work belong the "Studies" in the present volume.

It will perhaps be objected that the theory of descent has already been sufficiently established by Darwin and Wallace. It is true that their newly-discovered principle of selection is of the very greatest importance, since it solves the riddle as to how that which is useful can arise in a purely mechanical way. Nor can the transforming influence of direct action, as upheld by Lamarck, be called in question, although its extent cannot as yet be estimated with any certainty. The secondary modifications which Darwin regards as the consequence of a change in some other organ must also be conceded. But are these three factors actually competent to explain the complete transformation of one species into another? Can they transform more than mere single characters or groups of characters? Can we consider them as the sole causes of the regular phenomena of the development of the races of animals and plants ? Is there not perhaps an unknown force underlying these numberless developmental series as the true motor power-a "developmental force" urging species to vary in certain directions and thus 
calling into existence the chief types and subtypes of the animal and vegetable kingdoms?

At the time these "Studies" first appeared (1875) they had been preceded by a whole series of attempts to introduce into science such an unknown power. The botanists, Nägeli and Askenasy, had designated it the "perfecting principle" or the "fixed direction of variation;" Kolliker as the "law of creation ;" the philosophers, Von Hartmann and Huber, as the "law of organic development," and also "the universal principle of organic nature."

It was thus not entirely superfluous to test the capabilities of the known factors of transformation. We had here before us a question of the highest importance-a question which entered deeply into all our general notions, not only of the organic world, but of the universe as a whole.

This question-does there exist a special "developmental force"?-obviously cannot be decided by mere speculation; it must also be attempted to approach it by the inductive method.

The five essays in this volume are attempts to arrive, from various sides, somewhat nearer at a solution of the problem indicated.

The first essay on the "Seasonal Dimorphism of Butterflies" is certainly but indirectly connected with the question; it is therein attempted to discover the causes of this remarkable dimorphism, and by this means to indicate at the same time 
the extent of one of the transforming factors with reference to a definite case. The experiments upon which I base my views are not as numerous as I could desire, and if I were now able to repeat them they would be carried out more exactly than was possible at that time, when an experimental basis had first to be established. In spite of this, the conclusions to which I was led appear to be on the whole correct. That admirable and most conscientious observer of the North American butterflies, Mr. W. H. Edwards, has for many years experimented with American species in a manner similar to that which I employed for European species, and his results, which are published here in Appendix II. to the first essay, contain nothing as far as I can see which is not in harmony with my views. Many new questions suggest themselves, however, and it would be a grateful task if some entomologist would go further into these investigations.

The second essay directly attacks the main problem above indicated. It treats of the "Origin of the Markings of Caterpillars," and is to some extent a test of the correctness and capabilities of the Darwinian principles; it attempts to trace the differences in form in a definite although small group entirely to known factors.

Why the markings of caterpillars have particularly been chosen for this purpose will appear for two reasons. 
The action of Natural Selection, on account of the nature of this agency, can only be exerted on those characters which are of biological importance. As it was to be tested whether, besides Natural Selection and the direct action of external conditions, together with the correlative results of these two factors, there might not lie concealed in the organism some other unknown transforming power, it was desirable to select for the investigation a group of forms which, if not absolutely excluding, nevertheless appeared possibly to restrict, the action of one of the two known factors of transformation, that of Natural Selection; a group of forms consisting essentially of so-called "purely morphological" characters, and not of those the utility of which was obvious, and of which the origin by means of Natural Selection was both possible and probable $a b$ initio. Now, although the colouring can readily be sean to be of value to the life of its possessors, this is not the case with the quite independent markings of caterpillars; excepting perhaps those occasional forms of marking which have been regarded as special cases of protective resemblance. The markings of caterpillars must in general be considered as "purely morphological" characters, i. e. as characters which we do not know to be of any importance to the life of the species, and which cannot therefore be referred to Natural Selection. The most plausible explanation of 
these markings might have been that they were to be regarded as ornaments, but this view precludes the possibility of referring them either to Natural Selection or to the influence of direct changes in the environment.

The markings of caterpillars offered also another advantage which cannot be lightly estimated; they precluded from the first any attempt at an explanation by means of Sexual Selection. Although I am strongly convinced of the activity and great importance of this last process of selection, its effects cannot be estimated in any particular case, and the origin of a cycle of forms could never be clearly traced to its various factors, if Sexual Selection had also to be taken into consideration. Thus, we may fairly suppose that many features in the markings of butterflies owe their origin to Sexual Selection, but we are, at least at present, quite in the dark as to how many and which of these characters can be traced to this factor.

An investigation such as that which has been kept in view in this second essay would have been impracticable in the case of butterflies, as well as in the analogous case of the colouring and marking of birds, because it would have always been doubtful whether a character which did not appear to be attributable to any of the other transforming factors, should not be referred to Sexual Selection. It would have been impossible 
either to exclude or to infer an unknown developmental force, since we should have had to deal with two unknowns which could in no way be kept separate.

We escape this dilemma in the markings of caterpillars, because the latter do not propagate in this state. If the phenomena are not here entirely referable to Natural Selection and the direct action of the environment-if there remains an inexplicable residue, this cannot be referred to Sexual Selection, but to some as yet unknown power.

But it is not only. in this respect that caterpillars offer especial advantages. If it is to be attempted to trace transformations in form to the action of the environment, an exact knowledge of this environment is in the first place necessary, $i$. e. a precise acquaintance with the conditions of life under the influence of which the species concerned exist. With respect to caterpillars, our knowledge of the life conditions is certainly by no means as complete as might be supposed, when we consider that hundreds of Lepidopterists have constantly bred and observed them during a most extended period. Much may have been observed, but it has not been thought worthy of publication; much has also been published, but so scattered and disconnected and at the same time of such unequal credibility, that a lifetime would be required to sift and collect it. A comprehensive biology of 
caterpillars, based on a broad ground, is as yet wanting, although such a labour would be both most interesting and valuable. Nevertheless, we know considerably more of the life of caterpillars than of any other larvæ, and as we are also acquainted with an immense number of species and are able to compare their life and the phenomena of their development, the subject of the markings of caterpillars must from this side also appear as the most favourable for the problem set before us.

To this must be added as a last, though not as the least, valuable circumstance, that we have here preserved to us in the development of the individual a fragment of the history of the species, so that we thus have at hand a means of following the course which the characters to be traced to their causes-the forms of marking-have taken during the lapse of thousands of years.

If with reference to the question as to the precise conditions of life in caterpillars I was frequently driven to my own observations, it was because I found as good as no previous work bearing upon this subject. It was well known generally that many caterpillars were differently marked and coloured when young to what they were when old; in some very striking cases brief notices of this fact are to be found in the works, ${ }^{1}$

1 A most minute and exact description of the newly hatched larva of Chionobas Aëllo is given by the American entomologist, Samuel H. Scudder. Ann. Soc. Ent. de Belgique, xvi., 1873. 
more especially, of the older writers, and principally in that of the excellent observer Rösel von Rosenhof, the Nuremberg naturalist and miniature painter. In no single case, however, do the available materials suffice when we have to draw conclusions respecting the phyletic development. We distinctly see here how doubtful is the value of those observations which are made, so to speak, at random, i.e. without some definite object in view. Many of these observations may be both good and correct, but they are frequently wanting precisely in that which would make them available for scientific purposes. Thus everything had to be established de novo, and for this reason the investigations were extended over a considerable number of years, and had to be restricted to a small and as sharply defined a group as possible-a group which was easily surveyed, viz. that of the Hawk-moths or Sphinges.

Since the appearance of the German edition of this work many new observations respecting the markings of caterpillars have been published, such, for example, as those of W. H. Edwards and Fritz Müller. I have, however, made but little use of them here, as I had no intention of giving anything like a complete ontogeny of the markings in all caterpillars: larval markings were with me but means to an end, and I wished only to bring together such a number of facts as 
were necessary for drawing certain general conclusions. It would indeed be most interesting to extend such observations to other groups of Lepidoptera.

The third essay also, for similar reasons, is based essentially upon the same materials, viz. the Lepidoptera. It is therein attempted to approach the general problem-does there or does there not exist an internal transforming force?-from a quite different and, I may say, opposite point of view. The form-relationships of Lepidoptera in their two chief stages of development, imago and larva, are therein analysed, and by an examination of the respective forms it has been attempted to discover the nature of the causes which have led thereto.

I may be permitted to say that the fact here disclosed of a different morphalogical, with the same genealogical relationship, appears to me to be of decided importance. The agreement of the conclusions following therefrom with the results of the former investigation has, at least in my own mind, removed the last doubts as to the correctness of the latter.

The fourth and shortest essay on the "Transformation of the Axolotl into Amblystoma," starts primarily with the intention of showing that cases of sudden transformation are no proof of per saltum development. When this essay first appeared the view was still widely entertained that 
we had here a case proving per saltum development. That this explanation was erroneous is now generally admitted, but I believe that those who suppose that we have here to deal with some quite ordinary phenomenon which requires no explanation, now go too far towards the other extreme. The term "larval reproduction" is an expression, but no explanation; we have therefore to attempt to find out the true interpretation, but whether the one which I have given is correct must be judged of by others.

These four essays lead up to a fifth and concluding one "On the Mechanical Conception of Nature." Whilst the results obtained are here summed up, it is attempted to form them into a philosophical conception of Nature and of the Universe. It will be thought by many that this should have been left to professed philosophers, and I readily admit that I made this attempt with some misgiving. Two considerations, however, induced me to express here my own views. The first was that the facts of science are frequently misunderstood, or at any rate not estimated at their true value, by philosophers $;^{2}$ the second consideration was, that even certain naturalists and certainly very many non-naturalists, turn distrustfully from the results of science, because

- I am aware that this certainly cannot be said of philosophers like Lotze or Herbert Spencer; but these are at the same time both naturalists and philosophers. 
they fear that these would infallibly lead to a view of the Universe which is to them unacceptable, viz. the materialistic view. With regard to the former I wished to show that the views of the development of organic Nature inaugurated by Darwin and defended in this work are certainly correctly designated mechanical; with reference to the latter I wished to prove that such a mechanical conception of the organic world and of Nature in general, by no means leads merely to one single philosophical conception of Nature, viz. to Materialism, but that on the contrary it rather admits of legitimate development in a quite different manner.

Thus in these last four essays much that appears heterogeneous will be found in close association, viz. scientific details and general philosophical ideas. In truth, however, these are most intimately connected, and the one cannot dispense with the other. As the detailed investigations of the three essays find their highest value in the general considerations of the fourth, and were indeed only possible by constantly keeping this end in view, so the general conclusions could only grow out of the results of the special investigations as out of a solid foundation. Had the new materials here brought together been already known, the reader would certainly have been spared the trouble of going into the details of special scientific research. But as 
xxviii Preface to the English Edition.

matters stood it was indispensable that the facts should be examined into and established even down to the most trifling details. The essay "On the Origin of the Markings of Caterpillars" especially, had obviously to commence with the sifting and compilation of extensive morphological materials.

August Weismann.

Freiburg in Baden,

November, I88I. 


\section{CONTENTS,}

\section{門art E. \\ ON THE SEASONAL DIMORPHISM OF BUTTERFLIES.}

I.

The Origin and Significance of Seasonal Dimorphism, p. 1.

Historical preliminaries, I. Does not occur in other orders of insects, 4. Beginning of experimental investigation, 5. Lepidopterous foes, 7. First experiments with Araschnia Levana, Io. Experiments with Pieris Napi, 13. Discussion of results, I7. Origination of Prorsa from Levana, I9. Theoretical considerations, 23. The case of Papilio Ajax, 30. Experiments with Pieris Napi var. Bryonice, 39. The summer generations of seasonally dimorphic butterflies the more variable, 42 .

\section{II.}

Seasonal Dimorphism and Climatic Variation, p. 45.

Distinction between climatic and local varieties, 45. The case of Euchloe Belia and its varieties, 47. The case of Polyommatus Phlceas, 49. The case of Plebeius Agestis, 50.

\section{III.}

Nature of the Causes producing Climatic Varieties, p. 52.

Seasonal dimorphism of the same nature as climatic variation, 52. How does climatic change influence the markings of a butterfly? 52. The cause of this to be found in temperature, 54 . Part played by the organism itself, 58. Analogous seasonal dimorphism in Pierina, 6o. The part played by sexual selection, 62 . 
IV.

Why all Polygoneutic Species are not Seasonally Dimorphic, p. 63.

Homochronic heredity, 63. Caterpillars, pupæ and eggs of summer and winter generations of seasonally dimorphic butterflies alike, 64. The law of cyclical heredity, 65. Climatic variation of Pararga Egeria, 68. Continuous as distinguished from alternating heredity, 68. Return from dimorphism to monomorphism, 70 . Seasonally dimorphic species hibernate as pupæ, 7 I. Retrogressive disturbance of winter generations, 72. The case of Plebeius Amyntas, 75.

\section{$\mathrm{V}$.}

On Alternation of Generations, p. 80.

Haeckel's classification of the phenomena, 8o. Proposed modification, 81. Derivation of metagenesis from metamorphosis, 82. Primary and secondary metagenesis, 8.4. Seasonal dimorphism related to heterogenesis, 86. Heterogenesis and adaptation, 89. Differences between seasonal dimorphism and other cases of heterogenesis, 89. The case of Leptodora Hyalina, 93.

VI.

General Conclusions, p. 100.

Species produced by direct action of environment, Io०. The transforming influences of climate, 103. The origin of variability, 107. The influence of isolation, rog. Cyclically acting causes of change produce cyclically recurring changes, I I I. Specific constitution an important factor, II2. A "fixed direction of variation," II 4 .

\section{Appendix I., p. I I 7 .}

Experiments with Araschnia Levana, II7. Experiments with Pierince, $\mathbf{2} 2$.

Appendix II., p. 126.

Experiments with Papilio Ajax, 126. Additional experiments with Pap. Ajax, 131. Experiments with Phyciodes Tharos, 140: with Grapta Interrogationis, 149. Remarks on the latter, I52.

Explanation of the Plates, p. 159. 


\section{Part 玨.}

\section{ON THE FINAL CAUSES OF TRANSFORMATION.}

\section{I.}

THE ORIGIN OF THE MARKINGS OF CATERPILLARS.

Introduction, p. 16r.

I.

Ontogeny and Morphology of Sphinx Markings, p. 177.

The genus Charocampa, $177 ;$ C. Elpenor, $177 ;$ C. Porcellus, 184 . Results of the development of these species and comparison with other species of the genus, 188. The genus Deilephila, 199; $D$. Euphorbice, 201; D. Nicea, 207 ; D. Dahlii, 208; D. Vespertilio, 209; D. Galii, 21 I; D. Livornica, 215;D. Zygophylli, 217;D. Hippophaës, 218. Summary of facts and conclusions from this genus, 223. The genus Smerinthus, 232; S. Tilia, 233;S. Populi, 236; S. Ocellatus, 240. Results of the development of these species, 242. The genus Macroglossa, $245 ; M$. Stellatarum, 245 ; comparison of this with other species, 253. The genus Pterogon, 255; P. Enothera, 256; comparison with other species, 256. The genus Sphinx, 259; S. Ligustri, 259; comparison with other species, 26r. The genus Anceryx, 264; A. Pinastri, 265; comparison with other species, 268.

\section{II.}

Conchusions from Phylogeny, p. 270.

The Ontogeny of Caterpillars is a much abbreviated but slightly falsified repetition of the Phylogeny, 270. Three laws of development, 274. The backward transference of new characters to younger stages is the result of an innate law of growth, 278. Proof that new characters always originate at the end of the development; the red spots of S. Tilia, 282.

\section{III.}

Biological Value of Marking in general, p. 285.

Markings of Caterpillars most favourable to inquiry, 285. Are the Sphinx-markings purely morphological, or have they a biological value? 287 . 
IV.

Biological Value of Colour, p. 289.

General prevalence of protective colouring among caterpillars, 289 . Polymorphic adaptive colouring in $C$. Elpenor, C. Porcellus, $P$. Enothera, D. Vespertilio, D. Galii, D. Livornica, D. Hippophaës, 295. Habit of concealment primary; its causes, 298. Polymorphism does not here depend upon contemporaneous but upon successive double adaptation; displacement of the old by a new adaptation; proof in the cases of $D$. Hippophaës, D. Galii, $D$. Vespertilio, M. Stellatarum, C. Elpenor, and S. Convolvuli, 300.

V.

Biological Value of special Markings, p 308.

Four chief forms of marking among Sphingida, 309. Complete absence of marking among small caterpillars and among those living in obscurity, 3 Io. Longitudinal stripes among grass caterpillars, 3r2. Oblique striping. Coloured edges are the shadows of leaf ribs, 3r7. Eye-spots and ring-spots. Definition, 326 : Eye-spots not originally signs of distastefulness, 328 ; they are means of alarm, 329 ; experiments with birds, 330 ; possibility of a later change of function in eye-spots, 334. Ring-spots. Are they signs of distastefulness? Are there caterpillars which are edible and which possess bright colours? 335 ; experiments with lizards, 336 . In $D$. Galii, D. Euphorbice, D. Dahlii and D. Mauritanica the ring-spots are probably signs of distastefulness, $34 \mathrm{I}$. In $D$. Nicaa they are perhaps also means of exciting terror, $34^{2}$. The primary ring-spot in D. Hippophaës is a means of protection, 344. Subordinate markings. Reticulation, 347. The dorsal spots of $C$. Elpenor and C. Porcellus, 348. The lateral dots of S. Convolvuli, 348. Origination of subordinate markings by the blending of inherited but useless markings with new ones, 349 .

VI.

Objections to a Phyletic Vital Force, p. $35^{2}$.

Independent origination of ring-spots in species of the genus Deilephila, 352. Possible genealogy of this genus, 358 . Independent origination of red spots in several species of Smerinthus, 360 . Functional change in the elements of marking, 365. Colour change in the course of the ontogeny, 367 . 
VII.

Phyletic Development of the Markings of the Sphingida. Summary and Conclusion, p. 370.

The oldest Sphingida were devoid of marking, 370. Longitudinal stripes the oldest form of marking, $37 \mathrm{I}$. Oblique striping, 373. Spot markings, 375. The first and second elements of marking are mutually exclusive, but not the first and third, or the second and third, 377. Results with reference to the origin of markings; picture of their origin and gradual complication, 380. General results; rejection of a phyletic vital force, 389 .

\section{II.}

\section{ON PHYLETIC PARALLELISM IN METAMORPHIC SPECIES.}

Introduction, p. 390.

I.

Larva and Imago vary in Structure independently of each other, p. $40 \mathrm{r}$.

Dimorphism of one stage nnly, 402. Independent variability of the stages (heterochronic variability), 403. Constancy and varia. bility are not inherent properties of certain forms of marking, 407. Heterochronic variability is not explained by assuming a phyletic vital force, 4ro. Rarity of greater variability in pupæ. Greater variability more common among caterpillars than among the imagines. Causes of this phenomenon, 4I 2. Apparent independent variability of the single larval stages. Waves of variability, 4I6. Saturnia Carpini an instance of secondary variability, 419. Causes of the exact correlation between the larval stages and its absence between the larva and imago, 429.

II.

Does the Form-relationship of the Larva coincide with that of the Imago? $p .432$.

Family groups, 432. Families frequently completely congruent 435. Exception offered by the Nymphalida, 435. In transitional families the larvæ also show intermediate forms, 44I. Genera; almost completely congruent; the Nymphalideous genera can be based on the structure of the larvæ, 444. So also can certain subgenera, as Vanessa, 445. Incongruence in Pterogon, 450. Species; in congruence very common; S. Ocellatus and Populi, 45 r. Species 
of Deileprita show a nearer form-relationship as imagines than as larvæ, 454. Systemy not only the expressinn of morphological relationship, 455. Varieties; incongruence the rule; seasonal dimorphism ; climatic varieties; dimorphism of caterpillars; local varieties of caterpillars, 456. Result of the investigation, 458. Causes of incongruence, 460 . A phyletic vital force does not explain the phenomena, $46 \mathrm{r}$. This force is superfluous, 464 .

\section{III.}

Incongruences in other Orders of Insects, p. 48r.

Hymenoptera. The imagines only possess ordinal characters, $48 \mathrm{r}$. Double incongruence : different distance and different group-formation, 483. Diptera, 488. The larvæ form two types depending on different modes of life, 489 . The similarity of the grub-like larvæ of Diptera and Hymenoptera depends upon convergence, 494. These data again furnish strong arguments against a phyletic vital force, 496. The tribe Aphaniptera, 498. Results furnished by the form-relationship of Diptera and Hymenoptera, 499. Difference between typical and non-typical parts transient, $50 \mathrm{r}$.

IV.

Summary and Conclusion, $p .502$.

First form of incongruence, $5 \circ 3$. Second form of incongruence, 506. General conclusion as to the elimination of a phyletic vital force, 5II. Parallelism with the transformation of systems of organs, 513 .

\section{Appendix I., p. 520.}

Additional notes on the Ontogeny, Phylogeny, \&c., of Caterpillars. Ontogeny of Noctua larræ, 520. Additional descriptions of Sphinxlarvæ, 521. Retention of the subdorsal line by ocellated larvæ, 529. Phytophagic variability, 531. Sexual variation in larvæ, 534.

\section{Appendix II., p. 536.}

Acrcea and the Maracujà butterflies as larvæ, pupæ, and imagines, 536.

Explanation of the Plates, $p .546$. 


\section{Fart 玨王.}

\section{ON THE FINAL CAUSES OF TRANSFORMATION (continued).}

\section{III.}

THE TRANSFORMATION OF THE MEXICAN AXOLOTL INTO AMBLYSTOMA.

\section{Introduction, p. 555 .}

Experiments, 558. Significance of the facts, 563. The Axolotl rarely or never undergoes metamorphosis in its native country, 565 . North American Amblystomas, 570. Does the exceptional transformation depend upon a phyletic advancement of the species? $57 \mathrm{I}$. Theoretical bearing of the case, 574. Differences between Axolotl and Amblystoma, 575. These are not correlative results of the suppression of the gills, 578. Explanation by reversion, $58 \mathrm{r}$. Cases of degeneration to a lower phyletic stage: Filippi's sexually mature "Triton larve," 583. Analogous observations on Triton by Jullien and Schreibers, 59r. The sterility of the artificially produced Amblystomas tells against the former importance of the transformation, 594. It is not opposed to the hypothesis of reversion, 596. Attempted explanation of the sterility from this point of view, 597 . Causes which may have induced reversion in the hypothetical Mexican Amblystomas, 600. Saltness of the water combined with the drying up of the shores by winds, 604. Consequences of the reversion hypothesis, 609; Systematic, 609; an addendum to the "fundamental biogenetic law," 6II; General importance of reversion, 6I 2 . Postscript; dryness of the air the probable cause of the assumed reversion of the Amblystoma to the Axolotl, 6r3. Addendum, 622.

\section{IV.}

\section{ON THE MECHANICAL CONCEPTION OF NATURE.}

Introduction, p. 634 .

Results of the three foregoing essays : denial of a phyletic vital force, 634. Application of these results to inductive conclusions with reference to the organic world in general, 636 . The assumption of such a force is opposed to the fundamental laws of natural science, 637. The "vital furce" of the older natural philosopher, 640. Why was the latter abandoned? Commencement of a mechanical theory of life, 642 . 
I.

Are the Principles of the Selection Theory Mechanical? 645 .

Refutation of Von Hartmann's views, 645. Variability, 646. The assumption of unlimited variability no postulate of the selection theory, 647. The acknowledgment of a fixed and directed variability does not necessitate the assumption of a phyletic vital force, 647 . Heredity, 657. Useful modifications do not occur only singly, 657. New characters appearing singly may also acquire predominance, 659. A mechanical theory of heredity is as yet wanting, 665. Haeckel's " Perigenesis of the Plastidule," 667. Correlation, 670. The "specific type" depends upon the physiological equilibrium of the parts of the organism, 67I. The theoretical principles of the doctrine of selection are thus mechanical, 675. Importance of the physical constitution of the organism in determining the quality of variations, 676 . All individual variability depends upon unequal external influences, 677 . Deduction of the limitability of variation, 682. Deduction of local forms, 686. Parallelism between the ontogenetic and the phyletic vital force, 687. The two are inseparable, 690.

II.

Mechanism and Teleology, p. 694.

Von Baer's exaction from the theory of selection, 694. Justification of his claim, but the impossibility of the co-operation of a metaphysical principle with the mechanism of Nature, 695. Per saltum development (heterogeneous generation), 698. Weakness of the positive basis of this hypothesis, 699. The latter refuted by the impossibility of the co-operation of "heterogeneous generation "with natural selection, 702. The interruption by a metaphysical principle cannot be reconciled with gradual transformation, 705. The metaphysical (teleological) principle can only be conceived of as the ultimate ground of the mechanism of Nature, 709. Value of this knowledge for the harmonious conception of the Universe, 7II. Explanation of the spiritual by the assumption of conscious matter, 7 I4. The theory of selection does not necessarily lead to Materialism, $7 \mathrm{x} 6$.

INDEX - . $\quad . \quad+\quad . \quad$ p. 7 Ig. 


\section{STUDIES IN THE THEORY OF DESCENT.}

\section{羽art \\ ON THE SEASONAL DIMORPHISM OF BUTTERFLIES.}

\section{I. \\ The Origin and Significance of Seasonal DimorPHISM.}

THE phenomena here about to be subjected to a closer investigation have been known for a long period of time. About the year 1830 it was shown that the two forms of a butterfly (Araschnia) which had till that time been regarded as distinct, in spite of their different colouring and marking really belonged to the same species, the two forms of this dimorphic species not appearing simultaneously but at different seasons of the year, the one in early spring, the other in summer. To this phenomenon the term "seasonal dimorphism" was subsequently applied by Mr. A. R. Wallace, an expression of which the heterogeneous composition

$$
\text { q } N \text { B }
$$


may arouse the horror of the philologist, but, as it is as concise and intelligible as possible, I propose to retain it in the present work.

The species of Araschnia through which the discovery of seasonal dimorphism was made, formerly bore the two specific names $A$. Levana and $A$. Prorsa. The latter is the summer and the former the winter form, the difference between the two being, to the uninitiated, so great that it is difficult to believe in their relationship. A. Levana (Figs. I and 2, Plate I.) is of a golden brown colour with black spots and dashes, while $A$. Prorsa (Figs. 5 and 6, Plate I.) is deep black with a broad white interrupted band across both wings. Notwithstanding this difference, it is an undoubted fact that both forms are merely the winter and summer generations of the same species. I have myself frequently bred the variety Prorsa from the eggs of Levana, and vice versâ.

Since the discovery of this last fact a considerable number of similar cases have been established. Thus P. C. Zeller ${ }^{1}$ showed, by experiments made under confinement, that two butterflies belonging to the family of the 'Blues,' differing greatly in colour and marking, and especially in size, which had

1 "Über die Artrechte des Polyommatus Amyntas und Polysperchon." Stett. ent. Zeit. I849. Vol. x. p. I77-I82. [In Kirby's "Synonymic Catalogue of Diurnal Lepidoptera" Plebeius Amyntas is given as a synonym and $P$. Polysperchon as a var. of $P$. Argiades Pall. R.M.] 
On the Seasonal Dimorphism of Butterfies. 3

formerly been distinguished as Plebeius (Lycana) Polysperchon and P. Amyntas, were merely winter and summer generations of the same species; and that excellent Lepidopterist, Dr. Staudinger, proved the same ${ }^{2}$ with species belonging to the family of the 'Whites,' Euchloe Belia Esp. and E. Ausonia Hüb., which are found in the Mediterranean countries.

The instances are not numerous, however, in which the difference between the winter and summer forms of a species is so great as to cause them to be treated of in systematic work as distinct species. I know of only five of these cases. Lesser differences, having the systematic value of varieties, occur much more frequently. Thus, for instance, seasonal dimorphism has been proved to exist among many of our commonest butterflies belonging to the family of the 'Whites,' but the difference in their colour and marking can only be detected after some attention; while with other species, as for instance with the commonest of our small 'Blues,' Plebeius Alexis (=Icarus, Rott.), the difference is so slight that even the initiated must examine closely in order to recognize it. Indeed whole series of species might easily be grouped so as to show the transition from complete similarity of both generations, through scarcely

2 "Die Arten der Lepidopteren-Gattung Ino Leach, nebst einigen Vorbemerkungen über Localvarietäten." Stett. ent. Zeit. 1862. Vol. xxiii. p. 342 . 
perceptible differences, to divergence to the extent of varieties, and finally to that of species.

Nor are the instances of lesser differences between the two generations very numerous. Among the European diurnal Lepidoptera I know of about twelve cases, although closer observation in this direction may possibly lead to further discoveries. ${ }^{3}$ Seasonal dimorphism occurs also in moths, although I am not in a position to make a more precise statement on this subject, ${ }^{4}$ as my own observations refer only to butterflies.

That other orders of insects do not present the same phenomenon depends essentially upon the fact that most of them produce only one generation in the year; but amongst the remaining orders there occur indeed changes of form which, although

3 [Eng. ed. W. H. Edwards has since pointed out several beautiful cases of seasonal dimorphism in America. Thus Plebeius Pseudargiolus is the summer form of $P$. Violacea, and Phyciodes Tharos the summer form of P. Marcia. See Edwards' "Butterflies of North America," I868-79.]

" [Eng. ed. I learn by a written comniunication from Dr. Speyer that two Geometræ, Selenia Tetralunaria and S. Illunaria Hüb., are seasonally dimorphic. In both species the winter form is much larger and darker.] [Selenia Lunaria, S. Illustraria, and some species of Ephyra (E. Punctaria and E. Omicronaria) are likewise seasonally dimorphic. For remarks on the case of S. Illustraria see Dr. Knaggs in Ent. Mo. Mag., vol. iii. p. 238, and p. 256. Some observations on $E$. Punctaria were communicated to the Entomological Society of London by Professor Westwood in 1877 , on the authority of Mr. B. G. Cole. See Proc. Ent. Soc. I 877 , pp. vi, vii. R.M.] 
On the Seasonal Dimorphism of Butterfies. 5

not capable of being regarded as pure seasonal dimorphism, may well have been produced in part by the same causes, as the subsequent investigation on the relation of seasonal dimorphism to alternation of generation and heterogenesis will more fully prove.

Now what are these causes?

Some years ago, when I imparted to a lepidopterist my intention of investigating the origin of this enigmatical dimorphism, in the hope of profiting for my inquiry from his large experience, I received the half-provoking reply: "But there is nothing to investigate: it is simply the specific character of this insect to appear in two forms; these two forms alternate with each other in regular succession according to a fixed law of Nature, and with this we must be satisfied." From his point of view the position was right; according to the old doctrine of species no question ought to be asked as to the causes of such phenomena in particular. I would not, however, allow myself to be thus discouraged, but undertook a series of investigations, the results of which $I$ here submit to the reader.

The first conjecture was, that the differences in the imago might perhaps be of a secondary nature, and have their origin in the differences of the caterpillar, especially with those species which grow up during the spring or autumn and feed on different plants, thus assimilating different chemical 
substances, which might induce different deposits of colour in the wings of the perfect insect. This latter hypothesis was readily confuted by the fact, that the most strongly marked of the dimorphic species, $A$. Levana, fed exclusivelyon Urtica major. The caterpillar of this species certainly exhibits a well defined dimorphism, but it is not seasonal dimorphism: the two forms do not alternate with each other, but appear mixed in every brood.

I have repeatedly reared the rarer golden-brown variety of the caterpillar separately, but precisely the same forms of butterfly were developed as from black caterpillars bred at the same time under similar external conditions. The same experiment was performed, with a similar result, in the last century by Rösel, the celebrated miniature painter and observer of nature, and author of the well-known "Insect Diversions"-a work in use up to the present day.

The question next arises, as to whether the causes originating the phenomena are not the same as those to which we ascribe the change of winter and summer covering in so many mammalia and birds - whether the change of colour and marking does not depend, in this as in the other cases, upon the indirect action of external conditions of life, i. e., on adaptation through natural selection. We are certainly correct in ascribing white coloration to adaptation ${ }^{5}$-as with the ptarmigan, which is - [In 1860 Andrew Murray directed attention to the dis- 
white in winter and of a grey-brown in summer, both colours of the species being evidently of important use.

It might be imagined that analogous phenomena occur in butterflies, with the difference that the change of colour, instead of taking place in the same brood, alternates in different broods. ${ }^{6}$ The nature of the difference which occurs in seasonal dimorphism, however, decidedly excludes this view ; and moreover, the environment of butterflies presents such similar features, whether they emerge in spring or in summer, that all notions that we may be dealing with adaptational colours must be entirely abandoned.

I have elsewhere ${ }^{7}$ endeavoured to show that butterflies in general are not coloured protectively during flight, for the double reason that the colour

guising colours of species which, like the Alpine hare, stoat, and ptarmigan, undergo seasonal variation of colour. See a paper "On the Disguises of Nature, being an inquiry into the laws which regulate external form and colour in plants and animals." Edinb. New Phil. Journ., Jan. r86o. In r873 I attempted to show that these and other cases of "variable protective colouring " could be fairly attributed to natural selection. See Proc. Zoo. Soc., Feb. 4th, I873, pp. 153-162. R.M.]

- [A phenomenon somewhat analogous to seasonal change of protecting colour does occur in some Lepidoptera, only the change, instead of occurring in the same individual, is displayed by the successive individuals of the same brood. See Dr. Wallace on Bombyx Cynthia, Trans. Ent. Soc. Vol. v. p. 485 . R.M.]

7 "Über den Einfluss der Isolirung auf die Artbildung." Leipzig, 1872 , pp. 55-62. 
of the background to which they are exposed continually changes, and because, even with the best adaptation to the background, the fluttering motion of the wings would betray them to the eyes of their enemies. ${ }^{8} \quad$ I attempted also to prove at the same time that the diurnal Lepidoptera of our temperate zone have few enemies which pursue them when on the wing, but that they are subject to many attacks during their period of repose.

In support of this last statement I may here adduce an instance. In the summer of 1869 I placed about seventy specimens of Araschnia Prorsa in a spacious case, plentifully supplied with flowers. Although the insects found themselves quite at home, and settled about the flowers in very fine weather (one pair copulated, and the female laid eggs), yet I found some dead and mangled every morning. This decimation con-

- [Mr. A. R. Wallace maintains that the obscurely coloured females of those butterflies which possess brightly coloured males have been rendered inconspicuous by natural selection, owing to the greater need of protection by the former sex. See "Contributions to the Theory of Natural Selection," London, I870, pp. I12-II4. It is now generally admitted that the underside of butterflies has undergone protectional adaptation; and many cases of local variation in the colour of the underside of the wings, in accordance with the nature of the soil, \&c., are known. See, for instance, Mr. D. G. Rutherford on the colour-varieties of Aterica Meleagris (Proc. Ent. Soc. 1878, p. xlii.), and Mr. J. Jenner Weir on a similar phenomenon in Hipparchia Semele (loc. cit. p. xlix.) R.M.] 
tinued-many disappearing entirely without my being able to find their remains-until after the ninth day, when they had all, with one exception, been slain by their nocturnal foes-probably spiders and Opilionida.

Diurnal Lepidoptera in a position of rest are especially exposed to hostile attacks. In this position, as is well known, their wings are closed upright, and it is evident that the adaptational colours on the under side are displayed, as is most clearly shown by many of our native species. ${ }^{9}$

Now, the differences in the most pronounced cases of seasonal dimorphism-for example, in Araschnia Levana-are much less manifest on the under than on the upper side of the wing. The explanation by adaptation is therefore untenable; but I will not here pause to confute this view more completely, as I believe I shall be able to show the true cause of the phenomenon.

If seasonal dimorphism does not arise from the indirect influence of varying seasons of the year, it may result from the direct influence of the varying external conditions of life, which are, without doubt, different in the winter from those of the summer brood.

There are two prominent factors from which such an influence may be expected-temperature

- [The fact that moths which, like the Geometræ, rest by day with the wings spread out, are protectively marked on the upper side, fully corroborates this statement. R.M.] 
( - and duration of development, i. e., duration of the chrysalis period. The duration of the larval period need not engage our attention, as it is only very little shorter in the winter brood-at least, it was so with the species employed in the experiments.

Starting from these two points of view, I carried on experiments for a number of years, in order to find out whether the dual form of the species in question could be traced back to the direct action of the influences mentioned.

The first experiments were made with Araschnia Levana. From the eggs of the winter generation, which had emerged as butterflies in April, I bred caterpillars, and immediately after pupation placed them in a refrigerator, the temperature of the air of which was $8^{\circ}-10^{\circ} \mathrm{R}$. It appeared, however, that the development could not thus be retarded to any desired period by such a small diminution of temperature, for, when the box was taken out of the refrigerator after thirty-four days, all the butterflies, about forty in number, had emerged, many being dead, and others still living. The experiment was so far successful that, instead of the Prorsa form which might have been expected under ordinary circumstances, most of the butterflies emerged as the so-called Porima (Figs. 3, 4, 7,8 , and 9 , Plate I.) ; that is to say, in a form intermediate between Prorsa and Levana sometimes found in nature, and possessing more or less the 
marking of the former, but mixed with much of the yellow of Levana.

It should be here mentioned, that similar experiments were made in 1864 by George Dorfmeister, but unfortunately I did not get this information ${ }^{10}$ until my own were nearly completed. In these well-conceived, but rather too complicated experiments, the author arrives at the conclusion "that temperature certainly affects the colouring, and through it the marking, of the future butterfly, and chiefly so during pupation." By lowering the temperature of the air during a portion of the pupal period, the author was enabled to produce single specimens of Porima, but most of the butterflies retained the Prorsa form. Dorfmeister employed a temperature a little higher than I did in my first experiments, viz. $\mathrm{IO}^{\circ}-\mathrm{Il}^{\circ} \mathrm{R}$., and did not leave the pupæ long exposed, but after $5 \frac{1}{2}-8$ days removed them to a higher temperature. It was therefore evident that he produced transition forms in a few instances only, and that he never succeeded in bringing about a complete transformation of the summer into the winter form.

In my subsequent experiments I always exposed the pupæ to a temperature of $\mathrm{O}^{\circ}-\mathrm{r}^{\circ} \mathrm{R}$. ; they were placed directly in the refrigerator, and

10 " Über die Einwirkung verschiedener, während der Entwicklungsperioden angewendeter Wärmegrade auf die Färbung und Zeichnung der Schmetterlinge." A communication to the Society of Natural Science of Steiermark, 1864. 
taken out at the end of four weeks. I started with the idea that it was perhaps not so much the reduced temperature as the retardation of development which led to the transformation. But the first experiment had shown that the butterflies emerged between $8^{\circ}$ and $10^{\circ}$ R., and consequently that the development could not be retarded at this temperature.

A very different result was obtained from the experiment made at a lower temperature. ${ }^{11}$ Of twenty butterflies, fifteen had become transformed into Porima, and of these three appeared very similar to the winter form (Levana), differing only in the absence of the narrow blue marginal line, which is seldom absent in the true Levana. Five butterflies were uninfluenced by the cold, and remained unchanged, emerging as the ordinary summer form (Prorsa). It thus appeared from this experiment, that a large proportion of the butterflies inclined to the Levana form by exposure to a temperature of $0^{\circ}-I^{\circ} \mathrm{R}$. for four weeks, while in a few specimens the transformation into this form was nearly perfect.

Should it not be possible to perfect the transformation, so that each individual should take the Levana form? If the assumption of the Prorsa or Levana form depends only on the direct influence of temperature, or on the duration of the period of 
development, it should be possible to compel the pupæ to take one or the other form at pleasure, by the application of the necessary external conditions. This has never been accomplished with Araschnia Prorsa. As in the experiment already described, and in all subsequent ones, single specimens ap= peared as the unchanged summer form, others showed an appearance of transition, and but very few had changed so completely as to be possibly taken for the pure Levana. In some species of the sub-family Pierince, however, at least in the case of the summer brood, there was, on the contrary, a complete transformation.

Most of the species of our 'Whites' (Pierina) exhibit the phenomenon of seasonal dimorphism, the winter and summer forms being remarkably distinct. In Pieris Napi (with which species I chiefly experimented) the winter form (Figs. IO and 11 , Plate I.) has a sprinkling of deep black scales at the base of the wings on the upper side, while the tips are more grey, and have in all cases much less black than in the summer form; on the underside the difference lies mainly in the frequent breadth, and dark greenish-black dusting, of the veins of the hind wings in the winter form, while in the summer form these greenish-black veins are but faintly present.

I placed numerous specimens of the summer brood, immediately after their transformation into chrysalides, in the refrigerator $\left(0^{\circ}-I^{\circ}\right.$ R.), where 
I left them for three months, transferring them to a hothouse on September I Ith, and there (from September 26th to October 3rd) sixty butterflies emerged, the whole of which, without exceptionand most of them in an unusually strong degreebore the characters of the winter form. I, at least, have never observed in the natural state such a strong yellow on the underside of the hind wings, and such a deep blackish-green veining, as prevailed in these specimens (see, for instance, Figs. IO and II). The temperature of the hothouse $\left(12^{\circ}-24^{\circ}\right.$ R.) did not, however, cause the emergence of the whole of the pupæ; a portion hibernated, and produced in the following spring butterflies of the winter form only. I thus succeeded, with this species of Pieris, in completely changing every individual of the summer generation into the winter form.

It might be expected that the same result could be more readily obtained with $A$. Levanu, and fresh experiments were undertaken, in order that the pupæ might remain in the refrigerator fully two months from the period of their transformation (9-1oth July). But the result obtained was the same as before-fifty-seven butterflies emerged in the hothouse ${ }^{12}$ from September I 9 th to October 4th, nearly all of these approaching very near to the winter form, without a single specimen pre- 
senting the appearance of a perfect Levana, while three were of the pure summer form (Prorsa).

Thus with Levana it was not possible, by refrigeration and retardation of development, to change the summer completely into the winter form in all specimens. It may, of course, be objected that the period of refrigeration had been too short, and that, instead of leaving the pupæ in the refrigerator for two months, they should have remained there six months, that is, about as long as the winter brood remains under natural conditions in the chrysalis state. The force of this last objection must be recognized, notwithstanding the improbability that the desired effect would be produced by a longer period of cold, since the doubling of this period from four to eight weeks did not produce $^{13}$ any decided increase in the strength of the transformation. I should not have omitted to repeat the experiment in this modified form, but unfortunately, in spite of all trouble, I was unable to collect during the summer of 1873 a sufficient number of caterpillars. But the omission thus caused is of quite minor importance from a theoretical point of view.

For let us assume that the omitted experiment had been performed-that pupæ of the summer brood were retarded in their development by cold until the following spring, and that every specimen

${ }^{13}$ See Exps. 4, 9, and I I, Appendix I, 
then emerged in the perfect winter form, Levana. Such a result, taken in connexion with the corresponding experiment upon Pieris Napi, would warrant the conclusion that the direct action of a certain amount of cold (or of retardation of development) is able to compel all pupæ, from whichever generation derived, to assume the winter form of the species. From this the converse would necessarily follow, viz. that a certain amount of warmth would lead to the production of the summer form, Prorsa, it being immaterial from which brood the pupæ thus exposed to warmth might be derived. But the latter conclusion was proved experimentally to be incorrect, and thus the former falls with it, whether the imagined experiment with Prorsa had succeeded or not.

I have repeatedly attempted by the application of warmth to change the winter into the summer form, but always with the same negative result.

- It is not possible to compel the winter brood to assume the form of the summer generation.

$A$. Levana may produce not only two but three broods in the year, and may, therefore, be said to be polygonentic. ${ }^{14}$ One winter brood alternates with two summer broods, the first of which appears in July, and the second in August. The latter.

14 It seems to me very necessary to have a word expressing whether a species produces one, two, or more generations in the year, and I have therefore coined the expression mono-, di-,

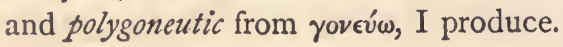


furnishes a fourth generation of pupæ, which, after hibernation, emerge in April, as the first brood of butterflies in the form Levana.

I frequently placed pupæ of this fourth brood in the hothouse immediately after their transformation, and in some cases even during the caterpillar stage, the temperature never falling, even at night, below $12^{\circ} \mathrm{R}$., and often rising during the day to $24^{\circ} \mathrm{R}$. The result was always the same : all, or nearly all, the pupæ hibernated, and emerged the following year in the winter form as perfectly pure Levana, without any trace of transition to the Provsa form. On one occasion only was there a Porima among them, a case for which an explanation will, I believe, be found later on. It often happened, on the other hand, that some few of the butterflies emerged in the autumn, about fourteen days after pupation; and these were always Prorsa (the summer form), excepting once a Porima.

From these experiments it appeared that similar causes (heat) affect different generations of $A$. Levana in different manners. With both summer broods a high temperature always caused the appearance of Prorsa, this form arising but seldom from the third brood (and then only in a few individuals), while the greater number retained the Levana form unchanged. We may assign as the reason for this behaviour, that the third brood has no further tendency to be accelerated in its development by the action of heat, but that by a longer 
duration of the pupal stage the Levana form must result. On one occasion the chrysalis stage was considerably shortened in this brood by the continued action of a high temperature, many specimens thus having their period of development reduced from six to three months. The supposed explanation above given is, however, in reality no explanation at all, but simply a restatement of the facts. The question still remains, why the third brood in particular has no tendency to be accelerated in its development by the action of heat, as is the case with both the previous broods?

The first answer that can be given to this question is, that the cause of the different action produced by a similar agency can only lie in the constitution, i.e., in the physical nature of the broods in question, and not in the external influences by which they are acted upon. Now, what is the difference in the physical nature of these respective broods? It is quite evident, as shown by the experiments already described, that cold and warmth cannot be the immediate causes of a pupa emerging in the Prorsa or Levana form, since the last brood always gives rise to the Levana form, whether acted on by cold or warmth. The first and second broods only can be made to partly assume, more or less completely, the Levana form by the application of cold. In these broods then, a low temperature is the mediate cause of the transformation into the Levana form. 
The following is my explanation of the facts. The form Levana is the original type of the species, and Prorsa the secondary form arising from the gradual operation of summer climate. When we are able to change many specimens of the summer brood into the winter form by means of cold, this can only depend upon reversion to the original, or ancestral, form, which reversion appears to be most readily produced by cold, that is, by the same external influences as those to which the original form was exposed during a long period of time, and the continuance of which has preserved, in the winter generations, the colour and marking of the original form down to the present time.

I consider the origination of the Prorsa from the Levana form to have been somewhat as follows :It is certain that during the diluvial period in Europe there was a so-called 'glacial epoch,' which may have spread a truly polar climate over our temperate zone ; or perhaps a lesser degree of cold may have prevailed with increased atmospheric precipitation. At all events, the summer was then short and comparatively cold, and the existing butterflies could have only produced one generation in the year ; in other words, they were monogoneutic. At that time $A$. Levana existed only in the Levana form. ${ }^{15}$ As the climate gradually be-

${ }^{15}$ [Eng. ed. In the German edition, which appeared in I874, I was not able to support this hypothesis by geographical data, and could then only ask the question "whether 
came warmer, a period must have arrived when

Levana, in the most northern portion of its area of distribution, appears in two or only in one generation?" This question is now answered by the Swedish Expedition to the Yenisei in 1876. Herr Philipp Trybom, one of the members of this expedition, observed $A$. Levana at the end of June and beginning of July, in the middle of Yenisei, in $60^{\circ}-63^{\circ} \mathrm{N}$. (Dagfjärilar från Yenisei in Översigt ap k. Vertensk. Akad. Förhandlingon, 1877 , No. 6.) Trybom found Levana at Yenisk on June $23 \mathrm{rd}$, at Worogova $\left(6 \mathrm{r}^{\circ} 5^{\prime}\right)$ on July ${ }^{\prime} \mathrm{rd}$, at Asinova $\left(6 \mathrm{I}^{\circ} 2^{\prime} 5^{\prime}\right)$ on July 4 th, at Insarowa $\left(62^{\circ} 5^{\prime}\right)$ on July 7 th, and at Alinskaja $\left(63^{\circ} 25^{\prime}\right)$ on July 9 th. The butterflies were especially abundant at the beginning of June, and were all of the typical Levana form. Trybom expressly states, "we did not find a single specimen which differed perceptibly from Weismann's Figs. I and 2 ("Saison-Dimorphismus' Taf. I.)."

The Swedish expedition soon left the Yenisei, and consequently was not able to decide by observations whether a second generation possessing the Prorsa form appeared later in the summer. Nevertheless, it may be stated with great probability that this is not the case. The districts in which Levana occurs on the Yenisei have about the same isotherm as Archangel or Haparanda, and therefore the same summer temperature. Dr. Staudinger, whose views I solicited, writes to me:- "In Finnmark (about $67^{\circ}$ N.) I observed no species with two generations; even Polyommatus Phlaas, which occurs there, and which in Germany has always two, and in the south, perhaps, three generations, in Finnmark has only one generation. A second generation would be impossible, and this would also be the case with Levana in the middle of Yenisei. I certainly have Levana and Prorsa from the middle of Amur, but Levana flies there at the end of May, and the summers are very warm." The middle of Amur lies, moreover, in $50^{\circ} \mathrm{N}$. lat., and therefore $10^{\circ}-13^{\circ}$ south of the districts ${ }^{\circ}$ of the Yenisei mentioned.

It must thus be certainly admitted that on the Yenisei $A$. Levana occurs only in the Levana form, and that consequently this species is at the present time, in the northernmost portion 
the summer lasted long enough for the interpolation of a second brood. The pupæ of Levana, which had hitherto hibernated th rough the long winter to appear as butterflies in the following summer, were now able to appear on the wing as butterflies during the same summer as that in which they left their eggs as larvæ, and eggs deposited by the last brood produced larvæ which fed up and hibernated as pupæ. A state of things was thus established in which the first brood was developed under very different climatic conditions from the second. So considerable a difference in colour and marking between the two forms as we now witness could not have arisen suddenly, but must have done so gradually. It is evident from the foregoing ex periments that the Prorsa form did not originate suddenly. Had this been the case it would simply signify that every individual of this species possessed the faculty of assuming two different forms according as it was acted on by warmth or cold, just in the same manner as litmus-paper becomes red in acids and blue in alkalies. The experiments

of its area of disiribution, in the same condition as that in which I conceive it to have been in mid Europe during the glacial period. It would be of the greatest interest to make experiments in breeding with this single-brooded Levana from the Yenisei, i.e., to attempt to change its offspring into the Prorsa form by the action of a high temperature. If this could not be accomplished it would furnish a confirmation of my hypothesis than which nothing more rigorous could be desired.] 
have shown, however, that this is not the case, but rather that the last generation bears an ineradicable tendency to take the Levana form, and is not susceptible to the influence of warmth, however long continued; while both summer generations, on the contrary, show a decided tendency to assume the Prorsa form, although they certainly can be made to assume the Levana form in different degrees by the prolonged action of cold.

The conclusion seems to me inevitable, that the origination of the Prorsa form was gradual-that those changes which originated in the chemistry of the pupal stage, and led finally to the Prorsa type, occurred very gradually, at first perhaps remaining completely latent throughout a series of generations, then very slight changes of marking appearing, and finally, after a long period of time, the complete Prorsa type was produced. It appears to me that the quoted results of the experiments are not only. easily explained on the view of the gradual action of climate, but that this view is the only one admissible. The action of climate is best comparable with the so-called cumulative effect of certain drugs on the human body; the first small dose produces scarcely any perceptible change, but if often repeated the effect becomes cumulative, and poisoning occurs.

This view of the action of climate is not at all new, most zoologists having thus represented it; only the formal proof of this action is new, and 
the facts investigated appear to me of special importance as furnishing this proof. I shall again return to this view in considering climatic varieties, and it will then appear that also the nature of the transformation itself confirms the slow operation of climate.

During the transition from the glacial period to the present climate $A$. Levana thus gradually changed from a monogoneutic to a digoneutic species, and at the same time became gradually more distinctly dimorphic, this character originating only through the alteration of the summer brood, the primary colouring and marking of the species being retained unchanged by the winter brood. As the summer became longer a third generation could be interpolated-the species became polygoneutic; and in this manner two summer generations alternated with one winter generation.

We have now to inquire whether facts are in complete accordance with this theory-whether they are never at variance with it-and whether they can all be explained by it. I will at once state in anticipation, that this is the case to the fullest extent.

In the first place, the theory readily explains why the summer but not the winter generations are capable of being transformed; the latter cannot possibly revert to the Prorsa form, because this is much the younger. When, however, it 
happens that out of a hundred cases there occurs one in which a chrysalis of the winter generation, having been forced by warmth, undergoes transformation before the commencement of winter, and emerges in the summer form, ${ }^{16}$ this is not in the least inexplicable. It cannot be atavism which determines the direction of the development; but we see from such a case that the changes in the first two generations have already produced a certain alteration in the third, which manifests itself in single cases under favourable conditions (the influence of warmth) by the assumption of the Prorsa form; or, as it might be otherwise expressed, the alternating heredity (of which we shall speak further), which implies the power of assuming the Prorsa form, remains latent as a rule in the winter generation, but becomes continuous in single individuals.

It is true that we have as yet no kind of insight into the nature of heredity, and this at once shows the defectiveness of the foregoing explanation; but we nevertheless know many of its external phenomena. We know for certain that one of these consists in the fact that peculiarities of the father do not appear in the son, but in the grandson, or still further on, and that they may be thus transmitted in a latent form. Let us imagine a character so transmitted that it appears in the first, third, and fifth generations, remaining latent

${ }^{16}$ See Exp. 10, Appendix I. 
in the intermediate ones; it would not be improbable, according to previous experiences, that the peculiarity should exceptionally, i. e., from a cause unknown to us, appear in single individuals of the second or fourth generation. But this completely agrees with those cases in which "exceptional" individuals of the winter brood took the Prorsa form, with the difference only that a cause (warmth) was here apparent which occasioned the development of the latent characters, although we are not in a position to say in what manner heat produces this action. These exceptions to the rule are therefore no objection to the theory. On the contrary, they give us a hint that after one Prorsa generation had been produced, the gradual interpolation of a second Prorsa generation may have been facilitated by the existence of the first. I do not doubt that even in the natural state single individuals of Prorsa sometimes emerge in September or October; and if our summer were lengthened by only one or two months this might give rise to a third summer brood (just as a second is now an accomplished fact), under which circumstances they would not only emerge, but would also have time for copulation and for depositing eggs, the larvæ from which would have time to grow up.

A sharp distinction must be made between the first establishment of a new climatic form and the transference of the latter to newly interpolated 
generations. The former always takes place very slowly; the latter may occur in a shorter time.

With regard to the duration of time which is necessary to produce a new form by the influence of climate, or to transmit to a succeeding generation a new form already established, great differences occur, according to the physical nature of the species and of the individual. The experiments with Prorsa already described show how diverse are individual proclivities in this respect. In Experiment No. I 2 it was not possible out of seventy individuals to substitute Prorsa for the Levana form, even in one solitary case, or, in other words, to change alternating into continuous inheritance; whilst in the corresponding experiments of former years (Experiment IO, for example), out of an equal number of pupæ three emerged as Prorsa, and one as Porima. We might be inclined to seek for the cause of this different behaviour in external influences, but we should not thus arrive at an explanation of the facts. We might suppose, for instance, that a great deal depended upon the particular period of the pupal stage at which the action of the elevated temperature began-whether on the first, the thirtieth, or the hundredth day after pupationand this conjecture is correct in so far that in the two last cases warmth can have no further influence than that of somewhat accelerating the emergence of the butterflies, but cannot change the Levana 
into the Prorsa form. I have repeatedly exposed a large number of Levana pupæ of the third generation to the temperature of an apartment, or even still higher $\left(26^{\circ}\right.$ R.), during winter, but no Prorsa were obtained. ${ }^{17}$

But it would be erroneous to assume a difference in the action of heat according as it began on the first or third day after transformation; whether during or before pupation. This is best proved by Experiment No. I 2, in which caterpillars of the fourth generation were placed in the hothouse several days before they underwent pupation; still, not a single butterfly assumed the Prorsa form. I have also frequently made the reverse experiment, and exposed caterpillars of the first summer brood to cold during the act of pupation A regular consequence was the dying off of the caterpillars, which is little to be wondered at, as the sensitiveness of insects during ecdysis is well known, and transformation into the pupal state is attended by much deeper changes.

Dorfmeister thought that he might conclude from his experiments that temperature exerts the greatest influence in the first place during the act

${ }^{17}$ When Dorfmeister remarks that hibernating pupæ which, at an early stage "were taken for development into a room, or not exposed to any cold, gave dwarfed, weakly and crippled," or otherwise damaged butterflies, this is entirely attributable to the fact that this able entomologist had neglected to supply the necessary moisture to the warm air. By keeping pupæ over water I have always obtained very fine butterflies. 
of pupation, and in the next place immediately after that period. His experiments were made, however, with such a small number of specimens that scarcely any safe conclusion can be founded on them; still, this conclusion may be correct, in so far as everything depends on whether, from the beginning, the formative processes in the pupa tended to this or that direction, the final result of which is the Prorsa or Levana form. If once there is a tendency to one or the other direction, then temperature might exert an accelerating or a retarding influence, but the tendency cannot be further changed.

It is also possible-indeed, probable-that a period may be fixed in which warmth or cold might be able to divert the original direction of development most easily; and this is the next problem to be attacked, the answer to which, now that the main points have been determined, should not be very difficult. I have often contemplated taking the experiments in hand myself, but have abandoned them, because my materials did not appear to me sufficiently extensive, and in all such experiments nothing is to be more avoided than a frittering away of experimental materials by a too complicated form of problem.

There may indeed be a period most favourable for the action of temperature during the first days of the pupal stage; it appears from Experiment No. 12 that individuals tend in different degrees 
to respond to such influences, and that the disposition to abandon the ordinary course of development is different in different individuals. In no other way can it be explained that, in all the experiments made with the first and second generations of Prorsa, only a portion of the pupæ were compelled by cold to take the direction of development of Levana, and that even from the former only a few individuals completely reverted, the majority remaining intermediate.

If it be asked why in the corresponding experiments with Pieris Napi complete reversion always occurred without exception, it may be supposed that in this species the summer form has not been so long in existence, and that it would thus be more easily abandoned; or, that the difference between the two generations has not become so distinct, which further signifies that here again.the summer form is of later origin. It might also be finally answered, that the tendency to reversion in different species may vary just as much as in different individuals of the same species. But, in any case, the fact is established that all individuals are impelled by cold to complete reversion, and that in these experiments it does not depend so particularly upon the moment of development when cold is applied, but that differences of individual constitution are much more the cause why cold brings some pupæ to complete, and others to partial, reversion, while yet others are 
quite uninfluenced. In reference to this, the American Papilio Ajax is particularly interesting.

This butterfly, which is somewhat similar to the European P. Podalirius, appears, wherever it occurs, in three varieties, designated as var. Telamonides, var. Walshii, and var. Marcellus. The distinguished American entomologist, W. H. Edwards, has proved by breeding experiments, that all three forms belong to the same cycle of development, and in such a manner that the first two appear only in spring, and always come only from hibernating pupæ, while the last form, var. Marcellus, appears only in summer, and then in three successive generations. A seasonal dimorphism thus appears which is combined with ordinary dimorphism, winter and summer forms alternating with each other; but the first appears itself in two forms or varieties, vars. Telamonides and Walshii. If for the present we disregard this complication, and consider these two winter forms as one, we should thus have four generations, of which the first possesses the winter form, and the three succeeding ones have, on the other hand, the summer form, var. Marcellus.

The peculiarity of this species consists in the fact that in all three summer generations only a portion of the pupæ emerge after a short period (fourteen days), whilst another and much smaller portion remains in the pupal state during the whole summer and succeeding winter, first 
emerging in the following spring, and then always in the winter form. Thus, Edwards states that out of fifty chrysalides of the second generation, which had pupated at the end of June, forty-five Marcellus butterflies appeared after fourteen days, whilst five pupæ emerged in April of the following year, and then as Telamonides.

The explanation of these facts is easily afforded by the foregoing theory. According to this, both the winter forms must be regarded as primary, and the Marcellus form as secondary. But this last is not yet so firmly established as Prorsa, in which reversion of the summer generations to the Levana form only occurs through special external influences; whilst in the case of Ajax some individuals are to be found in every generation, the tendency of which to revert is still so strong that even the greatest summer heat is unable to cause them to diverge from their original inherited direction of development, or to accelerate their emergence and compel them to assume the Marcellus form. It is here beyond a doubt that it is not different external influences, but internal causes only, which maintain the old hereditary tendency, for all the larvæ and pupæ of many different broods were simultaneously exposed to the same external influences. But, at the same time, it is evident that these facts are not opposed to the present theory; on the contrary, they confirm it, inasmuch as they are readily explained on 
the basis of the theory, but can scarcely otherwise be understood.

If it be isked what significance attaches to the duplication of the winter form, it may be answered that the species was already dimorphic at the time when it appeared in only one annual generation. Still, this explanation may be objected to, since a dimorphism of this kind is not at present known, though indeed some species exhibit a sexual dimorphism, ${ }^{18}$ in which one sex (as, for instance, the case of the female Papilio Turnus) appears in two forms of colouring, but not a dimorphism, as is here the case, displayed by both sexes. ${ }^{19}$ Another suggestion, therefore, may perhaps be offered.

In $A$. Levana we saw that reversion occurred in very different degrees with different individuals, seldom attaining to the true Levana form, and

${ }^{18}$ [For other remarkable cases of sexual dimorphism (not antigeny in the sense used by Mr. S. H. Scudder, Proc. Amer. Acad., vol. xii. 1877 , pp. $150-158)$ see Wallace "On the Phenomena of Variation and Geographical Distribution, as illustrated by the Papilionidæ of the Malayan Region," Trans. Linn. Soc., vol. xxv. 1865, pp. 5-io. R.M.]

${ }^{10}$ [Eng. ed. Dimorphism of this kind has since been made known : the North American Limenitis Artemis and L. Proserpina are not two species, as was formerly believed, but only one. Edwards bred both forms from eggs of Proserpina. Both are single-brooded, and both have males and females. The two forms fly together, but $L$. Artemis is much more widely distributed, and more abundant than $L$. Proserpina. See "Butterflies of North America," vol. ii.] 
generally only reaching the intermediate form known as Porima. Now it would, at all events, be astonishing if with $P$. Ajax the reversion were always complete, as it is precisely in this case that the tendency to individual reversion is so variable. I might, for this reason, suppose that one of the two winter forms, viz. the var. Walshii, is nothing else than an incomplete reversion-form, corresponding to Porima in the case of $A$. Levana. Then Telamonides only would be the original form of the butterfly, and this would agree with the fact that this variety appears later in the spring than Walshii. Experiments ought to be able to decide this. ${ }^{20}$ The pupæ of the first

${ }^{20}$ [Eng. ed. Edwards has since proved experimentally that by the application of ice a large proportion of the pupæ do indeed give rise to the var. Telamonides. He bred from eggs of Telamonides 122 pupæ, which, under natural conditions, would nearly all have given the var. Marcellus. After two months' exposure to the low temperature there emerged,from August 24th to October I6th, fifty butterflies, viz. twenty-two Telamonides, one intermediate form between Telamonides and Walshii, eight intermediate forms between Telamonides ánd Marcellus more nearly related to the former, stx intermediate forms between Telamonides and Marcellus, but more closely resembling the latter, and thirteen Marcellus. Through various mishaps the action of the ice was not complete and equal. See the "Canadian Entomologist," 1875, p. 228. In the newly discovered case of Phyciodes Tharos also, Edwards has succeeded in causing the brood from the winter form to revert, by the application of ice to this same form. See Appendix II. for a résumé of Edwards' experiments upon both Papilio Ajax and Phyciodes Tharos. R.M.] 
three generations placed upon ice should give, for the greater part, the form Telamonides, for the lesser portion Walshii, and for only a few, or perhaps no individuals, the form Marcellus. This prediction is based on the view that the tendency to revert is on the whole great; that even with the first summer generation, which was the longest exposed to the summer climate, a portion of the pupæ, without artificial means, always emerged as Telamonides, and another portion as Marcellus. The latter will perhaps now become Walshii by the application of cold.

One would expect that the second and third generations would revert more easily, and in a larger percentage, than the first, because this latter first acquired the new Marcellus form; but the present experiments furnish no safe conclusion on this point. Thus, of the first summer generation only seven out of sixty-seven pupæ hibernated, and these gave Telamonides; while of the second generation forty out of seventy-six, and of the third generation twenty-nine out of forty-two pupæ hibernated. But to establish safer conclusions, a still larger number of experiments is necessary. According to the experience thus far gained, one might perhaps still be inclined to imagine that, with seasonal dimorphism, external influences operating on the individual might directly compel it to assume one or the other form. I long held this view myself, but it is, 
nevertheless, untenable. That cold does not produce the one kind of marking, and warmth the other, follows from the before-mentioned facts, viz. that in Papilio Ajax every generation produces both forms; and, further, in the case of A. Levana I have frequently reared the fourth (hibernating) generation entirely in a warm room, and yet I have always obtained the winter form. Still, one might be inclined not to make the temperature directly responsible, but rather the retardation or acceleration of development produced through the action of temperature. I confess that I for a long time believed that in this action I had found the true cause of seasonal dimorphism. Both with $A$. Levana and $P$. Napi the difference between the duration of the pupal period in the winter and summer forms is very great, lasting as a rule, in the summer generation of $A$. Levana, from seven to twelve days, and in the winter generation about two hundred days. In this last species the pupal state can certainly be shortened by keeping them at an elevated temperature; but I have, nevertheless, only in one case obtained two or three butterflies at the end of December from caterpillars that had pupated in September, these generally emerging in the course of February and March, and are to be seen on the wing in warm weather during the latter month. The greatest reduction of the pupal period still leaves for this stage more than 100 days. 
From this last observation it follows that it is not the duration of development which, in individual cases, determines the form of the butterfly, and which consequently decides whether the winter or summer form shall emerge, but that, on the contrary, the duration of the pupal stage is dependent on the tendency which the forthcoming butterfly had taken in the chrysalis state. This can be well understood when we consider that the winter form must have had a long, and the summer form a short pupal period, during innumerable generations. In the former the habit of slow development must have been just as well established as that of rapid development in the latter; and we cannot be at all surprised if we do not see this habit abandoned by the winter form when the opportunity presents itself. But that it may be occasionally abandoned the more proves that the duration of the pupal development less determines the butterfly form than does the temperature directly, in individual cases.

Thus, for instance, Edwards explicitly states that, whereas the two winter forms of $P$. Ajax, viz. the vars. Walshii and Telamonides, generally appear only after a pupal period of I 50 to 270 days, yet individual cases occur in which the pupal stage is no longer than in the summer form, viz. fourteen days. ${ }^{21}$ A similar thing occurs with

${ }^{21}$ Thus from eggs of Walshii, laid on April roth, Edwards obtained, after a pupal period of fourteen days, from the ist 
A. Levana, for, as already explained, not only may the development of the winter form be forced to a certain degree by artificial warmth, but the summer generation frequently produces reversionforms without protraction of development. The intermediate reversion-form Porima was known long before it was thought possible that it could be produced artificially by the action of cold; it appears occasionally, although very rarely, at midsummer in the natural state.

If, then, my explanation of the phenomena is correct, the winter form is primary and the summer the secondary form, and those individuals which, naturally or artificially, assume the winter form must be considered as cases of atavism. The suggestion thus arises whether low temperature alone is competent to bring about this reversion, or whether other external influences are not also effective. Indeed, the latter appears to be the case. Besides purely internal causes, as previously pointed out in $P$. Ajax, warmth and mechanical motion appear to be able to bring about reversion.

That an unusually high temperature may cause reversion, I conclude from the following observation. In the summer of I869 I bred the first summer brood of $A$. Levana; the caterpillars pupated during the second half of June, and from to the 6th of June, fifty-eight butterflies of the form Marcellus, one of Walshii, and one of Telamonides. 
that time to their emergence, on 28 th June- 3 rd July, great heat prevailed. Now, while the intermediate form Porima had hitherto been a great rarity, both in the free state and when bred, having never obtained it myself, for example, out of many hundreds of specimens, there were among the sixty or seventy butterflies that emerged from the above brood, some eight to ten examples of Porima. This is certainly not an exact experiment, but there seems to me a certain amount of probability that the high summer temperature in this case brought about reversion.

Neither for the second cause to which I have ascribed the power of producing reversion can I produce any absolute evidence, since the experimental solution of all these collateral questions would demand an endless amount of time. I am in possession of an observation, however, which makes it appear probable to me that continuous mechanical movement acts on the development of the pupæ in a similar manner to cold, that is, retarding them, and at the same time producing reversion. I had, in Freiburg, a large number of pupæ of the first summer brood of Pieris Napi, bred from eggs. I changed residence while many caterpillars were in course of transformation and travelled with the pupæ in this state seven hours by rail. Although this brood of $P$. Napi, under ordinary circumstances, always emerges in the summer, generally in July of the same year, as the 
summer form (var. Napea), yet out of these numerous pupæ I did not get a single butterfly during the year I872. In winter I kept them in a warm room, and the first butterflies emerged in January, 1873, the remainder following in February, March, and April, and two females not until June. All appeared, however, as exquisite winter forms. The whole course of development was precisely as though cold had acted on the pupæ; and in fact, I could find no other cause for this quite exceptional deportment than the seven hours' shaking to which the pupæ were exposed by the railway journey, immediately after or during their transformation.

It is obviously a fact of fundamental importance to the theory of seasonal dimorphism, that the summer form can be readily changed into the winter form, whilst the latter cannot be changed into the summer form. I have thus far only made experiments on this subject with $A$. Levana, but the same fact appears to me to obtain for $P$. Napi. I did not, however, operate upon the ordinary winter form of $P$. Napi, but chose for this experiment the variety Bryonia, well known to all entomologists. This is, to a certain extent, the potential winter form of $P . N a p i$; the male (Fig. I4, Plate I.) exactly resembles the ordinary winter form in the most minute detail, but the female is distinguished from $N a p i$ by a sprinkling of greyish brown scales over the whole of the upper side of 
the wings (Fig. 15, Plate I.). This type, Bryonia, occurs in Polar regions as the only form of Napi, and is also found in the higher Alps, where it flies in secluded meadows as the only form, but in other localities, less isolated, mixed with the ordinary form of the species. In both regions Bryonice produces but one generation in the year, and must thus, according to my theory, be regarded as the parent-form of Pieris Napi.

If this hypothesis is correct-if the variety Bryonice is really the original form preserved from the glacial period in certain regions of the earth, whilst $N a p i$ in its winter form is the first secondary form gradually produced through a warm climate, then it would be impossible ever to breed the ordinary form Napi from pupæ of Bryonice by the action of warmth, since the form of the species now predominant must have come into existence only by a cumulative action exerted on numerous generations, and not per saltum.

The experiment was made in the following manner: In the first part of June I caught a female of Bryonice in a secluded Alpine valley, and placed her in a capacious breeding-cage, where she flew about among the flowers, and laid more than a hundred eggs on the ordinary cabbage. Although the caterpillars in the free state feed upon another plant unknown to me, they readily ate the cabbage, grew rapidly, and pupated at the end of July. I then brought the pupæ into a hothouse in 
which the temperature fluctuated between $12^{\circ}$ and $24^{\circ} \mathrm{R}$. ; but, in spite of this high temperature, and-what is certainly of more special importancenotwithstanding the want of cooling at night, only one butterfly emerged the same summer, and that a male, which, from certain minute characteristic markings, could be safely identified as var. Bryonia. The other pupæ hibernated in the heated room, and produced, from the end of January to the beginning of June, 28 butterflies, all of which were exquisite Bryonice.

Experiment thus confirmed the view that Bryonice is the parent-form of Napi, and the description hitherto given by systematists ought therefore properly to be reversed. Pieris Bryonice should be elevated to the rank of a species, and the ordinary winter and summer forms should be designated as vars. Napi and Napea. Still I should not like to take it upon myself to increase the endless confusion in the synonomy of butterflies. In a certain sense, it is also quite correct to describe the form Bryonice as a climatic variety, for it is, in fact, established, if not produced, by climate, by which agency it is likewise preserved; only it is not a secondary, but the primary, climatic variety of Napi. In this sense most species might probably be described as climatic varieties, inasmuch as under the influence of another climate they would gradually acquire new characters, whilst, under the influence of the climate now prevailing 
in their habitats, they have, to a certain extent, acquired and preserved their present form.

The var. Bryonice is, however, of quite special interest, since it makes clear the relation which exists between climatic variation and seasonal dimorphism, as will be proved in the next section. The correctness of the present theory must first here be submitted to further proof.

It has been shown that the secondary forms of seasonally dimorphic butterflies do not all possess the tendency to revert in the same degree, but that this tendency rather varies with each individual. As the return to the primary form is synonymous with the relinquishing of the secondary, the greater tendency to revert is thus synonymous with the greater tendency to relinquish the secondary form, but this again is equivalent to a lesser stability of the latter; it must consequently be concluded that the individuals of a species are very differently influenced by climatic change, so that with some the new form must become sooner established than with others. From this a variability of the generation concerned must necessarily ensue, i. e., the individuals of the summer generation must differ more in colour and marking than is the case with those of the winter generation. If the theory is correct, the summer generations should be more variable than the winter generations-at least, so long as the greatest possible equalization of individual variations has not occurred through the continued action of warmth, combined with the 
constant crossing of individuals which have become changed in different degrees. Here also the theory is fully in accord with facts.

In $A$. Levana the Levana form is decidedly more constant than the Prorsa form. The first is, to a slight extent, sexually dimorphic, the female being light and the male dark-coloured. If we take into consideration this difference between the sexes, which also occurs to a still smaller extent in the Prorsa form, the foregoing statement will be found correct, viz. that the Levana form varies but little, and in all cases considerably less than the Prorsa form, in which the greatest differences occur in the yellow stripes and in the disappearance of the black spots on the white band of the hind wing, these black spots being persistent Levana markings. It is, in fact, difficult to find two perfectly similar individuals of the Prorsa form. It must, moreover, be considered that the Levana marking, being the more complicated, would the more readily show variation. Precisely the same thing occurs in Pieris Napi, in which also the var. Astiva is considerably more variable than the var. Vernalis. From the behaviour of the var. Bryonia, on the other hand, which I regard as the parent-form, one might be tempted to raise an objection to the theory; for this form is well known to be extraordinarily variable in colour and marking, both in the Alps and Jura, where it is met with at the greatest altitudes. According to the theory, Bryonia should be less variable 
than the winter form of the lowlands, because it is the older, and should therefore be the more constant in its characters. It must not be forgotten, however, that the variability of a species may not only originate in the one familiar manner of unequal response of the individual to the action of varying exciting causes, but also by the crossing of two varieties separately established in adjacent districts and subsequently brought into contact. In the Alps and Jura the ordinary form of $\mathrm{Napi}$ swarms everywhere from the plains towards the habitats of Bryonia, so that a crossing of the two forms may occasionally, or even frequently, take place; and it is not astonishing if in some places (Meiringen, for example) a perfect series of intermediate forms between Napi and Bryonice is met with. That crossing is the cause of the great variability of Bryonia in the Alpine districts, is proved by the fact that in the Polar regions this form " is by no means so variable as in the Alps, but, judging from about forty to fifty Norwegian specimens, is rather constant." My friend, Dr. Staudinger, who has twice spent the summer in Lapland, thus writes in reply to my question. A crossing with $N a p i$ cannot there take place, as this form is never met with, so that the ancient parent-form Bryonice has been able to preserve its original constancy. In this case also the facts thus accord with the requirements of the theory. 
On the Seasonal Dimorphism of Butterflies. 45

II.

\section{Seasonal Dimorphism and Climatic VARIATION.}

IF, as I have attempted to show, seasonal dimorphism originates through the slow operation of a changed summer climate, then is this phenomenon nothing else than the splitting up of a species into two climatic varieties in the same district, and we may expect to find various connexions between ordinary simple climatic variation and seasonal dimorphism.. Cases indeed occur in which seasonal dimorphism and climatic variation pass into each other, and are interwoven in such a manner that the insight into the origin and nature of seasonal dimorphism gained experimentally finds confirmation. Before I go more closely into this subject, however, it is necessary to come to an understanding as to the conception "climatic variation," for this term is often very arbitrarily applied to quite dissimilar phenomena.

According to my view there should be a sharp distinction made between climatic and local varieties. The former should comprehend only such cases as originate through the direct action 
of climatic influences; while under the general designation of "local forms," should be comprised all variations which have their origin in other causes-such, for example, as in the indirect action of the external conditions of life, or in circumstances which do not owe their present existence to climate and external conditions, but rather to those geological changes which produce isolation. Thus, for instance, ancient species elsewhere long extinct might be preserved in certain parts of the earth by the protecting influence of isolation, whilst others which immigrated in a state of variability might become transformed into local varieties in such regions through the action of ' amixia,' ${ }^{1}$ i. e. by not being allowed to cross with their companion forms existing in the other portions of their habitat. In single cases it may be difficult, or for the present impossible, to decide whether we have before us a climatic form, or a local form arising from other causes; but for this very reason we should be cautious in defining climatic variation.

The statement that climatic forms, in the true sense of the word, do exist is well known to me, and has been made unhesitatingly by all zoologists ; indeed, a number of authentically observed facts

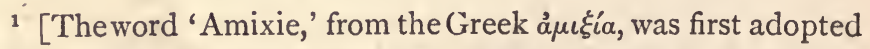
by the author to express the idea of the prevention of crossing by isolation in his essay " Über den Einfluss der Isolirung auf die Artbildung," Leipzig, I872, p. 49. R.M.] 
might be produced, which prove that quite constant changes in a species may be brought about by the direct action of changed climatic conditions. With butterflies it is in many cases possible to separate pure climatic varieties from other local forms, inasmuch as we are dealing with only unimportant changes and not with those of biological value, so that natural selection may at the outset be excluded as the cause of the changes in question. Then again the sharply-defined geographical distribution climatically governed, often furnishes evidence of transition forms in districts lying between two climatic extremes.

In the following attempt to make clear the relationship between simple climatic variation and seasonal dimorphism, I shall concern myself only with such undoubted climatic varieties. A case of this kind, in which the winter form of a seasonally dimorphic butterfly occurs in other habitats as the only form, i.e., as a climatic variety, has already been adduced in a former paragraph. I allude to the case of Pieris Napi, the winter form of which seasonally dimorphic species occurs in the temperate plains of Europe, whilst in Lapland and the Alps it is commonly found as a monomorphic climatic variety which is a higher development of the winter type, viz., the var. Bryonia.

Very analogous is the case of Euchloe Betia, a butterfly likewise belonging to the Pievina, 
which extends from the Mediterranean countries to the middle of France, and everywhere manifests a very sharply pronounced seasonal dimorphism. Its summer form was, until quite recently, described as a distinct species, E. Ausonia. Staudinger was the first to prove by breeding that the supposed two species were genetically related. ${ }^{2}$ This species, in addition to being found in the countries named, occurs also at a little spot in the Alps in the neighbourhood of the Simplon Pass. Owing to the short summer of the Alpine climate the species has in this locality but one annual brood, which bears the characters of the winter form, modified in all cases by the coarser thickly scattered hairs of the body (peculiar to many Alpine butterflies,) and some other slight differences. The var. Simplonia is thus in the Alps a simple climatic variety, whilst in the plains of Spain and the South of France it appears as the winter form of a seasonally dimorphic species.

This Euchloe var. Simplonia obviously corresponds to the var. Bryonice of Pieris Napi, and it is highly probable that this form of $E$. Belia must likewise be regarded as the parent-form of the species surviving from the glacial epoch, although it cannot be asserted, as can be done in the case of Bryonice, that the type has undergone

2 [Eng. ed. In 1844 , Boisduval maintained this relationship of the two forms. See Speyer's "Geographische Verbreit. d. Schmetterl.," i. p. 455.] 
no change since that epoch, for Bryonice from Lapland is identical with the Alpine form, ${ }^{3}$ whilst $E$. Simplonia does not appear to occur in Polar countries.

Very interesting also is the case of Polyommatus Phlaas, Linn., one of our commonest Lycanida, which has a very wide distribution, extending from Lapland to Spain and Sicily. ${ }^{4}$ If we compare specimens of this beautiful copper-coloured butterfly from Lapland with those from Germany, no constant difference can be detected; the insect has, however, but one annual generation in Lapland, whilst in Germany it is double-brooded; but the winter and summer generations resemble each other completely, and specimens which had been caught in spring on the Ligurian coast were likewise similarly coloured to those from Sardinia. (Fig. 2 I, Plate II.). According to these facts we might

3 According to a written communication from Dr. Staudinger, the female Bryonice from Lapland are never so dusky as is commonly the case in the Alps, but they often have, on the other hand, a yellow instead of a white ground-colour. In the Alps, yellow specimens are not uncommon, and in the Jura are even the rule.

- [According to W. F. Kirby (Syn. Cat. Diurn. Lepidop.), the species is almost cosmopolitan, occurring, as well as throughout Europe, in Northern India (var. Timeus), Shanghai (var. Chinensis), Abyssinia (var. Pseudophlaas), Massachusetts (var. Americana), and California (var. Hypophlaeas). In a long series from Northern India, in my own collection, all the specimens are extremely dark, the males being almost black. R.M.] 
believe this species to be extraordinarily indifferent to climatic influence; but the South European summer generation differs to a not inconsiderable extent from the winter generation just mentioned, the brilliant coppery lustre being nearly covered with a thick sprinkling of black scales. (Plate II., Fig. 22.) The species has thus become seasonally dimorphic under the influence of the warm southern climate, although this is not the case in Germany where it also has two generations in the year. ${ }^{5}$ No one who is acquainted only with the Sardinian summer form, and not with the winter form of that place, would hesitate to regard the former as a climatic variety of our $P$. Phlceas; or, conversely, the north German form as a climatic variety of the southern summer formaccording as he accepts the one or the other as the primary form of the species.

Still more complex are the conditions in another species of Lycanida, Plebeius Agestis (=Alexis Scop.), which presents a double seasonal dimorphism. This butterfly appears in three forms ; in Germany $\mathrm{A}$ and $\mathrm{B}$ alternate with each other as winter and summer forms, whilst in Italy B and C succeed each other as winter and summer

- [Eng. ed. From a written communication from Dr. Speyer, it appears that also in Germany there is a small difference between the two generations. The German summer brood has likewise more black on the upper side, although seldom so much as the South European summer brood.] 
forms. The form B thus occurs in both climates, appearing as the summer form in Germany and as the winter form in Italy. The German winter variety $A$, is entirely absent in Italy (as I know from numerous specimens which I have caught), whilst the Italian summer form, on the other hand, (var. Allous, Gerh.), does not occur in Germany. The distinctions between the three forms are sufficiently striking. The form A (Fig. I8, Plate II.) is blackish brown on the upper side, and has in the most strongly marked specimens only a trace of narrow red spots round the borders; whilst the form B (Fig. I 9, Plate II.) is ornamented with vivid red border spots ; and $\mathrm{C}$ (Fig. 20, Plate II.) is distinguished from $\mathrm{B}$ by the strong yellowish-brown of the under side. If we had before us only the German winter and the Italian summer forms, we should, without doubt, regard them as climatic varieties; but they are connected by the form $B$, interpolated in the course of the development of both, and the two extremes thus maintain the character of mere seasonal forms. 


\section{Nature of the Causes producing Climatic VARIETIES.}

IT has been shown that the phenomenon of seasonal dimorphism has the same proximate cause as climatic variation, viz. change of climate, and that it must be regarded as identical in nature with climatic variation, being distinguished from ordinary, or, as I have designated it, simple (monomorphic) climatic variation by the fact that, besides the new form produced by change of climate, the old form continues to exist in genetic connexion with it, so that old and new forms alternate with each other according to the season.

Two further questions now present themselves for investigation, viz. (I) by what means does change of climate induce a change in the marking and colouring of a butterfly? and (2) to what extent does the climatic action determine the nature of the change?

With regard to the former question, it must, in the first place, be decided whether the true effect of climatic change lies in the action of a high or low temperature on the organism, or whether it may 
not perhaps be produced by the accelerated development caused by a high temperature, and the retarded development caused by a low temperature. Other factors belonging to the category of external conditions of life which are included in the term " climate" may be disregarded, as they are of no importance in these cases. The question under consideration is difficult to decide, since, on the one hand, warmth and a short pupal period, and, on the other hand, cold and a long pupal period, are generally inseparably connected with each other; and without great caution one may easily be led into fallacies, by attributing to the influence of causes now acting that which is but the consequence of long inheritance.

When, in the case of Araschnia Levana, even in very cold summers, Prorsa, but never the Levana form, emerges, it would still be erroneous to conclude that it is only the shorter period of development of the winter generation, and not the summer warmth, which occasioned the formation of the Prorsa type. This new form of the species did not come suddenly into existence, but (as appears sufficiently from the foregoing experiments) originated in the course of many generations, during which summer warmth and a short development period were generally associated together. From the fact that the winter generation always produces Levana, even when the pupæ have not been exposed to cold but kept in a room, it would be 
equally erroneous to infer that the cold of winter had no influence in determining the type. In this case also the determining causes must have been in operation during innumerable generations. After the winter form of the species has become established throughout such a long period, it remains constant, even when the external influence which produced it (cold) is occasionally withdrawn.

Experiments cannot furrther assist us here, since we cannot observe throughout long periods of time; but there are certain observations, which to me appear decisive. When, both in Germany and Italy, we see Polyommatus Phlcas appearing in two generations, of which both the German ones are alike, whilst in Italy the summer brood is black, we cannot ascribe this fact to the influence of a shorter period of development, because this period is the same both in Germany and Italy (two annual generations), so that it can only be attributed to the higher temperature of summer.

Many similar cases might be adduced, but the one given suffices for proof. I am therefore of opinion that it is not the duration of the period of development which is the cause of change in the formation of climatic varieties of butterflies, but only the temperature to which the species is exposed during its pupal existence. In what manner, then, are we to conceive that warmth acts on the marking and colouring of a butterfly? This is a question which could only be completely answered 
by gaining an insight into the mysterious chemicophysiological processes by which the butterfly is formed in the chrysalis; and indeed only by such a complete insight into the most minute details, which are far beyond our scrutiny, could we arrive at, or even approximate to, an explanation of the development of any living organism. Nevertheless an important step can be taken towards the solution of this problem, by establishing that the change does not depend essentially upon the action of warmth, but upon the organism itself, as appears from the nature of the change in one and the same species.

If we compare the Italian summer form of Polyommatus Phlcas with its winter form, we shall find that the difference between them consists only in the brilliant coppery red colour of the latter being largely suffused in the summer form with black scales. When entomologists speak of a "black dusting" of the upper side of the wings, this statement must not of course be understood literally; the number of scales is the same in both forms, but in the summer variety they are mostly black, a comparatively small number being red. We might thus be inclined to infer that, owing to the high temperature, the chemistry of the material undergoing transformation in Phlcas is changed in such a manner that less red and more black pigment is produced. But the case is not so simple, as will appear evident when we consider 
the fact that the summer forms have not originated suddenly, but only in the course of numerous generations; and when we further compare the two seasonal forms in other species. Thus in Pieris Napi the winter is distinguished from the summer form, among other characters, by the strong black dusting of the base of the wings. But we cannot conclude from this that in the present case more black pigment is produced in the winter than in the summer form, for in the latter, although the base of the wings is white, their tips and the black spots on the fore-wings are larger and of a deeper black than in the winter form. The quantity of black pigment produced does not distinguish between the two forms, but the mode of its distribution upon the wings.

Even in the case of species the summer form of which really possesses far more black than the winter form, as, for instance, Araschnia Levana, one type cannot be derived from the other simply by the expansion of the black spots present, since on the same place where in Levana a black band crosses the wings, Prorsa, which otherwise possesses much more black, has a white line. (See Figs. I-9, Plate I.) The intermediate forms which have been artificially produced by the action of cold on the summer generation present a graduated series, according as reversion is more or less complete; a black spot first appearing in the middle of the white band of Prorsa, and then becoming en- 
larged until, finally, in the perfect Levana it unites with another black triangle proceeding from the front of the band, and thus becomes fused into a black bar. The white band of Prorsa and the black band of Levana by no means correspond in position; in Prorsa quite a new pattern appears, which does not originate by a simple colour replacement of the Levana marking. In the present case, therefore, there is no doubt that the new form is not produced simply because a certain pigment (black) is formed in larger quantities, but because its mode of distribution is at the same time different, white appearing in some instances where black formerly existed, whilst in other cases the black remains. Whoever compares Prorsa with Levana will not fail to be struck with the remarkable change of marking produced by the direct action of external conditions.

The numerous intermediate forms which can be produced artificially appear to me to furnish a further proof of the gradual character of the transformation. Ancestral intermediate forms can only occur where they have once had a former existence in the phyletic series. Reversion may only take place completely in some particular characters, whilst in others the new form remains constantthis is in fact the ordinary form of reversion, and in this manner a mixture of characters might appear which never existed as a phyletic stage; but particular characters could certainly never appear unless they were normal to the species at some 
stage of phyletic development. Were this possible it would directly contradict the idea of reversion. according to which new characters never make their appearance, but only such as have already existed. If, therefore, the ancestral forms of $A$. Levana (which we designate as Porima) present a great number of transitional varieties, this leads to the conclusion that the species must have gone through a long series of stages of phyletic development before the summer generation had completely changed into Prorsa. The view of the slow cumulative action of climatic influences already submitted, is thus confirmed.

If warmth is thus without doubt the agency which has gradually changed the colour and marking of many of our butterflies, it sufficiently appears from what has just been said concerning the nature of the change that the chief part in the transmutation is not to be attributed to the agency in question, but to the organism which is affected by it. Induced by warmth, there begins a change in the ultimate processes of the matter undergoing transformation, which increases from generation to generation, and which not only consists in the appearance of the colouring matter in one place instead of another, but also in the replacement of yellow, in one place by white and in another by black, or in the transformation of black into white on some portions of the wings, whilst in others black remains. When we consider with what 
extreme fidelity the most insignificant details of marking are, in constant species of butterflies, transmitted from generation to generation, a total change of the kind under consideration cannot but appear surprising, and we should not explain it by the nature of the agency (warmth), but only by the nature of the species affected. The latter cannot react upon the warmth in the same manner that a solution of an iron salt reacts upon potassium ferrocyanide or upon sulphuretted hydrogen; the colouring matter of the butterfly's wing which was previously black does not become blue or yellow, nor does that which was white become changed into black, but a new marking is developed from the existing one-or, as I may express it in more general terms, the species takes another course of development; the complicated chemico-physical processes in the matter composing the pupa become gradually modified in such a manner that, as the final result, a new marking and colouring of the butterfly is produced.

Further facts can be adduced in support of the view that in these processes it is the constitution of the species, and not the external agency (warmth), which plays the chief part. The latter, as Darwin has strikingly expressed it, rather performs the function of the spark which ignites a combustible substance, whilst the character of the combustion depends upon the nature of the explosive material. Were this not the case, increased 
warmth would always change a given colour ${ }^{1}$ in the same manner in all butterflies, and would therefore always give rise to the production of the same colour. But this does not occur; Polyommatus Phlaas, for example, becoming black in the south, whilst the red-brown Vanessa Urtice becomes black in high northern latitudes, and many other cases well known to entomologists might be adduced. ${ }^{2}$ It indeed appears that species of similar physical constitution, i.e., nearly allied species, under similar climatic influences, change in an analogous manner. A beautiful example of this is furnished by our Pierince. Most of the species display seasonal dimorphism; as, for instance, Pieris Brassica, Rapa, Napi, Krueperi, and Daplidice, Euchloe Belia and Belemia, and Leucophasia Sinapis, in all of which the difference between the winter and the summer forms is of a precisely

1 [Assuming that in all butterflies similar colours are produced by the same chemical compounds. R.M.]

${ }^{2}$ [Mr. H. W. Bates mentions instances of local variation in colour affecting many distinct species in the same district in his memoir "On the Lepidoptera of the Amazon Valley;" 'Trans. Linn. Soc., vol. xxiii. Mr. A. R. Wallace also has brought together a large number of cases of variation in colour according to distribution, in his address to the biological section of the British Association at Glasgow in 1876 . See "Brit. Assoc. Report," I876, pp. Iо0-1 10: For observations on the change of colour in British Lepidoptera according to distribution see papers by Mr. E. Birchall in "Ent. Mo. Mag," Nov., 1 876, and by Dr. F. Buchanan White, "Ent. Mo. Mag.," Dec., 1876 . The colour variations in all these cases are of course not protective as in the well-known case of Gnophos obscurata, \&c. R.M.] 
similar nature. The former are characterized by a strong black dusting of the base of the wings, and by a blackish or green sprinkling of scales on the underside of the hind wings, while the latter have intensely black tips to the wings, and frequently also spots on the fore-wings.

Nothing can prove more strikingly, however, that in such cases everything depends upon the physical constitution, than the fact that in the same species the males become changed in a different manner to the females. The parent form of Pieris Napi (var. Bryonia) offers an example. In all the Pierine secondary sexual differences are found, . the males being differently marked to the females ; the species are thus sexually dimorphic. Now the male of the Alpine and Polar var. Bryonia, which I conceive to be the ancestral form, is scarcely to be distinguished, as has already been mentioned, from the male of our German winter form $(P$. Napi, var. Vernalis), whilst the female differs considerably. ${ }^{3}$ The gradual climatic change which transformed the parent form Bryonice into Napi has therefore exerted a much greater effect on the female than on the male. The external action on the two sexes was exactly the same, but the response of the organism was different, and the cause of the difference can only be sought for in the fine differences of physical constitution which distinguish the male from the female. If we are

' See Figs. ro and 14, 1 r and I5, Plate I. 
unable to define these differences precisely, we may nevertheless safely conclude from such observations that they exist.

I have given special prominence to this subject because, in my idea, Darwin ascribes too much power to sexual selection when he attributes the formation of secondary sexual characters to the sole action of this agency. The case of Bryonice teaches us that such characters may arise from purely innate causes; and until experiments have decided how far the influence of sexual selection extends, we are justified in believing that the sexual dimorphism of butterflies is due in great part to the differences of physical constitution between the sexes. It is quite different with such sexual characters as the stridulating organs of male Orthoptera which are of undoubted importance to that sex. These can certainly be attributed with great probability to sexual selection.

It may perhaps not be superfluous to adduce one more similar case, in which, however, the male and not the female is the most affected by climate. In our latitudes, as also in the extreme north, Polyommatus Phlcas, already so often mentioned, is perfectly similar in both sexes in colour and marking; and the same holds good for the winter generation of the south. The summer generation of the latter, however, exhibits a slight sexual dimorphism, the red of the fore wings of the female being less completely covered with black than in the male. 
On the Seasonal Dimorphism of Butterflies. 63

\section{IV.}

Why all Polygoneutic Species are not Seasonally Dimorphic.

IF we may consider it to be established that seasonal dimorphism is nothing else than the splitting up of a species into two climatic varieties in one and the same locality, the further question at once arises why all polygoneutic species (those which produce more than one annual generation) are not seasonally dimorphic.

To answer this, it will be necessary to go more deeply into the development of seasonal dimorphism. This evidently depends upon a peculiar kind of periodic, alternating heredity, which we might be tempted to identify with Darwin's " inheritance at corresponding periods of life." It does not, however, in any way completely agree with this principle, although it presents a great analogy to it and must depend ultimately upon the same cause. The Darwinian "inheritance at corresponding periods of life"-or, as it is termed by Haeckel, "homochronic heredity"is characterized by the fact that new characters always appear in the individuals at the same stage 
of life as that in which they appeared in their progenitors. The truth of this principle has been firmly established, instances being known in which both the first appearance of a new (especially pathological) character and its transmission through several generations has been observed. Seasonally dimorphic butterflies also furnish a further valuable proof of this principle, since they show that not only variations which arise suddenly (and which are therefore probably due to purely innate causes) follow this mode of inheritance, but also that characters gradually called forth by the influence of external conditions and accumulating from generation to generation, are only inherited at that period of life in which these conditions were or are effective. In all seasonally dimorphic butterflies which I have been able to examine closely, I found the caterpillars of the summer and winter broods to be perfectly identical. The influences which, by acting on the pupæ, split up the imagines into two climatic forms, were thus without effect on the earlier stages of development. I may specially mention that the caterpillars, as well as the pupæ and eggs of $A$. Levana, are perfectly alike both in the summer and winter forms; and the same is the case in the corresponding stages of $P$. Napi and P. Bryonia.

I shall not here attempt to enter more deeply into the nature of the phenomena of inheritance. It is sufficient to have confirmed the law that 
influences which act only on certain stages in the development of the individual, even when the action is cumulative and not sudden, only affect those particular stages without having any effect on the earlier or later stages. This law is obviously of the greatest importance to the comprehension of metamorphosis. Lubbock $^{1}$ has briefly shown in a very clear manner how the existence of metamorphosis in insects can be explained by the indirect action of varying conditions on the different life-stages of a species. Thus the mandibles of a caterpillar are, by adaptation to another mode of nourishment, exchanged at a later period of life for a suctorial organ. Such adaptation of the various development-stages of a species to the different conditions of life would never give rise to metamorphosis, if the law of homochronic, or periodic, heredity did not cause the characters gradually acquired at a given stage to be transferred to the same stage of the following generation.

The origin of seasonal dimorphism depends upon a very similar law, or rather form, of inheritance, which differs from that above considered only in the fact that, instead of the ontogenetic stages, a whole series of generations is influenced. This form of inheritance may be formulated somewhat as follows:- When dissimilar conditions

1 "On the Origin and Metamorphoses of Insects," London, 187.4 . 
alternatingly influence a series of generations, a cycle is produced in which the changes are transmitted only to those generations which are acted upon by corresponding conditions, and not to the intermediate ones. Characters which have arisen by the action of a summer climate are inherited by the summer generation only, whilst they remain latent in the winter generation. It is the same as with the mandibles of a caterpillar which are latent in the butterfly, and again make their appearance in the corresponding (larval) stage of the succeeding generation. This is not mere hypothesis, but the legitimate inference from the facts. If it be admitted that my conception of seasonal dimorphism as a double climatic variation is correct, the law of " cyclical heredity,"2 as I may term it-in contradistinction to "homochronic heredity," which relates only to the ontogenetic stages-immediately follows. All those cases which come under the designation of 'alternation of generation,' can obviously be referred to cyclical heredity, as will be explained further on. In the one case the successive generations deport them-

2 I at first thought of designating the two forms of cyclical or homochronic heredity as ontogenetic- and phyletic-cyclical heredity. The former would certainly be correct; the latter would be also applicable to alternation of generation (in which actually two or more phyletic stages alternate with each other) but not to all those cases which I attribute to heterogenesis, in which, as with seasonal dimorphism, a series of generations of the same phyletic stage constitute the point of departure. 
selves exactly in the same manner as do the successive stages of development of the individual in the other; and we may conclude therefrom (as has long been admitted on other grounds) that a generation is, in fact, nothing else than a stage of development in the life of a species. This appears to me to furnish a beautiful confirmation of the theory of descent.

Now if, returning to questions previously solved, the alternating action of cold in winter and warmth in summer leads to the production of a winter and summer form, according to the law of cyclical heredity, the question still remains : why do we not find seasonal dimorphism in all polygoneutic butterflies?

We might at first suppose that all species are not equally sensitive to the influence of temperature: indeed, the various amounts of difference between the winter and summer forms in different species would certainly show the existence of different degrees of sensitiveness to the modifying action of temperature. But even this does not furnish an explanation, since there are butterflies which produce two perfectly similar ${ }^{3}$ generations

3 When Meyer-Dür, who is otherwise very accurate, states in his "Verzeichniss der Schmetterlinge der Schweiz," (r852, p. 207), that the winter and summer generations of P. Afgeria differ to a small extent in the contour of the wings and in marking, he has committed an error. The characters which this author attributes to the summer form are much more appli- 
wherever they occur, and which, nevertheless, appear in different climates as climatic varieties. This is the case with Pararga Ageria (Fig. 23, Plate II.), the southern variety of which, Meione (Fig. 24, Plate II.), is connected with it by an intermediate form from the Ligurian coast. This species possesses, therefore, a decided power of responding to the influence of temperature, and yet no distinction has taken place between the summer and the winter form. We can thus only attribute this different deportment to a different kind of heredity; and we may therefore plainly state, that changes produced by alternation of climate are not always inherited alternatingly, i. e. by the corresponding generations, but sometimes continuously, appearing in every generation, and never remaining latent. The causes which determine why, in a particular case, the one or the other form of inheritance prevails, can be only innate, i. e. they lie in the organism itself, and there is as little to be said upon their precise nature as upon that of any other process of heredity. In a similar manner Darwin admits a kind of double inheritance with respect to characters produced by sexual selection; in one form these characters remain limited to the sex which first acquired them, in the other form they are inherited by both sexes, without it cable to the female sex. There exists in this species a trifling sexual dimorphism, but no seasonal dimorphism. 
being apparent why, in any particular case, the one or the other form of heredity should take place.

The foregoing explanation may obtain in the case of sexual selection, in which it is not inconceivable that certain characters may not be so easily produced, or even not produced at all, in one sex, owing to its differing from the other in physical constitution. In the class of cases under consideration, however, it is not possible that the inherited characters can be prevented from being acquired by one generation owing to its physical constitution, since this constitution was similar in all the successive generations before the appearance of dimorphism. The constitution in question first became dissimilar in the two generations to the extent of producing a change of specific character, through the action of temperature on the alternating broods of each year, combined with cyclical heredity. If the law' of cyclical heredity be a general one, it must hold good for all cases, and characters acquired by the summer generation could never have been also transmitted to the winter generation from the very first.

I will not deny the possibility that if alternating heredity should become subsequently entirely suppressed throughout numerous generations, a period may arrive when the preponderating influence of a long series of summer generations may ultimately 
take effect upon the winter generation. In such a case the summer characters would appear, instead of remaining latent as formerly. In this manner it may be imagined that at first but few, and later more numerous individuals, approximate to the summer form, until finally the dimorphism entirely disappears, the new form thus gaining ascendency and the species becoming once more monomorphic. Such a supposition is indeed capable of being supported by some facts, an observation on $A$. Levana apparently contradicting the theory having been already interpreted in this sense. I refer to the fact that whilst some butterflies of the winter generation emerge in October as Prorsa, others hibernate, and appear the following spring in the Levana form. The winter form of Pievis Napi also no longer preserves, in the female sex, the striking coloration of the ancestral form Bryonice, a fact which may indicate the influencing of the winter generation by numerous summer generations. The double form of the spring generation of Papilio Ajax can be similarly explained by the gradual change of alternating into continuous heredity, as has already been mentioned. All these cases, however, are perhaps capable of another interpretation; at any rate, the correctness of this supposition can only be decided by further facts.

Meanwhile, even if we suppose the above ex- 
planation to be correct, it will not apply to the absence of seasonal dimorphism in cases like that of Pararga Ageria and Meione, in which only one summer generation appears, so that a preponderating inheritance of summer characters cannot be admitted. Another explanation must thus be sought, and I believe that I have found it in the circumstance that the butterflies named do not hibernate as pupæ but as caterpillars, so that the cold of winter does not directly influence those processes of development by which the perfect insect is formed in the chrysalis. It is precisely on this point that the origin of those differences of colour which we designate as the seasonal dimorphism of butterflies, appears to depend. Previous experiments give great probability to this statement. From these we know that the eggs, caterpillars, and pupæ of all the seasonally dimorphic species experimented with: are perfectly similar in the summer and winter generations, the imago stage only showing any difference. We know further from these experiments, that temperature-influences which affect the caterpillars never entail a change in the butterflies; and finally, that the artificial production of the reversion of the summer to the winter form can only be brought about by operating on the pupæ.

Since many monogoneutic species now hibernate in the caterpillar stage (e. g. Satyrus Proserpina, and Hermione, Epinephele Eudora, Furtina, 
Tithonus, Hyperanthus, Ida, $\mathcal{E} c$.), we may admit that during the glacial period such species did not pass the winter as pupæ. As the climate grew warmer, and in consequence thereof a second generation became gradually interpolated in many of these monogoneutic species, there would ensue (though by no means necessarily) a disturbance of the winter generation, of such a kind that the pupæ, instead of the caterpillars as formerly, would then hibernate. It may, indeed, be easily proved $a$ priori that whenever a disturbance of the winter generation takes place it only does so retrogressively, that is to say-species which at one time pass the winter as caterpillars subsequently hibernate in the egg, while those which formerly hibernate as pupæ afterwards do so as caterpillars. The interpolation of a summer generation must necessarily delay till further towards the end of summer, the brood about to hibernate; the remainder of the summer, which serves for the development of the eggs and young caterpillars, may possibly under these conditions be insufficient for pupation, and the species which hibernated in the pupal state when it was monogoneutic, may perhaps pass the winter in the larval condition after the introduction of the second brood. A disturbance of this kind is conceivable ; but it is certain that many species suffer no further alteration in their development than that of becoming digoneutic from monogoneutic. This follows 
from the fact that hibernation takes place in the caterpillar stage in many species of the sub-family Satyrida which are now digoneutic, as well as in the remaining monogoneutic species of the same sub-family. But we cannot expect seasonal dimorphism to appear in all digoneutic butterflies the winter generation of which hibernates in the caterpillar form, since the pupal stage in these species experiences nearly the same influences of temperature in both generations. We are hence led to the conclusion that seasonal dimorphism must arise in butterflies whenever the pupæ of the alternating annual generations are exposed throughout long periods of time to widely different regularly recurring changes of temperature.

The facts agree with this conclusion, inasmuch as most butterflies which exhibit seasonal dimorphism hibernate in the pupa stage. Thus, this is the case with all the Pierina, with Paprlio Machaon, P. Podalivius, and P. Ajax, as well as with Araschnia Levana. Nevertheless, it cannot be denied that seasonal dimorphism occurs also in some species which do not hibernate as pupæ but as caterpillars; as, for instance, in the strongly dimorphic Plebeius Amyntas. But such cases can be explained in a different manner.

Again, the formation of a climatic variety-and as such must we regard seasonally dimorphic forms-by no means entirely depends on the 
magnitude of the difference between the témperature which actson the pupæ: of the primary and that which acts on those of the secondary form; it rather depends on the absolute temperature which the pupæexperience. This follows without doubt from the fact that many species, such as our common Swallow-tail (Papilio Machaon), and also $P$. Podalivius, in Germany and the rest of temperate Europe, show no perceptible difference of colour between the first generation, the pupæ of which hibernate, and the second generation, the pupal period of which falls in July, whereas the same butterflies in South Spain and Italy are to a small extent seasonally dimorphic. Those butterflies which are developed under the influence of a Sicilian summer heat likewise show climatic variation to a small extent. The following consideration throws further light on these conditions. The mean summer and winter temperatures in Germany differ by about $14.9^{\circ} \mathrm{R}$.; this difference being therefore much more pronounced than that between the German and Sicilian summer, which is only about $3 \cdot 6^{\circ} \mathrm{R}$. Nevertheless, the winter and summer generations of $P$. Podalirius are alike in Germany, whilst the Sicilian summer generation has become a climatic variety. The cause of this change must therefore lie in the small difference between the mean summer temperatures of $15.0^{\circ}$ R. (Berlin) and 19.4 ${ }^{\circ}$ R. (Palermo). According to this, a given 
absolute temperature appears to give a tendency to variation in a certain direction, the necessary temperature being different for different species. The latter statement is supported by the facts that, in the first place, in different species there are very different degrees of difference between the slimmer and winter forms; and secondly, many digoneutic species are still monomorphic in Germany, first becoming seasonally dimorphic in Southern Europe. This is the case with $P$. Machaon and P. Podalivius, as already mentioned, and likewise with Polyommatus Phlceas. Zeller in I 846-47, during his journey in Italy, recognized as seasonally dimorphic in a small degree a large number of diurnal Lepidoptera which are not so in our climate. ${ }^{4}$

In a similar manner the appearance of seasonal dimorphism in species which, like Plebeius Amyntas, do not hibernate as pupæ, but as caterpillars, can be simply explained by supposing that the winter generation was the primary form, and that the increase in the summer temperature since the glacial period was sufficient to cause this particular species to become changed by the gradual interpolation of a second generation. The dimorphism of $P$. Amyntas can, nevertheless, be explained in another manner. Thus, there may

4 P. C. Zeller, "Bemerkungen über die auf einer Reise nach Italien und Sicilien gesammelten Schmetterlingsarten." Isis, I 847 , ii. - xii. 
have been a disturbance of the period of development in the manner already indicated, the species which formerly hibernated in the pupal stage becoming subsequently disturbed in its course of development by the interpolation of a summer generation, and hibernating in consequence in the caterpillar state. Under these circumstances we must regard the present winter form (var. Polysperchon) as having been established under the influence of a winter climate, this form, since the supposed disturbance in its development, having had no reason to become changed, the spring temperature under which its pupation now takes place not being sufficiently high. The interpolated second generation on the other hand, the pupal period of which falls in the height of summer, may easily have become formed into a summer variety.

This latter explanation agrees precisely with the former, both starting with the assumption that in the present case, as in that of $A$. Levana and the Pierina, the winter form is the primary one, so that the dimorphism proceeds from the said winter form and does not originate the winter but the summer form, as will be explained. Whether the winter form has been produced by the action of the winter or spring temperature is immaterial in judging single cases, inasmuch as we are not in a position to state what temperature is necessary to cause any particular species to become transformed. 
The reverse case is also theoretically conceivable, viz., that in certain species the summer form was the primary one, and by spreading northwards a climate was reached which still permitted the production of two generations, the pupal stage of one generation being exposed to the cold of winter, and thus giving rise to the production of a secondary winter form. In such a case hibernation in the pupal state would certainly give rise to seasonal dimorphism. Whether these conditions actually occur, appears to me extremely doubtful ; but it may at least be confidently asserted that the first case is of far more frequent occurrence. The beautiful researches of Ernst Hoffmann ${ }^{5}$ furnish strong evidence for believing that the great majority of the European butterflies have immigrated, not from the south, but from Siberia. Of 28 I species, I73 have, according to Hoffmann, come from Siberia, 39 from southern Asia, and only 8 from Africa, whilst during the greatest cold of the glacial period, but very few or possibly no species existed north of the Alps. Most of the butterflies now found in Europe have thus, since their immigration, experienced a gradually increasing warmth. Since seasonal dimorphism has been developed in some of these species, the summer form must in all cases have been the secondary one, as the experiments upon

- "Isoporien der europäischen Tagfalter." Stuttgart, x 873. 
the reversion of Pieris Napi and Araschnia Levana have also shown.

All the seasonally dimorphic butterflies known to me are found in Hoffmann's list of Siberian immigrants, with the exception of two species, viz., Euchloe Belemia, which is cited as an African immigrant, and Pieris Krueperi, which may have come through Asia Minor, since at the present time it has not advanced farther west than Greece. No considerable change of climate can be experienced by migrating from east to west, so that the seasonal dimorphism of Pieris Krueperi can only depend on a cause similar to that which affected the Siberian immigrants, that is, the gradual increase of temperature in the northern hemisphere since the glacial period. In this species also, the winter form must be the primary one. In the case of E. Belemia, on the other hand, the migration northwards from Africa certainly indicates removal to a cooler climate, which may have originated a secondary winter form, even if nothing more certain can be stated. We know nothing of the period of migration into southern Europe; and even migration without climatic change is conceivable, if it kept pace with the gradual increase of warmth in the northern hemisphere since the glacial epoch. Experiments only would in this case be decisive. If the summer generation, var. Glance, were the primary form, it would not be possible by the action of 
cold on the pupæ of this brood to produce the winter variety Belemia, whilst, on the other hand, the pupæ of the winter generation by the influence of warmth would be made to revert more or less completely to the form Glauce. It is by no means to be understood that the species would actually comport itself in this manner. On the contrary, I am of opinion that in this case also, the winter form is primary. The northward migration (from Africa to south Spain) would be quite insufficient, and the winter form is now found in Africa as well as in Spain. 
On Alternation of Generations.

Seasonal dimorphism has already been designated by Wallace as alternation of generation, ${ }^{1}$ a term which cannot be disputed so long as it is confined to a regular alternation of dissimilar generations. But little is gained by this definition, however, unless it can be proved that both phenomena are due to similar causes, and that they are consequently brought about by analogous processes. The causes of alternation of generation have, until the present time, been scarcely investigated, owing to the want of material. Haeckel alone has quite recently subjected these complicated phenomena generally to a searching investigation, and has arrived at the conclusion that the various forms of metagenesis can be arranged in two series. He distinguishes a progressive and a retrogressive series, comprising under the former those species "which, to a certain extent, are still in a transition stage from monogenesis to amphigenesis (asexual to sexual propagation), and the early progenitors

${ }^{1}$ [Trans. Linn. Soc., vol. xxv. 1865, p. 9. R. M.] 
On the Seasonal Dimorphism of Butterfies. 8I

of which, therefore, never exclusively propagated themselves sexually" (Trematoda, Hydromedusa): Under the other, or retrogressive form of metagenesis, Haeckel includes a " return from amphigenesis to monogenesis," this being the case with all those species which now manifest a regular alternation from amphigenesis to parthenogenesis (Aphides, Rotatoria, Daphnida, Phyllopoda, \&c). Essentially I can but agree entirely with Haeckel. Simply regarding the phenomena of alternation of generation as at present known, it appears to me to be readily admissible that these multiform modes of propagation must have originated in at least two different ways, which can be aptly formulated in the manner suggested by Haeckel.

I will, however, venture to adopt a somewhat different mode of conception, and regard the manner of propagation (whether sexual or asexual) not as the determining, but only as the secondary cause. I will further hazard the separation of the phenomena of alternating generations (in their widest sense) into two main groups according to their origin, designating the cases of one group as true metagenesis and those of the other as heterogenesis. ${ }^{2}$ Metagenesis takes its origin from a

2 It is certainly preferable to make use of the expression "metagenesis" in this special sense instead of introducing a new one. As a general designation, comprehending metagenesis and heterogenesis, there will then remain the expression "alternation of generation," if one does not prefer to say 
phyletic series of dissimilar forms, whilst heterogenesis originates from a phyletic series of similar forms-this series, so far as we can at present judge, always consisting of similar sexual generations. The former would thus nearly coincide with Haeckel's progressive, and the latter with his retrogressive metagenesis. Metagenesis may further originate in various ways. In the first place, from metamorphosis, as for example, in the propagation of the celebrated Cecidomyia with nursing larvæ. The power which these larvæ possess of propagating themselves asexually has evidently been acquired as a secondary character, as appears from the fact that there are many species of the same genus the larvæ of which do not nurse, these larvæ being themselves undoubted secondary forms produced by the adaptation of this stage of phyletic development to a mode of life widely different from that of the later stages. In the form now possessed by these larvæ they could never have represented the final stage of their ontogeny, neither could they have formerly possessed the power of sexual propagation. The conclusion seems inevitable that metagenesis has here proceeded from metamorphosis; that is to say, one stage of the ontogeny, by acquiring asexual propagation, has changed the originally existing metamorphosis into metagenesis.

"cyclical propagation." The latter may be well used in contradistinction to "metamorphosis." 


\section{On the Seasonal Dimorphism of Butterfies. 83}

Lubbock $^{3}$ is undoubtedly correct when, for cases like that just mentioned, he attempts to derive alternation of generations from metamorphosis. But if we exclude heterogenesis there still remain a large number of cases of true metagenesis which cannot be explained from this point of view.

It must be admitted, with Haeckel, that the alternation of generations in the Hydromedusæ and Trematoda does not depend, as in the case of Cecidomyia, upon the larvæ having acquired the power of nursing, but that the inferior stages of these species always possessed this power which they now only preserve. The nursing Trematode larvæ now existing may possibly have been formerly able to propagate themselves also sexually, this mode of propagation having at the present time been transferred to a later phyletic stage. In this case, therefore, metagenesis was not properly produced by metamorphosis, but arose therefrom in the course of the phyletic development, the earlier phyletic stages abandoning the power of sexual reproduction, and preserving the asexual mode of propagation. A third way in which metagenesis might originate is through polymorphosis. When the latter is combined with asexual reproduction, as is especially the case with the Hydrozoa, metagenesis may be derived therefrom. The successive stages of transformation of one and the same physiological in-

$s$ Loc. cit. chap. iv. 
dividual do not in these cases serve as the point of departure for alternation of generation, but the different contemporary forms living gregariously into which the species has become divided through functional differentiation of the various individuals of the same stock. Individuals are here produced which alone acquire the power of sexual reproduction, and metagenesis is thus brought about, these individuals detaching themselves from the stock on which they originated, while the rest of the individuals remain in combination, and retain the asexual mode of propagation. No sharp distinction can be otherwise drawn between this and the cases previously considered. ${ }^{4}$ The difference consists only in the whole cycle of reproduction being performed by one stock; both classes have the common character that the different phyletic stages never appear in the same individual (metamorphosis), but in the course of further phyletic development metagenesis at the same time arises, i. e. the division of these stages among a succession of individuals. We are therefore able to distinguish this primary metagenesis from the secondary metagenesis arising from metamorphosis.

4 The idea that alternation of generation is derived from polymorphism (not the reverse, as usually happens; i. e. polymorphism from alternation of generation) is not new, as I find whilst correcting the final proof. Semper has already expressed it at the conclusion of his interesting memoir, "Über Generationswechsel bei Steinkorallen," \&c. See "Zeitschrift f. wiss. Zool." vol. xxii. 1872 . 
It is not here my intention to enter into the ultimate causes of metagenesis ; in this subject we should only be able to advance by making vague hypotheses. The phenomenon of seasonal dimorphism, with which this work has mainly to deal, is evidently far removed from metagenesis, and it was to make this clear that the foregoing observations were brought forward. The characters common in the origin of metagenesis are to be found, according to the views previously set forth, in the facts that here the faculty of asexual and of sexual reproduction is always distributed among several phyletic stages of development which succeed each other in an ascending series (progressive metagenesis of Haeckel), whereas I find differences only in the fact that the power of asexual propagation may (in metagenesis) be either newly acquired (larva of Cecidomyia) or preserved from previous ages (Hydroida). It seems that in this process sexual reproduction is without exception lost by the earlier, and remains confined solely to the most recent stages.

From the investigations on seasonal dimorphism it appears that a cycle of generations can arise in an entirely different way. In this case a series of generations originally alike are made dissimilar by external influences. This appears to me of the greatest importance, since seasonal dimorphism is without doubt closely related to that mode of reproduction which has hitherto been exclusively 
designated as heterogenesis, and a knowledge of its mode of origination must therefore throw light on the nature and origin of heterogenesis in general.

In seasonal dimorphism, as I have attempted to show, it is the direct action of climate, and indeed chiefly that of temperature, which brings about the change in some of the generations. Since these generations have been exposed to the alternating influence of the summer and winter temperature a periodical dimorphism has been developeda regular cycle of dissimilar generations. It has already been asserted that the consecutive generations of a species comport themselves with respect to heredity in a manner precisely similar to that of the ontogenetic stages, and at the same time such succeeding generations point out the parallelism between metamorphosis and heterogenesis. If influences capable of directly or indirectly producing changes operate on any particular stage of development, these changes are always transmitted to the same stage. Upon this metamorphosis depends. In a precisely similar manner changes which operated periodically on certain generations ( $1,3,5$, for instance) are transmitted to these generations only, and not to the intermediate ones. Upon this depends heterogenesis. We have just been led to the comprehension of heterogenesis by cyclical heredity, by the fact that a cycle is produced whenever a series of generations exists under regularly alternating influences. 
In this cycle newly-acquired changes, however minute in character at first, are only transmitted to a later, and not to the succeeding generation, appearing only in the one corresponding, i.e. in that generation which exists under similar transforming influences. Nothing can more clearly show the extreme importance which the conditions of life must have upon the formation and further development of species than this fact. At the same time nothing shows better that the action of these conditions is not suddenly and violently exerted, but that it rather takes place by small and slow operations. In these cases the long-continued accumulation of imperceptibly small variations proves to be the magic means by which the forms of the organic world are so powerfully moulded. By the application of even the greatest warmth nobody would be able to change the winter form of $A$. Levana into the summer form ; nevertheless, the summer warmth, acting regularly on the second and third generations of the year, has, in the course of a lengthened period, stamped these two generations with a new form without the first generation being thereby changed. In the same region two different climatic varieties have been produced (just as in the majority of cases climatic varieties occur only in separate regions) which alternate with each other, and thus give rise to a cycle of which each generation propagates itself sexually. 
But even if seasonal dimorphism is to be ascribed to heterogenesis, it must by no means be asserted that those cases of cyclical propagation hitherto designated as heterogenesis are completely identical with seasonal dimorphism. Their identity extends only to their origin and manner of development, but not to the mode of operation of the causes which bring about their transformation. Both phenomena have a common mode of origination, arising from similar (monomorphic) sexual generations and course of development, a cycle of generations with gradually diverging characters coming into existence by the action of alternating influences. On the other hand, the nature of the changes by which the secondary differs from the primary generation may be referred to another mode of action of the exciting causes. In seasonal dimorphism the differences between the two generations are much less than in other cases of heterogenesis. These differences are both quantitatively less, and are likewise qualitative, affecting only characters of biological insignificance. ${ }^{5}$ The variations in question are mostly restricted to the marking and colouring of the wings and body, occasionally affecting also the form of the wing, and in a few cases the size of the body (Plebeius Amyntas), whilst the bodily structure-so far at

- See my essay "Über den Einfluss der Isolirung auf die Artbildung." Leipzig, 1872. 
least as my investigations extend-appears to be the same in both generations. ${ }^{6}$

The state of affairs is quite different in the remaining cases of heterogenesis; here the entire structure of the body appears to be more or less changed, and its size is often very different, nearly all the internal organs differing in the two generations. According to Claus," "we can scarcely find any other explanation of the mode of origination of heterogenesis than the gradual and slow advantageous adaptation of the organization to important varying conditions of life"-a judgment in which this author is certainly correct. In all such cases the change does not affect unimportant characters, as it does in butterflies, but parts of biological or physiological value; and we cannot, therefore, consider such changes to have originated through the direct action of altered conditions of life, but indirectly through natural selection or adaptation.

Thus, the difference between seasonal dimorphism and the other known cases of heterogenesis

- [In the case of monogoneutic species which, by artificial 'forcing,' have been made to give two generations in the year, it has generally been found that the reproductive system has been imperfectly developed in the second brood. A minute anatomical investigation of the sexual organs in the two broods of seasonally-dimorphic insects would be of great interest, and might lead to important results. R.M.]

" "Grundzüge der Zoologie." 2nd ed. Leipzig, r872. Introduction. 
consists in the secondary form in which the species appears in the former originating through the direct action of external conditions, whilst in the latter this form most probably originates through the indirect action of such influences. The first half of the foregoing proposition is alone capable of provisional proof, but it is in the highest degree probable that the latter half is also correct. Naturally we cannot say to what extent the direct action of external conditions plays also a part in true heterogenesis, as there have been as yet no experiments made on its origin. That direct action, working to a certain extent co-operatively, plays only a secondary part, while the chief cause of the change is to be found in adaptation, no one can doubt who keeps in view, for instance, the mode of propagation discovered by Leuckart in Ascaris nigrovenosa. In this worm, the one generation lives free in the water, and the other generation inhabits the lungs of frogs, the two generations differing from one another in size of body and structure of internal organs to an extent only possible with the true Nematoda.

To prevent possible misunderstanding, let it be finally noted-even if superfluous-that the changes causing the diversity of the two generations in seasonal dimorphism and heterogenesis are not of such a nature that the value of different "specific characters" can be attached to them. 
On the Seasonal Dimorphism of Butterfics. 9I

Distinctly defined specific characters. are well known not to occur generally, and it would therefore be erroneous to attach but little value to the differences in seasonal dimorphism because these chiefly consist in the colouring and marking of the wings. The question here under consideration is not whether two animal forms have the value of species or of mere varieties-a question which can never be decided, since the reply always depends upon individual opinion of the value of the distinctions in question, and the idea of both species and varieties is moreover purely conventional. The question is, rather, whether the distinguishing characters possess an equal constancythat is, whether they are transmitted with the same force and accuracy to all individuals; and whether they occur, therefore, in such a manner that they can be practically employed as specific characters. With respect to this, it cannot be doubtful for a moment that the colouring and marking of a butterfly possess exactly the same value as the constant characters in any other group of animals, such as the palate-folds in mice, the structure of the teeth in mammals, the number and form of the wing and tail feathers in birds, \&c. We have but to remember with what wonderful constancy often the most minute details of marking are transmitted in butterflies. The systematist frequently distinguishes between two nearly allied species, as for instance in the Lycanida, chiefly by the posi- 
tion of certain insignificant black spots on the under side of the wing $(P$. Alexis female, and $P$. Agestis); and this diagnosis proves sufficient, since $P$. Alexis, which has the spots in a straight row, has a different caterpillar to $P$. Agestis, in which the central spot is nearer the base of the hind wing!

For the reasons just given, I maintain that it is neither justifiable nor useful to designate the di- and polymorphism of butterflies as di- and polychroism, and thereby to attribute but little importance to these phenomena. ${ }^{8}$ This designation would be only justifiable if the differences of colour were due to other causes than the differences of form, using this last word in a narrow sense. But it has been shown that the same direct action of climate which originates new colours, produces also in some species differences of form (contour of wing, size, \&c.) ; whilst, on the other hand, it has long been known that many protective colours can only be explained by the indirect action of external conditions.

When I raise a distinction in the nature of the changes between seasonal dimorphism and the remaining known cases of heterogenesis, this must be taken as referring only to the biological or physiological result of the change in the transformed organism itself. In seasonal dimorphism only

${ }^{8}$ With reference to this subject, see the discussion by the Belgian Entomological Society, Brussels, I 873. 
On the Seasonal Dimorphism of Butterfies. 93

insignificant characters become prominently changed, characters which are without importance for the welfare of the species; while in true heterogenesis we are compelled to admit that useful changes, or adaptations, have occurred.

Heterogenesis may thus be defined either in accordance with my proposal or in the manner hitherto adopted, since it may be regarded as more morphological than the cyclical succession of differently formed sexual generations ; or, with Claus, as the succession of different sexual generations, "living under different conditions of existence"a definition which applies in all cases to seasonal dimorphism. Varying conditions of existence, in their widest sense, are the result of the action of different climates; and a case has been made known recently in which it is extremely probable that the climatic differences of the seasons have produced a cycle of generations by influencing the processes of nutrition. This case is quite analogous to that which we have observed in the seasonal dimorphism of butterflies, but with the distinction that the difference between the winter and summer generations does not, at least entirely, consist in the form of the reproductive adult, but almost entirely in its ontogeny-in the mode of its development. A comparison of this case with the analogous phenomenon in butterflies, may be of interest. In the remarkable fresh-water Daphnid, Leptodora hyalina Lillejeborg, it was 
proved some years ago by P. E. Müller, ${ }^{\circ}$ who studied the ontogeny, that this last was direct, since the embryo, before leaving the egg, already possesses the form, members, and internal organs of the adult. This was, at least, the case with the summer eggs. It was subsequently shown by Sars $^{10}$ that this mode of development only holds good for the summer brood, the winter eggs producing an embryo in the spring which possesses only the three first pairs of limbs, and, instead of compound eyes, only a single frontal eye, thus exhibiting briefly, at first, the structure of a Nauplius, and gradually acquiring that of Leptodora. The mature form derived from the winter eggs is not distinguishable from the later generations, except by the presence of the simple larval eye, which appears as a small black spot. The generations when fully developed are thus distinguished only by this minute marking, but the summer generation undergoes direct development, whilst the winter generation, on the contrary, is only developed by metamorphosis, beginning with the simplest Crustacean type, and thus fairly representing the phyletic development of the species. We therefore see, in this case, the combination of a metamorphic and a direct development taking place to a certain

- P. E. Müller, "Bidrag til Cladocerners Fortplantingshistorie," I 868.

${ }^{10}$ Sars, in "Förhandlinger i Videnskabs Selskabet i Christiania," r 873, part i. 
extent under our eyes. It cannot be proved with certainty what the cause of this phenomenon may be, but the conjecture is almost unavoidable that it is closely related to the origin of the seasonal dimorphism of butterflies, since both depend on the alternating climatic influences of summer and winter: it is most probable that these influences have directly ${ }^{11}$ brought about a shortening of the period of development in summer. Thus we have here a case of heterogenesis nearly related to the seasonal dimorphism of butterflies in a twofold manner-first, because the cycle of generations is also in this case brought about by the direct action of the external conditions of life; and secondly, the winter form is here also the primary, and the summer form the secondary one.

In accordance with the idea first introduced into science by Rudolph Leuckart, we have hitherto understood heterogenesis to be only the alternation of dissimilar sexual generations. From this point of view the reproduction of Leptodora can be as little ascribed to heterogenesis as can that of Aphis or Daphnia, although the apparent agamic reproduction of the winter and a portion of the summer generation is undoubtedly partheno-

" [Eng. ed. Recent researches on alternation of generation in the Daphnoidea have convinced me that direct action of external conditions does not in these cases come into consideration, but only indirect action.] 
genesis and not propagation by nursing. ${ }^{12}$ As has already been said, however, I would attribute no fundamental importance to the criterion of agamic reproduction-the more especially because we are ignorant of the physiological significance of the two modes of propagation; and further, because this principle of classification is entirely external, and only valuable in so far as no better one can be substituted for it. A separation of the modes of cyclical propagation according to their genesis appears to me-especially if practicable-not alone to be of greater value, but the only correct one, and for this the knowledge of the origin of seasonal dimorphism seems to me to furnish a possible method.

If, as was indicated above, we designate as metagenesis (in the narrow sense) all those cases in which it must be admitted that a series of differently aged phyletic stages have furnished the points of departure, and as heterogenesis those cases in which similar phyletic stages have been compelled to produce a cycle of generations by the periodic action of external influences, it is clear that the scope of heterogenesis is by this means considerably extended, and at the same time sharply and precisely defined.

Under heterogenesis then is comprised, not only

${ }^{12}$ See my memoir, "Über Bau und Lebenserscheinungen der Leptodora hyalina," Zeitschrift f. wiss. Zool., vol. xxiv. part 3, r.74. 
as heretofore the reproduction of Ascaris nigrovenosa, of Leptodora appendiculata, and of the cattlelice, but also that of the Aphides, Coccida, Daphnide, Rotatoria, and Phyllopoda, and, in short, all those cases in which we can determine the former identity of the two kinds of generations from their form, anatomical structure, and mode of reproduction. This conclusion is essentially supported by a comparison of the most closely allied species. Thus, for instance, when we see the genus Aphis and its allies related on all sides to insects which propagate sexually in all generations, and when we further observe the great similarity of the whole external and internal structure in the two kinds of generations of Aphis, we are forced to the conjecture that the apparent asexual reproduction of the Aphide is in reality parthenogenesis, i.e., that it has been developed from sexual reproduction. Neither can it be any longer disputed that in this case, as well as in that of Leptodora and other Daphnida, the same female alternately propagates parthenogenetically, and produces eggs requiring fertilization. This was established by Von Heyden ${ }^{13}$ some years ago, in the case of Lachmus Querci, and has been since confirmed by Balbiani. ${ }^{14}$

There can be no doubt that in all these cases the cycle of generations has been developed from

1 :Stettin. entom. Zeit., vol. xviii p. 83, I857.

14 Compt. Rend., vol. Ixxvii. p. I164, r 873. 
phyletically similar generations. But instances are certainly conceivable which present themselves with less clearness and simplicity. In the first place, we do not know whether parthenogenesis may not finally settle down into complete asexual reproduction. Should this be the case, it might be possible that from heterogenesis a mode of propagation would ultimately arise, which was apparently indistinguishable from pure metagenesis. Such a state of affairs might result, if the generations settling into asexual reproduction (as, for instance, the plant-lice), at the same time by adaptation to varying conditions of life, underwent considerable change of structure, and entered upon a metamorphosis to some extent retrogressive. We should then be inclined to regard these generations as an earlier phyletic stage, whilst, in fact, they would be a later one, and the idea of metagenesis would thus have been formed after the manner of heterogenesis.

On the other hand, it is equally conceivable that heterogenesis may have been developed from true metagenesis in the case of larvæ which, having acquired the faculty of asexual propagation, are similar in function to sexually mature insects. This possibility is not at first sight apparent. If the nursing-larvæ of the Cecidomyice were as much like the sexual insects as are the young Orthoptera to the sexually mature forms, we should not know whether to regard them as 
degraded sexual insects, or as true larvæ which had attained the power of asexual propagation. Their propagation would be considered to be parthenogenesis; and as it could not be denied that heterogenesis was here manifest, the mode of development of their particular kind of propagation might be proved, i. e., it might be demonstrated, that the generations now parthenogenetic were formerly mere reproductive larval stages.

I have only offered these last observations in order to show on what uncertain ground we are still standing with regard to this subject whenever we deal with the meaning of any particular case, and how much still remains to be done. It appears certain that the two forms of cyclical propagation, heterogenesis and metagenesis, originate in entirely distinct ways, so that it must be admitted that, under these circumstances, the idea of the existing conditions respecting the true genesis may possibly be erroneous. To indicate the manner in which the cyclical mode of propagation has arisen in any single case, would only be possible by a searching proof and complete knowledge of existing facts in addition to experiments. 


\section{VI.}

\section{General Conclusions.}

I SHALL not here give a repetition and summary of the results arrived at with respect to seasonal dimorphism, but rather the general conclusions derived from these results; and, at the same time, I may take the opportunity of raising certain questions which have not hitherto found expression, or have been but briefly and casually stated.

It must, in the first place, be admitted that differences of specific value can originate through the direct action of external conditions of life only. Of the truth of this proposition there can be no doubt, after what has been above stated concerning the difference between the two forms of any seasonally dimorphic species. The best proof is furnished by the older systematists, to whom the genetic relationship of the two forms was unknown, and who, with unprejudiced taxonomy, in many cases indicated their distinctness by separate specific names. This was the case with Araschnia Levana and Prorsa, Euchloe Belia and Ausonia, E. Belemia and Glauce, Plebeius Polysperchon and Amyntas. In the presence of these facts it 
can scarcely be doubted that new species can be formed in the manner indicated; and I believe that this was and is still the case, with butterflies at least, to a considerable extent; the more so with these insects, because the striking colours and markings of the wings and body, being in most cases without biological significance, are useless for the preservation of the individual or the species, and cannot, therefore, be objects of natural selection.

Darwin must have obtained a clear insight into this, when he attempted to attribute the markings of butterflies to sexual and not to natural selection. According to this view, every new colour or marking first appears in one sex accidentally, ${ }^{1}$ and is there fixed by being preferred by the other sex to the older coloration. When the new ornamentation becomes constant (in the male for example), Darwin supposes that it becomes transferred to the female by inheritance, either partially or completely, or not at all; so that the species, therefore, remains more or less sexually dimorphic, or (by complete transference) becomes again sexually monomorphic.

The admissibility of such different, and, to a certain extent, arbitrarily limited inheritance, has already been acknowledged. The question here concerned is, whether Darwin is correct when he

" ["Accidental" in the sense of our being in ignorance of the laws of variation, as so frequently insisted upon by Darwin. R.M.] 
in this manner attributes the entire coloration of butterflies to sexual selection. The origin of seasonal dimorphism appears to me to be against this view, howsoever seductive and grand the latter may seem. If differences as important as those which exist between the summer and winter forms of many butterflies can be called forth by the direct action of a changed climate, it would be extremely hazardous to attribute great importance to sexual selection in this particular case.

The principle of sexual selection appears to me to be incontestible, and I will not deny that it is also effective in the case of butterflies; but I believe that as a final explanation of colour this agency can be dispensed with, inasmuch as we see that considerable changes of colour can occur without the influence of sexual selection. ${ }^{2}$

? [Eng. ed. Since this was written I have studied the ornamental colours of the Daphnide; and, as a result, I no longer doubt that sexual selection plays a very important part in the marking and colouring of butterflies. I by no means exclude both transforming factors, however; it is quite conceivable, on the contrary, that a change produced directly by climate may be still further increased by sexual selection. The above given case of Polyommatus Phlceas may perhaps be explained in this manner. That sexual selection plays a part in butterflies, is proved above all by the odoriferous scales and tufts of the males discovered by Fritz Müller.] [For remarks on the odours emitted by butterflies and moths, see Fritz Müller in "Jena. Zeit. f. Naturwissen.," vol. xi. p. 99 ; also "Notes on Brazilian Entomology," Trans. Ent. Soc. I878, p. 2 I I. The odoriferous organs of the female Heliconince are fully described in a paper in "Zeit. f. Wissen. Zool." vol. xxx. p. 167. The position of 


\section{On the Seasonal Dimorphism of Butterflies. 103}

The question now arises, how far does the transforming influence of climate extend? When a species has become transformed by climatic change to such an extent that its new form possesses the systematic value of a new species, does it return to its older form by removal to the old climatic conditions? or would it under these circumstances become again transformed in a new manner? This question is not without importance, inasmuch as in the first case climatic influences would be of little value in the formation of species, and there would result at most only a fluctuation between two extremes. In the same manner as in seasonally dimorphic species the summer and winter forms now alternate with each other every year, so would the forms produced by warmth and cold then alternate in the greater periods of the earth's history. Other groups of animals are certainly changed by the action of different climatic influences; but in but-

the scent-tufts in the sphinx-moths is shown in Proc. Entom. Soc. I878, p. ii. Many British moths, such as Phlogophora meticulosa, Cosmia trapezina, \&c. \&c., have tufts in a similar position. The fans on the feet of Acidalia bisetata, Herminia barbalis, $H$. tarsipennalis, \&c., are also probably scent organs. A large moth from Jamaica, well known to possess a powerful odour when alive (Erebus odorus Linn.), has great scent-tufts on the hind legs. For the application of the theory of sexual selection to butterflies, see, in addition, to Darwin's "Descent of Man," Fritz Müller in "Kosmos," vol. ii. p. 42; also for January, 1879, p. 285 ; and Darwin in "Nature," vol. xxi. January 8 th, I 880, p. 237 . R.M.] 
terflies, as I believe I have proved, temperature plays the chief part, and as this only oscillates between rather narrow limits, it admits of no great differences of coloration.

The question thus suggests itself, whether species of butterflies only oscillate between two forms, or whether climatic change, when sufficiently great to produce variation, does not again originate a new form. Inasmuch as the reversion experiments with seasonally dimorphic butterflies appear to correspond with the latter view, I believe that this must be admitted. I am of opinion that an old form never again arises through change of climate, but always a new one; so that a periodically recurring change of climate is alone sufficient, in the course of a long period of time, to admit of new species arising from one another. This, at least, may be the case with butterflies.

My views rest essentially upon theoretical considerations. It has already been insisted upon, as results immediately from the experiments, that temperature does not act on the physical constitution of the individual in the same manner as acid or alkali upon litmus paper, i. e., that one and the same individual does not produce this or that coloration and marking according as it is exposed to warmth or cold; but rather that climate, when it influences in a similar manner many succeeding. generations, gradually produces such a change in 
the physical constitution of the species that this manifests itself by other colours and markings. Now when this newly acquired physical constitution, established, as we may admit, throughout a long series of generations, is again submitted to a constant change of climate, this influence, even if precisely similar to that which obtained during the period of the first form of the species, cannot possibly reproduce this first form. The nature of the external conditions may be the same, but not so the physical constitution of the species. Just in the same manner as a Pieris (as has been already shown), a Lyccena, or a Satyrus, produces quite different varieties under the transforming influence of the same climate, so must the variation originating from the transformed species of our present case after the beginning of the primary climate be different from that primary form of the species, although perhaps in a less degree. In other words, if only two different climates alternated with each other during the earth's geological periods, every species of butterfly submitted to these changes of climate would give rise to an endless series of different specific forms. The difference of climate would in reality be greater than supposed, and for any given species the climatic variation would not only occur through the periodic shifting of the ecliptic, but also through geological changes and the migrations of the species itself, so that a continuous change of 
species must have gone on from this sole cause of alternation of climate. When we consider that many species elsewhere extinct have become locally preserved, and when, further, to these we add those local forms which have arisen by the prevention of crossing (amixia), and finally take into consideration the important effects of sexual selection, we can no longer be astonished at the vast numbers of species of butterflies which we now meet with on the earth.

Should any one be inclined to conclude, from my reversion experiments with seasonally dimorphic butterflies, that the secondary species when exposed to the same climate as that which produced it must revert to the primary, he forgets that this reversion to the winter form is nothing but a reversion-i.e., a sudden return to a primary form through peculiar laws of inheritance-and by no means a gradual re-acquisition of this primary form under the gradual influence of the primary climate. Reversion to the winter form occurs also through other influences, as, for instance, by high temperature. Reversions of this kind, depending on laws of heredity, certainly happen with those cases of transmutation which do not alternate with the primary form, as in seasonal dimorphism, but which occur continuously. They would, however probably be more quickly suppressed in such cases than in seasonal dimorphism, where the constant alternation of the primary and secondary 
forms must always maintain the tendency of the latter to produce the former.

That the above conclusion is correct-that a secondary species, when exposed to the external conditions under the influence of which the primary form originated, does not again revert to the latter-is proved by experience with plants. Botanists ${ }^{3}$ assure us "that cultivated races which become wild, and are thus brought back to their former conditions of life, do not become changed into the original wild form, but into some new one."

A second point which appears to me to be elucidated by seasonal dimorphism, is the origin of variability. It has already been prominently shown that secondary forms are for the most part considerably more variable than primary forms. From this it follows that similar external influences either induce different changes in the different individuals of a species, or else change all individuals in the same manner, variability arising only from the unequal time in which the individuals are exposed to the external influence. The latter is undoubtedly the case, as appears from the differences which are shown by the various individuals of a secondary form. These

${ }^{8}$ Nägeli, "Entstehung und Begriff der naturhistorischen Art," Munich, 1865, p. 25. The author interprets the facts above quoted in a quite opposite sense, but this is obviously crroneous. 
are always only differences of degree and not of kind, as is perhaps most distinctly shown by the very variable $A$. Prorsa (summer form), in which all the occurring variations differ only by the Levana marking being more or less absent, and, at the same time, by approximating more or less to the pure Prorsa marking; but changes in a totally different direction never occur. It is likewise further evident, as has been mentioned above, that allied species and genera, and even entire families (Pieride), are changed by similar external inducing causes in the same manner-or, better, in the same direction.

In accordance with these facts the law may be stated, that, in butterflies at least, all the individuals of a species respond to the same external influences by similar changes, and that, consequently, the changes brought about by climatic influences take a fixed direction, determined by the physical constitution of the species. When, however, new climatic forms of butterflies, in which natural selection is completely excluded, and the nature of the species itself definitely determines the direction of the changes, nevertheless show variability from the very beginning, we may venture to conclude that every transformation of a species generally begins with a fluctuation of its characters. But when we find the primary forms of butterflies always far more constant, this shows that the continued crossing of the individuals of a 
species to a certain extent balances the fluctuations of form. Both facts taken together confirm the law formerly enunciated by $m e,{ }^{4}$ that in every species a period of variability alternates with one of (relative) constancy-the latter indicating the culmination, and the former the beginning or end, of its development. I here call to mind this law, because the facts which I advanced at that time, viz., Hilgendorf's history of the phyletic development of the Steinheim fossil shells, having since become somewhat doubtful, one might easily be inclined to go too far in mistrusting them and refuse to give them any weight at all. ${ }^{5}$

In the essay just indicated I traced the origin of a certain class of local forms to local isolation. I attempted to show that when a species finds itself in an isolated district in a condition (period) of variability, it must there necessarily acquire somewhat deviating characters by being prevented from crossing with the individuals of other regions, or, what comes to the same thing, a local form must originate. This production of local forms

" See my essay, "Über den Einfluss der Isolirung auf die Artbildung." Leipzig, 1872.

- [Eng. ed. In the summer of 1877 , Dr. Hilgendorf again investigated the Steinheim fossil shells, and found his former statements to be completely confirmed. At the meeting of the German Naturalists and Physicists at Munich, in 1877 , he exhibited numerous preparations, which left no doubt that the chief results of his first research were correct, and that there have been deposited a series of successively derived species together with their connecting intermediate forms.] 
results because the different variations which, for the time being, constitute the variability of the species, would always be in a different numerical proportion in the isolated district as compared with other regions; and further, because constancy is produced by the crossing of these (isolated) varieties among themselves; so that the resultant of the various components is (local) variation. If the components are dissimilar the resultant would also be different; and thus, from a theoretical point of view, there seems to me no obstacle in the way of the production of such local forms by the process of 'amixia.' I believe that I have further shown that numerous local forms can be conceived to have arisen through this process of preventive crossing, whilst they cannot be explained by the action of climatic influences.

That I do not deny the existence of true climatic forms in admitting this principle of 'amixia,' as has been frequently imagined, appears sufficiently from the treatise in question. The question arises, however, whether climatic influences may not also originate forms by 'amixia' by making a species variable. It would be difficult at present to decide finally upon this subject. If, however, in all cases a variation in a certain fixed direction occurred through climatic influences, a form could not arise by 'amixia' from such a variability, since the components could then produce resultants different only in degree and not 
in kind. But we are not yet able to extend our researches to such fine distinctions.

As a final, and not unimportant result of these investigations, I may once more insist that dissimilar influences, when they alternatingly affect a long series of originally similar generations in regularly recurring change, only modify the generations concerned, and not intermediate ones. Or, more briefly, cyclically acting causes of change produce cyclically recurring changes : under their influence series of monomorphic generations become formed into a cycle of di- or polymorphic generations.

There is no occasion to return here to the immediate evidence and proof of the foregoing law. In the latter, however, is comprised the questionis not the cycle of generations produced by cyclical heredity ultimately equivalent to Darwin and Haeckel's homochronic heredity which forms the ontogenetic stages into a cycle? It is possible that from this point, in the future, the nature of the processes of heredity, which are still so obscure, may be penetrated into, and both phenomena traced to the same cause, as can now be only surmised but not clearly perceived.

Finally, the most general, and in so far chief result of these investigations, appears to me to lie in the conclusion, which may be thus formulated :A species is only caused to change through the influence of changing external conditions of life, 
this change being in a fixed direction which entirely depends on the physical nature of the varying organism, and is different in different species, or even in the two sexes of the same species.

I am so little disposed to speak in favour of an unknown transforming power that I may here again insist that the transformation of a species only partly depends upon external influences, and partly on the specific constitution of the particular form. I designate this constitution 'specific,' inasmuch as it responds to the same inciting cause in a manner different to the constitution of another species. We can generally form a clear conception why this should be the case; for not only is there in another species a different kind of latent vital activity, but each species has also a different developmental history. It must be admitted that, from the earliest period of the formation of an organism, and throughout all its intermediate stages, properties which have become established, such as growth, nutrition, or tendency to development, have been transferred to the species now existing, each of which bears these tendencies in itself to a certain extent. It is these innate tendencies which determine the external and internal appearance of the species at every period of its life, and which, by their reaction to external factors, represent the life of the individual as well as that of the species. Since the sum of these inherited tendencies must vary more or less in every species, 
not only is the different external appearance of species as well as their physiological and biological diversity thus explained, but it necessarily follows therefrom, that different species must respond differently to those external causes which tend to produce a change in their form.

Now, this last conclusion is equivalent to the statement that every species, through its physical constitution, (in the sense defined) is impressed with certain fixed powers of variation, which are evidently extraordinarily numerous in the case of each species, but are not unlimited; they permit of a wide range for the action of natural selection, but they also limit its functions, since they certainly restrain the course of development, however wide the latter may be. I have elsewhere previously insisted ${ }^{6}$ that too little is ascribed to the part played by the physical constitution of species in the history of their transformation, when the course of this transformation is attributed entirely to external conditions. Darwin certainly admits the importance of this factor, but only so far as it concerns the individual variation, the nature of which appears to him to depend on the physical constitution of the species. I believe, however, that in this directive influence lies the precise reason why, under the most favourable external circumstances. a bird can never become transformed into a mam-

- See my essay, "Über die Berechtigung der Darwin'schen Theorie." Leipzig, г 868. 
mal-or, to express myself generally, why, from a given starting-point, the development of a particular species cannot now attain, even under the most favourable external conditions, any desired goal; and why, from this starting-point, given courses of development, even when of considerable latitude, must be restricted, just as a ball rolling down a hill is diverted by a fixed obstacle in a direction determined by the position of the latter, and depending on the direction of motion and the velocity at the moment of being diverted.

In this sense I agree with Askenasy's "fixed" direction of variation; but not if another new physical force directing variation itself is thereby intended. ' The explanation of the phenomena does not appear to me to require such an admission, and, if unnecessary, it is certainly not legitimate. According to my view, transmutation by purely internal causes is not to be entertained. If we could absolutely suspend the changes of the external conditions of life, existing species would remain stationary. The action of external inciting causes, in the widest sense of the word, is alone able to produce modifications; and even the neverfailing "individual variations," together with the inherited dissimilarity of constitution, appear to

' I expressly insist upon this here, because the notice of Askenasy's thoughtful essay which I gave in the "Archiv für Anthropologie" (1873) has frequently been misunderstood. 
me to depend upon unlike external influences, the inherited constitution itself being dissimilar because the individuals have been at all times exposed to somewhat varying external influences.

A change arising from purely internal causes seems to me above all quite untenable, because I cannot imagine how the same material substratum of physical constitution of a species can be transferred to the succeeding generation as two opposing tendencies. Yet this must be the case if the direction of development transferred by heredity is to be regarded as the ultimate ground both of the similarity and dissimilarity to the ancestors. All changes, from the least to the greatest, appear to me to depend ultimately only on external influences ; they are the response of the organism to external inciting causes. It is evident that this response must be different when a physical constitution of a different nature is affected by the same inciting cause, and upon this, according to my view, depends the great importance of these constitutional differences.

If, under "heredity," we comprise the totality of inheritance-that is to say, the physical constitution of a species at any time, and therefore the restricted and, in the foregoing sense, pre-determined power of variation, whilst under "adaptation" we comprehend the direct and indirect response of this physical constitution to the changes 
I 6 Studies in the Theory of Descent.

in the conditions of life, I can agree with Haeckel's mode of expression, and with him trace the transformation of species to the two factors of heredity and adaptation. 


\section{APPENDIX I.}

\section{EXPERIMENTS.}

\section{Experiments With Araschnia Levana.}

I. BRED from eggs laid by a female of the winter form on I2th-I $5^{\text {th }}$ May, I868, in a breeding-cage. The caterpillars emerged on 20th-22nd May, and pupated on 7 th-9th June. The pupæ, kept at the ordinary temperature, produced :-

On the Igth of June 4 butterflies.

\begin{tabular}{|c|c|c|c|}
\hline ” & 2oth & " & 5 \\
\hline$"$ & 2 I st & $"$ & IO \\
\hline " & $22 \mathrm{nd}$ & $"$ & 9 \\
\hline ", & $23 \mathrm{rd}$ & $"$ & 7 \\
\hline " & $25^{\text {th }}$ & $"$ & 13 \\
\hline & Total & • & 48 \\
\hline
\end{tabular}

All these butterflies were of the Prorsa type, 3 females having a considerable amount of yellow, but none with so much as figs. $3,4,7,8$, or 9. P1. I.

2. August I2th, I868, found larvæ of the third generation, which pupated at the beginning of September, and were kept in a room not warmed. In September three butterflies emerged in the Prorsa form, the remainder hibernating and producing, after being placed in a heated room at the end of February, from the Ist to the I7th of March, I869, more butterflies, all of the Levana form. 
3. Larvæ found on the I7th June, I869, were sorted according to colour; the yellow ones, with light brown spines, produced, at the ordinary temperature, on 8thI 2 th July, I 3 butterflies, 12 of which showed the ordinary Prorsa type, and one, a male, possessing more yellow than fig. 3, Pl. I., must be considered as a Porima type.

4. From caterpillars of the second generation, found at the same time as those of Exp. 3, 30 pupæ were placed in the refrigerator (temperature $8^{\circ}-10^{\circ}$ R.) on June 25th. When the box was opened on August 3rd, almost all had emerged, many being dead, and all, without exception, were of the intermediate form (Porima), although nearer the Prorsa than the Levana. type.

5. A large number of caterpillars of the second generation, found at the same time, pupated, and were kept at a high summer temperature. After a pupal period of about 19 days, some 70 butterflies emerged from 28th June to 5th July, all of the Prorsa form, with the exception of 5, which were strongly marked with yellow (Porima).

6. The 70 butterflies of the foregoing experiment were placed in an enclosure 6 feet high, and 8 feet long, in which, during warm weather, they freely swarmed on flowers. Copulation was only once observed, and but one female laid eggs on nettle on July 4th. At the high summer temperature prevailing at the time, these eggs produced butterflies after 30-3I days (third generation). All were Prorsa, with more or less yellow ; anong I 8 none were completely Porima.

7. Young larvæ of the fourth generation, found on the 8th of August, were reared in a hothouse $\left(17^{\circ}-20^{\circ} \mathrm{R}\right.$.). They pupated on 21st-23rd August. Of these :-

A. 56 pupæ were placed on ice $\left(0^{\circ}-I^{\circ} R\right.$.) for five weeks, and then allowed to hibernate in a room 
not warmed. In April, 1870, they all gave the Levana form, with the exception of a single Porima.

B. About an equal number of pupæ were placed in the hothouse, but without any result ; for, notwithstanding a temperature of $12^{\circ}-24^{\circ} \mathrm{R}$., not a single butterfly emerged in the course of October and November. The pupæ were then allowed to hibernate in an unheated room, and in April and May gave nothing but Levana.

8. Caterpillars of the second generation, found at the beginning of June, I870, pupated on I $3^{\text {th }}-15^{\text {th }}$ June, and gave, at the ordinary temperature, on June 29th3oth. 7 butterflies of the Prorsa form.

9. Pupæ of the same (second) generation were placed immediately after pupation on June ISth, I870, in a refrigerator $\left(0^{\circ}-I^{\circ} \mathrm{R}\right.$.), and after remaining there four weeks (till July 18 th) gave, at the ordinary summer temperature :-

On the 22nd of July, 2 Prorsa.

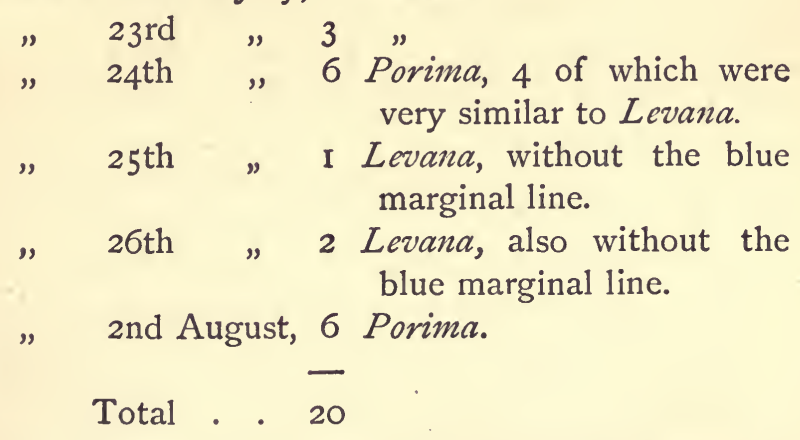

Of these 20 butterflies only 5 were of the pure Prorsa form.

I0. Full grown larvæ of the fourth generation, found on August 20th, I870, pupated on August 26th to September 5 th. The pupæ were divided into three portions:-

A. Placed in the hothouse $\left(12^{\circ}-25^{\circ} \mathrm{R}\right.$.), immediately after pupation and left there till October 20th. Of 
about 40 pupæ only 4 emerged, 3 of which were Prorsa and I Porima. The remaining pupæ hibernated and all changed into Levana the following spring.

B. Kept in a room heated to $6^{\circ}-15^{\circ} \mathrm{R}$. from November. Not a single specimen emerged the same year. This lot of pupæ were added to $C$ from November.

C. Placed on ice for a month immediately after pupation; then, from September 28th to October I9th in the hothouse, where no more butterflies emerged. The pupæ hibernated, together with those from lot $B$, in a room heated by water to $6^{\circ}-\mathrm{I} 5^{\circ} \mathrm{R}$., and gave :-

On the 6th of February, I female Levana.

\begin{tabular}{|c|c|c|}
\hline & 22nd & I male Levana. \\
\hline & $23 \mathrm{rd}$ & I male Levana. \\
\hline & $24^{\text {th }}$ & I female Levana. \\
\hline & $25^{\text {th }}$ & e and I female Levana. \\
\hline & 28th & $\begin{array}{l}\text { I male and I female Levana. } \\
\text { I male Levana. }\end{array}$ \\
\hline & I 3 th $\quad "$ & I female Levana. \\
\hline & I $5^{\text {th }}$ & le Levana. \\
\hline & Igth & I male Levana. \\
\hline & $\begin{array}{l}\text { 2nd of April, } \\
\text { 7th }\end{array}$ & $\begin{array}{l}2 \text { male and i female Levana. } \\
\text { I female Levana. }\end{array}$ \\
\hline & of May & $\begin{array}{l}\text { Levana. } \\
\text { Levana. }\end{array}$ \\
\hline
\end{tabular}

Total . I8 Levana, ro of which were females.

The exact record of the time of emergence is interesting, because it is thereby rendered apparent that different individuals respond more in different degrees to a higher than to the ordinary temperature. Whilst with many an acceleration of development of $\mathrm{I}-2$ months occurred, others emerged in April and May, i. e. at the time. of their appearance in the natural state. 
I I. Reared the second generation from eggs of the first generation. Emerged from the eggs on June 6th, I872, pupated on July gth. The pupæ were placed on ice $\left(0^{\circ}-r^{\circ} R\right.$.) from July Irth till September IIth, and then transferred to a hothouse, where all emerged:-

On the igth of September, 3 male Prorsa, I male Porima.

\begin{tabular}{|c|c|c|c|}
\hline & 2 Ist & " & $\begin{array}{l}\text { I3 Porima (I } 2 \text { males, I } \\
\text { female) } 2 \text { female Levana. }\end{array}$ \\
\hline & 22nd & ” & $\begin{array}{l}\text { I4 Porima (I } 2 \text { males, } 2 \text { fe- } \\
\text { males) and I female Le- } \\
\text { vana. }\end{array}$ \\
\hline , & $23 \mathrm{rd}$ & " & $\begin{array}{l}\text { Io female Levana, } 3 \text { male } \\
\text { Porima. }\end{array}$ \\
\hline " & $24^{\text {th }}$ & " & 5 female Levana. \\
\hline & $25^{\text {th }}$ & , & I female Levana. \\
\hline & 27 th & $"$ & 3 female Levaua. \\
\hline & $4^{\text {th }}$ & ctober, & I male Porima. \\
\hline
\end{tabular}

Total . . 57 butterflies ( 32 males and 25 females), only 3 of which were Prorsa, 32 Porima, and 22 Levana.

It must be pointed out, however, that among those specimens marked as "Levana" there were none which entirely corresponded with the natural Levana, or which indeed approximated so nearly to this form as did some of the specimens in Exp. 9. All were larger than the natural Levana, and possessed, notwithstanding the large amount of yellow, more black than any true Levana. In all artificially bred Levana the black band of the basal half of the hind wings is always interrupted with yellow, which is seldom the case with true Levana. The whole appearance of the artificial Levana is also coarser, and the contour of the wings somewhat different, the fore-wings being broader and less pointed. (See figs. 7 to $9, \mathrm{Pl}$. I.). 
12. Larvæ of the fourth generation, found on September 22nd, I872, were divided into two portions :-

A. Placed for pupation in an orchid-house at $12^{\circ}-$ $25^{\circ} \mathrm{R}$., and allowed to remain there till December. In spite of the high temperature not a single butterfly emerged during this time, whilst pupæ of Vanessa $C$-album and Pyrameis Atalanta, found at the same time, and placed in the same hothouse, emerged in the middle of October. From the middle of December the pupæ were kept in an unheated room, and they emerged very late in the spring of 1873 , all as Levana:-

On the 6 th of June, 7 Levana.

\begin{tabular}{|c|c|c|c|}
\hline ” & 8th & ” & 2 \\
\hline , & I I th & $"$ & 2 \\
\hline " & I 2 th & " & I \\
\hline " & I $5^{\text {th }}$ & $"$ & 6 \\
\hline " & I 6 th & $"$ & I \\
\hline " & Igth & $"$ & 2 \\
\hline & Total & & $2 \mathrm{I}$ \\
\hline
\end{tabular}

B. Kept in an unheated room during the winter. The butterflies emerged from the 28 th of May, all as Levana.

\section{Experiments with Pierina.}

13. Females of Pieris Rapa, captured in April, laid eggs on Sisymbrium Alliaria. From these caterpillars were obtained, which pupated on Ist-3rd June. The pupæ were placed on ice from June 3rd till September I Ith $\left(0^{\circ}-I^{\circ}\right.$ R.), and from September IIth till October 3 rd in the hothouse $\left(12^{\circ}-24^{\circ}\right.$ R. $)$, where there emerged :-

On the 23rd of October, I female.

$\begin{array}{llll}" & 24^{\text {th }} & " & \text { I female. } \\ " & 25^{\text {th }} & , & 2 \text { males, I female. } \\ " & 26 \text { th } & \text { I female. } \\ \text { 28th } & \text { Total } & \frac{\text { I male, I female. }}{3 \text { males, } 5 \text { females. }}\end{array}$


All these were sharply impressed with the characters of the winter form, the females all strongly yellow on the upper side, the males pure white; on the under side a strong black dusting on the hind wings, particularly on the discoidal cell. One pupa did not emerge in the hothouse, but hibernated, and gave in a heated room on January 20th, 1873, a female, also of the winter form.

14. Females of Pieris Napi, captured on 27th-28th April, 1872, laid eggs on Sisymbrium Alliaria. The larvæ bred from these pupated on May 28th to June 7 th. The pupæ, shortly after transformation, were placed on ice, where they remained till Sept. IIth (three months). Transferred to the hothouse on October 3rd, they produced, up to October 2oth, 60 butterflies, all with the sharply-defined characters of the winter form. The remaining pupæ hibernated in a room, and produced :-

On the 28th of April, 3 males, 6 females.

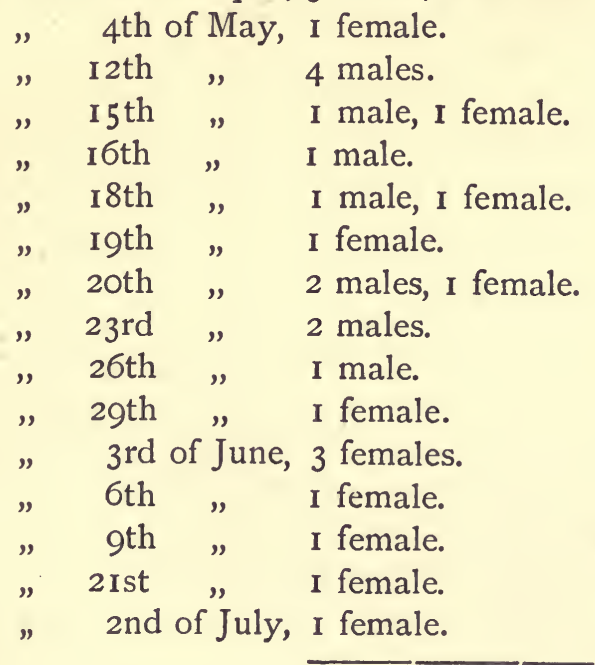

Total . . 15 males, 19 females.

15. Several butterflies from Exp. I4, which emerged in May, 1873, were placed in a capacious breeding- 
house, where they copulated and laid eggs on rape. The caterpillars fed on the living plants in the breedinghouse, and after pupation were divided into two portions:-

A. Several pupæ, kept at the ordinary summer temperature, gave butterflies on July 2 nd, having the characters of the summer form.

B. The remainder of the pupæ were placed on ice immediately after transformation, and remained over three months in the refrigerator (from July Ist till October Ioth). Unfortunately most of them perished through the penetration of moisture into the box. Only 8 survived, 3 of which emerged on the 2oth of October as the winter form; the others hibernated in an unheated room, and emerged at the beginning of June, I874. All 5 were females, and all exhibited the characters of the winter form. Notwithstanding a pupal period of eleven months, they did not possess these characters to a greater extent than usual, and did not, therefore, approximate to the parent form Bryonice.

16. On June I2th, I87I, specimens of Pieris Napi, var. Bryonice, were captured on a mountain in the neighbourhood of Oberstorf (Allgäuer Alpen), and placed in a breeding-house, where they flew freely about the flowers ; but although copulation did not take place, several females laid eggs on the ordinary garden cabbage. From these caterpillars were hatched, which at all stages of growth were exactly like those of the ordinary form of Napi. They throve well until shortly before pupation, when a fungoid epidemic decimated them, so that from 300 caterpillars only about 40 living pupæ were obtained. These also completely resembled the ordinary form of Napi, and showed the same polymorphism, some being beautifully green, others (the majority) straw yellow, and others yellowish grey. Only one butterfly emerged the same summer, a male, which, by the black 
dusting of the veins on the margin of the wings (upper side), could be with certainty recognized as var. Bryonice. The remaining pupæ hibernated in a heated room, and gave, from the end of January to the beginning of June, Io males and 5 females, all with the characters of the var. Bryonice. They emerged :-

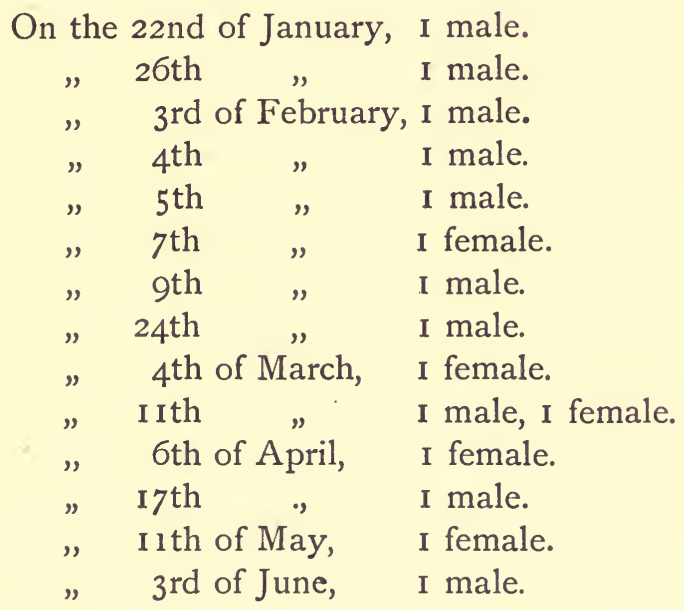

We here perceive that the tendency to accelerate development through the action of warmth is, in this case, also very different in different individuals. Of the I6 butterflies only I kept to the normal period of development from July 27 th to June 3 rd, fully ten months ; all the others had this period abbreviated, I male to eleven days, 8 specimens to six months, 4 to seven months, 2 to eight months, and I to nine months. 


\section{APPENDIX II.}

\section{Experiments with Papilio Ajax. ${ }^{1}$}

From eggs of var. Telamonides laid on the last of May larvæ were obtained, which gave on June $2.2 n d-26$ th, I 22 pupæ. These; as fast as formed, were placed on ice in the refrigerator in small tin boxes, and when all the larvæ had become transformed the pupæ were transferred to a cylindrical tin box (4 in. diam. and 6 in. high), and packed in layers between fine shavings. The tin box was set in a small wooden one, which was put directly on the ice and kept there till July 20th. From that date, by an unfortunate accident, the box, instead of being kept on the surface of the ice in an ice-house, as was intended, was placed on straw near the ice, so that the action of the cold was modified, the outside pupæ certainly experiencing its full effects, but the inside ones were probably at a somewhat higher temperature. The ice failed on August 2oth, so that the pupæ had been subjected to an equable low temperature in the refrigerator for three to four weeks, and to a lesser degree of cold in the ice-house for five weeks, the tem-

1 The experiments upon Papilio Ajax and Phyciodes Tharos, described in this Appendix, were made by Mr. W. H. Edwards (see his "Butterflies of North America;" also the "Canadian Entomologist," vol. vii. p. 228-240, and vol. ix. p. I-ro, 5 I -5 , and 203-6); and I have added them, together with some hitherto unpublished results, to Dr. Weismann's Essay, in order to complete the history of the subject of seasonal dimorphism up to the present time.-R.M. 
perature of the last place rising daily, as the ice had all thawed by August 20th. On opening the box it was found (probably owing to the cold not having been sufficiently severe) that the butterflies had commenced to emerge. Twenty-seven dead and crippled specimens were removed, together with several dead pupæ. One butterfly that had just emerged was taken out and placed in a box, and when its wings had fully expanded it was found to be a "Telamodides of the most pronounced type." The experimenter then states :"Early in the morning I made search for the dead and rejected butterflies, and recovered a few. It was not possible to examine them very closely from the wet and decayed condition they were in, but I was able to discover the broad crimson band which lies above the inner angle of the hind wings, and which is usually lined on its anterior side with white, and is characteristic of either Walshii or Telamonides, but is not found in Marcellus. And the tip only of the tail being white in Walshii, while both tip and sides are white in Telamonides, enabled me to identify the form as between these two. There certainly were no Walshii, but there seemed to be a single Marcellus, and excepting that all were Telamonides."

The remaining pupæ were kept in a light room where 3 Telamonides emerged the following day, and by September 4th 14 specimens of the same variety had emerged, but no Marcellus or intermediate forms. From the 4 th to the 2oth of September a few more Telamonides appeared, but between the 4th and 15 th of the month 12 out of 26 butterflies that had emerged were intermediate between Telamonides and Marcellus, some approximating to one form and some to the other form. The first pure Marcellus appeared on September 4th, and was followed by one specimen on the 6th, 8th, I3th and $15^{\text {th }}$ respectively. From this last date to 
October 3 rd, 6 out of ro were Marcellus and 3 intermediate. On September 3rd, a specimen intermediate between Telamonides and Walshii emerged, "in which the tails were white tipped as in Walshii, but in size and other characters it was Telamonides, though the crimson band might have belonged to either form." Butterflies continued to emerge daily up to September 2oth, after which date single specimens appeared at intervals of from four to six days, the last emergence being on October I 6 th. Thus, from the time the box was removed from the ice-house, the total period of emerging was fifty-seven days, some specimens having emerged before the removal of the box. With specimens of $P$. Ajax which appear on the wing the first season the natural pupal period is about fourteen days, individuals rarely emerging after a period of four to six weeks.

Between August 20th and October 16th, the 50 following butterflies emerged:-

On the 2oth of August, I male Telamonides.

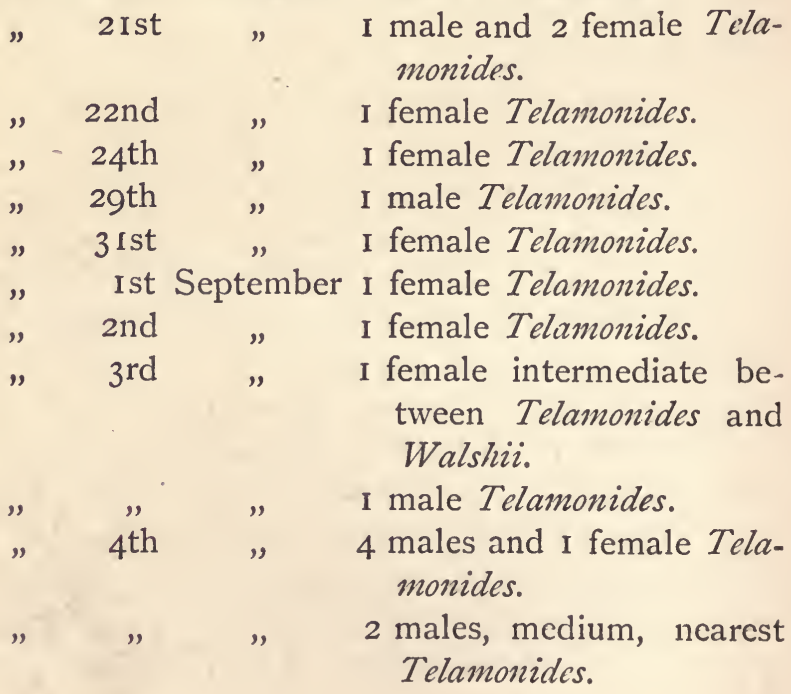


On the 4 th of September, 2 malẹs, medium, nearest Marcellus.

2 males, Marcellus.

I male and I female Telamonides.

I male medium, nearest Telamonides.

I male Marcellus.

I male Telamonides.

I male Marcellus and I female Telamonides.

I male Marcellus and I female medium, nearest Marcellus.

I male medium, nearest Marcellus.

I male medium, nearest Telamonides.

I male Marcellus

I male Marcellus and I female medium, nearest Marcellus.

I male medium, nearest Telamonides.

I male Marcellus.

I female Marcellus and I male Telamonides.

I male medium, nearest Marcellus.

I female Marcellus.

1 male Telamonides.

I male Marcellus.

I female Marcellus.

I female Marcellus.

I female medium, nearest Telamonides. 
On the 8th of October, I female medium, nearest Telamonides.

" 16th " I female medium, nearest Telamonides.

Total.

Telamonides . . . . 22 1 2 males, Io females Telamonides partly Walshii . I I female. Medium, nearest Telamonides 85 males, 3 females Medium, nearest Marcellus . 64 males, 2 females Marcellus . . . . 139 males, 4 females.

5030 males, 20 females.

All these butterflies were very uniform in size, being about that of the ordinary Telamonides. The specimens of Telamonides especially were "strongly marked, the crimson band in a large proportion of them being as conspicuous as is usual in Walshii, and the blue lunules near the tail were remarkably large and bright coloured. Of the Marcellus, in addition to the somewhat reduced size, the tails were almost invariably shorter than usual and narrower, and instead of the characteristic single crimson spot, nearly all had two spots, often large. In all these particulars they approach Telamonides."

Adding to the 'Telamonides which emerged after August 20th most of those specimens which were found dead in the box at that date, the total number of this form is thus brought up to nearly 50. Of the I 22 pupx with which Mr. Edwards started, 28 remained in a state fit for hibernation, several having died without emerging. Previous experiments had shown that 28 out of 122 pupæ is not an unreasonalble number to hibernate, so that the author concludes that the butterflies which emerged the same season would have done so naturally, and the effect of the artificial cold was not " to precipitate the emerging of any which would have slept" till the 
following spring. Now under ordinary circumstances all the butterflies which emerged the same season would have been of the Marcellus form, so that the cold changed a large part of these into the form Telamonides, some (probably from those pupæ which experienced the lowest temperature) being completely changed, and others (from those pupæ which were only imperfectly subjected to the cold) being intermediate, i.e., only partly changed. It appears also that several pupæ experienced sufficient cold to retard their emergence and stunt their growth, but not enough to change their form, these being the 13 recorded specimens of Marcellus. Had the degree of cold been equal and constant, the reversion would probably have been more complete. The application of cold produced great confusion in the duration of the pupal period, the emergence, instead of taking place fourteen days after the withdrawal of the cold, as might have been expected from Dr. Weismann's corresponding experiment with Pieris Napi (Appendix I. Exps. I 3 and I4), having been extended over more than two months.

From the results of this experiment it must be concluded that Telamonides is the primary form of the species.

\section{Additional Experiments with Papilio Ajax.}

[Communicated by Mr. W. H. EDWARDS, November 18th, 1879.]

ExP. I.-In I 877 chrysalides of P. Ajax and Grapta Interrogationis (the eggs laid by females of the form Fabricii) were experimented upon; but the results were not satisfactory, for the reason that the author having been absent from home most of the time while the pupæ were in the ice-box, on his return found the temperature above $5^{\circ}-6^{\circ} \mathrm{R}$. And so far as could be told, the ice had been put in irregularly, and there might have been intervals during which no ice at all was in the box. Six chry- 
salides of the Grapta so exposed produced unchanged Umbrosa, the co-form with Fabricii. But all chrysalides from the same lot of eggs, and not exposed to cold, also produced Umbrosa. Nothing was learnt, therefore, respecting this species.

But chrysalides of Ajax, exposed at same time, did give changed butterflies to some extent. From a lot of 8 , placed in the box when under twelve hours from pupation, and left for twenty-four days, there came 5 males and 3 females. Of these was I Telamonides in markings and coloration, and all the rest were between Marcellus and Telamonides. Two other chrysalides on ice for twenty-three days gave Telamonides, but 3 more exposed twenty-six days, and all one hour old when put on ice, were unchanged, producing Marcellus.

During the same season 6 other Ajax chrysalides were placed in the box, and kept at about $0^{\circ}-I^{\circ} \mathrm{R}$. One was one hour old, and remained for five days; I was one hour old, and remained for two days and three-quarters; 3 at three hours old for eight days; and I (age omitted), six days. All these gave unchanged butterflies of the form Marcellus.

ExP. 2.-In May, I878, many chrysalides were placed in the ice-box, being from eggs laid by Ajax, var. Walshii. The youngest were but ten to fifteen minutes from pupation, and were soft; others at intervals up to twentyfour hours (the chrysalis is hard at about twelve hours); after that, each day up to eight days after pupation. All were removed from the box on the same day, 28th May. The exposure was from nineteen to five days, those chrysalides which were put on ice latest having the shortest exposure. The author wished to determine if possible whether, in order to effect any change, it was necessary that cold should be applied immediately after pupation or if one or several days might intervene between pupation and refrigeration. Inasmuch as no colour begins 
to show itself in the pupæ till a few hours, or at most a day or two, before the butterfly emerges, it was thought possible that cold applied shortly before that time would be quite as effective as if applied earlier and especially very soon after pupation. The result was, that more than half of the chrysalides exposed before they had hardened died : I exposed at ten minutes, 2 at one hour, $I$ at two hours, 2 at three hours after pupation. On the other hand I at fifteen minutes produced a butterfly, I at two hours, another at twelve hours. The temperature was from $0^{\circ}-I^{\circ} R$. most of the time, but varied somewhat each day as the ice melted. The normal chrysalis period is from eleven to fourteen days, in case the butterfly emerges the same season, but very rarely an individual will emerge several weeks after pupation.

On the I4th day after taking the pupæ from the ice,

1 Telamonides emerged from a chrysalis which had been placed in the ice-box three days after pupation, and was on ice sixteen days.

On I9th day, I Telamonides emerged from a pupa put on the ice twelve hours after pupation, and kept there eleven days.

On 19th day, I Walshii emerged from a pupa two hours old, and on ice eleven days.

All the rest emerged Marcellus, unchanged, but at periods prolonged in a surprising way.

I on 43 rd day exposed I 5 minutes after pupation.

\begin{tabular}{|c|c|c|}
\hline$"$ 46th & $"$ & 2 hours \\
\hline $53 \mathrm{rd}$ & $"$ & 24 hours \\
\hline 62 nd & , & 6 days \\
\hline $63 \mathrm{rd}$ & , & 4 days \\
\hline 66th & " & 7 days \\
\hline $77^{\text {th }}$ & " & 4 days \\
\hline 8Ist & " & I 2 hours \\
\hline 9ist & , & 5 days \\
\hline 96th & ” & I9 hours \\
\hline
\end{tabular}


Five chrysalides lived through the winter, and all gave Telamonides in the spring of 1879.

It appeared, therefore, that the only effect produced by cold in all chrysalides exposed more than three days after pupation was to retard the emergence of the butterfly. But even in some of these earliest exposed, and kept on the ice for full nineteen days, the only effect seemed to be to retard the butterfly.

ExP. 3.-In June, 1879, eggs of the form Marcellus were obtained, and in due time gave 104 chrysalides. Of these one-third were placed in the ice-box at from twelve to twenty-four hours after pupation, and were divided into 3 lots.

$$
\begin{aligned}
& \text { Ist, } 9 \text { pupæ, kept on ice } 14 \text { days. } \\
& 2 \text { nd, I } 2 \text { " } \\
& \text { 3rd, I I ", } 20 \text { days. }
\end{aligned}
$$

Temperature $0^{\circ}-\mathrm{I}^{\circ} \mathrm{R}$. most of the time, but varying somewhat as the ice melted. (Both in I878 and I 879 Mr. Edwards watched the box himself, and endeavoured to keep a low temperature.)

Of the 69 chrysalides not exposed to cold, 34 gave butterflies at from elcven to fourteen days after pupation, and I additional male emerged I Ith August, or twentytwo days at lcast past the regular period of the species.

Of the iced chrysalides, from lot No. I emerged 4 females at eight days and a half to nine days and a half after removal from the ice, and 5 are now alive (Nov. I 8 ) and will go over the winter.

From lot No. 2 emerged I male and 5 females at eight to nine days; another male came out at forty days; and 5 will hibernate.

From lot No. 3 emerged 4 females at nine to twelve days; another male came out at fifty-four days; and 6 were found to be dead.

In this experiment the author wished to see as exactly as possible-First, in what points changes would occur. 
Second, if there would be any change in the shape of the wings, as well as in markings or coloration-that is, whether the shape might remain as that of Marcellus, while the markings might be of Telamonides or Walshii; a summer form with winter markings. Third, to ascertain more closely than had yet been done what length of exposure was required to bring about a decided change, and what would be the effect of prolonging this period. After the experiments with Phyciodes Tharos, which had resulted in a suffusion of colour, the author hoped that some similar cases might be seen in Ajax. The decided changes in 1878 had been produced by eleven and sixteen days' cold. In 1877 , an exposure of two days and three-quarters to eight days had failed to produce an effect.

From these chrysalides I I perfect butterflies were obtained, I male and Io females. Some emerged crippled, and these were rejected, as it was not possible to make out the markings satisfactorily.

From lot No. I, fourteen days came:-

I female between Marcellus and Telamonides.

2 females, Marcellus.

These 2 Marcellus were pale coloured, the light parts a dirty white; the submarginal lunules on hind wings were only two in number and small; at the anal angle was one large and one small red spot; the frontal hairs were very short. The first, or intermediate female, was also pale black, but the light parts were more green and less sordid; there were 3 large lunules; the anal red spot was double and connected, as in Telamonides; the frontal hairs short, as in Marcellus. These are the most salient points for comparing the several forms of Ajax. In nature, there is much difference in shape between Marcellus and Telamonides, still more between Marcellus and Walshii; and the latter may be distinguished from the other winter forms by the white tips of 
the tails. It is also smaller, and the anal spot is larger, with a broad white edging.

From lot No. 2, twenty days, came :-

I female Marcellus, with single red spot.

I female between Marcellus and Telamonides; general coloration pale ; the lunules all obsoles. cent; 2 large red anal spots not connected; frontal hairs medium length, as in Telamonides.

I female between Marcellus and Telamonides; colour bright and clear; 3 lunules; 2 large red spots; frontal hairs short.

I female Telamonides; colours black and green; 4 lunules; a large double and connected red spot; frontal hairs medium.

2 female Telamonides; colours like last; 3 and 4 lunules; 2 large red spots; frontal hairs medium.

From lot No. 3, twenty-five days, came:-

I male Telamonides; clear colours; 4 large lunules; I large, I small red spot; frontal hairs long.

I female Telamonides; medium colours; 4 lunules ; large double connected red spot; frontal hairs long.

In general shape all were Marcellus, the wings produced, the tails long.

From this it appeared that those exposed twenty-five days were fully changed ; of those exposed twenty days, 3 were fully, 2 partly, I not at all ; and of those exposed fourteen days, I partly, 2 not at all.

The butterflies from this lot of IO4 chrysalides, but which had not been iced, were put in papers. Taking 6 males and 6 females from the papers just as they came to hand, Mr. Edwards set them, and compared them with the iced examples.

Of the 6 males, 4 had I red anal spot only, 2 had I large I small; 4 had 2 green lunules on the hind wings, 2 had 
3 , and in these last there was a $4^{\text {th }}$ obsolescent, at outer angle; all had short frontal hairs.

Of the 6 females, 5 had but I red spot, I had I large I small spot; 5 had 2 lunules only, I had 3; all had short frontal hairs.

Comparing 6 of the females from the iced chrysalides, being those in which a change had more or less occurred, with the 6 females not iced:

I. All the former had the colours more intense, the black deeper, the light, green.

2. In 5 of the former the green lunules on hind wings were decidedly larger; 3 of the 6 had 4 distinct lunules, I had 3 , I had 3 , and a $4^{\text {th }}$ obsolescent. Of the 6 females not iced none had 4, 2 had 2, and a 3rd, the lowest of the row, obsolescent; 3 had 3 , the lowest being very small; one had 3 , and a 4 th, at outer angle, obsolescent.

3. In all the former the subapical spot on fore wing and the stripe on same wing which crosses the cell inside the common black band, were distinct and green; in all the latter these marks were either obscure or obsolescent.

4. In 4 of the former there was a large double connected red spot, and in one of the 4 it was edged with white on its upper side; 2 had I large and I small red spot. Of the latter 5 had I spot only, and the 6 th had I spot and a red dot.

5. The former had all the black portions of the wing of deeper colour but less diffused, the bands being narrower; on the other hand, the green bands were wider as well as deeper coloured. Measuring the width of the outermost common green band along the middle of the upper medium interspace on fore wing in tenths of a. millimetre, it was found to be as follows: 
On the iced pupæ. . . 81, 66, 76, 76, 66, 66.

On the not iced . . 56,56,5 I, 51, 46, 5 I.

Measuring the common black discal band across the middle of the lower medium interspace on fore wing:

On the iced pupæ . . 5 I, 66, 51, 51, 56, 61.

On the not iced . . 76,71, 66, 63,71, 76 .

In other words the natural examples were more melanic than the others.

No difference was found in the length of the tails or in the length and breadth of wings. In other words, the cold had not altered the shape of the wings.

Comparing I male iced with 6 males not iced:

I, The former had a large double connected red anal spot, edged with white scales at top. Of the 6 not iced, 3 had but I red spot, 2 had I large I small, I had I large and a red dot.

2. The former had 4 green lunules; of the latter 3 had 3,3 had only 2 .

3. The former had the subapical spot and stripe in the cells clear green; of the latter I had the same, 5 had these obscure or obsolescent.

4. The colours of the iced male were bright; of the others, 2 were the same, 4 had the black pale, the light sordid white or greenish-white.

Looking over all, male and female, of both lots, the large size of the green submarginal lunules on the fore wings in the iced examples was found to be conspicuous as compared with all those not iced, though this feature is included in the general widening of the green bands spoken of.

In all the experiments with $A j a x$, if any change at all has been produced by cold, it is seen in the enlarging or doubling of the red anal spot, and in the increased number of clear green lunules on the hind wings. Almost always the frontal hairs are lengthened and the colour of the wings deepened, and the extent of the black area is 
also diminished. All these changes are in the direction of Telamonides, or the winter form.

That the effect of cold is not simply to precipitate the appearance of the winter form, causing the butterfly to emerge from the chrysalis in the summer in which it began its larval existence instead of the succeeding year, is evident from the fact that the butterflies come forth with the shape of Marcellus, although the markings may be of Telamonides or Walshii. And almost always some of the chrysalides, after having been iced, go over the winter, and then produce Telamonides, as do the hibernating pupæ in their natural state. The cold appears to have no effect on these individual chrysalides. ${ }^{2}$

With every experiment, however similar the conditions seem to be, and are intended to be, there is a difference in results; and further experiments-perhaps many-will be required before the cause of this is understond. For example, in 1878 , the first butterfly emerged on the fourteenth day after removal from ice, the period being exactly what it is (at its longest) in the species in nature. Others emerged at 19-96 days. In 1879 , the emergence began on the ninth day, and by the twelfth day all had come out, except three belated individuals, which came out at twenty, forty, and fifty-four days. In the last experiment, either the cold had not fully suspended the changes which the insect undergoes in the chrysalis, or its action was to hasten them after the chrysalides were taken from the ice. In the first experiment, apparently the changes were absolutely suspended as long as the cold remained.

It might be expected that the application of heat to the hibernating chrysalides would precipitate the appearance of the summer form, or change the mark-

${ }^{2}$ This is a striking illustration of the diversity of individual constitution so frequently insisted on by Dr. Weismann in the foregoing portion of this work. 
ings of the butterfly into the summer form, even if the shape of the wings was not altered; that is, to produce individuals having the winter shape but the summer markings. But this was not found to occur. Mr. Edwards has been in the habit for several years of placing the chrysalides in a warm room, or in the greenhouse, early in the winter, thus causing the butterflies to emerge in February, instead of in March and April, as otherwise they would do. The heat in the house is $19^{\circ} \mathrm{R}$. by day, and not less than $3.5^{\circ} \mathrm{R}$. by night. But the winter form of the butterfly invariably emerged, usually Telamonides, occasionally Walshii.

\section{Experiments with Phyciodes Tharos.}

ExP. I.-In July, I875, eggs of $P$. Tharos were obtained on Aster Nova-Anglice in the Catskill Mountains, and the young larvæ, when hatched, taken to Coalburgh, West Virginia. On the journey the larvæ were fed on various species of Aster, which they ate readily. By the $4^{\text {th }}$ of September they had ceased feeding (after having twice moulted), and slept. Two weeks later part of them were again active, and fed for a day or two, when they gathered in clusters and moulted for the third time, then becoming lethargic, each one where it moulted with the cast skin by its side. The larvæ were then placed in a cellar, where they remained till February 7 th, when those that were alive were transferred to the leaves of an Aster which had been forced in a greenhouse, and some commenced to feed the same day. In due time they moulted twice more, making, in some cases, a total of five moults. On May 5 th the first larva pupated, and its butterfly emerged after thirteen days. Another emerged on the $30 t h$, after eight days pupal period, this stage being shortened as the weather became warmer. There emerged altogether 8 butterflies, 5 males 
and 3 females, all of the form Marcia, and all of the variety designated $C$, except I female, which was var. B. ${ }^{3}$

ExP. 2.-On May I8th the first specimens (3 male Marcia) were seen on the wing at Coalburgh; I female was taken on the Igth, 2 on the 23 rd, and 2 on the 24 th, these being all that were seen up to that date, but shortly after both sexes became common. On the 26 th, 7 females were captured and tied up in separate bags on branches of Aster. The next day 6 out of the 7 had laid eggs in clusters containing from 50 to 225 eggs in each. Hundreds of caterpillars were obtained, each brood being kept separate, and the butterflies began to emerge on June 29th, the several stages being :- egg six days, larva twenty-two, chrysalis five. Some of the butterflies did not emerge till the I5th of July. Just after this date one brood was taken to the Catskills, where they pupated, and in this state were sent back to Coalburgh. There was no difference in the length of the different stages of this brood and the others which had been left at Coalburgh, and none of either lot became lethargic. The butterflies from these eggs of May were all Tharos, with the exception of I female Marcia, var. C. Thus the first generation of Marcia from the hibernating larvæ furnishes a second generation of Tharos.

ExP. 3.-On July I6th, at Coalburgh, eggs were obtained from several females, all Tharos, as no other form was flying. In four days the eggs hatched; the larval stage was twenty-two, and the pupal stage seven days; but, as before, many larvæ lingered. The first butterfly emerged on August I8th. All were Tharos, and none

${ }^{3}$ The reader who wishes to acquire a detailed knowledge of the different varieties of this butterfly, of which a very large number are known, must consult the plates and descriptions in Edwards' "Butterflies of North America," vol. ii.. 
of the larvæ had been lethargic. This was the third generation from the second laying of eggs.

ExP. 4.-On August I5th, at Coalburgh, eggs were obtained from a female Tharos, and then taken directly to the Catskill Mountains, where they hatched on the 20th. This was the fourth generation from the third laying of eggs. In Virginia, and during the journey, the weather had been exceedingly warm, but on reaching the mountains it was cool, and at night decidedly cold. September was wet and cold, and the larvæ were protected in a warm room at night and much of the time by day, as they will not feed when the temperature is less than about $8^{\circ} \mathrm{R}$. The first pupa was formed September I 5 th, twenty-six days from the hatching of the larvæ, and others at different dates up to September 26th, or thirty-seven days from the egg. Fifty-two larvæ out of 127 became lethargic after the second moult on September I6th, and on September 26th fully one half of these lethargic larvæ commenced to feed again, and moulted for the third time, after which they became again lethargic and remained in this state. The pupx from this batch were divided into three portions :-

A. This lot was brought back to Coalburgh on October I 5 th, the weather during the journey having been cold with several frosty nights, so that for a period of thirty days the pupæ had at no time been exposed to warmth. The butterflies began to emerge on the day of arrival, and before the end of a week all that were living had come forth, viz., 9 males and ro females. "Of these 9 males 4 were changed to Marcia var. C, 3 were var. D, and 2 were not changed at all. Of the Io females 7 were changed, 5 of them to var. B, 3 to var. C. The other 2 females were not different from many Tharos of the summer brood, having large discal patches on under side of hind wing, besides the markings common to the summer brood." 
B. This lot, consisting of Io pupæ, was sent from the Catskills to Albany, New York, where they were kept in a cool place. Between October 2 Ist and Nov. 2nd, 6 butterflies emerged, all females, and all of the var. B. Of the remaining pupæ 'I died, and 3 were alive on December 27th. According to Mr. Edwards this species never hibernates in the pupal state in nature. The butterflies of this lot were more completely changed than were those from the pupæ of lot A.

C. On September 20th 18 of the pupæ were placed in a tin box directly on the surface of the ice, the temperature of the house being $3^{\circ}-4^{\circ} \mathrm{R}$. Some were placed in the box within three hours after transformation and before they had hardened; others within six hours, and others within nine hours. They were all allowed to remain on the ice for seven days, that being the longest summer period of the chrysalis. On being removed they all appeared dead, being still soft, and when they had become hard they had a shrivelled surface. On being brought to Coalburgh they showed no signs of life till October 2 Ist, when the weather became hot $\left(24^{\circ}-25^{\circ} \mathrm{R}\right.$.), and in two days I 5 butterflies emerged, "every one Marcia, not a doubtful form among them in either sex." Of these butterflies Io were males and 5 females; of the former 5 were var. C, 4 var. D, and I var. $B$, and of the latter $I$ was var. $C$, and 4 var. D. The other 3 pupæ died. All the butterflies of this brood were diminutive, starved by the cold, but those from the ice were sensibly smaller than the others. All the examples of var. $\mathrm{B}$ were more intense in the colouring of the under surface than any ever seen by Mr. Edwards in nature, and the single male was as deeply coloured as the females, this also never occurring in nature.

Mr. Edwards next proceeds to compare the behaviour 
of the Coalburgh broods with those of the same species in the Catskills :-

ExP. 5.-On arriving at the Catskills, on June I 8 th, a few male Marcia, var. D, were seen flying, but no females. This was exactly one month later than the first males had been seen at Coalburgh. The first female was taken on June 26 th, another on June 27 th, and a third on the 28th, all Marcia, var. C. Thus the first female was thirty-eight days later than the first at Coalburgh. No more females were seen, and no Tharos. The three specimens captured were placed on Aster, where two immediately deposited eggs ${ }^{4}$ which were forwarded to Coalburgh, where they hatched on July 3 rd. The first chrysalis was formed on the 2oth, its butterfly emerging on the 29th, so.that the periods were: egg six, larva seventeen, pupa nine days. Five per cent. of the larvæ became lethargic after the second moult. This was, therefore, the second generation of the butterfly from the first laying of eggs. All the butterflies which emerged were Tharos, the dark portions of the wings being intensely black as compared with the Coalburgh examples, and other differences of colour existed, but the general peculiarities of the Tharos form were retained. This second generation was just one month behind the second at Coalburgh, and since, in I875, eggs were obtained by Mr. Mead on July 27 th and following days, the larvæ from which all hibernated, this would be the second laying of eggs, and the resulting butterflies the first generation of the following season.

Thus in the Catskills the species is digoneutic, the first generation being Marcia (the winter form), and the second the summer form. A certain proportion of the

4 Mr. Edwards has shown also that Argynnis Myrina can lay fertile eggs when but a few hours out of the chrysalis. Canad. Ent., September, I876, vol. viii. No. 9. 
larvæ from the first generation hibernate, and apparently all those from the second.

Discussion of Results. - There are four generations of this butterfly at Coalburgh, the first being Marcia and the second and third Tharos. None of the larvæ from these were found to hibernate. The fourth generation under the exceptional conditions above recorded (Exp. 4) produced some Tharos and more Marcia the same season, a large proportion of the larvæ also hibernating. Had the larvæ of this brood been kept at Coalburgh, where the temperature remained high for several weeks after they had left the egg, the resulting butterflies would have been all Tharos, and the larvæ from their eggs would have hibernated.

The altitude of the Catskills, where Mr. Edwards was, is from 1650 to 2000 feet above high water, and the altitude of Coalburgh is 600 feet. The transference of the larvæ from the Catskills to Virginia (about $48^{\circ}$ lat.) and vice-vers $a$, besides the difference of altitude, had no perceptible influence on the butterflies of the several broods except the last one, in which the climatic change exerted a direct influence on part of them both as to form and size. The stages of the June Catskill brood may have been accelerated to a small extent by transference to Virginia, but the butterflies reserved their peculiarities of colour. (See Exp. 5.) So also was the habit of lethargy retained. ${ }^{5}$ The May brood, on the other hand,

${ }^{5} \mathrm{Mr}$. Edwards remarks that the habit of becoming lethargie is of great service to a digoneutic species in a mountain region where it is exposed to sharp changes of temperature. "If the fate of the species depended on the last larval brood of the year, and especially if the larvæ must reach a certain stage of growth before they were fitted to enter upon their hibernation, it might well happen that now and then an early frost or a tempestuous season would destroy all the larvæ of the district." 
taken from Virginia to the Catskills, suffered no retardation of development. (See Exp. 2.) It might have been expected that all the larvæ of this last brood taken to the mountains would have become lethargic, but the majority resisted this change af habit. From all these facts it may be concluded " that it takes time to naturalize a stranger, and that habits and tendencies, even in a butterfly, are not to be changed suddenly." "

It has been shown that Tharos is digoneutic in the Catskills and polygoneutic in West Virginia, so that at a great altitude, or in a high latitude, we might expect to find the species monogoneutic and probably restricted to the winter form Marcia. These conditions are fulfilled in the Island of Anticosti, and on the opposite coast of Labrador (about lat. $50^{\circ}$ ), the summer temperature of these districts being about the same. Mr. Edwards states, on the authority of Mr. Cooper, who collected in the Island, that Tharos is a rare species there, but has a wide distribution. No specimens were seen later than July 29, after which date the weather became cold, and very few butterflies of any sort were to be seen. It seems probable that none of the butterflies of Anticosti or Labrador produce a second brood. All the specimens examined from these districts were of the winter form.

In explanation of the present case Dr. Weismann wrote to Mr. Edwards :- "Marcia is the old primary form of the species, in the glacial period the only one. Tharos is the secondary form, having arisen in the course of many generations through the gradually working influence of summer heat. In your experiments cold has caused the summer generation to revert to the primary form. The reversion which occurred was complete in the females, but not in all the males. This

${ }^{6}$ Compare this with Weismann's remarks, pp. 19-22, and 53. 
proves, as it appears to me, that the males are changed or affected more strongly by the heat of summer than the females. The secondary form has a stronger constitution in the males than in the females. As I read your letter, it at once occurred to me whether in the spring there would not appear some males which were not pure Marcia, but were of the summer form, or nearly resembling it; and when $I$ reached the conclusion of the letter I found that you especially mentioned that this was so! And I was reminded that the same thing is observable in $A$. Levana, though in a less striking degree. If we treated the summer brood of Levana with ice, many more females than males would revert to the winter form. This sex is more conservative than the male-slower to change."

The extreme variability of $P$. Tharos was alluded to more than a century ago by Drury, who stated :- "In short, Nature forms such a variety of this species that it is difficult to set bounds, or to know all that belongs to it." Of the different named varieties, according to $\mathrm{Mr}$. Edwards, "A appears to be an offset of $B$, in the direction most remote from the summer form, just as in Papilio Ajax, the var. Walshii is on the further side of Telamonides, remote from the summer form Marcellus." Var. C leads from B through D directly to the summer form, whilst $A$ is more unlike this last variety than are several distinct species of the genus, and would not be suspected to possess any close relationship were it not for the intermediate forms. The var. B is regarded as nearest to the primitive type for the following reasons:In the first place it is the commonest form, predominating over all the other varieties in W. Virginia, and moreover appears constantly in the butterflies from pupæ submitted to refrigeration. Its distinctive peculiarity of colour occurs in the allied species $P$. Phaon (Gulf States) and $P$. Vesta (Texas), both of which are 
seasonally dimorphic, and both apparently restricted in their winter broods to the form corresponding to $\mathrm{B}$ of Tharos. In their summer generation both these species closely resemble the summer form of Tharos, and it is remarkable that these two species, which are the only ones (with the exception of the doubtful Batesii) closely allied to Tharos, should alone be seasonally dimorphic out of the large number of species in the genus.

Mr. Edwards thus explains the case under consideration :- "When Phaon, Vesta, and Tharos were as yet only varieties of one species, the sole coloration was that now common to the three. As they gradually became permanent, or in other words, as these varieties became species, Tharos was giving rise to several sub-varieties, some of them in time to become distinct and well marked, while the other two, Phaon and Vesta, remained constant. As the climate moderated and the summer became longer, each species came to have a summer generation; and in these the resemblance of bloodrelationship is still manifest. As the winter generations of each species had been much alike, so the summer generations which sprung from them were much alike. And if we consider the metropolis of the species Tharos, or perhaps of its parent species, at the time when it had but one annual generation, to have been somewhere between $37^{\circ}$ and $40^{\circ}$ on the Atlantic slope, and within which limits all the varieties and sub-varieties of both winter and summer forms of Tharos are now found in amazing luxuriance, we can see how it is possible, as the glacial cold receded, that only part of the varieties of the winter form might spread to the northward, and but one of them at last reach the sub-boreal regions and hold possession to this day as the sole representative of the species. And at a very early period the primary form, together with Phaon and Vesta, had made its way southward, where all three are found now." 


\section{EXPERIMENTS WITH .GRAPTA INTERROGATIONIS. ${ }^{7}$}

[Communicated by Mr. W. H EDWARDS, November 15 th, 1879.]

The experiments with this species were made in June, I879, on pupæ from eggs laid by the summer form Umbrosa of the second brood of the year, and obtained by confining a female in a bag on a stem of hop. As the pupæ formed, and at intervals of from six to twentyfour hours after pupation (by which time all the older ones had fully hardened), they were placed in the icebox. In making this experiment Mr. Edwards had three objects in view. Ist. To see whether it was essential that the exposure should take place immediately after pupation, in order to effect any change. 2ndly. To see how short a period would suffice to bring about any change. 3rdly. Whether exposing the summer pupæ would bring about a change in the form of the resulting butterfly. Inasmuch as breeding from the egg of Umbrosa, in June, in a former year, ${ }^{7}$ gave both Umbrosa (II) and Fabricii (6), the butterflies from the eggs obtained, if left to nature, might be expected to be of both forms. The last or fourth brood of the year having been found up to the present time to be Fabricii, and the Ist brood of the spring, raised from eggs of Fabricii (laid in confinement), having been found to be wholly $U m$ brosa, the latter is probably the summer and Fabricii the winter form. The two intervening broods, i.e. the and and 3 rd, have yielded both forms. This species hibernates in the imago state.

After the pupæ had been in the ice-box fourteen days they were all removed but 5, which were left in six days longer. Several were dead at the end of fourteen days. The temperature most of the time was $I^{\circ}-2^{\circ} \mathrm{R}$. ; but for

7 See Canad. Ent., vol. ix. p. 69. 
a few hours each day rose as the ice melted, and was found to be $3^{\circ}-6^{\circ} \mathrm{R}$.

From the fourteen-day lot 7 butterflies were obtained, 3 males and 4 females. From the twenty-day lot 4 males and I female; every one Umbrosa. All had changed in one striking particular. In the normal $U m$ brosa of both sexes, ${ }^{8}$ the fore wings have on the upper side on the costal margin next inside the hind marginal border, and separated from it by a considerable fulvous space, a dark patch which ends a little below the discoidal nervule; inside the same border at the inner angle is another dark patch lying on the submedian interspace. Between these two patches, across all the median interspaces, the ground colour is fulvous, very slightly clouded with dark.

In all the 4 females exposed to cold for fourteen days a broad black band appeared crossing the whole wing, continuous, of uniform shade, covering the two patches, and almost confluent from end to end with the marginal border, only a streak of obscure fulvous anywhere separating the two. In the case of the females from pupæ exposed for twenty days, the band was present, but while broad, and covering the space between the patches, it was not so dark as in the other females, and included against the border a series of obscure fulvous lunules. This is just like many normal females, and this butterfly was essentially unchanged.

In all the males the patches were diffuse, that at the apex almost coalescing with the border. In the 3 from chrysalides exposed fourteen days these patches were connected by a narrow dark band (very different from the broad band of the females), occupying the same position as the clouding of the normal male, but blackened and somewhat diffused. In the 4 examples

${ }^{8}$ Figures of the different forms of this species are given in vol. i. of Edward's "Butterflies of North America." 
from the twenty-day pupæ, this connecting band was scarcely as deeply coloured and continuous as in the other 3. Beyond this change on the submarginal area, whereby a band is created where naturally would be only the two patches, and a slight clouding of the intervening fulvous surfaces, there was no difference of the upper surface apparent between these examples of both sexes, and a long series of natural ones placed beside them.

On the under side all the males were of one type, the colours being very intense. There was considerably more red, both dark and pale, over the whole surface, than in a series of natural examples in which shades of brown and a bluish hue predominate. No charge was observed in the females on the under side.

It appears that fourteen days were as effective in producing changes as a longer period. In fact, the most decided changes were found in the females exposed the shorter period. It also appears that with this species cold will produce change if applied after the chrysalis has hardened. The same experiments were attempted in I878 with pupæ of Grapta Comma. They were put on ice at from ten minutes to six hours after forming, and subjected to a temperature of about $0^{\circ}-\mathrm{I}^{\circ} \mathrm{R}$. for eighteen to twenty days, but every pupa was killed. Chrysalides of Papilio Ajax in the same box, and partly exposed very soon after pupation, were not injured. It was for this reason that none of the Interrogationis pupæ were placed in the box till six hours had passed.

It appears further that cold may change the markings on one part of the wing only, and in cases where it does change dark or dusky markings melanises them;or it may deepen the colours of the under surface (as in the females of the present experiment). The females in the above experiment were apparently most susceptible 
to the cold, the most decided changes having been effected in them.

The resulting butterflies were all of one form, although both might have been expected to appear under natural circumstances.

Dr. Weismann's remarks on the foregoing experiments. -The author of the present work has, at my request, been good enough to furnish the following remarks upon Mr. Edward's experiments with $G$. Interrogationis :-

The interesting experiments of Mr. Edwards are here principally introduced because they show how many weighty questions in connexion with seasonal dimorphism still remain to be solved. The present experiments do not offer a direct but, at most, only an indirect proof of the truth of my theory, since they show that the explanation opposed to mine is also in this case inadmissible. Thus we have here, as with Papilio Ajax, two out of the four annual generations mixed, i.e., consisting of summer and winter forms, and the conclusion is inevitable that these forms were not produced by the gradual action of heat or cold. When, from pupæ of the same generation which are developed under precisely the same external conditions, both forms of the butterfly are produced, the cause of their diversity cannot lie in these conditions. It must rather depend on causes innate in the organism itself, i.e., on inherited duplicating tendencies which meet in the same generation, and to a certain extent contend with each other for precedence. The two forms must have had their origin in earlier generations, and there is nothing against the view that they have arisen through the gradual augmentation of the influences of temperature.

In another sense, however, one might perceive, in the facts discovered by Edwards, an objection to my theory.

By the action of cold the form Umbrosa, which flies in June, was produced. Now we should be inclined to 
regard the var. Umbrosa as the summer form, and the var. Fabricii, which emerges in the autumn, hibernates in the imago state, and lays eggs in the spring, as the winter form. It would then be incomprehensible why the var. Umbrosa (i.e., the summer form) should be produced by cold.

But it is quite as possible that the var. Umbrosa as that the var. Fabricii is the winter form. We must not forget that, in this species, not one of the four annual generations is exposed to the cold of winter in the pupal state. When, therefore, we have in such cases seasonal dimorphism, to which complete certainty can only be given by continued observations of this butterfly, which does not occur very commonly in Virginia, this must depend on the fact that the species formerly hibernated in the pupal stage. This question now arises, which of the existing generations was formerly the hibernating one-the first or the last?

Either may have done so a priori, according as the summer was formerly shorter or longer than now for this species. If the former were the case, the var. $F a$ bricii is the older winter form; were the latter the case, the var. Umbrosa is the original winter form, as shall now be more closely established.

Should the experiments which Mr. Edwards has performed in the course of his interesting. investigations be repeated in future with always the same results, I should be inclined to explain the case as follows :-

It is not the var. Fabricii, but Umbrosa, which is the winter generation. By the northward migration of the species and the relative shortening of the summer, this winter generation would be pushed forward into the summer, and would thereby lose only a portion of the winter characters which it had till that time possessed. The last of the four generations which occurs in Virginia is extremely rare, so that it must be regarded either as 
one of the generations now supposed to be originating, or as one now supposed to be disappearing. The latter may be admitted. Somewhat further north this generation would be entirely suppressed, and the third brood would hibernate, either in the imago state or as pupæ or caterpillars. In Virginia this third generation consists of both forms. We may expect that further north, at least, where it hibernates as pupæ, it will consist entirely, or almost entirely, of the var. Umbrosa. Still further north in the Catskill Mountains, as Edwards states from his own observations, the species has only two generations, and one might expect that the var. $U m$ brosa would there occur as the winter generation.

Should the foregoing be correct, then the fact that the second generation assumes the Umbrosa form by the action of cold, as was the case in Edward's experiments, becomes explicable. The new marking peculiar to this form produced by this means must be regarded as a complete reversion to the true winter form, the characters of which are becoming partly lost as this generation is no longer exposed to the influence of winter, but has become advanced to the beginning of summer.

The foregoing explanation is, of course, purely hypothetical; it cannot at present be asserted that it is the correct one. Many investigations based on a sufficiently large number of facts are still necessary to be able to attempt to explain this complicated case with any certainty. Neither should I have ventured to offer any opinion on the present case, did I not believe that even such a premature and entirely uncertain explanation may always be of use in serving the inventive principle, i.e., in pointing out the way in which the truth must be sought.

As far as I know, no attempt has yet been made to prove from a general point of view the interpolation of new generations, or the omission of single generations 
from the annual cycle, with respect to causes and effects. An investigation of this kind would be of the greatest importance, not only for seasonal dimorphism, but also for the elucidation of questions of a much more general nature, and would be a most satisfactory problem for the scientific entomologist. I may here be permitted to develope in a purely theoretical manner the principles in accordance with which such an investigation should be made :-

On the change in the number of generations of the annual cycle.-A change in the number of generations which a species produces annually must be sought chiefly in changes of climate, and therefore in a lengthening or shortening of the period of warmth, or in an increase or diminution of warmth within this period; or, finally, in both changes conjointly. The last case would be of the most frequent occurrence, since a lengthening of the period of warmth is, as a rule, correlated with an elevation of the mean temperature of this period, and vice vers $\hat{d}$. Of other complications I can here perceive the following :-

Climatic changes may be active or passive, i.e., they occur by a change of climate or by a migration and extension of the species over new districts having another climate.

By a lengthening of the summer, as I shall designate the shorter portion of the whole annual period of warmth, the last generation of the year would be advanced further in its development than before; if, for instance, it formerly hibernated in the pupal state, it would now pass the winter in the imago stage. Should a further lengthening of the summer occur, the butterflies might emerge soon enough to lay eggs in the autumn, and by a still greater lengthening the eggs also might hatch, the larvæ grow up and hibernate as pupæ. In this manner we should have a new generation interpolated, owing to 
the generation which formerly hibernated being made to recede step by step towards the autumn and the summer. By a lengthening of the summer there occurs therefore a retrogressive interruption of generations.

The exact opposite occurs if the summer should become shortened. In this case the last generation would no longer be so far developed as formerly; for instance, it might not reach the pupal stage, as formerly, at the beginning of winter, and would thus hibernate in a younger stage, either as egg or larvæ. Finally, by a continual shortening of the summer it would no longer appear at the end of this period but in the following spring; in other words, it would be eliminated. By a shortening of the summer accordingly the interruption of generations occurs by advancement.

The following considerations, which submit themselves with reference to seasonal dimorphism, are readily conceivable, at least, in so far as they can be arrived at by purely theoretical methods. Were the summer to become shorter the generation which formerly hibernated in the pupal stage would be advanced further into the spring. It would not thereby necessarily immediately lose the winter characters which it formerly possessed. Whether this would happen, and to what extent, would rather depend upon the intensity of the action of the summer climate on the generation in question, and on the number of generations which have been submitted to this action. Hitherto no attempts have been made to expose a monomorphic species to an elevated temperature throughout several generations, so as to obtain an approximate measure of the rapidity with which such climatic influences can bring about changes. For this reason we must for the present refrain from all hypothesis relating to this subject.

The disturbance of generations by the shortening of summer might also occur to a species in such a manner 
that the generation which formerly hibernated advances into the spring, the last of the summer generations at the same time reaching the beginning of winter. The latter would then hibernate in the pupal state, and would sooner or later also assume the winter form through the action of the cold of winter. We should, in this case, have two generations possessing more or less completely the winter form, the ancient winter generation now gradually losing the winter characters, and the new winter generation gradually acquiring these characters.

In the reverse case, i.e., by a lengthening of the summer, we should have the same possibilities only with the difference that the disturbance of generations would occur in a reverse direction. In this case it might happen that the former winter generation would become the autumnal brood, and more or less preserve its characters for a long period. Here also a new winter generation would be produced as soon as the former spring brood had so far retrograded that its pupæ hibernated.

I am only too conscious how entirely theoretical are these conjectures. It is very possible that observation of nature will render numerous corrections necessary. For instance, I have assumed that every species is able, when necessary, to adapt any one of its developmental stages to hibernation. Whether this is actually the case must be learnt from further researches; at present we only know that many species hibernate in the egg stage, others in the larval state, others as pupæ, and yet others in the perfect state. We know also that many species hibernate in several stages at the same time, but we do not know whether each stage of every species has an equal power of accommodation to cold. Should this not be the case the above conjectures would have to be considerably modified. To take up this subject, so as to completely master all the facts connected therewith, 
naturalists would have to devote their whole time and energy to the order Lepidoptera, which I have been unable to do.

From the considerations offered, it thus appears that the phenomena of seasonal dimorphism may depend on extremely complex processes, so that one need not be surprised if only a few cases now admit of certain analysis. We must also admit, however, that it is more advantageous to science to be able in the first place to analyze the simplest cases by means of breeding experiments, than to concern oneself in guessing at cases which are so complicated as to make it impossible at present to procure all the materials necessary for their solution. 
Plate. I.

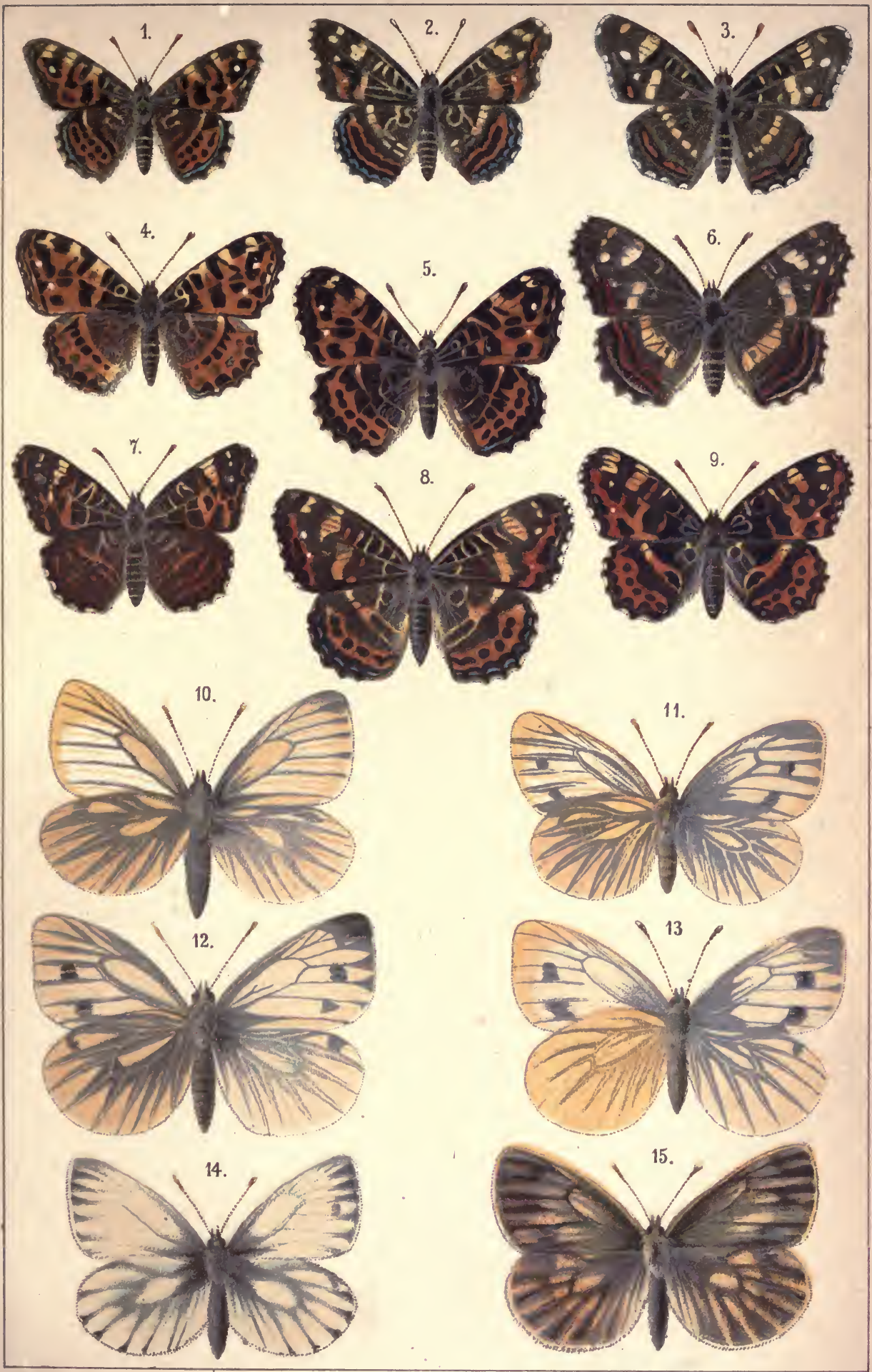




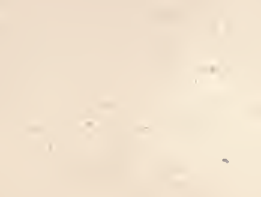


Plate II.

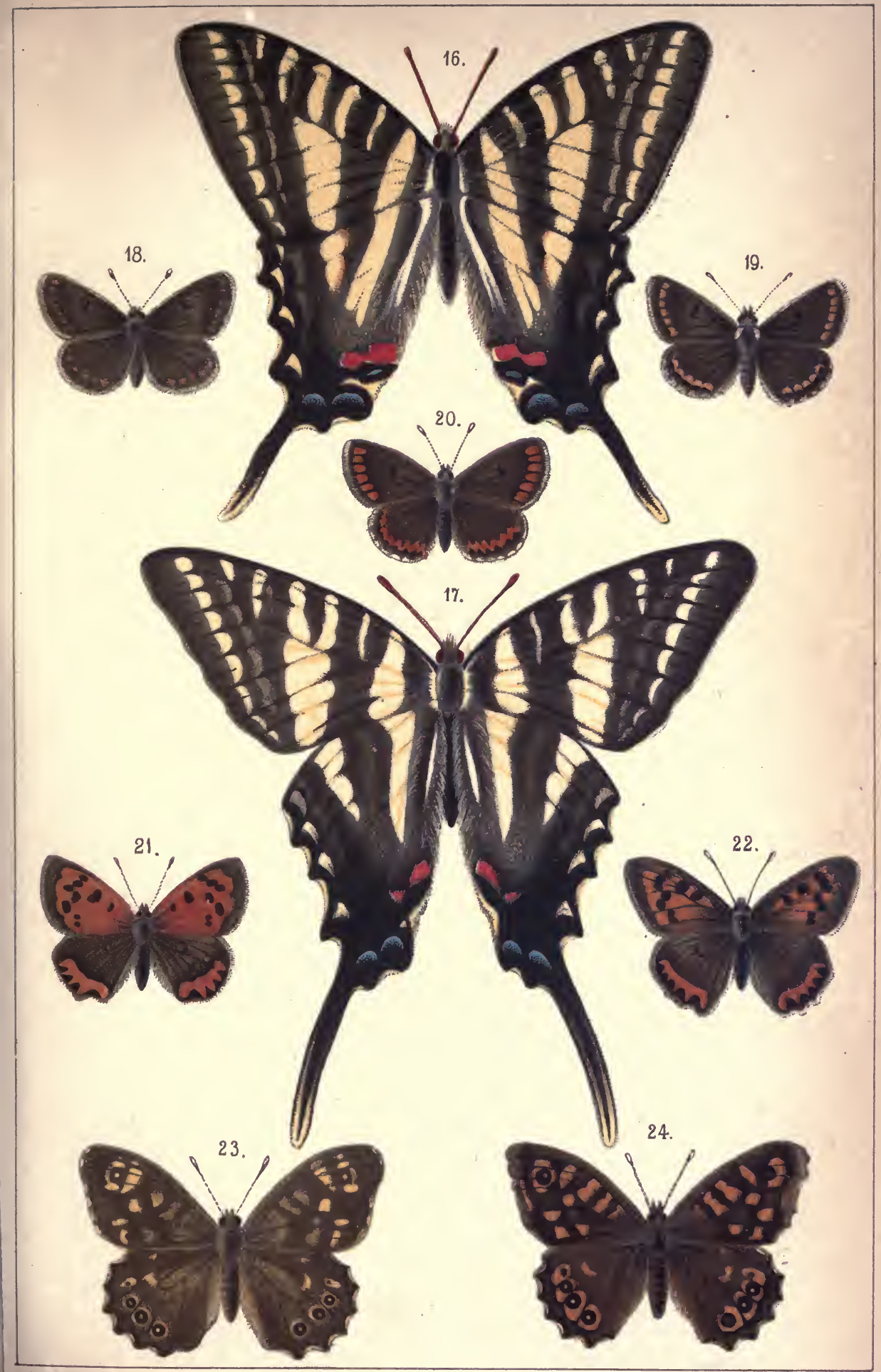




\section{EXPLANATION OF THE PLATES.}

\section{Plate I.}

Fig. I. Male Araschnia Levana, winter form.

Fig. 2. Female $A$. Levana, winter form.

Fig. 3. Male $A$. Levana, artificially bred intermediate form (so-called Porima).

Fig. 4. Female A. Levana, intermediate form (Porima), artificially bred from the summer generation, agreeing perfectly in marking with the winter form, and only to be distinguished from it by the somewhat darker ground colour.

Fig. 5. Male A. Levana, summer form (Prorsa).

Fig. 6. Female $A$. Levana, summer form (Prorsa).

Figs. 7 to 9. Intermediate forms (Porima), artificially bred from the first summer generation.

Figs. IO and I I. Male and female Pieris Napi, winter form, artificially bred from the summer generation; the yellow ground colour of the underside of the hind wings brighter than in the natural winter form.

Figs. 12 and 13. Male and female Pieris Napi, summer form.

Figs. I4 and 15. Pieris Napi, var. Bryonice, male and female reared from eggs.

\section{Plate II.}

Fig. 16. Papilio Ajax, var. Telamonides, winter form.

Fig. 17. P. Ajax, var. Marcellus, summer form. 
Fig. 18. Plebeius Agestis (Alexis, Scop.), German winter form.

Fig. 19. P. Agestis (Alexis, Scop.), German summer form.

Fig. 20. P. Agestis (Alexis, Scop.), Italian summer form. (The chief difference between figs. 19 and 20 lies on the under-side, which could not be here represented.)

Fig. 21. Polyommatus Phlcas, winter form, from Sardinia; the German winter and summer generations are perfectly similar.

Fig. 22. P. Phlcas, summer form, from Genoa.

Fig. 23. Pararga AEgeria, from Freiburg, Baden.

Fig. 24. P. Meione, southern climatic form of Ageria from Sardinia. 


\title{
STUDIES IN THE THEORY OF DESCENT.
}

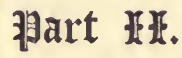 \\ ON THE FINAL CAUSES OF \\ TRANSFORMATION.
}

\section{I.}

THE ORIGIN OF THE MARKINGS OF CATERPILLARS.

INTRODUCTION.

THE general idea which has instigated the researches described in the present essay has already been expressed in the Preface, where it has also been explained why the markings of caterpillars, and especially those of the Sphinxlarvæ, were chosen for testing this idea.

The task presented itself in the following form :-In order to test the idea referred to, it must be investigated whether all the forms of marking which occur in the Sphinx-larvæ can or cannot be traced to known transforming factors.

That natural selection produces a large number of characters can be as little doubted as that $\%$ 
many varying external influences can bring about changes in an organism by direct action. That these two transforming factors, together with their correlatively induced changes, are competent to produce all characters, howsoever insignificant, has indeed been truly asserted, but has never yet been proved. The solution of the problem, however, appeared to me to depend particularly on this point. We are now no longer concerned in proving that a changing environment reacts upon the organism-this has already been shown-but we have to deal with the question whether every change is the result of the action of the environ. ment upon the organism. Were it possible to trace all the forms of markings which occur, to one of the known factors of species transformation, it could be thus shown that here at least an " innate power of development" was of no effect ; were this not possible, i.e. did there remain residual markings which could not be explained, then the notion of an "innate principle of development." could not be at once entirely discountenanced.

The attempt to solve this problem should commence by the acquisition of a morphological groundwork, so that the phyletic development of the markings might by this means be represented as far as possible. It cannot be stated with certainty, primâ facie, whether some form of development conformable to law is here to be found, 
but it soon becomes manifest that such is certainly the case in a great measure. In all species the young caterpillars are differently marked to the adults, and in many the markings change with each of the five stages of growth indicated by the four ecdyses, this gradational transformation of the markings being a "development" in the true sense of the word, i.e., an origination of the complex from the simple, the development of characters from those previously in existence, and never an inconstant, unconnected series of per saltum changes. This development of the markings in individuals very well reveals their phyletic development, since there can be no doubt but that we have here preserved to us in the ontogeny, as I shall establish more fully further on, a very slightly altered picture of the phyletic development. The latter can have been but slightly "falsified" in these cases, although it is indeed considerably abbreviated, and that in very different degrees; to the greatest extent in those species which are most advanced in their phyletic development, and to the least extent in those which are less advanced. From this the value of being able to compare a large number of species with respect to their ontogeny will appear. Unfortunately, however, this has only been possible to a very limited extent.

The youngest larval stages are those which are of the most importance for revealing the 
phyletic development, because they make us acquainted with the markings of the progenitors of the existing species. For these investigations it is therefore in the first place necessary to obtain fertile eggs. Female Sphingida, however, do not generally lay eggs in confinement, ${ }^{1}$ or at most only a very small number. In the case of many species (Deilephila Galii, D. Lineata, D. Vespertilio, D. Hippophaës) I have for this reason unfortunately been unable to observe the entire development, and such observations would in all probability have given especially valuable information.

I was certainly successful in finding the young larvæ of some of the above as well as of other species on their food-plants, but even in the most favourable instances only individuals of the second stage and generally older. When, however, notwithstanding this imperfection of the materials, and in spite of the important gaps thus inevitably caused in these series of observations, it has nevertheless been possible to form a picture, on the whole tolerably complete, of the phyletic development of the Sphinx-markings, this well indi-

${ }^{1}$ Only the species of Smerinthus can be made to lay eggs regularly in confinement ; Macroglossa Stellatarum laid a number in a large gauze-covered breeding-cage; the species of Deilephila could not be induced to lay more than single ones in such a cage. From species of Charocampa also I never obtained but a few eggs, and from Sphinx and Acherontia never more than single ones. 
cates what a fertile field is offered by the investigation of this subject, and will, I trust, furnish an inducement to others, not only to fill up the various gaps in the small family of the Sphingida, but also to treat other Lepidopterous families in a similar manner. Such an investigation of the Papilionida appears to me to be especially desirable ; not only of the few European but also of the American and Indian species. We know practically nothing, of the youngest stages of the Papilio larvæ from this point of view. No entomological work gives any description of the form and marking of the newly hatched larvæ, even in the case of our commonest species (Papilio Machaon and P. Podalirius), and I believe that I do not go too far when I assert that up to the present time nobody has observed them at this early stage. ${ }^{2}$ When, however, we consider that

2 [Eng. ed. Since the appearance of the German edition of this work, numerous descriptions of the young stages of caterpillars have been given, but in all cases without representing the relationship of the forms.] [In the excellent figures of larvæ at various stages of growth, given in some of the more recent works on Lepidoptera, there will be found much material which may be regarded as a contribution to the field of research entered on by the author in the present essay, i.e. the ontogeny and comparative morphology of larval markings, although it is much to be regretted that the figures and descriptions have not been given from this point of view. In his "Butterflies of North America," for example, W. H. Edwards figures the young as well as the adult larvæ of species of Apatura, Argynnis, Libythea, Phyciodes, Limenitis, Colias, Papilio, \&c. 
in these young caterpillars we have preserved to us the parent-form, extinct for centuries, of the

Burmeister, in his recently published "Lépidoptères de la République Argentine," figures the young stages of species of Caligo, Opsiphanes, Callidryas, Philampelus, \&c. Messrs. Hellins and Buckler have figured and described the early stages of large numbers of the caterpillars of British Lepidoptera, but their figures remain unpublished. The larvæ of many of our native species belonging to the genera Liparis, Taniocampa, Epunda, Cymatophora, Calocampa, \&c., are dull when young, but become brightly coloured at the last moult. Such changes of colour are probably associated with some change, either in the habits or in the environment; and a careful study of the ontogenetic development of such species in connection with their life-history would furnish results of great value to the present inquiry. The same remarks apply to those Noctuce larvæ which are brightly coloured in their young stages, and become dull when adult.

Among other papers which may be considered as contributions to the present subject, I may mention the following:In 1864 Capt. Hutton published a paper, "On the Reversion and Restoration of the Silkworm, Part II." (Trans. Ent. Soc. I864, p. 295), in which he describes the various stages of development of several species of Bombycida. In $\mathrm{I} 867$ G. Semper published accounts of the early stages of several Sphinx-larvæ ("Beiträge zur Entwicklungsgeschichte einiger ostasiatischer Schmetterlinge," Verhandl. k.k. Zoolog.-botan. Gesell. in Wien, vol. xvii.). The question as to the number of claspers in young Noctuce larvæ has been raised in notes by Dr. F. Buchanan White ("Ent. Mo. Mag.," vol. v. p. 204) and B. Lockyer ("Entomologist," I87 1, p. 438). A valuable paper, "On the Embryonic Larvæ of Butterflies," was published in I 87 I by S. H. Scudder ("Ent. Mo. Mag.," vol. viii. p. I 22). For remarks on the development of the larva of Papilio Merope, see J. P. Mansel Weale in Trans. Ent. Soc., r874, p. I31, and PI. I. ; also this author on the young stages of the larva of Gynanisx Isis, Trans. Ent. Soc., 1878, p. I84. For an 
existing species of Papilio, it must assuredly be of the greatest interest to become accurately acquainted with them, to compare them with the earliest stages of allied species, and to follow the gradual divergence of the succeeding stages in different directions, thus forming a picture of the phyletic development of an evolving group. In the course of such observations numerous collateral results would doubtless come out. Investigations of this kind, whether conducted on this or on any other group, would, above all, show the true systematic affinities of the forms, $i . e$. , their genealogical affinities, and that in a better way than could be shown by the morphology of the perfect insects or the adult caterpillars alone. If I am diffident in founding these conclusions upon the development of the Sphinx-markings treated

account of the development of the larvæ of certain North American species of Satyrus, see W. H. Edwards in the "Canadian Entom.," vol. xii. p. 21. Mr. P. H. Gosse's recent description of the newly hatched caterpillar of Papilio Homerus (Proc. Ent. Soc. 1879, p. 1v), furnishes a good illustration of the value of studying the ontogeny. The natural affinities of the Papilionidae were at one time much disputed, some systematists placing this family at the head of the Lepidoptera, and others regarding them as being more closely allied to the moths. Mr. Gosse's observation tends to confirm the latter view, now generally received by Lepidopterists, since he states that the larva in question "suggests one of the great Saturniada, such as Samia Cecropia." Mr. Scudder, in the paper above referred to, adopts an analogous argument to show the close relationship between the Papilionida and Hesper. ida. R.M.] 
of in the present essay, this arises entirely from a knowledge of the imperfections in the basis of facts. If however, through the united labours of many investigators, the individual development of all the species of Sphingida now existing should at some future period be clearly laid before us, we should then not only have arrived at a knowledge of the relative ages of the different species, genera and families, but we should also arrive at an explanation of the nature of their affinities.

It is erroneous to assert that Classification has only to take form-relationship into consideration ; that it should and can be nothing else than the expression of form-relationship. The latter is certainly our only measure of blood-relationship, but those who maintain the assertion that formand blood-relationship are by no means always synonymous, are undoubtedly correct. I shall in a future essay adduce facts which leave no doubt on this point, and which prove at the same time that modern systematists-especially in the order Lepidoptera-havealwaysendeavoured-although quite unconsciously-to make the blood-relationship the basis of their classification. For this reason alone, larvæ and pupæ would have an important bearing upon the establishment of systematic groups, although certainly in a manner frequently irregular.

It must be admitted that so long as we are able to compare the species of one group with 
those of another in one form only, we are often unable to ascertain the blood-relationship. ${ }^{3}$ In such cases we can only determine the latter from the form-relationship, and as these are not always parallel, any conclusion based on a single form must be very unsound. If, for instance, butterflies emerged from the egg directly, without passing through any larval stage, a comparison of their resemblances of form would alone be of systematic value; we should unite them into groups on the ground of these resemblances only, and the formation of these groups would then much depend upon the weight assigned to this or that character. We might thus fall into error, not only through a different valuation of characters but still more because two species of near bloodrelationship frequently differ from one another in form to a greater extent than from other species. We should have no warrant that our conception of

${ }^{3}$ [Mr. A. G. Butler has recently furnished a good illustration of the danger of classifying Lepidoptera according to the affinities of the perfect insects only, in his paper, "On the Natural Affinities of the Lepidoptera hitherto referred to the Genus Acronycta of authors," Trans. Ent. Soc. I879, p. 3 I3. If the author's views are ultimately accepted, the species at present grouped under this genus will be distributed among the Arctiida, Liparida, Notodontidce, and Noctuce. Mr. Butler's determination of the affinities of the species supposed to belong to the genus mentioned, is based chiefly upon a comparative examination of the larvæ, and this is far more likely to show the true blood-relationship of the species than a comparison of the perfect insects only. A study of the comparative ontogeny can alone give a final answer to this question. R.M.] 
the form-relationship expressed the genealogical connection of the species. But it would be quite different if every species presented itself in two or three different forms. If in two species or genera the butterflies as well as the larvæ and pupæ exhibited the same degree of form-relationship, the probability that this expressed also the bloodrelationship would then be exceedingly great. Now this agreement certainly does not always occur, and when these different stages are related in form in unequal degrees, the problem then is to decide which of these relationships expresses the genealogy. This decision may be difficult to arrive at in single cases, since the caterpillar may diverge in form from the next bloodrelated species to a greater extent than the butterfly, or, conversely, the butterfly may diverge more widely from its nearest blood-related species than the caterpillar.

For such cases there remains the developmental history of the caterpillar, which will almost always furnish us to a certain extent with information respecting the true genealogical relationship of the forms, because it always reveals a portion of the phyletic (ancestral) development of the species. If we see two species of butterflies quite dissimilar in form of wing and other characters, we should be inclined, in spite of many points of agreement between them, to place them in entirely different genera. But should we then 
find that not only did their adult larvæ agree in every detail of marking, but also that the entire phyletic development of these markings, as revealed by the ontogeny of the larvæ, had taken precisely the same course in both species, we should certainly conclude that they possessed a near blood-relationship, and should place them close together in the same genus. Such an instance is afforded by the two Hawk-moths, Charocampa Elpenor and C. Porcellus, as will appear in the course of these investigations. These two species were placed by Walker in different genera, the form relationship of the' imagines being thus correctly represented, since Porcellus (imago), is indeed more nearly related in form to the species of the genus Pergesa, Walker, than to those of the genus Charocampa. ${ }^{4}$ Nevertheless, these species must remain in the same genus, as no other arrangement expresses their degree of bloodrelationship.

An intimate knowledge of the developmentstages of caterpillars thus offers, even from a systematic point of view, an invaluable means of judging the degree of blood-relationship, and from this standpoint we must regard the study of the caterpillar as of more importance than that of the perfect insect. Certainly all groups would not be

4 [In his recent revision of the Sphingida, Mr. A. G. Butler (Trans. Zoo. Soc., vol. ix. part x.) retains Walker's arrangement. R.M.] 
so rich in information as the Sphingida, or, as I am inclined to believe, the Papiiionida, since all families of caterpillars do not possess such a marked and diversified pattern, nor do they present such a varied and characteristic bodily form. The representation of the true, i.e., the blood-relationship, and through this the formation of natural groups with any completeness, can certainly only be looked for when we are intimately acquainted with the different stages of development of the larvæ of numerous species in every group, from their emergence from the egg to their period of pupation. The genealogical relationship of many forms at present of doubtful systematic position would then be made clear. This investigation, however, could not be the work of a single individual ; not only because the materials for observation are too great, but, above all, because they are spread over too wide a field. It is not sufficient to study the European types only-we should endeavour to learn as much as possible of the Lepidoptera of the whole world. But such observations can only be made on the spot. Why should it not be possible to trace the development from the egg, even under a tropical sky, and to devote to breeding and observing, a portion of that time which is generally spent in mere collecting? I may perhaps be able to convince some of the many excellent and careful observers among entomologists, that beyond the necessary and valuable 
search for new forms, there is another field which may be successfully worked, viz., the precise investigation of the development of known species.

The first portion of the present essay consists of the determination of this development in those species of Sphingide which have been accessible to me. Seven genera are successively treated of, some completely, and others only in some of their stages; and thus I have sought to present a picture of the course of development of the markings in each genus, by comparing the species with each other, and with allied forms in cases where the young stages were unknown. In this portion, as far as possible, the facts only have been given, the working up of the latter into general conclusions upon the development of marking being reserved for the second portion. A complete separation of facts from generalizations could not, however, be carried out; it appeared convenient to close the account of each genus with a summary of the results obtained from the various species.

After having established that the markings of the Sphinx-caterpillars had undergone an extremely gradual phyletic development, conformable to law, in certain fixed directions, it appeared desirable to investigate the causes of the first appearance of these markings, as well as of their subsequent development. The question as to the biological significance of marking here presented itself in the first place for solution, and the third 
section is devoted to this subject. If it is maintained that marking is of no importance to the life of the insect, or that it is so only exceptionally, and that it is in reality, as it appears to be, a character of purely morphological, i.e., physiological, insignificance, then its striking phylogenetic development conformable to law cannot be explained by any of the known factors of species transformation, and we should have to assume the action of an innate transforming power. In the present investigations, this subject in particular has been extensively treated of, and not only the markings of Sphinx-caterpillars, but also those of caterpillars in general, have been taken into consideration. The results arrived at are indeed quite opposed to this assumption-marking is shown to be a character of extreme importance to the life of the species, and the admission of a phyletic vital force must, at least from the present point of view, be excluded. This leads to the fifth section, in which I have attempted to test certain objections to the admission of a "phyletic vital force." The sixth section finally gives a summary of the results obtained.

I may now add a few explanations which are necessary for understanding the subsequent descriptions. It was found impossible to avoid the introduction of some new technicalities for describing the various elements of larval markings, especially as the latter had to be treated of scientifically. I have therefore chosen the simplest 
and most obvious designations, all of which have already been employed by various authors, but not in any rigorously defined sense. I understand by the "dorsal line" that which runs down the middle of the back; the lines above and below the spiracles will be respectively distinguished as the "supra-" and "infra-spiracular" lines, and the line between the dorsal and spiracular as the "subdorsal line." The distinction between "ringspots" and "eye-spots" will be made manifest in the course of the investigation. A glance at any of the existing descriptions of larvæ will show how necessary it was to introduce a precise terminology. Even when the latter is exact as far as it, goes, the want of precise expressions not only makes the descriptions unnecessarily long, but it also considerably increases the difficulty of comparing one species with another, since we can never be sure whether the same designation applies to the same homologous character. For instance, when the larva of Charocampa Elpenor is said to have "a light longitudinal line on the sides of the thoracic segments," this statement is indeed correct; but it is not apparent whether the line is above or below, and consequently it does not appear whether it is the equivalent of the longitudinal line "on the sides" of the segments in other species. If, however, it is said that this line is "subdorsal on the thoracic segments, and on the eleventh abdominal segment," it is therebyindicated 
that we have here a residue of the same marking which is found completely developed in many other Sphinx-larvæ, and indeed in the young stages of this same species. The mode of describing caterpillars hitherto in vogue is in fact unscientific; the descriptions have not been made with a view to determining the morphology of the larvæ, but simply to meet the practical want of being able to readily identify any species that may be found: even for this purpose, however, it would have been better to have employed a more precise mode of description. 
The Origin of the Markings of Caterpillars. I 77

I.

Ontogeny and Morphology of Sphinx Markings.

THE GENUS CHAROCAMPA, DUPONCHEL.

Although by no means in favour of the excessive subdivision of genera, I am of opinion that Ochsenheimer's genus Deilephila has been correctly separated by Duponchel into the two genera Charocampa and Deilephila, sensî strictiori. Such a division may appear but little necessary if we examine the perfect insects only; but the developmental history of the caterpillars shows that there is a wide division between the two groups of species, these groups however being branches of one stem.

Charocampa Elpenor, Linn.

Some captured females laid single eggs sparsely on grass, wood, and especially on the tarlatan with which the breeding-cage was covered. The eggs are nearly spherical, but somewhat compressed, of a grass-green colour, a little lighter, and somewhat larger (1.2 millim.) than those of Deilephila Euphorbice. During the development of the 
embryo the eggs first became yellowish-green, and finally yellowish.

\section{First Stage.}

The young caterpillars are four millimeters in length, and immediately after hatching are not green, but of a yellowish-white opalescent colour, the large and somewhat curved caudal horn being black. The caterpillars were so transparent that under a low magnifying power the nervous, tracheal, and alimentary systems could be beautifully seen. As soon as the larvæ began to feed (on Epilobium parviflorum) they became green in consequence of the food appearing through the skin, but the latter also gradually acquired a dark green colour (Pl. IV., Fig. I 7). All the specimens (some twenty in number) were exactly alike, and showed no trace of marking.

\section{Second Stage.}

The first ecdysis occurred after 5-6 days, the length of the caterpillars being from nine to ten millimeters. After this first moult they appeared of a shining green, the horn, which was black during the first stage, becoming a little red at the base, while a fine white subdorsal line extended from the horn to the head (Fig. I 8). The head and legs were green; the divisions between the segments appeared as fine light rings, and the entire upper surface of thesegments was also crossed 
by fine transverse rings, as was also the case in the first stage.

At the beginning of the present stage no trace of the eye-spots could be detected; but a few days after the first moult it was observed that the white subdorsal line was no longer straight on the fourth and fifth segments, but had become curved upwards into two small crescents. The latter soon stood out more strongly, owing to the filling up of their concavities with darker green. These are the first rudiments of the eye-spots (Figs. I9 and 30 ). A very fine white line now connected the spiracles (infra-spiracular line), and could be traced from the last segment to the head. This line takes no further part in the subsequent development of the markings, but disappears in the following stage. The blood-red colour of the base of the black caudal horn is retained till the fifth stage, and then also disappears.

Before the second moult, which occurs after another period of 5-6 days, the caterpillars, which were about $\mathrm{I} .3$ centimeters in length, had assumed their characteristic tapering, slug-like form. I did not notice that the larvæ at this stage possessed the power of withdrawing the three foremost segments into the two succeeding ones, as is so frequently to be observed in the adults; neither were these two segments so strikingly enlarged as they are at an earlier period. 


\section{Third Stage.}

After the second ecdysis the marking and colouring only undergo change with respect to the eye-spots. The concavities of the crescent-shaped portions of the subdorsal line become black, ${ }^{1}$ the remainder of this line at the same time losing much of its whiteness, and thus becoming less distinct, whilst the crescents assume the appearance of small eye-spots (Fig 20). During this stage the curved, crescent-formed portions become prepared for complete separation from the remainder of the subdorsal line; and just before the third moult the eye-spots become sharply defined both in front and behind, whilst the black ground-colour curves upwards, and the white spots gradually become lenticular and commence to enlarge (Fig. 2 I).

\section{Fourth Stage.}

The third moult takes place after another interval of 5-6 days, the eye-spots then becoming very prominent. The white nucleus of the front spot is kidney-shaped, and that of the hind spot egg-shaped; whilst the black ground-colour extends as a slender border upwards along the sides of the spots, but does not completely surround them till towards the end of the present stage (Fig. 2I). The

1 The deposition of black pigment may commence immediately before ecdysis. 
central portion of the white spots at the same time becomes of a peculiar violet-brown colour inclining to yellow above, the peripheral region alone remaining pure white.

Of the subdorsal line only traces are now to be recognized, and these are retained, with almost unchanged intensity, sometimes into the last stage, remaining with the greatest persistence on the three front and on the penultimate segments, whilst on those containing the eye-spots, i.e., the fourth and fifth, not a trace remains. At the present stage the peculiar mingling of colours becomes apparent over the whole of the upper surface; the green is no longer uniform, but a mixture of short and gently sinuous, dark-green striations on a lighter ground now appear. On the sides of the caterpillar these stripes, which are at first indistinct, but become more strongly pronounced in the next stage, are arranged obliquely on the spiracles, with the lower portions directed forwards.

\section{Fifth Stage.}

The fourth moult occurs 7-8 days after the third, the caterpillar being $4--5$ centimeters in length. Whilst all the specimens hitherto observed were with one exception light green, they now mostly changed their colourand became dark brown. In one case only did the brown colour appear in the previous (fourth) stage. The striations 
previously mentioned appear as dull and interrupted dirty yellow streaks, the same dirty yellow colour showing itself continuously on the sides of the four front segments. Of the subdorsal line only a distinct trace is now to be seen on the eleventh and on the three front segments, whilst on the third segment the formation of another eye-spot commences to be plainly perceptible by a local deposition of black (Fig. 23). This third spot does not, however, become completely developed, either in this or in the last stage, but the subdorsal line remains continuous on the three front segments. Among other changes at this stage, there occurs a considerable shortening of the caudal horn, which at the same time loses its beautiful black and red colours and becomes brownish.

The two large eye-spots have now nearly attained complete development. The kidneyshaped white spot has become entirely surrounded by black; and on the brown, red, and yellow tints present in this spot during the last stage, a nearly black spot has been developed-the pupil of the eye (Fig. 33). In order to establish a definite terminology for the different portions of the eyespot, I shall designate the pupil as the "nucleus," the light ground on which the pupil stands as the "mirror," and the black ground which surrounds the mirror as the "ground-area."

In this fifth stage the larva attains a length 
The Origin of the Markings of Caterpillars. 183

of six centimeters, after which the fifth moult takes place, the caterpillar becoming ready for pupation in the sixth stage. No striking changes of colouring or marking occur after the present stage, but only certain unimportant alterations, which are, however, of the greatest theoretical interest.

\section{Sixth Stage.}

In this stage the eye-like appearance of the spots on the front segments becomes still more distinct than in the fifth stage; at the same time these spots repeat themselves on all the other segments from the fifth to the eleventh, although certainly without pupils, and appearing only as diffused, deep black spots, of the morphological significance of which, however, there cannot be the least doubt. They are situated in precisely the same positions on the 5-II segments as those on the third and fourth-near the front, and above and below the subdorsal line. A feeble indication of the latter can often be recognized (Fig. 23).

In all dark-brown specimens the repeated spots can only be detected in a favourable light, and after acquiring an intimate knowledge of the caterpillar ; but in light-brown and green specimens they appear very sharply defined.

There is one other new character which I have never observed at an earlier period than the sixth 
stage, viz. the small dots which appear in pairs near the posterior edge of segments 5-II. These dots cannot have been developed from the subdorsal line, as they are situated higher than the latter. Their colour varies according to the ground-colour of the caterpillar, but it is always lighter, being light-green in green specimens, dull yellow in those that are light brown, and grey in the blackish-brown caterpillars. These "dorsal spots," as I shall term them, are chiefly of interest because they are present in Charocampa Porcellus, in which species they appear one stage earlier than in $C$. Elpenor.

\section{Cherocampa Porcellus, Linn.}

Females captured on the wing, laid in the breeding-cage single eggs of a light green colour, spheroidal in form, and very similar to those of C. Elpenor.

\section{First Stage.}

The caterpillars on first hatching measure 3.5 millimeters in length, and are of a uniform light green colour, with a fine white transverse line on the posterior edge of each segment, precisely similar to that which appears in the second stage of $C$. Elpenor. They resemble the latter species still further in showing a fine white subdorsal line, which can easily be recognized by the naked eye (Fig. 24). Although the adult larva is 
The Origin of the Markings of Caterpillars. 185

distinguished from all the other known species of Charocampa by the absence of a caudal horn, a distinct but very small one is nevertheless present at this first stage, and is indeed retained throughout the entire course of development, but does not increase further in size, and thus gradually becomes so small in proportion to the size of the caterpillar that it may be entirely overlooked.

The first moult takes places after $4-5$ days.

\section{Second Stage.}

The blue-green coloration remains unchanged; but a somewhat darker green dorsal line becomes apparent down the middle of the back (the dorsal vessel?), and the subdorsal line now becomes very broad and pure white, being much more conspicuous than in any stage of C. Elpenor (Fig. 25). The tapering of the three front segments occurs at this stage, and oblique, dark-green striations on a lighter ground stand out distinctly on the spiracles. As with $C$. Elpenor, the first traces of the future eye-spots appear during the second stage; not in the present case as a curvature of the subdorsal line, but as a spot-like widening of the latter, of a brighter white than the somewhat greenish colour of the remainder of the line.

\section{Third Stage.}

After the second moult, the formation of the dark "ground area" of the eye-spots commences by 
the appearance of a little brown on the under edge of the foremost of the white spots, this coloration gradually increasing in extent and in depth. At the same time both spots become more sharply distinguishable from the subdorsal line, which becomes constantly greener (Fig. 27). The brown colour soon grows round the white of the front eye-spot, which becomes so far perfected; whilst the completion of the hind spot is effected slowly afterwards. The formation of the eye-spots does not therefore proceed any more rapidly in this species than in $C$. Elpenor.

At the end of the present stage the length of the caterpillar is about four centimeters; the ground colour is still sea-green; the subdorsal line is much diminished, completely fading away at its lower edge, but remaining sharply defined above, against the green ground-colour (Fig. 26).

\section{Fourth Stage.}

After the third moult all the caterpillars (5) became brown, this change occurring therefore one stage earlier than is generally the case with $C$. Elpenor. In single instances the brown colour appeared in the third stage. The subdorsal line had disappeared from all the segments but the three first and the last. The eye-spots now rapidly attained complete development ; they contained a black pupil, and gave the insect a truly repulsive appearance when, on being threatened by danger, 
it drew in the front segments, and expanded the fourth (Fig. 28). The eye-spots of the fifth segment are much less developed than in C. Elpenor; they remain small, and are not readily detected. On the other hand, there now appear on all the segments with the exception of the last, just as in the sixth stage of $C$. Elpenor, distinct rudiments of eye-spots, which present the appearance of irregular, roundish, black spots on the front borders of the segments, at the height of the former subdorsal line. In this latter region the black pigment is disposed as a longitudinal streak, and to this a median line is added, the whole forming a marking which perhaps makes the caterpillar appear still more alarming to its foes. This marking is, however, only to be distinctly recognized on the three first segments. The "dorsal spots" mentioned in the case of $C$. Elpenor then appear very distinctly on segments 5 - I I.

The caterpillars continued to feed for eleven days after the third moult, at the end of which period the fourth moult took place, but without the occurrence of any change of marking. The larvæ then buried themselves, the complete development having taken 28-29 days.

The development of the Porcellus caterpillar was twice followed; in 1869 in twelve, and in 1874 in five specimens. In no case did I obtain caterpillars which remained green throughout the entire course of development, although this colour 
is stated in the books to occur occasionally in these larvæ; neither have I been able to find any figure of an adult green specimen, so that it must in the meantime be admitted that such specimens, if they occur at all, are exceptional instances. ${ }^{2}$ The theoretical bearing of this admission will appear later on.

Results of the development of Cherocampa Elpenor and C. Porcellus; comparison of these with the OTHER KNOWN SPECIES OF CHAROCAMPa.

The first stage of Elpenor shows that the most remote ancestor of the genus possessed no kind of marking, but was uniformly green. At a later period, the white longitudinal stripe which I have designated the "subdorsal line" made its appearance, and at a still later period this line vanished, with the exception of a few more or less distinct remnants, whilst, at the same time, from certain

2 [Mr. Herbert Goss states (Proc. Ent. Soc. I878, p. v.) that according to his experience, the green and brown varieties of $C$. Porcellus (erroneously printed as Elpenor in the passage referred to) are about equally common, the former colour not being in any way confined to young larvæ. Mr. Owen Wilson in his recent work, "The Larvæ of British Lepidoptera and their food-plants," figures (Pl. VIII., Figs. 3 and 3 a) the two forms, both apparently in the adult state. During the years I 878-79, my friend, Mr. J. Evershed, jun., took five of these full-grown larvæ in Surrey, one of these being the green variety. In order to get more statistics on this subject, I applied this year (1880) to Messrs. I)avis of Dartford, who informed me that among $18-20$ adult caterpillars of Porcellus in their possession, there was only one green specimen. R.M.] 
The Origin of the Markings of Caterpillars. I 89

portions of it, the eye-spots of the fourth and fifth segments became developed. After the perfecting of the eye-spots, weak repetitions of the latter appeared as black spots on all the segments except the last.

In Porcellus the caterpillar emerges from the egg with the subdorsal line, the first stage of Elpenor being omitted, From this fact we may venture to conclude that Porcellis is the younger species, or, what comes to the same thing, that it has further advanced in development. The whole subsequent history of Porcellus agrees with this view, its course of development being essentially but a repetition of the phenomena displayed by Elpenor, and differing only in one point, viz. that all new characters make their appearance one stage earlier than in the latter species. This is the case with the transformation of the green into a brown ground-colour; with the repetition of the eye-spots on the remaining segments in the form of suffused black spots ; and with the appearance of the light "dorsal spots." Only the eyespots themselves appear, and the snout-like tapering of the front segments occurs in the same stage as in Elpenor, i.e. the second.

From these data alone, we may venture to infer the occurrence of four chief stages in the phyletic development of the genus. The first stage was simply green, without any marking; the second showed a subdorsal line; the third, eye-spots on 
the third and fourth segments; and the fourth stage showed a repetition of the eye-spots, although but rudimentary; on all the remaining segments with the exception of the twelfth.

Now if we compare the other known species of Charocampa larvæ with the above, we shall arrive at the interesting conclusion that all these species can be arranged in three groups, which correspond exactly with the three last phyletic stages as just deduced from the ontogeny of $C$. Elpenor and Porcellus.

Of the genus Charocampa, ${ }^{3}$ over fifty species have been described, ${ }^{4}$ of which the larvæ of only

- I unite the genera Pergesa and Darapsa of Walk. with Charocampa, Dup.; the first appears to me to be quite untenable, since it is impossible that two species, of which the caterpillars agree so completely as those of $C$. Elpenor and Porcellus, can be located in different genera. Porcellus indeed was referred to the genus Pergesa because of its different contour of wings, an instance which distinctly shows how dangerous it is to attempt to found Lepidopterous genera without considering the caterpillars. The genus Darapsa also appears to me to be of very doubtful value, and in any case requires further confirmation with respect to the larval forms.

4 [Mr. A. G. Butler (Trans. Zoo. Soc., vol. ix., part. x., I876) gives a list of about eighty-four species of Charocampa, and sixteen of Pergesa, besides numerous other species belonging to several genera placed between Charocampa and Pergesa. ' Of Darapsa, he states "that this genus was founded upon most heterogeneous material, the first three species being referable to Hübner's genus Otus, the fifth to Walker's genus Diodosida, the sixth and eighth to the genus Daphnis of Hübner, the seventh, ninth, and tenth to Charocampa of Duponchel; there therefore remains only the fourth species, allied to Cherocampa, but 
fifteen are known in the form which they possess at the last ontogenetic stage.

Group I.-I can furnish but little information with respect to this group. The first species with which I became acquainted was Charocampa Syriaca, ${ }^{5}$ of which I saw two blown caterpillars in Staudinger's collectien, and which I have figured in Pl. IV., Fig. 29. The larva is green, and has the short oblique stripes over the legs common to so many species of Charocampa, the only marking besides these being a simple white subdorsal line, without any trace of eye-spots. This species exactly corresponds therefore with the second ontogenetic stage of C. Elpenor and Porcellus. The account of the species, both in the larval and perfect state, is unfortunately so imperfect, that we cannot with certainty infer the age of the two caterpillars from their size. If the moth were of the same size as Elpenor, then the caterpillar figured, having a length of 5.3 centimeters, would not be in the last but in the penultimate stage, and it remains doubtful whether it may not acquire eye-spots in the last stage.

That species exist, however, which in their last stage correspond to the second stage of Elpenor, is shown by two of the forms belonging to Walker's genus Darapsa, which was founded on apparently sufficiently distinct." The species still retained in the genus Darapsa is D. rhodocera, Wlk., from Haiti. R.M.]

- [Otus Syriacus of Butler's revision. R.M.] 
the characters of the imagines only. Ten species of this genus are given in Gray's catalogue, the adult larva of two of these being known through the excellent figures of Abbot and Smith. ${ }^{6}$ These two caterpillars possess the characteristic tapering form in a very marked degree; one is figured in the attitude so often assumed by our species of Charocampa on the approach of danger, the three front segments being withdrawn into the fourth. (Fig. 34, P1. IV., is copied from this Plate). There are no eye-spots either in $D$. Myron or $D$. Choerilus, ${ }^{7}$ but only a broad white subdorsal line;: underneath which, and to a certain extent proceeding from it, there are oblique white stripes, precisely similar to those which meet the subdorsal line in the third stage of $C$. Porcellus. ${ }^{8}$

- Abbot and Smith. "The Natural History of the rarer Lepidopterous Insects of Georgia, collected from the observations of John Abbot, with the plants on which they feed." London, $\mathrm{x} 797,2$ vols. fol.

' [Otus Chorilus and O. Myron of Butler's revision. R.M.]

${ }^{8}$ [To this group may also be added Ampelophaga Rubiginosa, Ménétriés, from China and Japan, the caterpillar of which, having the distinct subdorsal line without any trace of eyespots, is figured by Butler (loc. cit., Pl. XCI., Fig. 4). This author also gives a figure of another species belonging to the subfamily Charocampina (Pl. XC., Fig. II), viz. Acosmeryx Anceus, Cram., from Amboina, Java, Silhet, and S. India; the caterpillar is green, with seven oblique yellow stripes along the sides, and a very conspicuous white subdorsal line with a red border above. As there are no eye-spots, this species may be referred to the present group provisionally, although its general marking is very distinct from that of the Charocampa group. R.M.] 
Group 2.-This group contains numerous species which; like our native $C$. Elpenor and Porcellis, show eye-spots on the fourth and fifth segments, whilst these markings are absent, or at most only present in traces, on the remainder. To this section there belong, besides the two species mentioned, five others, viz. in Europe, C. Celerio and Alecto (not certainly known ?) $;^{9}$ in India, C, Nessus, Drury, and Lucasiz, Boisduval ; ${ }^{10}$ and an unnamed species from Port Natal.

In the species belonging to this group the subdorsal line may be more or less retained. Thus, C. Celerio, according to Hübner's figure, has a broad yellow line extending from the horn to the sixth segment, whilst it is completely absent on the three front segments. In the unnamed species from Port Natal ${ }^{11}$ the subdorsal line extends to the front edge of the fifth segment, and on the fourth segment only is there a perfect eye-spot, whilst on the succeeding segments traces of such markings can be recognized as dark spots similar

- [Eng. ed. Dr. Staudinger has since obtained the caterpillar of $C$. Alecto from Beyrout; it possesses "a very distinct subdorsal line, and on the fourth segment a beautiful eye-spot, which is repeated with gradual diminution to segments 7 -8.]

10 Figured in "A Catalogue of Lepidopterous Insects in the Museum of the East India Company," by Thomas Horsfield and Frederick Moore. London, I857. Vol. i., Pl. XI.

${ }^{11}$ Figured in Trans. Ent. Soc., New Series, vol. iv., Pl. XIII. 
to those in Elpenor and Porcellus. The transition to the third group is through another unnamed species from Mozambique, ${ }^{12}$ in which rather large eye-spots have become developed on the fourth and fifth segments and these are followed by a subdorsal line, which only appears distinctly at certain places. On this broken subdorsal line, and not completely separated from it, there are small, roundish eyespots, situated near the front edge of each segment; these being, therefore, a somewhat more perfect repetition of the front eye-spots. ${ }^{13}$

\section{Ibid.}

13 [The following species figured by Butler (loc. cit. Pls. XC. and XCI.) appear to belong to the second group-Charocampa Japonica, Boisd., which is figured in two forms, one brown, and the other green. The former has two distinct ocelli on the fourth and fifth segments, and a distinct rudiment on the sixth, whilst the subdorsal line extends from the second eye-spot to the caudal horn, and beneath this line the oblique lateral stripes stand out conspicuously in dark brown on a lighter ground. The ocelli are equally well developed on the fourth and fifth segments in the green variety, the subdorsal line commencing on the sixth segment, and extending to the caudal horn; there is no trace of a third eye-spot, nor are there any oblique lateral stripes; the insect is almost the exact counterpart of $C$. Elpenor in its fourth stage. (See Fig. $2 \mathrm{I}, \mathrm{Pl}$. IV.) Pergesa Mongoliana, Butl., is brown, without a trace of the subdorsal line except on the three front segments, and with only one large eye-spot on the fourth segment. Charocampa Lezeisii, Butl., from Japan, is likewise figured in two forms. The brown variety has the subdorsal line on the three front segments only, distinct ocelli on the fourth and fifth segments, and gradually diminishing rudiments on the remaining seg- 
Group 3.-In the species of this group the eye-spots are repeated on all the segments. I am acquainted with seven such Charocampa larvæ, of which $C$. Bisecta, Horsfield, ${ }^{14}$ shows some affinity to the foregoing group, since the eyespots on segments 6-I I have not yet attained

ments. The green form appears to be transitional between the present and the third group, as it possesses a distinct, but rudimentary eye-spot on the third segment, besides the fully developed ones on the fourth and fifth, and very conspicuous, but gradually decreasing repetitions of rudimentary ocelli on segments 6-10. To this group may be added Charocampa Aristor, Boisd., the caterpillar of which is figured by Burmeister (Lép. Rép. Arg., Pl. XV., Fig. 4) in the characteristic attitude of alarm, with the front segments retracted, and the ocelli on the fourth segment prominently exposed. The subdorsal line is present in this species. Burmeister also figures two of the early stages (Pl. XV., Fig. 7, A and B), and describes the complete development of Philampelus Labrusca, another species belonging to the subfamily Charocampina. The earliest stage (3-4 days old) is simple green, with no trace of any marking except a black spot on each side of the fourth segment, the position of the future ocelli. A curved horn is present both in this stage and the following one, during which the caterpillar is still green, but now has seven oblique red lateral stripes. The caudal horn is shed at the second moult, after which the colour becomes darker, the adult larva (figured by Madame Mérian, in her work on Surinam, "pl. 34 and Sepp., pl. 32) being mottled brown. In addition to the ocellus on the fourth segment, there is another slightly larger on the eleventh segment, so that this species may perhaps be another transition to the third group; but our knowledge is still too imperfect to attempt to generalize with safety. R.M.]

${ }^{14}$ Cat. Lep. Ins. East Ind. Comp., Pl. XIII. [Figured also by Butler (=Charocampa Silhetensis, Walker), loc. cit. Pl. XCII., Fig. 8. R.M.] 
full perfection. In C. Oldenlandice, Fabr., ${ }^{15}$ and in C. Alecto from India, ${ }^{16}$ the eye-spots appear to be perfectly alike on all the segments; whilst in C. Acteus, Cram., ${ }^{17}$ and in the North American C. Tersa ${ }^{18}$ (P1. IV., Fig. 35) they are smaller on the other segments than on the fourth; and in C. Celerio, Linn., from India, ${ }^{19}$ the size of the spots diminishes from the head to the tail.

In this group also the subdorsal line is retained in a very variable degree. In some species it appears to have completely vanished (C. Acteus, Celerio); in others it is present as a light stripe extending along all the segments ( $C$. Alecto); whilst in others it is retained as a broad white stripe, which extends only to the fourth segment (C. Tersa, Fig. 35). In species possessing eyespots, the subdorsal line is thus a very variable character. It is, however, an interesting fact that even in the present group, which has made the greatest step forward, the subdorsal line is of general occurrence, because the eye-spots in all these species may have almost a similar development to those of Elpenor and Porcellus. The ontogeny of the tropical species would alone

${ }^{16}$ Cat. Lep. Ins. East Ind. Comp., Pl. XIII. [Figured also by Butler, loc. cit. Pl. XCI., Fig. I. R.M.]

- ${ }^{16}$ Horsfield and Moore, loc. cit. Pl. X.

${ }^{17}$ 1bid. [= Pergesa Acteus, Walker. R.M.] R.M.]

${ }^{18}$ [Figured also by Burmeister, loc. cit. Pl. XV., Fig. 3 .

19 Horsfield and Moore, loc. cit., Pl. XI. 
give a definite reply on this point, but unfortunately. we are not acquainted with any of the young forms, so that we can but presume that some of them at least would show only in the first stage the simple subdorsal line without eyespots; that in the second stage the primary pairs of eye-spots would be formed on the fourth and fifth segments, whilst the transference of these spots to the remaining segments would take place in the last stage.

The foregoing assumption is based immediately on the ontogeny of Elpenor and Porcellus; it is supported by the considerable size attained by the eye-spots in many species of the third group, and would receive additional confirmation by observations on the Indian C. Celerio, supposing that Horsfield's statements do not arise from a confusion of species. This skilful observer, who was the first to breed systematically a large number of tropical larvæ, has given a figure of the Indian caterpillar of $C$. Celevio, according to which this species possesses eye-spots on all the segments from the fourth to the tenth. The European form of this same species has eye-spots only on segments four and five, a fact which does not appear to have been known to Horsfield, as no mention of it is made in his notice of the Indian species. If the caterpillar figured is really that of Celerio, which I consider to be by no means improbable, not only is it thus shown that in the 
species of the third group the ocelli on the hind segments have a secondary origin through a repetition of the primary ones of the front segments, but we can also establish that the same species in two different regions may arrive at two different phyletic stages.

If, finally, we sum up the facts taught by the ontogeny of the two German species, and the adult forms of the other species, we can form therefrom a tolerably complete picture of the course of development of the genus Charocampa. Of the four phyletic stages indicated by the ontogeny of Elpenor and Porcellus, three still form the terminus of the development of existing species. The great differences among the caterpillars of this genus can be very simply explained on the view that they stand at different levels of phyletic development;-some species having remained far behind (Group I), others having advanced further (Group 2), and others having reached the highest point of development (Group 3). The fact that the species of the third group are only tropical accords well with this view, since many facts prove that phyletic development proceeds more rapidly in the tropics than in temperate climates.

The striking markings of the Charocampa larvæ may, in brief, be stated to originate from a local transformation of two portions of the subdorsal line into eye-spots, and the subsequent 
transference of these two primary ocelli to the other segments. The eye-spots always originate on segments four and five, and from these the transference mostly occurs backwards, although in certain cases it takes place at the same time forwards. Herein, i.e. in the origin of the eyespots, there lies a great distinction between the genus Charocampa and the genus Deilephila, with which it was formerly associated, and in which the origin of a very similar kind of marking can be traced to quite another source.

\section{The Genus Deilephila, Ochsenheimer.}

I am acquainted with the caterpillars of nine European and one North American species, these differing in marking to such a wonderful extent that they appear to offer at first sight but little hope of being able to trace them to a common form. These ten species can be separated, according to their markings, into five groups, which I will briefly define before entering upon their ontogeny.

The first group consists of three species, and comprises the commonest and most widely-ranging of all the European species, Deilephila Euphorbice, as well as $D$. Dahlii from Sardinia and Corsica, and $D$. Niccea, a species of very restricted range, which appears to occur only in one small district on the French coast of the Mediterranean. These 
three species agree in marking to the extent of their possessing in the adult form two rows of ring-spots on each side, whilst the subdorsal line is completely absent.

The second group, consisting also of three species, shows a great resemblance to Euphorbia, but has only one row of ring-spots. It contains D. Vespertilio, D. Galii, and the Algerian D. Mauritanica.

For the third group I only know one representative, D. Livornica, Esp., which possesses a single row of ring-spots connected by a subdorsal line.

Another group is composed of D. Zygophylli, which occurs on the shores of the Caspian Sea, and the North American D. Lineata; these species possessing a strongly-marked subdorsal line, associated with more or less distinct ring-spots, which I shall designate as "open rings," because their black border does not intersect the subdorsal line, but has the form of an arch above and below it.

In the last group, represented by $D$. Hippophaës, which occurs at the foot of the Alps (Wallis), and southward as far as Andalusia, there is only a broad subdorsal line, generally without any trace of a row of spots.

The important differences of marking displayed by these five groups are not in any way accidental, but they represent different stages of phyletic development; or, in other words, the five groups 
are of different ages, the first (Euphorbice, \&c.) being the youngest, and the last (Hippophaës) the oldest of the genus.

According to their phyletic age, the groups follow each other in inverse order, the first being Hippophaës, the second that of Zygophylli, the third that of Livornica, the fourth that of Galii, and the fifth and youngest that of Euphorbia. Only in this last am I acquainted with the complete development of one species, for which reason I commence with this group, thus proceeding from the youngest to the oldest forms, instead of taking the more natural course from the simplest and oldest to the youngest and most complicated.

\section{Deiliphila Euphorbie, Linn.}

Some captured females were at once placed in an enclosure about the size of a small sitting-room. It was evident that they did not feel quite at home under these conditions, frequently beating their heads and wings against the tarlatan, but some of them nevertheless laid eggs at the base of the leaves of Euphorbia Cyparissias. The eggs much resemble those of Charocampa Elpenor, being spheroidal in form, but rather smaller, and of a somewhat darker green. They were laid in small clusters composed sometimes of as many as seven, the single eggs being placed near together, but never touching, and seldom at the point of the 
leaf, but generally near the end of a twig, where young shoots are in close proximity. During the embryonic development the eggs become coloured, first yellow and partly blackish, and finally completely black.

\section{First Stage.}

The young caterpillars (Fig. 37, Pl. V.) immediately after hatching measure four millimeters in length; they are at first rather light, but in the course of half-an-hour they are seen by the naked eye to become of a deep velvety black; later, on increasing in size, they again become paler, appearing of a greenish-black, and subsequently blackish-green. On further increasing in size (Fig. 38), they are blackish-green, with the horn, head, legs, and a crescent-shaped chitinous plate on the back of the prothorax black. There are also on the last segment a double and two single black chitinous plates. Of the later marking of the caterpillar there is scarcely anything present. The spiracles appear as white spots, and on each segment there are a number (mostly ten) of small warts, each of which emits a single bristle.

When the young larvæ have attained a length of seven millimeters they are olive-green, and do not contrast so brilliantly with the green of the Euphorbia leaves as before; neither do they as yet possess any markings. 
The Origin of the Markings of Caterpillars. 203

\section{Second Stage.}

The first ecdysis occurs after five days, and with this there appears quite suddenly a very complicated pattern. The ground colour is now a light yellowish-green (Fig. 39), and on each of the twelve segments, near the front border, there is a pure white round spot in the middle of a large black transverse spot. I shall designate these, in accordance with the nomenclature employed for Charocampa, as the white "mirrors" on black " ground-areas," both together constituting " ringspots," as distinguished from "eye-spots" proper, in which a "nucleus," the pupil of the eye, is also added. In many, but not in all specimens, very distinct traces of a subdorsal line can be seen as a light whitish stripe connecting the white spots. The horn, the thoracic and prolegs, and some spots on the head, are black.

The caterpillars remain unaltered till after four days, when, having a length of $\mathrm{I} 7$ millimeters, the second moult takes place, bringing with it changes quite as great as those which occurred with the first.

\section{Third Stage.}

The caterpillar now assumes the shagreened appearance which it possesses in the adult state. Small white warts are arranged in rows from the dorsal to the spiracular line, and again underneath 
this line on the abdominal legs. These dots are not only of value as a character for differentiating the genera Deilephila and Charocampa, but they also play a part in the peculiar spot-marking which will be shown later on. The ground-colour of the caterpillar is now light green (Fig. 40), replaced by black on certain parts. From the black "ground-area" of the ring-spots, two black triangles extend towards the posterior borders of the segments, but usually without reaching them.

The ring-spots are not essentially changed, although it may be observed that in most specimens the shagreen-dots under each ring-spot are somewhat larger, and stand closer together than in other places. In the following stage they become fused into a second white "mirror," so that two ring-spots stand one above the other, their black ground-areas meeting. The formation of the second ring-spot sometimes takes place in the present stage (Fig. 42).

The subdorsal line has now completely vanished, whilst the spiracular-]ine ${ }^{20}$ appears as a broad stripe above the legs. The horn is yellow with a black point, and the black spots on the head have increased in size.

s) To be accurate this should be designated the infraspiracular line; but this term cannot be well applied except in cases where there is also a supra-spiracular line, as, for instance, in Anceryx (Hyloicus) Pinastri. 


\section{Fourth Stage.}

The third moult, which again occurs after four days, is not accompanied by such important changes. The green ground-colour has now completely disappeared, and is replaced by a dull black. The caterpillars are now, as also in the previous stage, extremely variable. Thus, for example, a triangular patch of the green groundcolour may be retained on the posterior edge of the segments (Fig. 4I), those specimens which possess this character generally having their markings retarded in development, as shown by the absence of the second "mirror" of the ring-spots.

In Fig. 4I the shagreen-dots from which this second "mirror" is subsequently formed, are distinctly larger than the others, and on the eleventh segment two of them have already coalesced.

\section{Fifth Stage.}

After another period of four days, the fourth moult takes place. The marking remains the same, but the colours become more vivid; the brick-red of the head, horn, dorsal line and legs, changing into a fiery red. The spiracular line, formerly green alternating with yellow, generally becomes resolved into a row of reddish-yellow spots. Ten days later the caterpillar $(8 \cdot 5$ centimeters in length), ceases to feed, and prepares for pupation. 
In this last stage also there is great variability of colour, but although each particular character is subject to fluctuation, the individuals of the same brood show but little variation among themselves. ${ }^{21}$ Thus, the dorsal line is sometimes black, and sometimes red, or again, this colour interrupted with black, so that only small red spots mark its course." The head may be entirely red, or this colour mixed with black. On the under side of the caterpillar, red generally predominates, but in some specimens this is replaced by black. The ground-colour is also variable, being generally a shining brownish-black, but sometimes dull coaly black. The shagreen-dots are sometimes white and sometimes yellow, and the "mirrors" of the ring-spots are also often yellowish.

The most interesting variation, however, appears to me to be the following:-In many specimens from Kaiserstuhl (Breisgau), the red was unusually vivid, and was not limited to the ordinary places, but occupied also the triangles on the posterior edges of the segments (Fig. 44), which are green in the third and fourth stages (Fig. 42): This variety has also been figured by Hübner. In

${ }^{21}$ Upon this fact obviously depends the statement of that extremely accurate observer Rösel, that the caterpillar of Euphorbice is but very slightly variable ("Insektenbelustigungen," Bd. iii. p. 36). I formerly held the same opinion, till I convinced myself that this species is very constant in some localities, but very variable in others. It appears that local influences make the caterpillar variable. 
one individual (Fig. 43), the under ring-spots were wanting, whilst the upper ones possessed a beautiful red nucleus fading away anteriorly, and showing the first step in the formation of a complete eye-spot.

I cannot positively assert that a fifth moult occurs in the last ten days, although I am very doubtful whether this is the case. It is certain, however, that some time before pupation, and whilst the larva is still feeding, the striking colours fade out, and become replaced chiefly by black.

The ontogeny of this species is obviously but a very incomplete representation of its phyletic development This is at once apparent from the large gap between the first and second stages. It is not possible that a row of ring-spots can have arisen suddenly; in all probability they have been developed from a subdorsal line, which in Euphorbice is now only indicated in the second stage by a faint line. This conjecture is raised to a certainty when we call in the aid of the remaining species of Deilephila.

\section{Deilephila Nicka, De Prunner.}

I only know this species from blown larvæ in Staudinger's collection, and Duponchel's figure, of which Fig. 5 I, Pl. VI. is a copy. The adult insect possesses two perfectly separated rows of ringspots. Duponchel figures also two younger stages, of which the youngest is probably the third stage. 
The larva is 18 millimeters in length, of a leafgreen colour, and shows no trace of a subdorsal line, but possesses the two rows of ring-spots, which only differ from those of the succeeding stages in the green colour of the "mirror."

\section{Deilephila Dahlit, Treitschke.}

I am familiar with numerous specimens in various stages, collected in Sardinia by Dr. Staudinger, and preserved by inflation.

The first stage is blackish, and shows no kind of marking; thus agreeing with the corresponding stage of Euphorbia. The second stage is unfortunately not represented in Staudinger's collection.

The third stage shows a row of ring-spots, which are, however, connected by a very distinct and sharply defined subdorsal line. In the fourth stage a second row of (under) ring-spots is added, whilst the subdorsal line generally at the same time disappears.

The caterpillar remains unchanged during the fifth stage, when it shows a great resemblance in marking to Euphorbice; neither does it appear to differ essentially from this species in colour, so far as can be judged from preserved specimens and single figures (in Duponchel and Hübner). I have, moreover, seen several larvæ in the last stage, and the subdorsal could be distinctly recognized as a broad light stripe.

Of the four groups, the second (that of Galii), 
appears to me to be of but very little importance, as I shall now proceed to show from the development of $D$. Vespertilio.

\section{Deilephila Vespertilio, Fabricius.}

Hitherto I have unfortunately been unable to obtain fertile eggs of this species, so that I can say nothing about the first stage. The latter would have been of interest, not only because of the marking, but also because of the presence of a residual caudal horn.

I am likewise only acquainted with the end of the second stage, having found, at the end of June I 873, a single caterpillar on Epilobium Rosmarinifolium, just previous to its second ecdysis. In the case of such young caterpillars, however, the new characters which appear in the succeeding stage are generally perceptible through the transparent chitinous skin at the end of the preceding stage, so that the markings of the insect are thus caused to change. The caterpillar found was about i 6 millimeters long, and of a beautiful smooth and shining grass-green (Fig. I3). A broad white subdorsal line extended from the first to the penultimate segment, from which the horn was completely absent. On close inspection the first traces of the ring-spots could be detected near the anterior edge of each segment as feeble, round, yellow, ill-defined spots, situated on the subdorsal line itself (Fig. I 3). On the first segment only there is 
no spot, and here no ring-spot is afterwards formed. Besides these markings, there was only to be seen a yellowish-white spiracular line.

This solitary specimen unfortunately buried itself before the moult for which it had prepared itself had occurred; but this ecdysis is associated with a very important transformation. This statement is founded on a blown specimen in Staudinger's collection; it is only I 8 millimeters in length, but already shows the later grey colouring in place of the beautiful green. In this, the third stage, the broad white subdorsal line bears on each segment a red spot enclosed between black crescents above and below (Fig. $49 \mathrm{~A}$ ). In the fourth stage, during which I have seen many living caterpillars, the subdorsal line is still distinctly present in some individuals (Fig. 14), but the spots ("mirrors") are now completely surrounded by a narrow black ring ("ground-area"), which sharply separates them from the subdorsal line (Fig. 49 B). In the fifth stage this ring becomes a somewhat irregularly formed black "ground-area," whilst the subdorsal line completely vanishes (Figs. 5 I and 49 C). The mirrors are white, but generally have a reddish nucleus, which obviously corresponds to the primary yellow spots from which the whole development of the ring-spots originates. This character is, however, sometimes absent; and many other variations also occur in the earlier stages, all of which can be 
The Origin of the Markings of Caterpillars. 2 I I

easily explained as cases of arrested, or retarded development. Thus, the subdorsal line often disappears earlier, and is only present in the fourth stage as a feeble light stripe.

\section{Deilephila Galit, Fabricius.}

The markings of this species appear to be developed in a precisely similar manner to those of $D$. Vespertilio. The adult larva, as in the last species, shows no trace of a subdorsal line. A row of large black spots, each having an irregular round, yellowish-white nucleus, is situated on an olive-green, blackish-brown, brown, or dirty yellow ground. I have, unfortunately, also in this case been unable to procure fertile eggs. There is, however, one figure of a caterpillar, 2.5 centimeters long, by Hübner, which is of a light-green colour, and has five longitudinal lines; one dorsal, two subdorsal, and a spiracular line. The subdorsal is white, and bears in the place of the ring-spots small red dots, whilst the line itself is bordered with black where the red spots are situated. Hübner has probably figured the third stage, so that we may venture to conclude that in the second stage there is a subdorsal line either quite free from spots, or only showing such feeble rudiments as are to be seen in the second stage of Vespertilio.

I found two specimens in the fourth stage in the Upper Engadine. One of these (Fig. 45) 
was already of a dark, blackish-green groundcolour $^{22}$ with a broad, greenish-white subdorsal line sharply defined throughout its entire length, and containing ring-spots of a sulphur-yellow with an orange-red nucleus; the black "ground-area" did not encroach upon the subdorsal line, but was confined to two faint crescents situated above and below the "mirror." Only the two foremost "mirrors" (on the second and third segments) were without nuclei.

The remaining peculiarities of coloration are shown in the figure. I may here only point out the shagreening present on the sides and a portion of the under surface.

The specimen figured was 3.3 centimeters long; a second example measured 2.8 centimeters in length, and was essentially similar, but showed that a considerable amount of variability must prevail at this stage of development. It was pitchy black, with a very indistinct subdorsal line and a few ring-spots, the "mirrors" of which were also sulphur-yellow, with the orange-red nucleus. The shagreening was quite as strong as in the firstspecimen, the dots being yellow instead of white. It is specially to be observed, because of its important theoretical bearing, that in this larva the ring-spots were absent on the three front segments, and on the fourth only, a faint indication of one could be perceived. In the caterpillar figured ${ }^{22}$ The green is considerably too light in Fig. 45 . 
the ring-spots increase also in distinctness from the tail to the head.

\section{Fifth Stage.}

The two specimens just mentioned, after moulting, acquired the well-known markings of the adult caterpillar already briefly described above. The fifth is the last stage.

The larva is known to occur in several variations, Rösel having figured it in three forms ; light green, olive-green, and dirty yellow. It has not been since considered worth the trouble to attend to the subject of caterpillar coloration. Thus, Wilde, ${ }^{23}$ in his well-known work, takes no notice of Rösel's observation, but simply describes the caterpillar of Galii as "blackish olive-green."

Having had an opportunity of observing twentyfive adult specimens of this somewhat scarce species at one time, I am able to state that it is not in this instance di- or polymorphism, but a case presenting a great degree of variability, with which we have to deal. There are not several sharply-defined types of coloration; but the extremes are connected by numerous intermediate forms. The extreme forms, however, certainly preponderate.

I have never met with Rösel's light-green form ; neither was there a dark-green specimen among

${ }_{23}$ "Die Pflanzen und Raupen Deutschlands." Berlin, I86o, p. 83 . 
the twenty-five mentioned, and I only know this variety from single individuals, found at a former period. Among the twenty-five caterpillars; all gradations of colour occurred, from pitchy black to light clay-yellow, and even to an almost whitishyellow; some were brownish-black, others of a beautiful chestnut-brown, and others yellowish brown, dark clay-yellow, or brownish-red. Out of twenty-one specimens of which the groundcolours were noted, there were nine black, nine clay-yellow, and three brown; each of the three groups again showing various minor modifications of colour. The other colours also varied somewhat. Thus, the "mirrors" were sometimes white, sometimes strong yellow, and occasionally they also contained a reddish nucleus.

The variations in the shagreening were especially interesting, inasmuch as these appeared to have a striking connection with the general colouring of the caterpillar. Black specimens seldom show such sparse shagreening as that represented in P1. V., Fig. 46, but are generally thickly scattered with large shagreen-dots right up to the dorsal line (Fig. 47, Pl. VI.), then strikingly resembling the adult larva of $D$. Euphorbice. The light ochreous-yellow individuals, on the other hand, were sometimes entirely without shagreening (Fig. 48, P1. VI.), being smooth, and much resembling the light ochreous-yellow or yellowishred caterpillar of D. Nicca (Fig. 5 I, Pl. VI.). 
I have never seen a caterpillar of Galii which showed traces of the subdorsal line in the last stage, nor have I ever met with one which possessed a second row of " mirror" spots; so that retrogression or a sudden advance in development does not appear to occur.

Of the North African D. Mauritanica, which likewise belongs to the Galii group, I have not been able to obtain specimens or figures of the younger stages. The adult caterpillar is very similar to that of Euphorbia, but differs in the absence of the second row of ring-spots. For this reason it must be regarded as a retarded form at an older stage of phyletic development.

I now proceed to the Livornica group.

\section{Deilephila Livornica, Esper.}

This, the only European species here to be considered, possesses almost the same markings as Galii in its fourth stage, i.e., a subdorsal line with interpolated ring-spots. The species is known to be rare, and I have not been able to obtain living specimens, but I have examined several blown larvæ, all of which agree in having the ring-spots sharply distinct from the whitish subdorsal line, so that the latter is thereby interrupted. Figures of the adult larva are given in the works of Hübner, Boisduval, and Duponchel. In most specimens the ground- 
colour is brown, although Boisduval ${ }^{24}$ also figures a 1 ght-green specimen; from which it may be inferred, from analogy with Galii and Vespertilio, that the first stages are green. In Dr. Staudinger's collection there is a young larva, probably in the fourth stage, the ground-colour of which is light ash-grey. The dorsal and subdorsal lines are white, the latter showing in the positions where the ring-spots subsequently appear, small white "mirrors" with red nuclei, exactly corresponding to the stage of Vespertilio represented in Fig. 49 A, Pl. VI. The "mirrors" are nothing more than dilatations of the subdorsal line, which is not therefore interrupted by them. The black "ground-area" does not surround the "mirrors" completely, but borders them only above and below, and is much more strongly developed above, extending in this direction to the dorsal line.

The fourth group comprises the two species D. Lineata, Fabr., and D. Zygophylli, Ochs., the former being the North American representative of our D. Livornica, but differing in remaining permanently at the fourth stage of this last species. I am acquainted with $D$. Lineata only through the figure of the adult larva given by Abbot and Smith, which figure, judging from the position and form of the spots, I am compelled to believe is not quite correct, notwithstanding the excellence ${ }^{24}$ Fig. 62, Pl. VII., is copied from Boisduval. 
of the other illustrations. The ground-colour of the caterpillar is green; the subdorsal yellow, bordered with black, slightly curved, arched lines, which nowhere interrupt its continuity. This North American species appears therefore to be an older form than our Livornica.

\section{Deilephila Zygophylli, Ochsenheimer.}

This species, which is the next allied form to D. Lineata, is an inhabitant of Southern Russia. I have seen four specimens of the caterpillar in Dr. Staudinger's collection, three of which are certainly in the last ontogenetic stage. The ground-colour appears ash-grey, ash-brown, or blackish with whitish granulations. A broad white subdorsal line extends to the base of the black caudal horn, this line in one specimen appearing at first sight not to possess a trace of spot rudiments (Fig. 50). On closer investigation, however, there could be observed, in the same position where the ring-spots stand in the other species of Deilephila, small black crescents above and below the subdorsal line. In other specimens the white subdorsal line had also become expanded in these positions into distinct spots; indeed, in one individual light white mirror-spots, bordered above and below by black crescents, stood on the subdorsal line (Fig. $50 \mathrm{~A}$ ).

It is thus in this distinguishing character that the caterpillar is extremely variable, and we may 
suppose either that this species is now in a state of transition to a higher stage of phyletic development, or else that the ring-spots were formerly more strongly developed, and are now degenerating. The developmental history of the larva could alone decide which of these two views is correct. There would be no difficulty in procuring materials for this purpose if one of the numerous and zealous Russian naturalists would take up the subject.

\section{Deilephila HippophaËs, Esper.}

This is the only representative of the fifth and oldest group known to me. The moth resembles D. Euphorbice to the extent of being sometimes confounded with it, a circumstance which is made the more remarkable by the fact that the caterpillars are so completely different.

The adult larva of this local moth has been made known by the figures, more or less exact, in the works of Hübner, Boisduval, and Duponchel. Wilde also gives a description of it, although from a foreign source. I will not here delay myself by criticizing the different descriptions and figures; they are partly correct, partly inexact, and sometimes altogether erroneous ; they were of no avail for the question which here primarily concerns us, and new observation had to be undertaken.

I have been able to compare altogether about forty caterpillars, thirty-five of which were living. All these specimens possessed nearly the same 
greyish-green ground-colour, and most of them had exactly the simple marking as represented, for instance, in Hübner's figure, i. e., a rather broad greenish-white subdorsal line, somewhat faded at the edges, and without a trace of spots on any of the segments with the exception of the eleventh, on which there was a yellowish, black-bordered mirror-spot, with a broad, diffused, vivid orangered nucleus. Specimens also occur, and by no means uncommonly, in which no other markings are to be seen than those mentioned; there were nine among twenty-eight examples compared from this point of view.

In many other individuals of this species small red spots appear on the subdorsal line, exactly in the positions where the ring-spots are situated in the other species of the genus (Fig. 6o), so that these spots are thus repetitions of the single ringspot-a fact which must appear of the greatest interest in connection with the development of the markings throughout the whole genus. But this is not all, for again in other specimens, these red spots stand on a large yellow " mirror," and in one individual (Fig. 59), they had become developed into well-formed ring-spots through the addition of a black border. We have thus presented to us in one and the same stage of a species, the complete development of ring-spots from a subdorsal line. These facts acquire a still greater interest, as showing how new elements of marking are produced. 
The spots on the subdorsal line decrease from the posterior to the anterior segments, so that they must undoubtedly be regarded as a repetition or transference of the ring-spot previously developed on the eleventh segment. I will now proceed to furnish proofs in support of this statement.

I have never met with any specimens having ring-spots on all the segments - in the most prominent instances these spots were present on segments 10-5. This was the case in three out of the twenty-eight caterpillars minutely examined. On all these segments, however, the ring-spots were not equally developed, but increased in perfection from the posterior towards the anterior segments. In the larva represented in Fig. 59 for example, there is a completely developed ring-spot on segment IO, which, although possessing but a feeble black "ground-area," is still distinctly bordered; on segment 9 this border is less sharp, and not so dark, and it is still less sharp and much lighter on segments 8 and 7 , whilst it has completely disappeared from segment 6, the yellow "mirror" having at the same time lost in size. On segment 5, only two small contiguous reddish spots, the first rudiments of the nucleus, ${ }^{25}$ can be recognized on close inspection.

Specimens in which the spots extend from the eleventh to the seventh segment are of more

${ }^{25}$ The fading of the red anteriorly has not been represented in the figure. 
frequent occurrence, five having been found among the twenty-eight. In these the spots diminish anteriorly in size, perfection, and intensity of colour. Still more frequently (in eleven specimens) are the ring-spots or their rudiments restricted to the tenth and ninth segments, the spot on the latter being without exception less developed than that on the former segment.

An anteriorly progressing formation of ringspots thus undoubtedly occurs, the spots generally diminishing in perfection very suddenly towards the front segments; and specimens, such as that represented in Fig. 60, Pl. VII., in which traces of ring-spots are to be seen on all the segments from the tenth to the fifth, are of rare occurrence.

From what elements of marking are these secondary ring-spots resulting from transference developed? They do not, as in the case of the primary eye-spots of the Charocampina, originate in the separation of one portion of the subdorsal line, and the subsequent formation of this detached spot into a "mirror ;" but they arise from the formation of a nucleus, first one and then two of the shagreen-dots on the subdorsal line acquiring a yellowish or reddish colour (Fig. 61, P1. VII., segments 6 and 7). The ground on which these two spots are situated then becomes yellow (Fig. 6I, P1. VII., segment 8), and a more or less distinct black border, having the form of two small crescents, is afterwards formed. At a later period these two 
crescents and also the two primary nuclei coalesce, producing a ring-spot which, as in Fig. 6I, P1. VII., segment 9, can be distinctly resolved into two portions.

It certainly cannot be denied that these facts may also be theoretically interpreted in a reverse sense. We might interpret the phenomena in this case, as also in that of $D$. Zygophylli, as a gradual disappearance from the front towards the hind segments of ring-spots formerly present, a view which could only be refuted by the ontogeny of the species. I have not been fortunate enough to procure eggs of $D$. Hippophaës, so that the younger stages are unknown to me. Among my caterpillars, however, there were two in the fourth stage of development, but these did not show ring-spots on all the segments, as we should expect on the above view; on the contrary, no trace of such spots could be seen on any of the segments with the exception of the eleventh, on which there was a ring-spot less perfectly developed than in the last stage.

In this fourth stage the larva of D. Hippophaës is of a lighter green (Fig. 58), the subdorsal yellowish with sharp boundaries, and the infraspiracular line pure white, as in the next stage. The shagreening is present, but none of the shagreen-dots are red or reddish, and no trace of a ring-spot can be detected on the subdorsal line with the exception of that on the eleventh segment. 
In this last position this line is somewhat widened, and a long, diffused, rose-red spot can there be recognized upon it (Fig. $58 \mathrm{~A}$ ). The black "groundarea" present in the fifth stage is as yet absent, and the spot is not so sharply separated anteriorly from the subdorsal line as it becomes later.

From these observations we might venture to expect that in the third stage of Hippophaës, the subdorsal line would also be free from this spot on the eleventh segment, and it is possible that in the second stage this line is itself absent.

\section{The Genus Deilephila: Summary of Facts and Conclusions.}

Regarding only the adult larvæ of the species of Deilephila, these represent in their five groups, five stages in the phyletic development of the genus; but if we also take into consideration the developmental history, two more stages must be added, viz., that in which the caterpillar possesses no particular marking, as was found to be the case in the first stage of the development of $D$. Euphorbice and D. Dahlii; and a second stage with a subdorsal line, but without any ring-spot formations. Seven stages of phyletic development must therefore be distinguished.

Stage I.-No species with entire absence of marking in the adult form now occurs.

Stage 2.-A subdorsal, accompanied by a spiracular line, extends from the caudal horn to the 
first segment. This also no longer forms the final stage of the ontogeny, but is, however, undoubtedly retained in the second stage of several species (D. Vespertilio, Livornica, Lineata, and perhaps also Galii).

Stage 3.-The subdorsal line bears a ring-spot on the penultimate segment; the other markings as in the last stage. D. Hippophaës only belongs to this stage, a small number of specimens, however, showing a transition to the following stage by the transference of ring-spots from the posterior to the anterior segments.

Stage 4.-Open ring-spots appear on the subdorsal line on all the segments from the eleventh to the first. D. Zygophylli and the North American $D$. Lineata belong here.

Stage 5.-Closed ring-spots are situated on the subdorsal line. Of the known species, only $D$. Livornica concludes its development at this phyletic stage.

Stage 6.-A single row of ring-spots replaces the subdorsal line. D. Galii, Vespertilio, and Mauritanica represent this stage at the conclusion of their ontogeny. ${ }^{26}$

Stage 7.-A double row of ring-spots. Only D. Dahlii, Euphorbia, and Nicae attain to this highest stage of Deilephila marking, the two first

${ }^{26}$ [The caterpillar of Deilephila Euphorbiarum, figured by Burmeister (Lép. Rép. Arg., Pl. XVI, Fig. I) belongs to this stage. R.M.] 
species in the fourth stage, and Niccea in the third stage of its ontogeny.

Although our knowledge of the history of the development of the individual species is still so fragmentary, we may conclude with certainty that the development of the markings has been uniform throughout-that it has proceeded in the same manner in all species. All the species appear to be making for the same goal, and the question thus arises whether there may not be an innate force urging their phyletic development. The rigorous examination of this conception must be reserved for a later section. Here, as we are only occupied essentially in establishing facts, it must be remarked that retrogression has never been observed. The young larval forms of a species never show the markings of a later phyletic stage than the older larval forms; the development takes the same course in all species, only making a greater advance in the same direction in some than in others.

Thus, Nicae and Euphorbice have advanced to the seventh phyletic stage, Zygophylli and Hippophaees only to the third, and some specimens of Zygophylli to the fourth. But at whatever phyletic stage the ontogeny of a species may terminate, the young larval stages always display the older phyletic stages. Thus, Galii in its last ontogenetic stage reaches the sixth phyletic stage; in its penultimate stage it reaches the fifth 
phyletic stage; and in its third stage; the fourth phyletic stage is represented, so that little imagination is required to anticipate that in the second stage the third or second phyletic stage would be pictured.

If we tabulate the development of the various species, indicating the ontogenetic stages by Arabic numerals, and the stages of the phylogeny which are reached in each stage of the ontogeny by Roman numerals, we obtain a useful synopsis of the series of developments, and, at the same time, it shows how many gaps still remain to be filled up in order to complete our knowledge even of this small group of species.

Table of Development of the Species of Deilephila.

\begin{tabular}{|c|c|c|c|c|c|}
\hline Deilephila. & $\begin{array}{l}\text { Ontogeny } \\
\text { Stage x. }\end{array}$ & $\begin{array}{l}\text { Ontogeny } \\
\text { Stage } 2 .\end{array}$ & $\begin{array}{l}\text { Ontogeny } \\
\text { Stage } 3 .\end{array}$ & $\begin{array}{l}\text { Ontogeny } \\
\text { Stage 4. }\end{array}$ & $\begin{array}{l}\text { Ontogeny } \\
\text { Stage } 5 .\end{array}$ \\
\hline I. Hippophaës & ? & ? & ? & III. & III.-IV. \\
\hline 2. Zygophylli & ? & $?$ & ? & $?$ & III.-IV. \\
\hline 3. Lineata & ? & ? & ? & ? & IV. \\
\hline 4. Livornica & ? & ? & $?$ & IV. & V. \\
\hline 5. Galii & ? & ? & IV. & V. & VI. \\
\hline 6. Vespertilio & ? & II. (?) & IV. & V. & VI. \\
\hline 7. Mauritanica & ? & ? & ? & ? & VI. \\
\hline 8. Dahlii & I. & ? & VI. & VII. & VII. \\
\hline 9. Euphorbiæ & I. & V. & VI. & VII. & VII. \\
\hline ıо. Nicæa & ? & ? & VII. & VII. & VII. \\
\hline
\end{tabular}


From this very incomplete table we perceive that, in certain instances, the stages can be represented as a continuous series of phyletic steps, as in the case of D. Galii; that in others certain steps may be omitted, as with $D$. Euphorbia, in which grade I. of stage I is immediately followed by grade $\mathrm{V}$. in stage 2 . In reality the gap caused by this omission is still greater than would appear, as grade V. is only indicated, and not actually reached, the subdorsal not being present as a sharply-defined line, but only as a faint stripe. The suppression of phyletic steps increases with the advancement in phyletic development. The higher the step to which a species finally attains, the greater is the tendency of the initial stages to be compressed, or omitted altogether.

From what has thus far been seen with respect to the development of $D$. Hippophaës, there may be drawn what to me appears to be a very important conclusion, viz. that the ring-spots of Deilephita first originated on the segment bearing the caudal horn, and were then gradually transferred as secondary spots to the preceding segments. Complete certainty would be given to this conclusion by a knowledge of the young forms of other phyletically retarded species, especially those of the American D. Lineata, and perhaps also those of Zygophylli and Livornica. The few observations on the development of $D$. Galii already recorded give support to this 
view, since the absence of ring-spots on the three front segments in the young caterpillar (one instance), or their less perfect formation on these segments (second instance), indicates a forward transference of the spots.

If the foregoing view be accepted, there follows from it a fundamental difference between the development of the genera Charocampa and Deilephila. In the former the formation of the eye-spots proceeds from a subdorsal line, but they first appear on two of the front segments, and are then transferred to the posterior segments. In Deilephila, on the other hand, a single ring-spot is formed on the penultimate segment bearing the caudal horn, and this is repeated on the anterior segments by secondary transference. With respect to the origination of the ring-spot also, there is a distinction between this genus and Charocampa, inasmuch as the first step towards the eyeformation in the latter consists in the separation of a curved portion of the subdorsal line, whilst in Deilephila the nuclear spot first seems to originate and the separation of the mirror-spot from the subdorsal line appears to occur secondarily. It is difficult here to draw further conclusions, since the first appearance of the primary ring-spot has not yet been observed, and no more certain inference respecting the history of the formation of the primary ring-spots can be drawn from the manner in which the secondary ring-spots are formed. 
Because in Hippophaës the formation of the secondary ring-spots begins with the red coloration of one or two shagreen-dots, it does not follow that the primary spot on the eleventh segmerit also originated in this manner; and this is not without importance when we are concerned with the causes which underlie the formation of ring-spots. In Charocampa also, the formation of the primary eye-spots appears to differ from that of the secondary-in the latter the black "ground-area" first appearing, and in the former the "mirrorspot." The secondary eye-spots certainly remain rudimentary in this last genus, so that the evidence in support of this conclusion is thus much weakened; but it must be admitted that we are here on ground still too uncertain to admit of wider conclusions being based thereon.

As a final result of the investigation, we may advance the opinion that the existing species of the genus Deilephila have reached five different phyletic stages, and that their very different external appearance is explained by their different phyletic ages; the appearance from these caterpillars of moths so extremely similar, can otherwise be scarcely understood.

It may appear almost unnecessary to bring forward additional proofs in support of this interpretation of the facts, but in a field where the data are so scanty, no argument which can be drawn from them should be considered as super- 
fluous. The variations which occasionally occur in the larvæ, however, to a certain extent furnish a proof of the correctness of the theoretical interpretation offered.

When, in the ontogeny of these species, we actually see before us a series of stages of phyletic development, we must admit that ordinary reversion may occur, causing an adult caterpillar to show the characters of the young. Forms reverting to an earlier phyletic stage must, on the whole, occur but seldom, as this stage is removed further back in the ontogeny. Thus, indications of the subdorsal line must occur but rarely in the adult larvæ of Euphorbia, and still less frequently in Nicca, whilst they must be expected to be of more common occurrence in Vespertilio, and also, as has already been seen, in Dahlii. In this last species, as also in Vespertilio, the completelydeveloped subdorsal line is still present in the third stage, whilst it is possessed by Euphorbice only in the second stage, and then in a rudimentary condition.

The state of affairs may in fact be thus described: Among several hundred adult larvæ of Dahlii found in Sardinia by Dr. Staudinger, there were some which did not actually possess a distinct subdorsal line, but in place thereof, and as its last indication, a feeble light stripe. One of Dr. Staudinger's caterpillars showed also a distinct line between the closed eye-spots. In the last 
stage of Vespertilio this line appears still more frequently, whilst in Euphorbia it is extremely rare, and when present it only appears as a faint indication. This is the case with one of the specimens figured in Hübner's work as an "aberration," and also with one in Dr. Staudinger's collection. Of Niccea I have at most seen only eight specimens, none of which showed any trace of the long-vanished subdorsal line.

It must be expected that any ontogenetic stage would most readily revert to the preceding phyletic stage, so that characters present in the preceding stage are consequently those which would most commonly arise by reversion. This postulate of the theory also finds confirmation in the facts. Caterpillars which, when full grown, belong to the seventh phyletic stage, e.g. D. Euphorbice, not unfrequently show variations corresponding to the sixth stage, i.e. only one instead of two rows of ring-spots - the upper and first-appearing series. On the other hand, forms reverting to the fifth phyletic stage (ring-spots with connecting subdorsal line) occur but very rarely. I have never met with such cases in adult living caterpillars of D. Euphorbia, although in one instance such a larva was found in the fourth ontogenetic stage; but the strikingly dark, brownish subdorsal line which connected the otherwise perfectly developed ring-spots, completely disappeared in the fifth stage of the ontogeny. Those larvæ which, in the adult. 
state, belong to the sixth phyletic stage, not unfrequently show the characters of the fifth stage inore or less developed, as, for example, $D$. V espertilio. ${ }^{27}$

THE GENUS SMERINTHUS, LATREILLE.

The caterpillars of this genus are very similar in appearance, and all possess extremely simple

${ }^{27}$ [In concluding this account of the Charocampine I may call attention to the following species, which have since been figured by Burmeister :-Pachylia Ficus, Linn. (loc. cit. Pl. XIV,, Figs. I and 2); during the three first stages the larva is uniformly green, with a yellow subdorsal line, and below this ten oblique yellow stripes slanting away from the head; after the third moult the colour completely changes, the whole area of the body being divided into two distinct portions by the subdorsal line, above which the colour is red, and underneath of a pale green; the oblique stripes have almost disappeared; no occelli nor annuli are present. Pachylia Syces, Hübn. (loc. cit. Fig. 3); very similar to the last species in its young stages (figured also by Mérian, Surin. pl. 33). Philampelus Vitis, Linn. (loc. cit. Figs. 4 and 5); two stages represented ; between first and second moults green, with oblique paler stripes slanting in same direction as in Pachylia, and each one containing a red streak surrounding the spiracle. When adult, the ground-colour is yellow above and green beneath, the whole surface being mottled with deep black and red transverse markings; the oblique stripes whitish, bordered with black at their lower extremities (figured also by Mérian, pls. 9 and 39). Philampelus Anchemolus, Cram. (loc.cit. Pl. XV., Fig. I; Mérian, pl. 47); green when young, with seven oblique red stripes; when adult, uniformly brown, with seven pale yellow lateral markings, the first four of which are spots, and the remainder broad oblique stripes slanting forwards. Fhilampelus Labrusce, (sẹe note I3, p. I95). R.M.7 
markings. The occurrence of numerous stages of development of these markings is thus excluded, and the study of the ontogeny therefore promised to furnish less information concerning the phyletic development of the genus than in the case of the preceding genera. This investigation has nevertheless also yielded interesting results, and the facts here recorded will be found of value in likewise throwing light on the causes which have produced the markings of caterpillars.

I shall commence, as in former cases, with the developmental history. I have easily been able to obtain fertile eggs of all the species of Smerinthus known to me. Impregnated females laid large numbers of eggs in confinement, and also bred females of the commoner species can readily be made to copulate, when pinned, and exposed in a suitable place in the open air. A male soon appears under these circumstances, and copulation is effected as readily as though the insect were not fastened in the way indicated.

\section{Smerinthus Tiliæ, Linn. ${ }^{28}$}

The light green eggs are nearly spherical, and

${ }^{28}$ [Mimas Tilice of Butler's revision. The author states that this genus is "easily distinguished from Laothoë by the form of the wings, the outer margin of secondaries deeply excavated below the apex, and the secondaries narrow and not denticulated." Here again we have a clashing of the results arrived at by a study of the ontogeny of the larvæ, on the one hand, and the founding of genera on the characters of the imagines 
after fourteen days (beginning of July) the young larvæ emerge. These are also of a light green colour, and are conspicuous for the great length of the caudal horn, which is nearly half as long as the body. This horn is likewise of a light green at first, but becomes dark violet in the course of an hour. No trace of any markings can be detected at this stage.

As soon as the caterpillars are hatched they commence to nibble the empty egg shells; then they run about with great activity, and after several hours take up their position on the largest vein on the under side of the lime leaves, where they remain for a long period. In this situation they have the same form and colour as the leafvein, and are very difficult to discover, which would not be the case if they reposed obliquely or transversely to the vein. In about 4-5 days the caterpillars undergo their first moult, and enter upon the second stage. On each side of the segments II-4, there now appear seven oblique whitish stripes on a somewhat darker

only, on the other. Of the three species discussed by Dr. Weismann, Mr. Butler, following other authors, refers Tilia to the genus Mimas, Populi to Laothoë, and Ocellatus to Smerinthus. It is to be hoped that when our knowledge of the developmental history of larvæ is more complete in all groups, a reconciliation between the results of the biological investigator and the pure systematist will be brought about, so that a genus may not, as at present, have such very different values when regarded from these two points of view. R.M.] 
green ground; these slope in the direction of the caudal horn. Owing to the transparency of the skin, a dark green dorsal line appears in the position of the underlying dorsal vessel, the green contents of the alimentary canal being distinctly visible through the absence of adipose matter in the tissues. The larvæ possess also a fine whitish subdorsal line, which extends from the horn to the head. The horn at this stage becomes black with a yellowish red base.

In the third stage, which occurs after six or seven days, the oblique stripes appear darker, and the subdorsal line disappears.

\section{Fourth Stage.}

After another period of $4-5$ days the third moult takes place, and there now commences a dimorphism which will perhaps be better designated as variability, since the two extremes are connected by transitional forms. The majority of the larvæ have, as in the preceding stage, pure white oblique stripes, but many of them possess a blood-red spot on the anterior side of the stripes, this spot showing all gradations in size and depth of colour between maximum development and a mere trace. Special interest attaches to these spots, as they are the first rudiments of the coloured border of the oblique stripes which occurs in so many Sphinx caterpillars.

In the fifth stage-the last of the larval de- 


\section{Studies in the Theory of Descent.}

velopment - the red spots become more strongly pronounced. Among eighty caterpillars from one brood there were about twenty without any red whilst the remainder were ornamented with more or less vivid blood-red spots, often large and irregular in form. In some specimens the spots had become drawn out into lines, ${ }^{29}$ forming a coloured edge to the oblique white stripes, similar to that possessed by the larva of Sphinx Ligustri. The caterpillar is thus represented in many figures, but generally the coloured stripe is made too regular, as in reality it is always irregularly defined above, and never so sharp and even as in Sphinx Ligustri. The character is here obviously not yet perfected, but is still in a state of development.

\section{Smerinthus Populi, Linn.}

From green spherical eggs there emerged larvæ 6.5 millimeters in length without any markings. They were of a light greenish-white, the large head and long caudal horn being of the same colour. The posterior boundary of the segments appears as a light shining ring (P1. VI. Fig. 55).

The characteristic markings of the genus appear on the following day without the occurrence of any moult : seven oblique white stripes arise from near the dorsal line, and extend along the sides in a direction parallel to that of the horn. On the three front segments they are represented only by

${ }^{2 y}$ The caterpillar is thus figured by Rösel. 
three small white spots (Fig. 56). The caterpillar likewise possesses a marking of which the adult species of the genus retain only a trace, viz., a well-developed, pure white subdorsal line, which is crossed by the six anterior oblique stripes, and uniting with the upper part of the seventh extends to the caudal horn.

I long believed that the markings described were first acquired in the second stage, as I was possessed with the generally accepted idea that the changes of form and colour in insects could only occur at the period of ecdysis. I at first thought that the moult had escaped my notice, and I was only undeceived by close observation of individual specimens.

\section{Second Stage.}

The first moult took place after five days, the larvæ being 1.4 centimeters in length. Only unimportant changes of marking are connected therewith. The subdorsal line loses much in thickness and definition, and the first and last of the oblique stripes become considerably broader than the intermediate ones (Fig. 57). The green ground colour and also the stripes acquire a yellowish hue.

On the other hand, there occur changes in form. The head, which was at first rounded, becomes of the characteristic triangular shape, with the apex upwards, common to all the species of the genus, 
and at the same time acquires two white lines, which unite above at the apex of the angle. The shagreening of the skin now also takes place, and the red spot at the base of the horn is formed.

There appears to be at this stage a general tendency for the suffusion of red, the thoracic legs also becoming of this colour.

\section{Third Stage.}

The second moult occurs after six or eight days, the marking only changing to the extent of the subdorsal line becoming still more indistinct. This line can now only be distinctly recognized on the three front segments in a few individuals, whilst in the majority it is completely absent. Sometimes the ferruginous red spots on the oblique stripes now appear, but this character is not completely developed till the fifth stage. - Out.of about ninety bred specimens in which I followed the entire development, only one possessed such spots, and these were situated on both sides of the sixth segment.

\section{Fourth Stage.}

The third moult, which takes place after another period of six days, is not associated with any change of marking.

In this stage also I observed in one specimen (not the one just mentioned) the ferruginous spots, and again only on the sixth segment. On account of the theoretical conclusions which may be drawn 


\section{The Origin of the Markings of Caterpillars. 239}

from this localization of the spots-supposing it to be of general occurrence-it becomes of importance to institute observations with different broods, so as to investigate their first appearance, frequency, and local limitation. It appears to me very probable that, with respect to frequency and time of appearance, there would be great differences, since, in the last stage, it is just this character which shows a great variability. It would be more remarkable if it should be established that the first appearance of the spots was always limited to a certain segment; and there would then be a great analogy with the first appearance of the eye-spots in Charocampa and the ring-spots in Deilephila.

\section{Fifth Stage.}

The adult caterpillar does not differ in marking to any considerable extent from the preceding stages. The first and last stripes do not appear larger than the intermediate ones, as the latter now increase in size. Many specimens were entirely without red spots; in others they were present, but were small and inconspicuous, whilst in others again there were two spots, one above the other, of a vivid ferruginous red, these coalescing in some cases, and thus forming one spot of a considerable size. I have never seen these spots formed into a regular, linear, coloured border to the white oblique stripes-as occasionally happens in Tilic-either in living specimens, blown larvæ, or in figures. 


\section{Smerinthus Ocellatus, Linn.}

The green eggs much resemble those of Populi, as also do the newly hatched caterpillars, which, as in the case of this last species, are entirely without markings: As with Populi, the markings are formed in the course of the first stage, and are distinctly visible before the first moult. The long caudal horn is of a red colour.

After two to three days the caterpillars moult, their length then being one centimeter ; the seven beautiful oblique white stripes, and the fine white subdorsal line, are more strongly pronounced, the latter becoming broader in front. They differ from Populi in having the oblique stripes united in the dorsal line.

The second moult occurs after another three days, and brings no important change; only the fine subdorsal line becoming somewhat fainter. Neither is the third moult, which takes place four days later, associated with the appearance of any essentially new character. The oblique stripes remain as before, but their upper portions now stand on a somewhat darker green ground colour, whilst the subdorsal line vanishes, leaving distinct traces only on the three or four front segments.

The fourth moult follows after a period of seven days, and my bred larvæ underwent scarcely any alteration in marking. Only small differences in coloration became perceptible in the head and 
horn, these changing to bluish. Specimens occur, although but rarely, which show in this last stage red spots in the vicinity of the oblique stripes, just in the same manner as with Populi, in which species, however, they occur more commonly. I only once found an adult larva of Ocellatus possessing reddish-brown spots above and below the oblique stripes, ${ }^{30}$ exactly as in one of the specimens figured by Rösel. ${ }^{31}$

30 [In $1879 \mathrm{Mr}$. E. Boscher found about thirty full-grown caterpillars of this species in the neighbourhood of Twickenham, ten to twelve of which were feeding on Salix viminalis, and the remainder, from a locality not far distant, on Salix triandra. The whole of the specimens taken on the plant first named, had the red-brown spots above and below the oblique stripes more or less completely developed, as I myself had an opportunity of observing. In these spotted specimens the groundcolour was bright yellowish-green, and in the others this colour was dull whitish-green above, passing into bluish-green below. Should these observations receive wider confirmation, it would be fair to conclude that this species is now in two states of phyletic development, the more advanced stage being represented by the brighter spotted variety. (See also Proc. Ent. Soc. I879, p. xliv.). Mr. Peter Cameron has recently suggested (Trans. Ent. Soc. I880, p. 69) that the reddishbrown spots on the Smerinthus caterpillars may serve for purposes of disguise, as they closely resemble, both in colour and form, certain galls (Phytoptus) of the food-plants of these species. If this view be admitted, these spots must be considered as a new character, now being developed by natural selection. The variation in the ground-colour of the two forms of $S$. Ocellatus may possibly be phytophagic, but this can only be decisively settled by a series of carefully conducted experiments. R. M.]

31 “Insekten-Belustigungen," Suppl. Pl. 38, Fig. 40. 
In this stage also there remains almost always on the three to six front segments, a more or less distinct residue of the subdorsal, which extends backwards from the head as a whitish line intersecting the foremost oblique stripes. 70, Pl. VII.)

Results of the Developmental History of Smerinthus Tilie, Populi and Ocellatus.

From the meagre materials furnished by these three obviously nearly related species, we may at least conclude that, with respect to marking, three stages of development can be distinguished:(I) Simple (green) coloration without marking; (2) subdorsal lines crossed by seven pairs of oblique stripes; (3) more or less complete absence of the subdorsal lines, the oblique stripes remaining, and showing a tendency to become edged with a red border.

Which of the three species is the oldest I will not attempt to decide. If we might venture to form any conclusion from the frequency of the red spots, Tilice would be the youngest, i.e., the species which has made the farthest advance. But this does not agree with the fact that the oblique stripes appear somewhat later in this species. Both these distinctions are, however, too unimportant to enable us to build certain conclusions on them. Neither does a comparison of the adult 
larvæ with other species of Smerinthus furnish any further information of importance.

Of the genus Smerinthus, Latr., thirty species were catalogued by Gray, ${ }^{32}$ of which I am only acquainted with the larvæ of eight (five European, and three North American). None of these in the last stage possess a complete subdorsal line together with oblique stripes. Neither, on the other hand, do any of them show a more advanced stage of development in having the red spots constantly formed into coloured border-stripes. We must therefore admit that they have all reached nearly the same stage of phyletic development. On turning to the doubtfully placed genus Calymnia, Boisduval, which is represented in Gray by only one species, figured by Westwood ${ }^{33}$ as a Smerinthus, we first meet with an older stage of development of the genus.

The adult caterpillar of $C$. Panopus, from the East Indies, possesses, in addition to the oblique stripes, a completely developed subdorsal line, ${ }^{34}$

32 "Catalogue of Lepidop." British Museum. [Butler divides the subfamily Smerinthine into I 7 genera, containing 79 species, viz. Metamimas, 2; Mimas, 4; Polyptychus, 7; Lophostethus, I ; Sphingonapiopsis, r ; Langia, 2 ; Triptogon, 23 ; Laothoë, 2 ; Cressonia, 3 ; Paonias, 2 ; Calasymbolus, 5 ; Smerinthus, 5 ; Pseudosmerinthus, 2; Daphnusa, 4; Leucophlebia, 5 ; Basiana, ro; Caquosa, r. R.M.]

${ }_{33}$ "Cabinet Orient. Entom.," p. I3, Pl. VI., Fig. 2. [Butler places this species doubtfully among, the Sphingina. R.M.] ${ }^{34}$ "Catalogue of the Lepidop. Insects of the E.I. Co.," by Horsfield and Moore. Pl. VIII., Fig. 6. 
and thus corresponds to the first stage of S. Populi. This species may possibly retain in its ontogeny a stage in which the oblique stripes are also absent, whilst the subdorsal line is present. From the early disappearance of the subdorsal line in the species of Smerinthus, we may venture to conclude that this character appeared at an early stage of the phylogeny, whilst the oblique stripes represent a secondary form of marking, as shall be further established subsequently. ${ }^{35}$

${ }^{36}$ [The larvæ of four other species of this subfamily have since been made known through Mr. Butler's figures. Smerinthus Tatarinovii, Ménetriés (loc. cit. Pl. XC., Fig. I6), from Japan, is "pale sea-green, tuberculated with white, with seven lateral, oblique, crimson-edged white stripes.". There is no trace of the subdorsal line shown in the figure, so that this species thus appears to be in the third phyletic stage of development. Smerinthus Planus, Walker, from China (loc. cit. Pl. XCII., Fig. II), is "pale green, with white or yellow lateral stripes." A trace of the subdorsal line remains on the front segments, thus showing that the species is in the second phyletic stage of development. Triptogon Roseipennis, Butler, from Hakodadi (loc. cit. Pl. XCI., Fig. 6), is represented as yellow, with seven oblique white stripes, with large irregular triangular red spots extending from the anterior edge of the stripes, nearly across each segment. It is probably in the third phyletic stage. The Indian Polyptychus Dentatus, Cramer (loc. cit. Pl. XCI., Fig. Io), is "bluish-green at the sides, with oblique purple stripes, with a broad, dorsal, longitudinal, golden-green band, bordered by subtriangular purple spots, one above each stripe." The dorsal band is bordered by coloured stripes, which may be the subdorsal lines; but the position in which it is figured, and its very different mode of coloration, make it very difficult to compare satisfactorily with the foregoing species. The genus Ambulyx is closely allied to the Smerinthina, and the two 
THE GENUS MACROGLOSSA, OCHSENHEIMER.

The adult larvæ of five species are known, and to these I can now add a sixth. In Gray the genus contains twenty-six species. ${ }^{36}$ I cannot find any figures or descriptions of the young stages of these caterpillars, and I have myself only observed the complete ontogeny of one species.

By placing a captured female $M$. Stellatarum in a capacious breeding-cage, in the open air, I was enabled to procure eggs. The moth hovered about over the flowers, and laid its small, grassgreen, spherical eggs (partly when on the wing), singly, on the leaves, buds, and stalks of Galium Mollugo. Altogether I 30 were obtained in three days. ${ }^{37}$

following species may be here mentioned: A. Gannascus, Ståll, figured by Burmeister (loc. cit. Pl. XIII., Fig. 5), is green, with a yellow subdorsal line, and seven oblique white lateral stripes, edged with red. A. Liturata, Butl. (loc. cit. Pl. XCI., Fig. 2), is yellowish-green above, passing into bluish-green below. The subdorsal is present on the three front segments, and is followed by a row of white, elongated patches, one on each segment, these being the upper portions of a row of lateral oblique stripes. The thickened upper extremities of the latter are edged with red, and their arrangement is very suggestive of their having arisen from the breaking up of a subdorsal line. R.M.]

${ }^{86}$ [Butler catalogues 43 species of this genus. R.M.]

${ }^{37}$ The deposition of eggs was accomplished by the insect laying hold of the point of a twig with its legs during flight, and curving its abdomen upwards against a leaf, the wings being kept vibrating. The egg is instantaneously fastened to the leaf. This operation is repeated from twice to four times 


\section{First Stage.}

After about eight days the caterpillars emerge. They are only two millimeters in length, and are at firstyellowish, butsoon becomegreen, set with small single bristles, and they possess a short greenish caudal horn, which afterwards becomes black. The head is greenish-yellow. The young larvæ are entirely destitute of marking. (Pl. III., Fig. I).

\section{Second Stage.}

The first moult takes place after four days, the caterpillar now acquiring the marking which it essentially retains to pupation.

Fine white subdorsal and spiracular lines appear, and at the same time a dark green dorsal line, which, however, does not arise from the deposition of pigment, as is generally the case, but from a division in the folds of the fatty tissue along this position. (Fig. 2, Pl. III.)

The colour is now dirty green in all specimens, the skin being finely shagreened.

\section{Third Stage.}

The second moult, occurring after another period of four days, does not bring any change of

successively, the moth then hovering over and sucking at the flowers for some time. The eggs exactly resemble in colour the young green buds of Galium. 
marking, the colour only becoming somewhat darker. Length, twelve millimeters.

\section{Fourth Stage.}

The third moult (after another four days) likewise brings only a change of colouring, which is of such a nature that the caterpillar becomes dimorphic. At the same time that peculiar roughening of the skin takes place which, in the case of Charocampcr, was designated as "shagreening." The colour is now light grass-green in some specimens, and dark green in others; in these last the subdorsal line is edged above with dark brown, and the spiracles are also of this colour. Length, seventeen millimeters.

\section{Fifth Stage.}

Four days later, after the fourth ecdysis, the dimorphism becomes a polymorphism. Five chief types can be distinguished :-

Variety I.-Light green (Fig. 7, P1. III.); dorsal line, blackish-green, strongly marked; subdorsal line broad, pure white, edged above with dark green; spiracular line, chrome-yellow; horn, black, with yellow tip and blue sides. Spiracles, blackish-brown, with narrow yellow border; legs, and extremities of prolegs, vermilion-red.

Variety II.-Blackish-brown (Fig. 6, P1. III.); head and prothorax, yellowish-brown; markings the same as above. 
Variety III.-Blackish-green or greenish-black (Figs. IO and II, P1. III.); subdorsal line with blackish-green border above, gradually passing into a light green ground-colour; spiracular line,chrome yellow; head and prothorax, greenish-yellow.

Variety $I V$.-Light green (Figs. 4 and I 2, Pl. III.); dorsal line quite feeble; subdorsal broad, only faintly edged with dark green; subspiracular line, faint yellowish; head and prothorax, green.

Variety $V$.-Brownish-violet (Fig. 8, P1. III.); the black dorsal line on a reddish ground either narrow or broad.

From these five varieties we see that the different types do not stand immediately next to one another; they are, in fact, connected by numerous transitional forms, the ground-colour varying greatly, being dark or light, yellowish or bluish. (Compare Figs. 4, 5, 7, and I 2.) The markings remain the same in all, but may be of very different intensities. The dorsal line is often only very feebly indicated, and the subdorsal line is frequently but faintly edged; the latter is also sometimes deep black above and bordered rather darkly beneath, the sides then being of a dark green, often with blackish dots on the yellow spiracular line (Fig. 5, Pl. III.), this likewise being frequently edged with black. Only the horn and legs are alike in all forms. The green ground-colour passes into blackish-green, greenish 
or brownish-black, and again, from reddish-brown to lilac (Fig. 3), this last being the rarest colour.

The designation "polymorphism" may here appear very inapplicable, since we have no sharply distinct forms, but five very variable groundcolours connected by numerous intermediate modes of coloration. Should, however, the term "variability" be suggested, I am in possession of an observation which tends to show that the different colours have to a certain extent become fixed. I found a brown caterpillar, the five front segments of which were light green on the left side, and the fifth segment brown and green mixed (Fig. 9, Pl. III.). Such parti-coloration can evidently only appear where we have contending characters which cannot become combined; just as in the case of hermaphrodite bees, where one half of a segment is male and the other half female, the two characters never becoming fused so as to produce a truly intermediate form. ${ }^{38}$ From this observation, I conclude that some of the chief

${ }^{23}$ [Figures of a remarkable case of gynandromorphism in a butterfly (Cirrochroa Aoris, Doubl.) have recently been published by Prof. Westwood (Trans. Ent. Soc. r880, p. Ir3). On the right fore and hind-wings of a male specimen there are patches of female colouring, thus bearing out in a very striking manner the above views concerning the non-fusibility of characters (in this case sexual) which have been long fixed. Complete (i.e. half-and-half) gynandromorphism is not uncommon in butterflies. R.M.] 
varieties of Stellatarum have already become so far removed from one another that they must be regarded as intermediate fixed forms, the colours of which no longer become fused together when they occur in one individual, but are developed in adjacent regions. Other facts agree with this conclusion. Thus, among the I 40 adult larvæ which I bred from the batch of eggs above mentioned, the transition forms were much in the minority. There were forty-nine green and sixty-three brown caterpillars, whilst only twentyeight were more or less transitional.

On these grounds I designate the phenomenon as "polymorphism," although it may not yet have reached, as such, its sharpest limits. This would be brought about by the elimination of the intermediate forms. ${ }^{39}$

39 [I have long held the opinion that the di-and trimorphism displayed by certain butterflies has originated through polymorphism from ordinary variability. I will not here enter into details, but will only cite a few instances indicating the general direction of the arguments. The phenomenon to which I refer is that so ably treated of by Mr. A. R. Wallace (see Part I., p. 32, note 18) and others. One male has often two or more distinctly coloured females, and in such cases one form of the female generally resembles the male in colour. Cases of polymorphic mimetic females may for the present be excluded, in order to reduce the argument to its greatest simplicity. Thus, in the case of native species, Colias Edusa has two females, one having the orange ground-colour of the male, and the other the well-known light form, var. Hclice. So, also, Argynnis Paphia has a normal female and the dark melanic form var. Valezina. Numerous other cases might be mentioned 
Immediately before pupation, all the caterpillars, both green and brown, acquire a lilac coloration. The fifth stage lasts seven days, and the whole larval development twenty-three days, the period from the deposition of the eggs to the appearance of the moth being only thirty-one days.

I have treated of the polymorphism of Stellatarum in detail, not only because it has hitherto remained unknown, and an analysis of such cases has been completely ignored,,$^{40}$ but more particularly because, it appears to me, that important conclusions can be drawn therefrom. Moreover,

among exotic species; and, looking at the phenomenon as a whole, it is seen to be one of gradation. For instance, our common "Blues" (Plebeius Icarus, P. Thetis, \&c.) have females showing a complete gradation between the ordinary blue male and the brown female coloration. In a large number of specimens of Callosune Eupompe in my cabinet, collected in Arabia by the late J.K. Lord, there is a completely graduated series of females, varying from individuals having the scarlet tips of the fore-wings as strongly developed as in the males, to specimens without a trace of such colouring; and the same is the case with other species of this and allied genera. In such instances it is only necessary for the intermediate female forms to become extinct, in order to have true cases of dimorphism. It is significant that in 1877 , when Colias Edusa appeared in this country in such extraordinary profusion, large numbers of intermediate forms were captured, these forming an uninterrupted series connecting the normal female and the var. Helice. R.M.]

${ }^{40}$ [Many of our best describers of caterpillars, such as the late Edward Newman, Messrs. Hellins and Buckler, \&c., have described the various forms of numerous polymorphic species, but not from the point of view of the comparative morphology and ontogeny of the markings. R.M.] 
such an extreme multiplicity of forms is interesting, since, so far as I know, polymorphism to this extent has not been observed in any insect.

The theoretical bearing of this polymorphism will be treated of subsequently. It is not in any way connected with a more advanced development of the markings, since $M$. Stellatarum shows in this respect a very low state of development. This species displays only two stages:-(I), complete absence of all markings; and (2), a simple subdorsal, with dorsal and spiracular lines. We must therefore admit that the phyletic development of the markings has for a long time remained at a standstill, or, what expresses the same thing, that the marking which the adult larva now possesses is extremely old.

In order to complete my observations on $M$. Stellatarum, I now add some remarks on the pupa, the colour variations of which it appeared of importance to investigate, owing to the extraordinary variability of the caterpillar, The pupa varies but very slightly; the ochreous yellow groundcolour sometimes passes into reddish, and sometimes into greenish; the rather complicated blackish-brown marking of streaky lines is very constant, especially on the wing portions, being at most only more or less strongly pronounced. The minute colour variations of the pupa therefore have no connection with the colour of the caterpillar, both green and brown larvæ furnishing sometimes 
reddish-yellow and sometimes greenish-yellow pupæ.

The comparison of $M$. Stellatarum with the other known species of the genus, brings scarcely any addition to our knowledge of the phyletic development. Thus, the two European species of which the caterpillars are known, viz. $M$. Fuciformis and Bombyliformis, ${ }^{41}$ show essentially the same markings as Stellatarum, the chief element being a well-developed subdorsal line. The Indian $M$. Gilia, Herrich-Schäf., possesses also this line, ${ }^{42}$ and, together with the East Indian M. Corythus, Walk., ${ }^{43}$ has oblique stripes in addition; the stripes do not, however, cross this line, but commence underneath it, and probably originated at a later period than the subdorsal line. Should this be the case, we must regard $M$. Corythus as representing a later phyletic stage. According to Duponchel's figures, in both $M$. Fuciformis and Bombyliformis small oblique stripes (red) occur near the spiracles, but these have nothing to do with the oblique stripes of $M$. Gilia just mentioned, as they run in a contrary direction. Of the two European species, I have

${ }^{41}$ [In Butler's revision both these species are placed in the genus Hemaris. $\quad$ R.M.]

42 [This species is figured also by Butler (loc. cit. P1. XC., Fig. 9), who represents it with seven oblique green lines between the spiracles and below the subdorsal line. R.M.]

43 "Cat. E. Ind. Co. Mus.," Pl. VIII., Fig. 2. [Walker, Lepidop. Heter. VIII., p. 92, No. 14,1856 ; this species is strictly confined to Java. R.M.] 
only seen the living caterpillar of Fuciformis, and this possessed no oblique stripes.

To these five species I am now enabled to add a sixth, viz. Macroglossa Croatıca, ${ }^{44}$ a species inhabiting Asia Minor and Eastern Europe, of which a specimen and notice were kindly forwarded to me by Dr. Staudinger. The adult caterpillar much resembles that of $M$. Stellatarum in form and marking, but the subdorsal line appears much less distinctly defined, and the dorsal and spiracular lines seem to be entirely absent. The colour is generally green, but varies to red, and the subdorsal is more distinct and sharper in the young than in the adult larva. 'The markings of this species do not therefore in any way surpass those of Stellatarum, but are, on the contrary, much simpler. ${ }^{45}$

4 [Eng. ed. The caterpillar is described and figured by Millière, "Iconographie des Chenilles et Lépidoptères inédits," tome iii., Paris, I869; also in the Annales, Soc. Linn. de Lyon, $\mathrm{I} 8 \mathrm{7I}$ and $\mathrm{I} 873$.$] [This sp. =Hemaris Croatica,$ Esper., of Butler's revision. R.M.]

${ }^{45}$ [The following additional species of the subfamily Macroglossine have been figured by Butler:-Lophura Hyas, Walk. (loc. cit. Pl. XC., Figs. I and 2), Hong-Kpng, Silhet, and Java. The larva is apparently figured in two stages, the younger being red-brown with oblique white stripes, and the head and three front segments green. The larger specimen is green, mottled with red-brown, and no oblique stripes. In both figures the subdorsal line is indicated. The whole colouring is very suggestive of protective resemblance. Hemaris Hylas, Linn., from China, Japan, Ceylon, India, Australia, and Africa (loc. cit. Pl. XC., Fig. 4). The upper part of the body is light blue, and the lower part 
THE GENUS PTEROGON, BOISD. ${ }^{46}$

Although I am acquainted with only a small portion of the developmental history of a single species of this genus, I will here proceed to record this fragment, since, taken in connection with two other species, it appears to me sufficient to determine, at least broadly, the direction of development which this genus has taken.

green, the two areas being separated by a white subdorsal line bordered above with brown. The dorsal line is feebly represented. Macroglossa Belis, Cram., N. India (loc. cit. Pl. XC., Fig. 6 ), is figured with the ground-colour deep indigo; a conspicuous white subdorsal, and a yellow spiracular line is present; on the side of each segment, between the two lines mentioned, there is a large red spot with a yellow nucleus (? eye-spots), the spots decreasing in size towards the head and tail; these probably confer upon this species some special protective advantage. Macroglossa Pyrrhosticta, Butler, China and Japan (loc. cit. Pl. XC., Fig. 8), is greenish-white with dorsal and subdorsal lines, and seven dark oblique stripes along the sides, below the subdorsal line. Of the foregoing species Hemaris Hyas appears to be in the same phyletic stage as M: Stellatarum and $M$. Croatica, \&c., whilst M. Pyrrhosticta is probably, together with M. Corythus and M. Gilia, in another and more advanced stage, which is also passed through by Lophura Hyas in the course of its ontogenetic development. This last species (adult) and $M$. Belis may represent phyletic stages still further advanced. Caliomma Pluto, Walk., of which the caterpillar is figured by Burmeister (loc. cit. Pl. XIII., Fig. I), appears to be a case of special protective resemblance to a twig or branch of its foodplant. Figured also by Chavannes; Bull. Soc. Vadoise des Sci. Nat., Dec. 6th I854. R.M.].

${ }^{46}$ [Genus Pterogon, Boisd., = Proserpinus and Lophura (part). Butler, loc. cit. p. 632. The species above treated of $=$ Proserpinus [Enothera, Fabr. R.M.] 
Pterogon CEnothere, Fabr.

The adult larva, as made known by many, and for the most part good figures, has very complicated markings, which do not seem derivable from any of the elements of marking in the Sphingida hitherto considered. I was therefore much surprised at finding a young caterpillar of this species, only twelve millimeters in length, of a light green colour, without any trace of the subsequent latticed marking, and with a broad white subdorsal line extending along all the twelve segments. (P1. VII., Fig. 63). Judging from the size and subsequent development, this caterpillar was probably in the third stage.

The same colouring and marking remained during the following (fourth) stage; but in the position occupied by the caudal horn in other Sphingida, there could now be observed the rudiment of a future ocellus in the form of a round yellowish spot (P1. VII., Fig. 64). The subdorsal line disappears suddenly in the fifth stage, when the larva becomes dark green (rarely) or blackish brown; the latticed marking and the small oblique stripes are also acquired, together with the beautifully developed eye-spots, consisting of a yellow mirror with black nucleus and ground-area (P1. VII., Fig. 65).

The North American Pterogon Gaurce and $P$. $A b b o t i{ }^{47}$ also show markings precisely similar to ${ }^{47}[$ These species $=$ Thyreus Abboti and Proserpinus Gaurce 
those of this European species in the adult state; but in the two former the markings are of special interest as indicating the manner in which the primary Sphinx-marking has become transformed into that of the apparently totally different adult P. Enothera. P. Gaure is green, with a complicated latticed marking, which closer observation shows to arise from the dorsal line being resolved into small black dots, whilst the subdorsal line is broken up into black, white-bordered triangles. This caterpillar therefore gives fresh support to the remarkable phenomenon that the animals as well as the plants of North America are phyletically older than the European fauna and flora, a view which also appeared similarly confirmed by Deilephila Lineata, the representative form of D. Livornica. In entire accordance with this is the fact that the larva of $P$. Gaurce is without the eye-spot on the eleventh segment, and instead thereof still shows the original although small caudal horn. The perfect insect also resembles our $P$. Enothera in colour and marking, but not in the form of the wings.

That the caterpillars of the genus Pterogon originally possessed the caudal horn we learn

of Butler's revision. Of the former he states :- " Transformations described, and larva and imago figured, Am. Ent. ii. p. 123, 1870 ; the larva is also figured by Scudder in Harris's 'Correspondence,' Pl. III., Fig. I (I 869 ), and by Packard in his 'Guide,' p. 276, Fig. 203." R.M.] 
from $P$. Gorgoniades, Hübn., ${ }^{48}$ a species now inhabiting south-east Russia, and for a knowledge of which I am indebted to Dr. Staudinger's collection. There are in this about eight blown specimens, from 3.7 to 3.9 centimeters in length, which show a marking, sometimes on a red and sometimes on a green ground, which unites this species with the young form of $P$. Enothera, viz., a broad white subdorsal line, extending from the small caudal horn to the head. In addition to this, however, the caterpillar possesses an extraordinarily broad white red-bordered infra-spiracular line, a fine white dorsal stripe, and a similar line between the subdorsal and spiracular, i.e. a supraspiracular line.

The caterpillars in Staudinger's collection, notwithstanding their small size, all belong to the last stage, as the moth itself does not measure more than 2.6 centimeters in expanse, and is therefore among the smallest of the known Sphingida. This species has therefore in the adult condition a marking very similar to that of Enothere when young-it bears to Enothera the same relationship that Deilephila Hippophaës does to D. Euphorbia, only in the present case the interval between the two species is greater. Gorgoniades is obviously a phyletically older species, as we perceive from the marking and from the possession of a horn.

${ }^{18}$ [Proserpinus (Sphinx) Gorgon, Esp. R.M.] 
We certainly do not yet know whether Enothere possesses a horn in its earliest stages, although in all probability it does so ; in any case the ancestor of Enotherce had a horn, since the closely allied $P$. Gaurce now possesses one.

We thus see that also in the genus Pterogon the marking of the caterpillars commences with a longitudinal line formed from the subdorsal; an infra-spiracular or also a supra-spiracular line (Gorgoniades) being added. A latticed marking is developed from the linear marking by the breaking up of the latter into spots or small patches, which finally (in Enotherce) become completely independent, their connection with the linear marking being no longer directly perceptible.

\section{THE GENUS SPHINX, LINN.}

Of this genus (in the narrow sense employed by Gray) I have only been able, in spite of all trouble, to obtain fertile eggs of one species. The females cannot be induced to lay in confinement, and eggs can only be obtained by chance.

I long searched in vain the literature of this subject for some account of the young stages of these caterpillars, and at length found, in a note to Rösel's work, an observation of Kleemann's on the young forms of Sphinx Ligustri, which, although far from complete, throws light on certain points.

From a female of S. Ligustri Kleemann obtained 400 fertile eggs. The caterpillars on emerging 
are "at first entirely light yellowish-green, but become greener after feeding on the fresh leaves ;" the horn is also at first light green, and then becomes "darker." The young larvæ spin webs, by which they fasten themselves to the leaves of their food-plant (this, so far as I know, has not been observed in any species of Sphingida). They moult four times, the border round the head and the purple stripes appearing after the third moult, these stripes "having previously been entirely white." The ecdyses follow at intervals of about six days, increasing to about ten days after the fourth moult. ${ }^{49}$

From this short account we gather that in the third stage the marking consists of seven oblique white stripes, which acquire coloured edges in the fourth stage, a fact which I have myself frequently observed. On the most important point Kleemann's observations unfortunately give no information--the presence or absence of a subdorsal line in the youngest stages. That he does not mention this character, can in no way be considered as a proof of its actual absence. I am rather inclined to believe that it is present in the first, and perhaps also in the second stage. There occur, however, species of the genus Sphinx (sensî strictiori) which possess a subdorsal line when young, as I think may be certainly inferred from the fact 
The Origin of the Markings of Caterpillars. 26I

that the remains of such a line are present in the adult larva of $S$. Convolvuli.

This conclusion becomes still more certain on comparing the markings with those of a nearly allied genus; without such comparison the separation of the genus Macrosila, Boisd., from Sphinx is scarcely justifiable. If to these two genera we add Dolba, Walk., and Acherontia, Ochs., we must be principally struck with the great similarity in the markings, which often reaches to such an extent that the differences between two species consist entirely in small shades of colour, while the divergence of the moths is far greater.

Of the genera mentioned, I am acquainted altogether with fourteen species of caterpillars:Macrosila Hasdrubal, Rustica, ${ }^{50}$ and Cingulata $;^{50}$ Sphinx Convolvuli, Ligustri, Carolina, ${ }^{50}$ Quinquemaculata, ${ }^{50}$ Drupiferarum, ${ }^{50}$ Kalmia, ${ }^{50}$ and Gordins ; ${ }^{50}$ Dolba Hylaus ; ${ }^{50}$ Acherontia Atropos, Styx, ${ }^{51}$ and Satanas. ${ }^{51}$ With one exception all these caterpillars possess oblique stripes of the nature of those of the Smerinthus larvæ, and most of them are without any trace of a subdorsal line; one species-the North American $M$. Cingulata-has a completely developed subdorsal; and the typical European species, $S$. Convolvuli, has a rudimentary

6o Figured and described by Abbot and Smith. [Macrosila (Sphinx) Cingulata is figured also by Burmeister, loc. cit. Pl. XII., Fig. I. R.M.]

${ }^{51}$ Figured in "Cat. Lep. E. Ind. Co." 
subdorsal line. The ground-colour in most of these species is of the same green as that of the leaves of their food-plants; some are brown, i.e. earth-coloured; and in these the markings do not appear so prominently; others again possess very striking colours ( $A$. Atropos), the oblique stripes in these cases being very vivid. Only $M$. Hasdrubal ${ }^{52}$. separates itself completely from this

52 See the figure in Sepp's Surinam Lepidoptera, P. 3, Pl. CI., I848. A specimen in alcohol of the adult caterpillar is in the Berlin Museum. [The following is the synonymy of the above mentioned species:-Macrosila Hasdrubal, Walk.= Pseudosphinx (Sphinx) Tetrio, Linn.; M. Cingulata = Protoparce (Sphinx) Cingulata, Fabr.; M. Rustica $=$ Protoparce (Sphinx) Rustica, Fabr.; Sphinx Convolvuli, Linn. = Protoparce Convolvuli; S. Carolina, Linn. = P. Carolina; the other species remain in the genera, as given above. The following additional species of Sphingina and Acherontiince have been figured by Butler :--Pseudosphinx Cyrtolophia, Butl., from Madras (loc. cit. Pl. XCI., Figs. II and 13); Protoparce Orientalis, Butl., from India, China, Java, \&c. (Pl. XCI., Fig. I6); Diludia Vates, Butl. from India, \&c. (Pl. XCI., Fig. I8); Nephele Hespera, Fabr., from India, Australia, \&c. (Pl. XCI., Fig. 20); Acherontia Morta, Hübn., from Java, China, India, \&c. (Pl. XCII., Fig. 9); and A. Medusa, Butl., from nearly the same localities as the last (Pl. XCII., Fig. Io). Most of these species fall under Dr. Weismann's general remarks, so that it is unnecessary to give detailed descriptions. The most divergent marking is that of P. Cyrtolophia, which has a broad white dorsal line bordered with pink, and two large pink ovals on the back of the four anterior segments, the hindmost and larger of these being bisected by the dorsal line. In $N$. Hespera the subdorsal line is present on segments 6 to I I only, and it is highly significant that the oblique stripes are absent from these segments, but are present on the anterior segments, where the subdorsal line 


\section{The Origin of the Markings of Caterpillars. 263}

system of classification, since this species is deep black with narrow yellow rings, the horn and last segment being red.

The large and most striking caterpillar of $M$. Hasdrubal is the same which Wallace has made use of for his theory of the brilliant colours of caterpillars. The explanation of the origin of this widely divergent mode of marking could only be furnished by the ontogeny, in which one or another of the older phyletic stages will certainly have been preserved.

fails. With reference to the larva of $A$. Atropos, Mr. Mansel Weale states (Proc. Ent. Soc. I878, p. v.) that in S. Africa the ordinary form feeds generally on Solanacea, whilst the darker and rarer variety is found only on species of Lantana. The following species of these subfamilies are figured by Burmeister: Amphonyx Jatropha (loc. cit. Pl. XI., Fig. I); Protoparce (Diludia) Florestan, Cram. (Fig. 2); Sphinx Justicia, Walk. (Fig. 3); Protoparce (Diludia) Lichenea, Walk.(Fig. 4); Sphinx (Protoparce) Cingulata, Fabr. (Pl. XII., Fig. I); and Sphinx Cestri (Fig. 5). All these species have the characteristic Sphinx-like markings. Dilophonota Ello, Linn. (Pl. XII., Fig. 2), is greenish-brown with a yellow subdorsal line, and $D$. Hippothöon (Fig. 4), yellow with a whitish subdorsal. Neither of these has oblique stripes. D. Enotrus, Cram. (Fig. 3), has neither stripes nor subdorsal, but is uniform brown above, passing into green beneath. Protoparce Albiplaga, Walk. (Pl. XIII., Fig. 2, also Mérian, Pl. III., and Abbot and Smith, I., Pl. XXIV.), pale green with large yellow, black-bordered patches surrounding the spiracles. Pseudosphinx Tetrio, Linn. (Pl. XIII., Fig. 3), and P. Scyron (Fig. 4) are black with broad transverse belts, yellow and white respectively, encircling the middle of each segment. These light bands serve very effectively to break up the uniform surface of the large bodies of these insects. R.M.] 
Strictly speaking the same should be said of the other species-nevertheless their comparison with the so similarly marked Smerinthince, together with the circumstance that in certain species a subdorsal line can be traced, makes it appear correct to suppose that here also the subdorsal was the primary marking, this line being subsequently entirely replaced by the oblique stripes. The Sphingince would therefore be a younger group than the Smerinthince, a conclusion which is borne out by the fact that in the former the oblique stripes have reached a higher development, being always of two, and sometimes even of three colours (S. Drupiferarum, white, red, black), whilst in the species of Smerinthus they only occasionally possess uniformly coloured borders.

\section{THE GENUS ANCERYX, BOISD.}

Although this genus is not admitted into most of the European catalogues-the solitary European species representing it being referred to the genus Sphinx, Linn..$^{53}$ - its separation from Sphinx appears to me to be justified, not because of the striking differences presented by the moths, but because the caterpillars, judging from the little we know of them, likewise show a similar degree of difference.

${ }^{53}$ [The species referred to is placed by Butler in Hübner's genus Hyloicus. $\quad$ R.M.] 


\section{The Origin of the Markings of Caterpillars. 265}

I have frequently succeeded in obtaining fertile eggs of Anceryx Pinastri and I will now give the developmental history of this caterpillar, which has already been figured with great accuracy in Ratzeburg's excellent work on forest insects. Rösel was acquainted with the fact that the " pine moth" laid its eggs singly on the needles of the pine in June and July, and he described them as "yellowish, shining, oval, and of the size of a millet seed."

On emerging, the caterpillars are six millimeters in length, of a light yellow colour, the head shining black with a yellow clypeus. The caudal horn, which is forked at the tip, is also at first yellowish, but soon becomes black. No particular marking is as yet present, but a reddish stripe extends along the region of the dorsal vessel, and the course of the spiracles is also marked by an orangered line. (Fig. 53, A \& B, Pl. VI.)

As soon as the young larvæ are filled with food they acquire a greenish streak. The first moult occurs after four days, and immediately after this there is still an absence of distinct markings, with the exception of a greenish-white spiracular line. In the course of some hours, however, the original light green ground-colour becomes darker, and at the same time a sharp, greenish-white subdorsal line appears, together with a parallel line extending above the spiracles, which, in Pterogon Gorgoniades, has already been designated as the "supra-spiracular." The dorsal line is absent: 
the head is light green, with two narrow blackish brown lines surrounding the clypeus; the horn and thoracic legs are black; claspers, reddish green; length, twelve to thirteen millimeters. (Fig. 54.)

\section{Third Stage.}

After another period of four days the second moult occurs, neither colour nor marking being thereby affected. Only the horn, now no longer forked, becomes brownish with a black tip. The young caterpillars are now, as before, admirably adapted to the pine needles, on which they feed by day, and from which they can only be distinguished with difficulty.

\section{Fourth Stage.}

The third moult also brings no essential change. The ground-colour and marking remain the same, only the spiracles, which were formerly dull yellowish, are now of a vivid brick-red. The horn becomes yellowish-red at the base.

\section{Fifth Stage.}

The marking is only completely changed in the fifth and last stage. A broad reddish-brown dorsal line replaces the subdorsal, more or less completely. The supra-spiracular line also becomes broken up into numerous short lengths, whilst the green ground-colour in some specimens becomes more or 
less replaced by a brownish shade extending from the back to the sides. Horn, black; the upper part of the first segment with a corneous plate, similar to that of the Deilephila larvæ.

This stage is very variable, as shown by the figures in various works. The variations arise on the one hand from the struggle between the green ground-colour and the reddish-brown extending from above, and, on the other hand, from a more or less complete disappearance of the associated longitudinal lines. The latter are sometimes completely retained, this being the case in a caterpillar figured by Hübner (Sphinges, III., Legitime C, b), where both the subdorsal and supra-spiracular lines are continuous from segment I I to segment I, an instance which may perhaps be regarded as a reversion to the primary form.

The entire change of the marking from the fourth to the fifth stage depends upon the fact that the young larvæ resemble the needles of the pine, whilst the adults are adapted to the branches. I shall return to this later.

The ontogeny of $A$. Pinastri makes us acquainted with three different forms of marking : (I) simple coloration without marking; (2) a marking composed of three pairs of parallel longitudinal lines; (3) a complicated marking, arising from the breaking up of the last and the addition of a darker dorsal line.

Of the fourteen species placed by Gray in the 
genus Anceryx, I find, in addition to the one described, notices of only two caterpillars :-

A. Coniferarum, ${ }^{54}$ a North American species, lives on Pinus Palustris, and was figured by Abbot and Smith. Colour and marking very similar to A. Pinastri.

A. Ello, Linn., ${ }^{55}$ according to the authority of Mérian, is described by Clemens ${ }^{56}$ as dark brown, " with a white dorsal line, and irregular white spots on the sides." It lives on a "species of Psidium or Guava."

Most of the species of Anceryx appear to live on Coniferce, to which they show a general and decided adaptation. In the absence of decisive information, I partly infer this from the names, as Anceryx Juniperi (Africa). It has long been known that in our $A$. Pinastri the mixture of brown and fir-green, interspersed with conspicuous irregular light yellowish and white spots, causes the adult larva to present a very perfect adaptation to its environment. Of this caterpillar Rösel states :- "After eating it remains motionless, and is then difficult to see, because it is of the same colour as its food, since its brown dorsal line has almost the colour of the pine twigs; and who

\footnotetext{
64 [ = Ellema Coniferarum, of Butler's revision. R.M.]

${ }^{55}$ [= Dilophonota Ello of Butler's revision. R.M.]

60 "Synopsis of the North American Sphingides." Philadelphia,
} 1859. 
The Origin of the Markings of Caterpillars. 269

is not familiar with the fact that beneath the green needles there is also much yellow to be found?"

This adaptation to the needles and twigs obviously explains why this caterpillar in the adult condition is so far removed from those of the genus Sphinx, while the moths are so nearly related that they were only separated as a distinct genus when we became acquainted with a large number of species. 


\section{II. \\ Conclusions from Phylogeny.}

THE considerations previously set forth are entirely based on Fritz Müller's and Haeckel's view, that the development of the individual presents the ancestral history in muce, the ontogeny being a condensed recapitulation of the phylogeny.

Although this law is generally true-all recent investigations on development having given it fresh confirmation-it must not be forgotten that this "recapitulation" is not only considerably abbreviated, but may also be "falsified," so that a searching examination into each particular case is very desirable.

The question thus arises, in the first place, as to whether the markings of caterpillars, so distinct at the different stages of growth, are actually to be regarded as residual markings inherited from the parent form; or whether their differences do not depend upon the fact that the caterpillar, in the course of growth, is exposed to different external conditions of life, to which it has adapted itself by assuming a different guise.

The former is undoubtedly the case. It can 
by no means be denied that the conditions of life in young caterpillars are sometimes different to those of the adults. It will, in fact, be shown later on, that in certain cases the assumption of a new guise at an advanced age actually depends upon adaptation to new conditions of life; but as a rule, the external conditions remain very similar during the development of the larva, as follows from the fact that a change of food-plant never takes place. ${ }^{1}$ We should therefore rather expect a complete similarity of marking throughout the entire larval period, instead of the great differences which we actually observe.

Different circumstances appear to me to show that the markings of young larvæ are only exceptionally due to a new adaptation, but that as a rule they depend upon heredity. In the first place, there is the fact that closely allied species, exposed to precisely similar external conditions, as, for instance, Charocampa Elpenor and Porcellus, possess exactly the same markings when young, these markings nevertheless appearing at different stages of growth. Thus, the subdorsal line first

1 [The larvæ of many moths which feed on deciduous trees during the autumn and hibernate, are stated to feed on lowgrowing plants in the spring, before the buds of their foodtrees open. On the other hand, low-plant feeders, such as Triphana Fimbria, \&c., are stated to sometimes feed at night in early spring on the buds of trees. The habits and ontugeny of these species are of special interest in connection with the present researches, and are well worthy of investigation. R.M.] 
appears in Elpenor in the second stage, whilst in Porcellus it is present during the first stage. If this line were acquired by the young larva for adapting it at this age to special conditions of life, it should appear in both species at the same stage. Since this is not the case, we may conclude that it is only an inherited character derived from the adult ancestor of the two species, and now relegated to the young stages, being (so to speak), pushed further back in one species than in the other.

But the strongest, and, as it appears to me, the most convincing proof of the purely phyletic significance of the young larval markings, is to be found in the striking regularity with which these are developed in a similar manner in all allied species, howsoever different may be their external conditions of life. In all the species of the Charocampa group (the genera Charocampa and Deilephila) the marking-no matter how different this may be in later stages-arises from the simple subdorsal line. This occurs even in species which live on the most diverse plants, and in which the markings can be of no biological importance as long as the larvæ are so small as to be only visible through a lens, and where there can be no possible imitation of leaf-stalks or veins, the leaves and caterpillars being so very distinct.

Moreover, when in the Macroglossina (the genera Macroglossa, Pterogon, and Thyreus) we 


\section{The Origin of the Markings of Caterpillars. 273}

see precisely the same simple marking (the subdorsal) line retained throughout all the stages in two genera, whilst in the Smerinthince this line vanishes at a very early stage, and in the Sphingince is only present in traces, we can give but one explanation of these facts. We have here a fragmentary series representing the phyletic development of the Sphinx-markings, which latter have arisen from one original plan-the simple subdorsal line-and have then undergone further development in various directions. As this subsequent development advanced, the older phyletic stages would always be relegated to younger ontogenetic stages, until finally they would be but feebly represented even in the youngest stage $(D$. Euphorbia), or else entirely eliminated (most of the species of the genus Sphinx). I believe that no other sufficient explanation of these facts can be adduced. Granting that the correctness of the above views can no longer be doubted, we may now take up the certain position that the ontogeny of larval markings reveals their phylogeny, more or less completely, according to the number of phyletic stages omitted, or, in some exceptional cases, falsified. In other words, the ontogeny of larval markings is a more or less condensed and occasionally falsified recapitulation of the phylogeny.

Considering this to be established, we have next to deal with the uniformity of the develop- 


\section{Studies in the Theory of Descent.}

mental phenomena, from which we may then attempt to trace out the inciting causes underlying this development.

The law, or, perhaps better, the line of direction followed by the development, is essentially the following :-

I. The development commences with a state of simplicity, and advances gradually to one of complexity.

2. New characters first make their appearance in the last stage of the ontogeny.

3. Such characters then become gradually carried back to the earlier ontogenetic stages, thus displacing the older characters, until the latter disappear completely.

The first of these laws appears almost selfevident. Whenever we speak of development, we conceive a progression from the simple to the complex. This result therefore does nothing but confirm the observation, that we have actually here before us a development in the true sense of the word, and not simply a succession of different independent conditions.

The two following laws, on the other hand, lay claim to a greater importance. They are not now enunciated for the first time, but were deduced some years ago by Würtemberger ${ }^{2}$ from a study

2 "Neuer Beitrag zum geologischen Beweise der Darwin'schen Thecrie." r873, Nos. $x$ and 2. [This principle, in common with many others which have only been completely worked out 


\section{The Origin of the Markings of Caterpillars. 275}

of the ammonites. In this case also the new characters predominate in the later periods of life, and are then transferred back to the younger ontogenetic stages in the course of phyletic development. "The change in the character of the shell in ammonites, first makes itself conspicuous in the last chamber; but in the succeeding generations this change continually recedes towards the beginning of the spiral chambers, until it prevails throughout the greater part of the convolutions."

In the same sense must also be conceived the case which Neumayr and Paul have recently made known respecting certain forms of Melanopsis from the West Sclavonian Paludina bed. In $M$. Recurrens the last convolutions of the shell are smooth, this being a new character; the small upper convolutions, however, are delicately ribbed, as is also the case with the last convolution of the immediate progenitor. The embryonic con-

of late years, is foreshadowed by Darwin. Thus, he states when speaking of inheritance at corresponding periods of life : "I could give a good many cases of variations (taking the word in the largest sense) which have supervened at an earlier age in the child than in the parent" ("Origin of Species," Ist ed., I860, p. 444). In the case of inherited diseases also : "It is impossible to . . . doubt that there is a strong tendency to inheritance in disease at corresponding periods of life. When the rule fails, the disease is apt to come on earlier in the child than in the parent; the exceptions in the other direction being very much rarer." ("Variation of Animals and Plants under Domestication," Ist ed., I868, vol. ii., p. 83.) R.M.] 
volutions again are smooth, and the author believes (on other grounds) that the more remote progenitor possessed a smooth shell.

In this case therefore, and in that of the ammonites, every shell to a certain extent proclaims the ancestral history of the species ; in one and the same shell we find different phyletic stages brought into proximity. The markings of caterpillars do not offer similar facilities; nevertheless I believe that by their means we are led somewhat further, and are able to enter more deeply into the causes underlying the processes of transformation, because we can here observe the living creature, and are thus enabled to study its life-history with more precision than is possible with a fossil species.

When, in 1873 , I received Würtemberger's memoir, I was not only struck with the agreement of his chief results with those which I had arrived at by the study of larval markings, but I was almost as much astonished at the great difference in the interpretation of the facts. The latter indicate the gradual backward transference of a new character from the latest to the earlier ontogenetic stages. Without further confirmation Würtemberger assumes that it is to a certain extent self-evident that the force producing this backward transference is the same as that which, according to his view, first called forth the character in question in the last stage, viz., natural selection. "Variations acquired at an advanced 
age of the organism may, when advantageous, be inherited by the succeeding generations, in such a manner that they always appear a little earlier than in the preceding generations."

It is certainly theoretically conceivable that a newly acquired character, when also advantageous to the earlier stages, might be gradually transferred to these stages, since in this case those individuals in which this character appeared earliest would have the greatest chance of surviving. In the case of the development of larval markings, however, there are facts which appear to me to show that such backward transference of a new character is, in a certain measure, independent of the principle of utility, and that it must therefore be referred to another cause-to the innate law of growth which rules every organism.

When, in the larva of $C$. Elpenor, we perceive that the two eye-spots which are first formed on the fourth and fifth segments appear subsequently on the other segments as faint traces of no biological value whatever, we cannot explain this phenomenon by natural selection. We should rather say that in segmented animals there is a tendency for similar characters to be repeated on all the segments; and this simply amounts to the statement, that an innate law of growth is necessary for the repetition of such newly acquired characters.

The existence of such a law of growth, acting 
independently of natural selection, may therefore be considered as established, and indeed cannot be disputed (Darwın's “correlation of growth"). In the present case it appears to me that an innate law of this kind, determining the backward transference of new characters, is deducible from the instances already :quoted in another sense, viz., from the fact that in many cases characters which are decidedly advantageous to the adult are transferred to the younger stages, where they are at most of but indifferent value, and can certainly be of no direct advantage. This is the case with the oblique stripes of Smerinthus, which, in the adult larvæ, resemble the leaf ribs, as will be shown more fully later on, and, in conjunction with the green coloration, cause these caterpillars to be very difficult of detection on their food-plants. The insects are easily overlooked, and can only be distinctly recognized on close inspection.

Now these oblique stripes appear, in all the Smerinthus caterpillars known to me, in the second, and sometimes even in the first stage, i.e. in larvæ of from 0.7 to I centimeter in length. The stripes are here much closer together than the ribs of any of the leaves of either willow, poplar, or lime, and can therefore have no resemblance to these leaves. The young caterpillars are certainly not rendered more conspicuous by the oblique stripes, since they can only be recognized on close inspection. It is for this reason that the stripes have not been eliminated by natural selection. 


\section{The Origin of the Markings of Caterpillars. 279}

The remarkable phenomenon of the backward transference of newly acquired characters may therefore be formulated as follows:-Changes which have arisen in the later ontogenetic stages have a tendency to be transferred back to the younger stages in the course of phyletic development.

The facts of development already recorded furnish numerous proofs that this transference occurs gradually, and step by step, taking the same course as that which led to the first establishment of the new character in the final ontogenetic stage.

Did this law not obtain, the ontogeny would lose much of the interest which it now possesses for us. It would then be no longer possible, from the ontogenetic course of development of an organ or of a character, to draw a conclusion as to its phylogeny. If, for instance, the eye-spots of the Charocampa larvæ, which must have been acquired at a late age, were transferred back to the younger ontogenetic stages in the course of phyletic development, as eye-spots already perfected, and not showing their rudimentary commencement as indentations of the subdorsal line, the phenomenon would then give us no information as to the manner of their formation.

It is well known to all who have studied the developmental history of any group of animals, that no organ, or no character, however complex, 
appears suddenly in the ontogeny; whereas, on the other hand, it appears certain that new, or more advanced, but simpler characters, predominate in the last stage of development. We are thus led to the following modification of the foregoing conclusion:-Newly acquired characters undergo, as a whole, backward transference, by which means they are to a certain extent displaced from the final ontogenetic stage by characters which appear later.

This must be a purely mechanical process, depending on that innate law of growth, the action of which we may observe without being able to explain fully. Under certain conditions the operation of this law may be prevented by natural selection. Thus, for instance, if the young caterpillars of Anceryx Pinastri have not acquired the characteristic marking of the adults, it is probably because they are better protected by their resemblance to the green pine-needles than they would be if they possessed the pattern of the larger caterpillars in their last stage.

The backward transference of newly acquired characters may also possibly be accelerated when these characters are advantageous to the younger stages; but this transference takes place quite independently of any advantage if the characters are of indifferent value, being then entirely brought about by innate laws of growth.

That new characters actually predominate in 
the last stage of the ontogeny, may also be demonstrated from the markings of caterpillars. It is, of course, not hereby implied, that throughout the whole animal kingdom new characters can only appear in the last ontogenetic stage. Haeckel is quite correct in maintaining that the power of adaptation of an organism is not restricted to any particular period. Under certain circumstances transformations may occur at any period of development ; and it is precisely insects undergoing metamorphosis that prove this point, since their larvæ differ so widely from their imagines that the earlier stages may be completely disguised. It is here only signified that, with respect to the development of caterpillars, new characters first appear in the adult. The complexity of the markings, which so frequently increases with the age of the caterpillar, can scarcely bear any other interpretation than that the new characters were always acquired in the last stage of the ontogeny. In certain cases we are able, although with some uncertainty, to catch Nature in the act of adding a new character.

I am disposed to regard the blood-red or rustred spots which occur in the last stage of the three species of Smerinthus larvæ in the neighbourhood of the oblique stripes as a case in point. It has already been shown that these red spots must be regarded as the first rudiments of the linear coloured edges which reach complete development in the 
genus Sphinx. In some specimens of Smerinthus Tilice the spots coalesce so as to form an irregular coloured edge to the oblique stripes. In S. Populi they occur in many individuals, but remain always in the spot stage; whilst $S$. Ocellatus is but seldom, and $S$. Quercus appears never to be spotted.

The spots both of S. Tilice and Populi certainly do not show themselves exclusively in the fifth (last) stage, but also in the fourth, and sometimes in Populi even as early as the third stage, from which we might be disposed to conclude that the new character did not first appear in the last stage. But the majority of the spotted individuals first acquire their spots in the fifth stage, and only a minority in the fourth; so that their occasional earlier appearance must be ascribed to the backward transference of a character acquired in the fifth stage. Moreover, the fourth and fifth stages of the caterpillars are closely analogous both in size, mode of life, and marking, and are therefore analogous with reference to the environment, so that it is to be expected that new characters, when depending on adaptation, would be rapidly transferred from the fifth stage to the fourth. ${ }^{3}$ We should

${ }^{8}$ [If the reddish-brown spots on the larva of $S$. Populi have the protective function assigned to them by Mr. Peter Cameron (Trans. Ent. Soc. 1880, p. 69), it can be readily understood that they would be of service to the insect in the fourth stage, and the backward transference of this character might thus be accelerated by natural selection, in accordance with the above principles. (See, also, note ${ }^{30}$, p. 24I.) R.M.] 
The Origin of the Markings of Caterpillars. 283

thus have a case of the acceleration by natural selection, of processes determined by innate causes. Why changes should predominate in the last stage, is a question closely connected with that of the causes of larval markings in general, and may therefore be investigated later.

But if we here assume in anticipation that all new markings depend on adaptation to the conditions of life, and arise through natural selection, it will not be difficult to draw the conclusion that such new characters must prevail in the last stage. There are two conditions favouring this view; the size of the insect, and the longer duration of the last stage. As long as the caterpillar is so small as to be entirely covered by a leaf, it only requires a good adaptation in colour in order to be completely hidden; independently of which, it is also possible that many of its foes do not consider it worth attacking at this stage. The last stage, moreover, is of considerably longer duration than any of the four preceding ones; in Deilephila Euphorbice this stage lasts for ten days, whilst the remaining stages have a duration of four days ; in Sphinx Ligustri the last stage also extends over ten days, and the others over six days.

In its last stage, therefore, a caterpillar is for a longer period exposed to the danger of being discovered by its foes; and since, at the same time, its enemies become more numerous: and its increased size makes it more easy of detection, it 


\section{Studies in the Theory of Descent.}

is readily conceivable that a change in the conditions of life, such, for instance, as removal to a new food-plant, would bring about the adaptation of the adult larva as its chief result.

I shall next proceed to show how far the assumption here made-that all markings depend on natural selection-is correct. 
The Origin of the Markings of Caterpillars. 285

\section{III.}

Biological Value of Marking in General.

HAving now described the development of larval markings, so far as possible from their external phenomena, and having traced therefrom the underlying law of development, I may next proceed to the main problem-the attempt to discover those deeper inciting causes which have produced marking in general.

The same two contingencies here present themselves as those which relate to organic life as a whole ; either the remarkably complex and apparently incomprehensible characters to which we give the name of markings owe their origin to the direct and indirect gradual action of the changing conditions of life, or else they arise from causes entirely innate in the organism itself, $i . e$. from a phyletic vital force. I have already stated in the Introduction why the markings of caterpillars appear to me such particularly favourable characters for deciding this question, or, more precisely, why these characters, above any others, appear to me to render such decision more easily 
possible; repetition is here therefore unnecessary.

The whole of the present investigation had not been planned when I joined with those who, from the first, admitted the omnipotence of natural selection as an article of faith or scientific axiom. A question which can only be solved by the inductive method cannot possibly be regarded as settled, nor can further evidence be considered unnecessary, because the first proofs favour the principle. The admission of a mysteriously working phyletic power appears very unsatisfactory to those who are striving after knowledge; the existence of this power, however, is not to be considered as disproved, because hundreds of characters can be referred to the action of natural selection, and many others to that of the direct action of the conditions of life. If the development of the organic world is to be considered as absolutely dependent on the influence of the environment, not only should we be able here and there to select at pleasure characters which appeared the most accessible for elucidating this point, but it becomes in the first place necessary to attempt to completely refer all characters belonging to any particular group of phenomena, however small this group might be, to known transforming factors. We should then see whether this were possible, or whether there would remain residual phenomena not explicable by known 
principles and compelling us to admit the existence of a force of development innate in the organism. In any case the "phyletic vital force" can only be got rid of by a process of elimination -by proving that all the characters generally occurring throughout the group of phenomena in question, must be attributed to other causes, and that consequently nothing remains for the action of the supposed phyletic vital force, which would in this manner be negatived, since we cannot infer the presence of a force if the latter exerts no action whatever.

I shall here attempt such an investigation of the group of phenomena displayed by larval markings, with special reference to those of the Sphingida. The alternatives upon which we have to decide are the following:-Are the markings of caterpillars purely morphological characters, produced entirely by internal causes? or, are they simply the response of the organism to external influences?

The solution of these questions will be arrived at by seeking to refer all the markings present to one of the known transforming factors, and the success or failure of this attempt will give the required decision. The first question to be attacked is obviously this,-whether the Sphinx-markings are actually, as they appear at first sight, purely morphological characters. If it can be shown that all these markings were originally of 
biological value, they must be attributed to the action of natural selection.

Did I here at once proceed to establish the biological. value of larval markings - and especially of those of the Sphingida-so as to arrive in this manner at a conclusion as to their dependence upon naturalselection, it would beimpossible to avoid the consideration of the total coloration of the caterpillars, since the marking frequently consists only of a local strengthening of the colour, and cannot be comprehended without coming to this understanding. The action of the markings also often appears to be opposed to that of the colouring, making the caterpillar again conspicuous; so that the two factors must necessarily be considered together. I shall therefore commence the investigation with colour in general, and then proceed to treat of marking. 
The Origin of the Markings of Caterpillars. 289

IV.

Biological Valuẽ of Colour.

THE general prevalence of protective colouring among caterpillars has already been so frequently treated of that it is not here my intention to recall particular instances. In order to judge of the effect of marking, however, it will be well to bear in mind that these insects, being generally defenceless and thus requiring protection, have acquired the most diverse means of rendering themselves in some measure secure from their foes.

The sharp spines which occur on the caterpillars of many butterflies (Vanessa, Melitca, Argynnis), and the hairs on those of many moths, serve for protective purposes. Among other means of protection-although in a different sense -we have in all the species of the great family of the Papilionida the strikingly coloured (yellowish red) odour-emitting tentacles concealed near the head, and suddenly protruded for terrifying foes; and likewise the forked horn at the tail of the caterpillars of the genus of moths Harpyia, the 
tentacles of which can be suddenly protruded in a similar manner. Adaptive colours and forms combined with certain habits ${ }^{1}$ are, however, much

${ }^{1}$ [For cases of correlation of habit with protective resemblance in larvæ, see a paper in "Ann. and Mag. of Nat. Hist.," Feb., г878, pp. ז59, 160. Also Fritz Müller on a Brazilian Cochliopod larva, Trans. Ent. Soc. I878, p. 223. Mr. Mansel Weale states, with reference to S. African Sphingida (Proc. Ent. Soc. 1878 , p. vi.), that many species when seized "have a habit of doubling up the body, and then jumping a considerable distance with a spring-like action. This is especially the case with species having eye-like markings; and it is probable that if attacked by birds in a hesitating manner, such species might effect their escape amid the grass or foliage." Many of the defensive weapons and habits of larvæ are doubtless means of protection from ichneumons and other parasitic foes. In the case of saw-flies, Mr. Peter Cameron has shown (Trans. Ent. Soc. 1878, p. 196) that the lashing about of the posterior part of the body may actually frighten away such enemies. The grotesque attitude and spider-like appearance and movements of the caterpillar of Stauropus Fagi are considered by Hermann Müller ("Kosmos," Nov., 1879, p. I23) to be means of protection from ichneumons. Among the most remarkable means of defence possessed by larvæ is that of secreting a liquid, which Mr. W. H. Edwards has shown, in the case of certain North American Lycanida ("Canadian Entomologist." vol. x., I $878, \mathrm{pp} .3-9$ and $131-136)$, to be attractive to ants, who regularly attend these caterpillars, in the same manner and for the same purpose as they do our aphides. The mutual advantage derived by the ants and larvæ was discovered in the case of Lycana Pseudargiolus. Mr. Edwards states that the mature larva of this species is singularly free from Hymenopterous and Dipterous parasites:- "Why this species, and doubtless many other Lycance, are thus favoured will, perhaps, in some degree appear from a little incident to be related. On 2 oth June, in the woods, I saw a mature larva on its food-plant; and on its back, facing towards the tail of the larva, stood motionless one 
more common than defensive weapons. Thus, the caterpillars of the Noctuce belonging to the genus Catocala and its allies, feed only at night on the green leaves of various forest-trees; by day they rest in crevices of the bark on the tree trunk, which they resemble so perfectly in the colour of their peculiar glossy dull grey or brownish skin beset with small humps, that only sharp eyes can

of the larger ants.... At less than two inches behind the larva, on the stem, was a large ichneumon-fly, watching its chance to thrust its ovipositor into the larva. I bent down the stem, and held it horizontally before me, without alarming either of the parties. The fly crawled a little nearer and rested, and again nearer, the ant making no sign. At length, after several advances, the fly turned its abdomen under and forward, thrust out its ovipositor, and strained itself to the utmost to reach its prey. The sting was just about to touch the extreme end of the larva, when the ant made a dash at the fly, which flew away, and so long as I watched-at least five minutesdid not return. The larva had been quiet all this time, its tubes out of sight, and head buried in a flower-bud, but the moment the ant rushed and the fly fled, it seemed to become aware of the danger, and thrashed about the end of its body repeatedly in great alarm. But the tubes were not protruded, as I was clearly able to see with my lens. The ant saved the larva, and it is probable that ichneumons would in no case get an opportunity to sting so long as such vigilant guards were about. It strikes me that the larvæ know their protectors, and are able and willing to reward them. The advantage is mutual, and the association is friendly always." Those who are familiar with Mr. Belt's description of the standing armies of ants kept by the "bull's-horn thorn" ("Naturalist in Nicaragua," pp. 218-222) and by certain Cecropice and Melastome, will be struck with the analogy between these and the foregoing case. R.M.] 
detect them, even when we are familiar with their habits. $^{2}$

The striking resemblance of many moths to splinters of wood is well known, and to this is added a habit which helps their disguise, viz., that of remaining stiff and motionless on the approach of danger, just like a splinter projecting from the branch. $^{3} \quad$ Among the moths coming under this category may be mentioned Cucullia Verbasci, and particularly those of the genus $X y$ lina, which, when at rest, closely resemble a broken splinter of wood in the colour and marking of their fore wings, and when touched, have a habit of drawing in their legs and falling without opening their wings as though dead.

That simple adaptive colouring prevails widely

${ }^{2}$ [The adaptive resemblance is considerably enhanced in Catocala and in Lasiocampa Quercifolia by the row of fleshy protuberances along the sides of these caterpillars, which enables them to rest on the tree trunks by day without casting a sharp shadow. The hairs along the sides of the caterpillar of Pacilocampa Populi doubtless serve the same purpose. (See a paper by Sir John Lubbock, Trans. Ent. Soc. 1878, p. 242 ; also Peter Cameron, ibid., I880, p. 75.) It is well known to collectors that one of the best methods of finding the caterpillars of the Catocale is to feel for them by day on the barks of their respective food-trees, or to beat for them at night. R.M.]

${ }^{3}$ [See Wallace's "Contributions to the Theory of Natural Selection," rst ed., p. 62. Also a paper in "Ann. Mag. Nat. Hist." Feb. 1878 , p. 159 , for cases in point. Rösel in 1746 mentioned this habit in Calocampa Exoleta. Hermann Müller has recorded many other similar instances on the authority of Dr. Speyer ; see "Kosmos," Nov., I879, p. Ir4. R.M.] 
among caterpillars is shown by the large number of green species. ${ }^{4}$ It may be fairly said that all caterpillars which possess no other means of protection or defence are adaptively coloured. These facts are now well known; so also is the explanation of the varied and striking colours of many caterpillars given by Wallace. ${ }^{5}$ There is, how-

" [Andrew Murray called attention to this fact in 1859 ("Edinburgh New Philos. Journ.," Jan., I860, p. 9). This view is also corroborated by the fact that no internal feeders are green; see note 2, p. 3 ro and Proc. Zoo. Soc. 1873, p. I59. R.M.]

${ }^{5}$ [Proc. Ent. Soc. March 4th, 1867 ; and "Contributions to the Theory of Natural Selection," Ist ed., pp. II 7-1 22 ; also Darwin's "Descent of Man," 2nd ed., p. 325. Among the most important recent additions to the subject of the colours, spines, and odours of caterpillars, I may call attention to a paper by Fritz Müller ("Kosmos," Dec., 1877), the following abstract of which I communicated to the Entomological Society (Proc. 1878, pp. vi, vii) :- " The larvæ of Dione Juno and Acrea Thalia live gregariously, and are brown in colour; they are covered with spines, but, being of dull colours, their spiny protection (which in the case of D. Juno is very imperfect) would not preserve them unless they were distinguished as inedible at the right time, and not after being seized, in accordance with the principles laid down by Mr. Wallace. It is suggested that the social habits of the larvæ, which lead them to congregate in large numbers, make up for their want of colour, since their offensive odour then gives timely warning to an approaching enemy. The caterpillars of Colanis Julia and Dione Vanille are equally wanting in bright colours, but are solitary in their habits, and these species rest on the under side of the leaf when feeding. On the other hand, the caterpillars of Heliconius Eucrate, Colanis Dido, and C. Isabella, which are of solitary habits, and which freely expose themselves, are very gaudily coloured, and there- 
ever, novelty in the proof contained in the foregoing descriptions of larval development, as to fore most conspicuous. As examples of nearly allied larvæ, of which some species are gregarious and others solitary, Fritz Müller mentions Morpho and Brassolis, which are gregarious; while Opsiphanes and Caligo are solitary. The larva of Papilio Pompeius also is gregarious, and those of $P$. Nephation, $P$. Polydamas, and $P$. Thoas are solitary..... Fritz Müller sums up his observations by remarking that those caterpillars which live alone, and lack the bright colouring as a sign of offensiveness, must hide themselves ; as those of C. Julia and $D$. Vanilla. The spiny covering is much less a protection against birds than against smaller enemies; and they may, by the protective habit of living together, diffuse around themselves an offensive atmosphere, even to man, and thus gradually becoming shorter (as with $D$. Juno), the spines of these caterpillars become useless, and finally are altogether dropped." See also Sir John Lubbock's "Note on the Colours of British Caterpillars," Trans. Ent. Soc. 1878, p. 239. Mr. Peter Cameron finds (Trans. Ent. Soc. I880, pp. 7I and 75) that these remarks are also applicable to the larvæ of certain sawflies. In $1877 \mathrm{Mr}$. J. W. Slater published a paper "On the Food of gaily-coloured Caterpillars" (Trans. Ent. Soc. I877, p. 205), in which he suggested that such caterpillars might derive their distasteful qualities from feeding on plants containing poisonous or otherwise noxious principles. A much larger number of observations will be required, however, before this view can be accepted as of general application. A beautiful illustration of the theory of warning colours is given by Belt in his "Naturalist in Nicaragua," p. 321. All the frogs found in the woods round St. Domingo are, with one exception, protectively coloured ; they are of nocturnal habits, and are devoured by snakes and birds. The exception was a species of bright red and blue colours, which hopped about by day and made no attempt at concealment. From these facts Mr. Belt concluded that this species was inedible, and on trying the experiment with ducks and fowls this was found to be the case. R.M.] 
the manner in which the di- and polymorphism of caterpillars cán be explained from the external phenomena which they present, these phenomena being well adapted for showing the great importance of protective colouring to the larvæ. We have here presented a double adaptation, although not quite of the nature of that which I formerly admitted on hypothetical grounds. ${ }^{\circ}$ In the first place, from the developmental history there results the conclusion that all Sphinx-larvæ which, in the adult state, are di- or polymorphic, are unicolorous when young. Thus, the caterpillars of Charocampa Elpenor all remain green till the fourth stage, when they mostly become light or dark brown, and only very seldom retain their green colour. Charocampa Porcellus behaves in a precisely similar manner; as also does Pterogon Enothera, which inhabits the same localities, and is found on the same food-plant, but is not very closely related to the Charocampa. In this species also ( $P$. Enothera) the brown is more common than the green form in the adult state, both varieties showing a complicated marking. The young larvæ possess only a light green colour, and a pure white subdorsal line as the only marking; they are so well adapted to the leaves of their food-plants, Epilobium Hirsutum, and $E$. Rosmarinifolium, that they can only be detected

- See the essay "Über den Einfluss der Isolirung auf die Artbilding." Leipzig, $\bullet 872$, p. 22. 
with great difficulty. After the third moult they become brown, and can be easily seen when at rest on their food-plant.

Now in all known caterpillars brown colours are adaptive, sometimes causing a resemblance to the soil, and at others to dead leaves or branches. As soon, therefore, as the caterpillars have attained a considerable size, they remain concealed by day. ${ }^{7}$ The truth of this observation not only appears from various entomological notes, but I have frequently convinced myself of its accuracy. I well remember from the earliest times that $C$. Elpenor, especially when the larva is adult, always rests by day among the dead branches and leaves of its shrub-like food-plant, Epilobium Hirsutum; and even when this species lives on the low-growing Epilobium Parviflorum, it conceals itself by day on the ground, among the tangled leaves and branches. I have observed that Sphinx Convolvuli has a precisely similar habit, for which reason it is difficult to obtain, even in localities where it occurs very commonly.

In the neighbourhood of Basle I once found at mid-day a brown caterpillar of Pterogon Enotherce on an isolated dead branch of Epilobium Rosmarinifolium, and I was informed by Herr RiggenbachStähelina-collector of great experience who accompanied me-that these caterpillars always rest (by day) on withered plants as soon as they

\footnotetext{
" [See also preceding note 5, p. 294. R.M.]
} 
become brown, but before this change they are only to be found on green plants.

Thus, it cannot well be doubted that the change of colour is associated with a change in the habits of life, and the question arises as to which has been the primary change.

If the view here entertained, that the later brown coloration is adaptive, be correct, the species must have first acquired the habit of concealing itself by day on the ground and among dead herbage, before the original green colour could have been changed into brown by natural selection. This must represent the actual facts of the case.

Nearly allied species which at an advanced age are not dimorphic, but are darkly coloured in all individuals, are especially calculated to throw some light on this point. For instance, the caterpillar of Deilephila Vespertilio, which comes under this denomination, is light green when young, and rests both by day and night on the leaves of the plant on which it feeds. As soon as it acquires its dark colour-after the third moult-it changes its habits, concealing itself by day on the ground and feeding only by night. For this reason collectors prefer seeking for it in the evening, or with a lantern by night.

The most instructive case, however, is that of Deilephila Hippophaës, in which no change of colour is associated with age, the caterpillar, 
throughout its whole life, remaining of a greyish green, which exactly matches the colour of the leaves of its food-plant, Hippophae Rhamnoides. Nevertheless this species also possesses the habit of feeding only at night as soon as it has attained to a considerable size, hiding itself by day at the root of its food-plant. Collectors expressly state that this larva can scarcely be found by day, and recommend that it should be sought for at night with a lantern.

From the foregoing facts and considerations it may fairly be concluded, that the habit of hiding by day, possessed by these and other allied caterpillars, was acquired when they resembled the leaves in colour, and that the adaptation to the colour of the soil, or dead foliage and withered branches, ensued as a secondary consequence.

But why have these caterpillars acquired such a habit, since they appear to be perfectly protected by their resemblance in colour to the green leaves? The answer to this question is easily given when we consider in which species this habit generally occurs.

Does the habit prevail only among the species of the one genus Deilephila, and in all the species of this genus? This is by no means the case, since, on the one hand, many species of Deilephila, such as D. Euphorbia, Galii, Niccea, and Dahlii, do not possess the habit, and, on the other hand, it occurs in species of other genera, such as Macro- 
glossa Stellatarum, Sphinx Convolvuli, and Acherontia Atropos.

The habit in question must therefore be the result of certain external conditions of life common to all those species which rest by day. The mode of life common to them all is that they do not live on trees with large leaves or with thick foliage, but on low plants or small-leaved shrubs, such as the Sea Buckthorn. ${ }^{8}$ I believe I do not err when I attribute the habit possessed by the adult larvæ, of concealing themselves by day, to the fact that the green colour is protective only so long as they are small-or, more precisely speaking, as long as their size does not considerably exceed that of a leaf or twig of their food-plant. When they become considerably larger, they must become conspicuous in spite of their adaptive colour, so that it would then be advantageous for them to conceal themselves by day, and to feed only by night. This habit they have acquired, and still observe, even when the secondary adaptation to the colour of the soil, \&c., has not been brought about. We learn this from $D$. Hippophaës, which

8 [Eng. ed. The habit of hiding by day occurs also in those caterpillars which resemble the bark of their food-trees. Thus Catocala Sponsa and Promissa conceal themselves by day in crevices of the bark, and are, under these circumstances, only found with difficulty. Dr. Fritz Müller also writes to me that in Brazil the caterpillars of Papilio Evander rest in this manner in large numbers, crowded together into dense masses, on the trunks of the orange-trees, which they resemble in colour.] 
remains green throughout its whole larval existence; and no less from the green forms of the adult larvæ of Sphinx Convolvuli, Charocampa Elpenor, and Porcellus, all of which conceal themselves by day in the same manner as their brown allies.

It may be objected that there are Sphinx-larvæ -instances of which I have myself adducedwhich live on low small-leaved plants, and which nevertheless do not hide themselves by day. This is the case with the spurge-feeding $D$. Euphorbice, so common in many parts of Germany. This caterpillar must, however, be classed with those which, on account of their distastefulness, or for other reasons to be subsequently considered, are rejected by birds and other larger foes, and which, as Wallace has shown, derive advantage from being coloured as vividly as possible. I shall return to this subject later, when treating of the biological value of special markings.

On the other hand, it is readily conceivable that, from the conditions of life of caterpillars living on trees or shrubs with dense foliage, the habit of resting by day and descending from the tree for concealment would not have been acquired. Such larvæ are sufficiently protected by their green colour among the large and numerous leaves; and I shall have occasion to show subsequently that their markings increase this protective resemblance.

The di- or polymorphism of the larvæ of the 
Sphingida does not therefore depend upon a contemporaneous double adaptation, but upon the replacement of an old protective colour by a new and better one, and therefore upon a successive double adaptation. The adult caterpillars of $C$. Elpenor are not sometimes brown and sometimes green because some individuals have become adapted to leaves and others to the soil, but because the anciently inherited green has not yet been completely replaced by the newly acquired brown coloration, some individuals still retaining the old green colour.

When, in another place, ${ }^{\ominus}$ I formerly stated " that a species can become adapted in this or that manner to given conditions of life, and that by no means can only one best adapted form be allowed for each species," this statement is theoretically correct speaking generally, but not in its application to the present class of cases. A comparison with one another of those caterpillars which repose by day, distinctly shows that they all possess a tendency to abandon the green and assume a dull colour, but that this process of replacement has advanced further in some species than in others. It will not be without interest to follow this operation in some detailed cases, since we may thus obtain an insight into the processes by which polymorphism has arisen, as well as into the con-

- "Über den Einfluss der Isolirung auf die Artbildung:" Leipzig, 1872 , p. 21 . 
nection between this phenomenon and simple variability.

In $D$. Hippophaës the process has either not yet commenced, or is as yet in its first rudiments. If we may trust the statements of authors, together with the ordinary green form there occurs, rarely, a silver-grey variety, which may be regarded as the beginning of a process of colour substitution. Among thirty-five living specimens of this scarce species which I was able to procure, the grey form did not occur, neither have I found it in collections.

In Macroglossa Stellatarum we see the transforming process in full operation. A large number of individuals (about thirty-five per cent.) are still green; the number of dark-coloured individuals reaches forty-six per cent., these, therefore, preponderating; whilst between the two extremes there are about nineteen per cent. of transition forms, showing all possible shades between light green and dark blackish-brown or brownishviolet, and even, in solitary individuals, pure violet (See Figs. 3-I 2, P1. III.). The relatively small number of the intermediate forms, taken in connection with the fact that all the 140 specimens employed in my investigation were obtained from one female, leads to the conclusion that these forms owe their existence to cross-breeding. It would be superfluous to attempt to prove this last conclusion with reference to the before-mentioned 
The Origin of the Markings of Caterpillars. 303

case, in which a caterpillar was streaked with brown and green (Fig. 9, P1. III.).

The process of transformation, as already mentioned, advances in such a manner that the intermediate forms diminish relatively to the dark individuals. This is found to be the case with Sphinx Convolvuli, and almost to the same extent with Charocampa Elpenor, in both of which species the green caterpillars are the rarest. ${ }^{10}$ Forms truly intermediate in colour between green and brown no longer occur, but apparently only different shades of light and dark brown, passing into brownish-black.

The process has again made a further advance in Charocampa Porcellus and Celerio as well as in Pterogon Enothera. In all these species the green form occurs, ${ }^{11}$ but so rarely that very few collectors have seen it. The brown form has therefore in these cases nearly become the predominant type, and the solitary green specimens which occasionally occur, may be regarded as reversions to an older phyletic stage.

Deilephila Livornica appears to have reached a similar stage, but the caterpillar of this species has been so imperfectly observed, that it is

${ }^{10}$ I am unfortunately not able to give exact numbers showing the relative proportions of the different forms, since I have never bred S. Convolvuli from eggs, nor C. Elpenor in sufficient numbers.

" [With reference to C. Porcellus, see note 2, p. I88. R.M.] 
difficult to determine, even approximately, the relative proportion of the brown to the green individuals. I have only seen one of the latter in Dr. Staudinger's collection (Compare Fig. 62, Pl. VII.).

In Deilephila Vespertilio, Euphorbice, Dahlii, Mauritanica, Nicaa, and Galii, the green form has completely disappeared. The blackish olivegreen colour shown by many caterpillars of the two last species, can be considered as a faint retention of the light green colour which they formerly possessed, and which they both show at the present time in their young stages.

Beginning with the appearance of single darker individuals, we pass on in the first place to a greater variability of colouring, and from this, by the greater diminution of the intermediate forms, to polymorphism; the complete extermination of these forms ending in dimorphism. The whole process of transformation has been thus effected :As the new colouring always prevailed over the old, the latter was at length completely displaced, and the caterpillars, which were at first simply variable, became polymorphic and then dimorphic, finally returning to monomorphism.

We thus see the process of transformation still going on, and no doubt can arise as to its inciting causes. When a character can with certainty be ascribed to adaptation, we can explain its origin in no other way than by the action of 


\section{The Origin of the Markings of Caterpillars. 305}

natural selection. If, as I believe, it can and has been shown, not only that caterpillars in general possess adaptive colours, but that these colours can change during the lifetime of one and the same species, in correspondence with external conditions, we must certainly gain a very high conception of the power which natural selection exerts on this group of living forms. ${ }^{12}$

12 [In the class of cases treated of in the foregoing portions of this essay, the external conditions remain unaltered during the lifetime of the caterpillar, but change of habit, and in some cases of colour, occurs when the insect has attained a size sufficient to make it conspicuous. Cases are, however conceivable $\grave{a}$ priori, and are realized by observation, in which the environment itself may undergo change during the lifetime of the individual caterpillar. Thus, in the case of hibernating species, the colour which is adaptive to the autumnal colours of the foliage of their food-trees would not assimilate to that of the newly-opened leaves in the spring. I have already quoted (Proc. Zoo. Soc. I 873, p. I 55) as instances of what may be called "seasonal adaptation," the larvæ of Geometra Papilio. naria, Acidalia Degeneraria, and Gnophos Obscurata, and many more could be named. These species undergo a change of colour before or after hibernation, the change being always adaptive to the environment.

It has long been known that caterpillars which feed on flowers or on plants of variously-coloured foliage, in some cases partake of the colour of their food. See, for instance, Dr. L. Möller's memoir, "Die Abhängigkeit der Inseckten von ihrer Umgebung," I 867, and B. D.Walsh "On Phytophagic Varieties and Phytophagic Species," Proc. Ent. Soc. Philadelph., vol. iii., p. 403. In I $869 \mathrm{Mr}$. R. McLachlan published a paper entitled "Observations on some remarkable varieties of Sterrha Sacraria, Linn., with general notes, on variation in Lepidoptera" (Trans. Ent. Soc. r865, p. 453), in which he gave many illustrations of this phenomenon. The larva of Heliothis 
Peltiger, according to Mr. Reading's description (Newman's "British Moths," p. 438), is another case in point. In I 874 a number of instances were published by Mr. Thomas G. Gentry in a paper entitled "Remarkable Variations in Coloration, Ornamentation, \&c., of certain Crepuscular and Nocturnal Lepidopterous Larvæ " "Canadian Entomologist," vol. vi., p. 85. See also W. H. Edwards' description of the summer and autumnal larvæ of Lycana Pseudargiolus; Ibid., vol. x., pp. I2, 13).

The caterpillars of the Sphingida appear also in some cases to vary in a manner very suggestive of phytophagic influences. The observations upon $S$. Ocellatus recorded in the previous note (p. 24r) may perhaps be interpreted in this sense. In order to get experimental evidence upon this subject, I may add that Mr. E. Boscher was good enough at my request to repeat his observations, and conduct some breeding experiments during the present year (1880). In the same locality as that previously mentioned, seven larvæ were found feeding on Salix. viminalis, all of which were the bright green spotted variety; and in the same osier-bed six more were found on another species of Salix, two of these being the bluish-green variety, and the other four the bright green form. Unless we have here a local race, these observations, in connection with those of last year, tend to show that the light green form is associated with Salix viminalis. When found in the natural state feeding on apple, the caterpillar of this species is generally, perhaps invariably, the bluish-green form. In order to try the effect of breeding the larvæ $a b$ ovo on distinct food-plants, a large number of eggs laid by a female Ocellatus in July were divided into three batches, one being supplied with Salix triandra, another with $S$. viminalis, and the third lot with apple. The experiment unfortunately failed in great part, owing to most of the larvæ dying off, three from the third lot only surviving; but these were all of the bluish-green form, which colour was shown by all the caterpillars of this batch from their earliest stage. The observation is thus so far successful, as it goes to support the view that the variety mentioned is associated with apple (and $S$. triandra?) My friend Mr. W. J. Argent informs me that he had a number of specimens of Sphinx 


\section{The Origin of the Markings of Caterpillars. 307}

Ligustri in his possession this autumn, some of which had been found on lilac and others on laurestinus, and he states that all those on the latter plant had the ground-colour distinctly darker than in those feeding on lilac. I learn also from Mr. W. Davis, of Dartford, that he found a number of these larvæ this year feeding on ash, and that they were all differently coloured to those found on lilac or privet, being of a more greyish-green. Another case of colour-variation in larvæ is that Emmelesia Unifasciata, specimens of which I have recently had an opportunity of examining, through the courtesy of Mr. W. Davis. This species feeds on the seeds of a species of Bartsia when the capsules are in various stages of growth, and (omitting details of marking) those caterpillars found on the green capsules were green, whilst those on the brown capsules were of a corresponding colour.

On the whole I am inclined to believe that sufficient importance has not hitherto been given to phytophagic variability as a factor in determining larval coloration, and a large field for experimental investigation here lies open for future work. The obscure chemico-physiological processes which may perhaps be shown by such researches to lead to phytophagic variation, cannot, I am persuaded, produce any great divergence of character if unaided; but when such causes of variability play into the hands of natural selection variations of direct protective advantage to the species, we can easily see that this allimportant agency would seize upon and perpetuate such a power of adaptability to a variable environment. (See Proc. Zoo. Soc. I873, p, I 58, and "Nature," vol. xiv., pp. 329 and 33o. R.M.] 


\section{V.}

Biological Value of Special Markings.

THE following questions now present themselves: Have the markings of caterpillars any biological value, or are they in a measure only sports of nature? Can they be considered as partially or entirely the result of natural selection, or has this agency had no share in their production?

The problem here offers itself more distinctly than in any other group of living forms, because it presents an alternative without a third possibility. In other words, if it is not possible to show that larval markings have a distinct biological significance, there remains only for their explanation the assumption of a phyletic force, since the direct action of the environment is insufficient to account for such regularity of development throughout a series of forms. The explanation by sexual selection is excluded $a b$ initio, since we are here concerned with larvæ, and not with reproductive forms. ${ }^{1}$

${ }^{1}$ [In 1879 Mr. George Francis, of Adelaide, forwarded from the latter place a number of moths (a species of Anapcea) 


\section{The Origin of the Markings of Caterpillars. 309}

The biological significance of marking-if such significance it possess-will be most easily investigated by examining whether species with similar markings have any conditions of life in common which would permit of any possible inference as to the significance of the markings.

Among the Sphingida we find four chief forms of marking ; (I) complete absence of all marking ; (2) longitudinal stripes; either a simple subdorsal or this together with a spiracular and dorsal line; (3) oblique stripes; (4) eye-spots and ring-spots, single, paired, or in complete rows.

Now if we consider in which species these four kinds of marking are of general occurrence, not together with their larvæ (in alcohol) and cocoons (Proc. Ent. Soc. 1879 , p. xvi), and in an accompanying note he stated that the male larva when living is of "a bright emerald green, with red and pink markings on the back, and yellow, black, and white streaks on the sides." The male larva is described as being smaller than the female, and as possessing all the brilliant colours, the latter "having no red markings, but only white, yellow, and green, with a little black." I was at first disposed to think that we might be dealing here with two distinct species having differently marked larvæ; but Mr. Francis this present year (1880) forwarded a large number of the living cocoons of this species, which I separated according to size, and, on the emergence of the moths (August), I found that all those from the small cocoons were males, and those from the larger cocoons females. There can be no doubt, therefore, that we have but one species in this case, the larva of which presents the remarkable phenomenon of sexual difference of coloration. As an analogous fact I may here mention the well-known case of Orgyia Antiqua, the larva of which differs in the colour of the tufts of hair according to sex. R.M.] 
only in the small group of the Sphingida but in the whole order Lepidoptera, we shall arrive at the following results:-

I. Complete absence of marking, so common in the larvæ of other insects, such as the Coleoptera, is but seldom found among Lepidopterous caterpillars.

To this category belong all the species of Sesiida (the genera Sesia, Trochilia, Sciapteron, Bembecia, \&c.), the larvæ of which, without exception, are of a whitish or yellowish colour, and live partly in the wood of trees and shrubs and partly in the shoots of herbaceous plants. Subterranean larvæ also, living at the roots of plants, such as Hepialus Humuli at the roots of hop, and H. Lupulinus at those of Triticum Repens, possess neither colour nor marking. These, like the foregoing, are yellowish-white, evidently because they are deprived of the influence of light. ${ }^{2}$ The larvæ of

2 [I have already given reasons for suspecting that the colour of green caterpillars may be due to the presence of chlorophyll (or some derivative thereof) in their tissues (see Proc. Zoo. Soc. 1873, p. I59). This substance appears to be one of great chemical stability, and, according to Chautard, who has detected it in an unaltered state in the tissues of certain leaf-feeding insects by means of its absorption spectrum ("Comp. Rend." Jan. I $3^{\text {th }}$, I $_{73}$ ), it resists the animal digestive processes (Ann. Ch. Phys. [5], iii., I-56). If this view should be established by future observations, we must regard the green colour of caterpillars as having been produced, when protective, from phytophagic variability by the action of natural selection; and the absence of colour in internal feeders, above referred to, 
certain small moths, such as Tortrix Arbutana and Pomonana, which live in fruit, and many casebearing Tineina, are likewise without marking and devoid of bright colour, being generally whitish.

Many of the small caterpillars which feed exteriorly are also-so far as my experience extendswithout definite markings, these being among the most minute, such as the greenish leaf-mining species of Nepticula. It is among the larger species that we first meet with longitudinal and oblique stripes. Eye-spots do not occur in any of these larvæ, a circumstance of the greatest importance for the biological significance of this character, as will be shown subsequently. The small size of the caterpillars cannot be the sole cause of the absence of such eye-spots, since in young Smerinthus caterpillars one centimeter long, the oblique stripes are beautifully developed, and the larvæ of many of the smaller moths considerably exceed this size. The surface of these caterpillars therefore, i.e., the field on which markings are displayed, is not absolutely too small for the development of such a character.

is only secondarily due to the exclusion of light, and depends primarily on the absence of chlorophyll in their food. In connection with this I may adduce the fact, that some few species of Nepticula (N. Oxyacanthella, N. Viscerella, \&c.) are green, although they live in leaf-galleries where this colour can hardly be of use as a protection; but their food (hawthorn and elm) contains chlorophyll. See also note 2, p. 293. Further investigations in this direction are much needed. R.M.] 
Besides the larvæ of the Micro-lepidoptera and of those species living in the dark, there is also a complete absence of marking in the young stages of many caterpillars. Thus, all the Sphingida of which I have been able to observe the development, show no markings immediately after emergence from the egg; in many they appear very soon, even before the first moult, and, in other species, after this period.

2. The second category of markings, longitudinal stripes, is very widely distributed among the most diverse families. This character is found among the larvæ of butterflies, Sphingida, Noctuce, Microlepidoptera, \&c., but in all these groups it is absent in many species. This last fact is opposed to the view that this character is purely morphological, and leads to the supposition that it may have a biological value, being of service for the preservation of the individual, and therefore of the species.

I find that such marking is of service, stripes extending longitudinally along the upper surface of the caterpillar generally making the latter less conspicuous. This, of course, does not hold good under all circumstances, since there are many species with very striking colours which possesss longitudinal stripes. Let us consider, however, a case of adaptive colouring, such as a green caterpillar, which, on this account only, is difficult to see, since it accords with the colour of the plant 


\section{The Origin of the Markings of Caterpillars. 3 I 3}

on which it lives. If it is a small caterpillar, i.e., if its length and thickness do not considerably exceed that of the parts of its food-plant, it can scarcely be better concealed-stripes would hardly confer any special advantage unless the parts of the plant were also striped. But the case is quite different if the caterpillar is considerably. larger than the parts of the plant (leaves, stalks, \&c.). The most perfect adaptive colouring would not now prevent it from standing out conspicuously as a larger body, among the surrounding parts of the plants. It must be distinctly advantageous therefore to such a caterpillar to be striped, since these markings to a certain extent divide the large body into several longitudinal portions - they no longer permit it to be seen as a whole, and thus act more effectively than mere assimilative colouring in causing it to escape detection. This protection would be the more efficacious if the stripes resembled the parts of the plant in colour and size, such, for instance, as the lines of light and shadow produced by stalks or by long and sharp-edged leaves,

If this view be correct, we should expect longitudinal stripes to be absent in the smallest caterpillars, and to be present more especially in those species which live on plants with their parts similarly disposed, i.e., on plants with numerous thin, closely-growing stalks and grass-like leaves, or on plants with needle-shaped leaves. 
It has already been mentioned that the smallest species are devoid of longitudinal striping. The larvæ of the Micro-lepidoptera show no such marking, even when they do not live in the dark, but feed either on the surface or in superficial galleries of the leaves (Nepticula, \&c.), in which they must be exposed to almost as much light as when living on the surface. The fact that the subdorsal line sometimes appears in very young Sphinx-larvæ is explained, as has already been shown, by the gradual backward transference of adaptational characters acquired in the last stage of development.

It can easily be demonstrated that longitudinally striped caterpillars mostly live on plants, of which the general appearance gives the impression of a striped arrangement. We have only to consider in connection with their mode of life, any large group of adaptively coloured species marked in this manner. Thus, among the butterflies, nearly all the Satyrince possess larvæ conspicuously striped-a fact which is readily explicable, because all these caterpillars live on grasses. This is the case with the genera Melanargia, Erebia, Satyrus, Pararge, Epinephele, and Canonympha, no species of which, so far as the larvæ are known, is without longitudinal stripes, and all of which feed on grasses. It is interesting that here also, as in certain Sphingide, some species are brown, i.e., adapted to the soil, whilst the majority are green, 


\section{The Origin of the Markings of Caterpillars. 315}

and are therefore adapted to living grass. Just as in the case of the Sphingida also, the brown species conceal themselves by day on the earth, whilst some of the green species have likewise acquired this habit. I have already shown how this habit originates from the increasing size of the growing larva, which would otherwise become too conspicuous, in spite of adaptive colour and marking, A beautiful confirmation of this view is found in the circumstance that only the largest species of Satyrus, such as $S$. Proserpinus, Hermione, Phcedrus, \&c., possess brown caterpillars. I should not be surprised if a more exact investigation of these species, which have hitherto been but seldom observed, revealed in some cases a dimorphism similar to that of the Sphingida; and I believe that I may venture to predict that the young stages of all these brown larvæ-at present quite unknown-are, as in the last-named group, green.

Besides the Satyrince, most of the larvæ of the Pierince and Hesperide possess longitudinal stripes, which are generally less strongly pronounced than in the former subfamily. Some of the Pierine live on Cruciferce, of which the narrow leaves and thin leaf- and flower-stalks present nothing but a linear arrangement; other species of this group, however, feed on Leguminosa (Lathyrus, Lotus, Coronilla, Vicia), and some few on broad-leaved bushes (Rhammus). This last fact may appear to be 
opposed to the theory; but light lateral stripes, such for example, as those possessed by Gonepteryx Rhamni, can never be disadvantageous, and may be of use, even on large leaves, so that if we consider them as an inherited character, there is no reason for natural selection to eliminate them. In the case of caterpillars living on vetch, clover, and other Leguminosa, it must not be forgotten that, although their food-plants do not present any longitudinal arrangement of parts, they always grow among grasses, the species feeding on such plants always resting between grass stems, and very frequently on the grass itself, so that they can have no better protective marking than longitudinal stripes. The striping of the Hesperide larvæ, which partly feed on grasses but mostly on species of Leguminosa, can be explained in a similar manner.

It is not here my intention to go through all the groups of Lepidoptera in this manner. The instances adduced are quite sufficient to prove that longitudinal stripes occur wherever we should expect to find them, and that they really possess the biological significance which I have ascribed to them. That these markings are occasionally converted into an adaptive imitation of certain special parts of a plant, is shown by the larvæ of many moths, such for example as Chesias Spartiata, which lives on broom (Spartium Scoparium), 
its longitudinal stripes deceptively resembling the sharp edges of the stems of this plant. ${ }^{3}$

3. Oblique striping. Can the lilac and white oblique stripes on the sides of a large green caterpillar, such as those of Sphinx Ligustri; or the red and white, or white, black, and red stripes of Smerinthus Tilice and Sphinx Drupiferarum respectively, be of any possible use? Have we not here just one of those cases which clearly prove that such a character is purely morphological, and worthless for the preservation of the individual? Does not Nature occasionally sport with purposeless forms and colours; or, as it has often been poetically expressed, does she not here give play to the wealth of her phantasy?

At first sight this indeed appears to be the case. We might almost doubt the adaptive importance of the green ground-colour on finding coloured stripes added thereto, and thus-as one might suppose-abolishing the beneficial action of this ground-colour, by making the insect strikingly conspicuous. But this view would be decidedly incorrect, since oblique stripes are of

${ }^{8}$ [The same applies to Pseudoterpna Cytisaria, also feeding on broom at the same time of the year. The most striking cases of adaptive resemblance brought about by longitudinal stripes are to be found among fir and pine feeders, species belonging to the most diverse families (Hyloicus Pinastri, Trachea Piniperda, Fidonia Piniaria, \&c., \&c.) all being most admirably concealed among the needle-shaped leaves. R.M.] 
just the same importance as longitudinal stripes. The former serve to render the caterpillar difficult of detection, by making it resemble, as far as possible, a leaf; they are imitations of the leaf-veins.

Nobody who is in the habit of searching for caterpillars will doubt that, in cases where the oblique stripes are simply white or greenish-white, it is extremely difficult to see the insect on its food-plant, e.g. S. Ocellatus on Salix; not only because it possesses the colour of the leaves, but no less because its large body does not present an unbroken green surface, which would bring it into strong contrast with the leaves, and thus arrest the attention. In the case of the species named, the coloured area of the body is divided by oblique parallel stripes, just in the same manner as a willow leaf. In such instances of course we have not presented to us any special imitation of a leaf with all its details-there is not a perfect resemblance of the insect to a leaf, but only an arrangement of lines and interspaces which does not greatly differ from the division of a leaf by its ribs.

That this view is correct is shown by the occurrence of this form of marking. It is on the whole rare, being found, besides in many Sphingida, in isolated cases in various families, but is always confined to those larvæ which live on ribbed leaves, and never occurring in species which feed on grasses or on trees with needle-shaped leaves. This has 
already been shown with respect to the Sphingida, in which the oblique stripes are only completely developed in the subfamilies Smerinthince and Sphingina. The species of Smerinthus all live on trees such as willows, poplars, lime, oak, \&c., and all possess oblique stripes. The genus Anceryx also belongs to the Sphingina, and these caterpillars, as far as known, live on trees with needle-shaped leaves. The moths of this last genus are very closely allied to the species of Sphinx, not only in form and colour, but also in many details of marking. The larvæ are however different, this distinction arising entirely from their adaptation to needle-shaped leaves, the Sphinx caterpillars being adapted to ordinary foliage. The species of Anceryx, as has been already shown, are brown mixed with green, and never possess even a trace of the oblique stripes, but have a latticed marking, consisting of many interrupted lines, which very effectively serves to conceal them among the needles and brown bark of the Coniferce.

Of the Sphingince living on plants with ordinary foliage, not a single species is without oblique stripes. I am acquainted with ten species of caterpillars and their respective food-plants, viz. Sphinx Carolina, Convolvuli, Quinquemaculata, Prini,Drupiferarum, Ligustri; Macrosila Rustica and Cingulata; Dolba Hylaus and Acherontia Atropos. 
Besides among the Sphingina, oblique stripes occur in the larvæ of certain butterflies, viz. Apatura Iris, Ilia, and Clytie, all of which live on forest trees (aspen and willows), and are excellently adapted to the leaves by their green colour. In addition to these, I am acquainted with the larvæ of some few moths, viz. of Aglia Tau and Endromis Versicolora, both of which also live on forest trees.

Oblique stripes also occasionally occur in the smaller caterpillars of Noctuce, Geometra, and even in those of certain Pyrales, in all of which they are shorter and differently arranged. In these cases also, my theory of adaptation holds good, but it would take us too far if I attempted to go more closely into them. I will here only mention the extraordinary adaptation shown by the caterpillar of Eriopus Pteridis. This little Noctuid lives on Pteris Aquilina; it possesses the same green colour as this fern, and has double oblique white stripes crossing at a sharp angle on each segment, these resembling the lines of sori of the fern-frond so closely, that the insect is very difficult to perceive.

After all these illustrations it can no longer remain doubtful that the oblique stripes of the Sphingida are adaptive. But how are the coloured edges bordering these stripes in so many species to be explained?

I must confess that I long doubted the possi- 
bility of being able to ascribe any biological value to this character, which appeared to me only conspicuous, and not protective. Cases may actually occur in which the brightly coloured edges of the oblique stripes make the caterpillar conspicuousjust in the same manner as any marking may bring about a conspicuous appearance by presenting a striking contrast of colour. I am acquainted with no such instance, however. As a rule, in all welladapted caterpillars, considering their colour in its totality, this is certainly not the case. The coloured edges, on the contrary, enhance the deceptive appearance by representing the oblique shadows cast by the ribs on the under-side of the leaf; all these caterpillars rest underneath the leaves, and never on the upper surface.

This explanation may, perhaps, at first sight appear far-fetched, but if the experiment be made of observing a caterpillar of Sphinx Ligustri on its food-plant, not immediately before one's eyes in a room, but at a distance as under natural conditions, it will be found that the violet edges do not stand out brightly, but show a colour very similar to that of the shadows playing about the leaves. The coloured edges, in fact, produce a more effective breaking up of the large green surface of the caterpillar's body, than whitish stripes alone. Of course if the insect was placed on a bare twig in the sun, it would be easily visible at a distance; the larva never rests in such a position, however, 
but always in the deep shadow of the leaves, in which situation the coloured edges produce their peculiar effect. It may be objected that the oblique white stripes, standing simply on a darkgreen ground-colour, would produce the same effect, and that my explanation therefore leaves the bright colouring of these edges still unaccounted for. I certainly cannot say why in Sphinx Ligustri these edges are lilac, and in S. Drupiferarum, S. Prini, and Dolba Hylaus red, nor why they are black and green in Macrosila Rustica, and blue in Acherontia Atropos. If we knew exactly on what plants these caterpillars fed originally, we might perhaps indulge in comparing with an artistic eye the shadows playing about their leaves, seeing in one case more red, and in another more blue or violet. The coloured stripes of the Sphingide must be regarded as the single strokes of a great master on the countenance of a human portrait. Looked into closely, we see red, blue, or even green spots and strokes; but all these colours, conspicuous when close, disappear on retreating, a general effect of colour being then produced, which cannot be precisely described by words.

Quite in accordance with this explanation, we see caterpillars with the brightest coloured stripes concealing themselves in the earth by day, and betaking themselves to their food-plants only in the dusk of the evening or dawn of morning and 
even during the night; i.e. in a light so faint that feeble colours would produce scarcely any effect. The bright blue of Acherontia Atropos, for example, would give the impression of oblique shadows without any distinctive colour.

It is precisely the case of this last caterpillar, which formerly appeared to me to present insurmountable difficulties to the explanation of the coloured stripes by adaptation, and I believed that this insect would have to be classed with those species which are brightly coloured because they are distasteful, and are avoided by birds. But although we have no experiments on this point, I must reject this view. Unfortunately, we know scarcely anything of the ontogeny of this caterpillar; but we know at least that the young larvæ (stage four) are greener than the more purely yellow ones of the fifth stage (which, however, are also frequently green), and we know further that some adults are of a dark brownish grey, without any striking colours. From analogy with the dimorphism of the species of Charocampa and Sphinx, fully considered previously, it must therefore be concluded that in this case also, a new process of adaptation has commenced-that the caterpillar is becoming adapted to the soil in and on which it conceals itself by day. ${ }^{4}$ An insect which

4 The geographical distribution of the dark form indicates that in the case of this species also, the form referred to is replacing the yellow (green) variety. Whilst in the middle of 
acquires undoubted protective colours cannot, however, be classed with those which possess an immunity from hostile attacks.

That the coloured edges are correctly explained as imitations of the oblique shadows of the leafribs, may also be proved from another point of view. Let us assume, for the sake of argument, that these coloured stripes are not adaptive, and that they have not been produced by natural

Europe (Germany, France, Hungary) the dark form is extremely rare, in the south of Spain this variety, as I learn from Dr. Noll, is almost as common as the yellow one. I hear also from Dr. Staudinger that in South Africa (Port Natal) the dark form is somewhat the commoner, although the golden-yellow and, more rarely, the green varieties, occur there. I have seen a caterpillar and several moths from Port Natal, and these all agree exactly with ours. The displacement of the green (yellow) form by the dark soil-adapted variety, appears therefore to proceed more rapidly in a warm than in a temperate climate. [Eng. ed. Dr. Noll writes to me from Frankfort that the caterpillar of Acherontia Atropos in the south of Spain does not, as with us, conceal itself by day in the earth, but on the stems underneath the leaves. "At Cadiz, on the hot, sandy shore, Solanum violaceum grows to a height of three feet, and on a single plant I often found more than a dozen Atropos larvæ resting with the head retracted, It can easily be understood why the lateral stripes are blue when one has seen the south European Solanea, on which this larva is at home. Solanum violaceum is scarcely green : violet tints alternate with brown, green, and yellow over the whole plant, and between these appear the yellow-anthered flowers, and golden-yellow berries of the size of a greengage. Thus it happens that the numerous thorns, an inch long, between which the caterpillar rests on the stem, pass from violet into shades of blue, red, green, and yellow."] 


\section{The Origin of the Markings of Caterpillars. 325}

selection, but by a hypothetical phyletic force. We should then expect to see them appear at some period in the course of the phyletic development-perhaps at first only in solitary individuals, then in several, and finally in all ; but we certainly could not expect that at first single, irregular, coloured spots should arise in the neighbourhood of the oblique white stripes-that these spots should then multiply, and fusing together, should adhere to the white stripes, so as to form an irregular spot-like edge, which finally becomes formed into a straight, uniformly broad stripe. The phyletic development of the coloured edges takes place, however, in such a manner, the species of Smerinthus, as has already been established, showing this with particular distinctness. In $S$. Tilice the course of development can be followed till the somewhat irregular red border is formed. In the species of Sphinx this border has become completely linear. It is very possible that the ontogeny of S. Ligustri or Drupiferarum would reveal the whole process, although it may also be possible that owing to the contraction of the development, much of the phylogeny is already lost.

I have now arrived at the consideration of the last kind of marking which occurs in the Sphingide, viz. :-

4. Eye-spots and Ring-spots.-These markings, besides among the Sphingida, are found only in a very few caterpillars, such as certain tropical 
Papilionida and Noctuce. I know nothing of the conditions of life and habits of these species, however, and without such knowledge it is impossible to arrive at a complete explanation.

With Darwin, I take an eye-spot to be "a spot within a ring of another colour, like the pupil within the iris," but to this central spot "concentric zones" may be added. In the Charocampa larvæ and in Pterogon Enothere, in which complete ocelli occur, there are alway three zonesa central spot, the pupil, or, as I have called it, the " nucleus ;" then a light zone, the " mirror ;" and, surrounding this again, a dark zone (generally black), the "ground-area."

As ring-spots I will consider those ocelli which are without the nucleus (pupil), and which are not therefore, strictly speaking, deceptive imitations of an eye, but present a conspicuous light spot surrounded by a dark zone.

Between these two kinds of markings there is, however, no sharp boundary, and morphologically they can scarcely be separated. Species with ring-spots sometimes have nuclei, and ocellated larvæ in some cases possess only a pale spot instead of a dark pupil. I deal here with the two kinds separately, because it happens that they appear in two distinct genera, in each of which they have their special developmental history. Ring-spots originate in a different position, and in another manner than eye-spots; but it must not, on this 


\section{The Origin of the Markings of Caterpillars. 327}

account, be assumed without further inquiry, that they are called into existence by the same causes ; they must rather be investigated separately, from their origin.

Eye-spots are possessed by the genera Charocampa and Pterogon; ring-spots by the genus Deilephila. In accordance with the data furnished by the above-given developmental histories, the origination of these markings in the two genera may be thus represented :-

In the genera named, eye-spots and ring-spots are formed by the transformation of single portions of the subdorsal line.

In Charocampa the primary ocelli originate on the fourth and fifth segments by the detachment of a curved portion of the subdorsal, this fragment becoming the "mirror," and acquiring a dark encircling zone ("ground-area"). The nucleus (pupil) is added subsequently.

In Deilephila we learn from the development of D. Hippophaës, that the primary annulus arises on the segment bearing the caudal horn (the eleventh) by the deposition of a red spot on the white subdorsal line, which is somewhat enlarged in this region. The formation of a dark "ground-area " subsequently occurs, and with this, at first the partial, and then the complete, detachment of the mirror-spot from the subdorsal line takes place.

In both genera the spots arise at first locally on one or two segments, from which they are trans- 
ferred to the others as a secondary character. In Charocampa this transference is chiefly backwards, n Deilephila invariably forwards.

We have now to inquire whether complete eye-spots-such as those of the Charocampa larvæ-have any significance at all, and whether they are of biological importance. It is clear at starting, that these spots do not belong to that class of markings which make their possessors more difficult of detection; they have rather the opposite effect.

We might thus be disposed to class ocellated caterpillars with those " brightly coloured" species which, like the Heliconince and Danaince among butterflies, possess a disgusting taste, and which to a certain extent bear the signal of their distastefulness in their brilliant colours. But even if I had not found by experiment that our native Charocampa larvæ were devoured by birds and lizards, and that they are not therefore distasteful to these insect persecutors, from the circumstance that these caterpillars are all protectively coloured, it could have been inferred that they do not belong to this category. It has been found that all adaptively coloured caterpillars are eaten, and one and the same species cannot possibly be at the same time inconspicuously (adaptively) and conspicuously coloured; the one condition excludes the other.

What other significance can eye-spots possess 
than that of making the insects conspicuous? Had we to deal with sexually mature forms, we should, in the first place, think of the action of sexual selection, and should regard these spots as objects of taste, like the ocelli on the feathers of the peacock and argus-pheasant. But we are here concerned with larvæ, and sexual selection is thus excluded.

The eye-spots must therefore possess some other significance, or else they are of no importance at all to the life of the insect, and are purely " morphological characters;" in which case, supposing this could be proved, they would owe their existence exclusively to forces innate in the organism itself-a view which very closely approaches the admission of a phyletic vital force.

I am of opinion, however, that eye-spots certainly possess a biological value as a means of terrifying -they belong to that numerous class of characters which occur in the most diverse groups of animals, and which serve the purpose of making their possessors appear as alarming as possible.

The caterpillars of the Sphingide are known to behave themselves in different manners when attacked. Some species, such, for instance, as Sphinx Ligustri and Smerinthus Ocellatus, on the approach of danger assume the so-called Sphinx attitude; if they are then actually seized, they dash themselves madly to right and left, by this means not only attempting to get free, but also to terrify 
their persecutor. This habit frequently succeeds with men, and more especially with women and children; perhaps more easily in these cases than with their experienced foes, birds.

The ocellated Charocampa larvæ behave differently. They remain quiet on being attacked, and do not put on a Sphinx-like attitude, but only withdraw the head and three small front segments into the large fourth segment, which thus becomes much swollen, and is on this account taken for the head of the insect by the inexperienced. ${ }^{5} \quad$ Now the large eye-spots are situated on the fourth segment, and it does not require much imagination to see in such a caterpillar an alarming monster with fiery eyes, especially if we consider the size which it must appear to an enemy such as a lizard or small bird. Fig. 28 represents the larva of $C$. Porcellus in an attitude of defence, although but imperfectly, since the front segments can be still more withdrawn.

These facts and considerations do not, however, amount to scientific demonstration, and I therefore made a series of experiments, in order to determine whether these caterpillars did actually frighten small birds. The first experiment proved but little satisfactory. A jay, which had been domesticated for years, to which I threw a caterpillar of Charo-

${ }^{5}$ [For Mr. J. P. Mansel Weale's remarks on the habits of certain ocellated S. African Sphinx-larvæ see note I, p. 290. R.M.] 
campa Elpenor, did not give the insect any time for manœuvring, but killed it immediately by a strong blow with its bill. This bird had been tame for years, and was in the habit of pecking at everything thrown to him. Perhaps a wild jay (Garrulus Glandarius) would have treated the insect differently, but it is hardly possible that such a large and courageous bird would have much respect for our native caterpillars. I now turned to wild birds. A large brown Elpenor larva was placed in the food-trough of an open fowl-house from which the fowls had been removed. A flock of sparrows and chaffinches (Fringilla Domestica and Coelebs) soon flew down from the neighbouring trees, and alighted near the trough to pick up stray food in their usual manner. One bird soon flew on to the edge of the trough, and was just about to hop into it when it caught sight of the caterpillar, and stood jerking its head from side to side, but did not venture to enter. Another bird soon came, and behaved in a precisely similar manner; then a third, and a fourth; others settled on the perch over the trough, and a flock of ten or twelve were finally perched around. They all stretched their heads and looked into the trough, but none flew into it.

I now made the reverse experiment, by removing the caterpillar and allowing the birds again to assemble, when they hopped briskly into the trough. 
I often repeated this experiment, and always with the same result. Once it could be plainly seen that it was really fear and not mere curiosity that the birds showed towards the caterpillar. The latter was outside the trough amongst scattered grains of food, so that from one side it was concealed by the trough. A sparrow flew down obliquely from above, so that at first it could not see the caterpillar, close to which it alighted. The instant it caught sight of the insect, however, it turned in evident fright and flew away.

Of course these experiments do not prove that the larger insectivorous birds are also afraid of these caterpillars. Although I have not been able to experiment with such birds, I can certainly prove that even fowls have a strong dislike to these insects. I frequently placed a large Elpenor larva in the poultry yard, where it was soon discovered, and a fowl would run hastily towards it, but would draw back its head just when about to give a blow with the bill, as soon as it saw the caterpillar closely. The bird would now run round the larva irresolutely in a circle-the insect in the meantime assuming its terrifying attitude-and stretching out its head would make ten or twenty attempts to deal a blow with its bill, drawing back again each time. All the cocks and hens acted in a similar manner, and it was often five or ten minutes before one particularly courageous bird would give the first peck, which would soon be 
followed by a second and third, till the caterpillar, appearing palatable, would finally be swallowed.

These experiments were always made in the presence of several persons, in order to guard myself against too subjective an interpretation of the phenomena; but they all invariably considered the conduct of the birds to be as I have here represented it. ${ }^{\boldsymbol{B}}$

If it be admitted that the ocelli of caterpillars are thus means of exciting terror, the difficulty of their occurring in protectively coloured species at once vanishes. They do not diminish the advantage of the adaptive colouring, because they do not make the caterpillars conspicuous, or at least any more easily visible at a distance, excepting when the insects have assumed their attitude of alarm. But these markings are of use when, in spite of protective colouring, the larva is attacked by an enemy. The eye-spots accordingly serve the caterpillar as a second means of defence, which is resorted to when the protective colouring has failed.

By this it must not be understood that the ocelli of the Charocampa larvæ invariably possess only this, and no other significance for the life of the insect. Every pattern can be conceived to render

- [Some experiments with the caterpillar of C. Elpenor, confirming these results, have been made by Lady Verney. See "Good Words," Dec. 1877 , p. 83 8. R.M.] 
its possessor in the highest degree conspicuous by strongly contrasted and brilliant colouring, so that it might be anticipated that perfect eye-spots in certain unpalatable species would lose their original meaning, and instead of serving for terrifying become mere signals of distastefulness. This is perhaps the case with Charocampa Tersa (Fig. 35), the numerous eye-spots of which make the insect easily visible. Without experimenting on this point, however, no certain conclusion can be ventured upon, and it may be equally possible that in this case the variegated ocelli with bright red nuclei resemble the blossoms of the food-plant (Spermacoce Hyssopifolia). ${ }^{7}$ I here mention this possibility only in order to show how an inherited form of marking, even when as well-defined and complicated as in the present case, may, under certain circumstances, be turned in quite another direction by natural selection, for the benefit of its possessor. Just in the same manner one and the same organ, such, for instance, as the limb of a crustacean, may, in the course of phyletic development, perform very different functions-first serving for locomotion, then for respiration, then for reproduction or oviposition, and finally for the acquisition of food.

7 [The eye-spots on $C h$. Nerii have thus been supposed by some observers to be imitations of the flowers of the periwinkle, one of its food-plants. See, for instance, Sir John Lubbock's "Scientific Lectures," p. 5I. R.M.] 
I now proceed to the consideration of the biological value of incomplete eye-spots, or, as I have termed them, ring-spots. Are these also means of terrifying, or are they only signals of distastefulness?

I must at the outset acknowledge that on this point I am able to offer but a very undecided explanation. The decision is only to be arrived at by experiments conducted with each separate species upon which one desires to pronounce judgment. It is not here legitimate to draw analogical inferences, and to apply one case to all, since it is not only possible, but very probable, that the biological significance of ring-spots changes in different species. Nothing but a large series of experiments could completely establish this. Unfortunately I have hitherto failed in obtaining materials for this purpose. I would have deferred the publication of this essay for a year, could I have foreseen with certainty that such materials would have been forthcoming in sufficient quantity during the following summer; but this unfortunately depends very much upon chance, and I believed that a preliminary conclusion would be preferable to uncertainty. Perhaps some entomologist to whom materials are more easily accessible, may, by continuing these experiments, accomplish this object.

The experiments hitherto made by other observers, are not sufficient for deciding the question 
under consideration. Weir, ${ }^{8}$ as is well known, showed that certain brightly coloured and conspicuous larvæ were refused by insectivorous birds ; and Butler ${ }^{9}$ proved the same for lizards and frogs. These experiments are unfortunately so briefly described, that in no case is the species experimented with mentioned by name, so that we do not know whether there were any Sphinx caterpillars among them. ${ }^{10}$ I have likewise experimented in this direction with lizards, in order to convince myself of the truth of the statement that (I) there are caterpillars which are not eaten on account of their taste, and (2) that such larvæ possess bright colours. I obtained positive, and on the whole, very decided results. Thus, the common orange and blue striped caterpillars of Bombyx Neustria enjoýed complete immunity from the attacks of lizards, whilst those of the nearly allied Eriogaster Lanestris and L. Pini were devoured, although not exactly relished. That the hairiness is not the cause of their being unpalatable, is shown by the: fact that $L$. Pini is much more hairy than $B$. Neustria. The very conspicuous yellow and black ringed caterpillar of Euchelia Facobaa gave also most decided results. I frequently placed this

8 "On Insects and Insectivorous Birds," Trans. Ent. Soc. I869, p. 2 I

Ibid., p. 27.

${ }^{10}$ [Messrs. Weir and Butler inform me that they have not experimented with Sphinx-larvæ. R.M.] 


\section{The Origin of the Markings of Caterpillars. 337}

insect in a cage with Lacerta Viridis, but they would never even notice them, and I often saw the caterpillars crawl over the body, or even the head of the lizards, without being snapped at. On every occasion the larvæ remained for several days with the lizards without one being ever missed. The reptiles behaved in a precisely similar manner with respect to the moth of E. Facobar, not one of which was ever touched by them. The yellow and black longitudinally striped caterpillars of Pygara Bucephala were also avoided, and so were the brightly coloured larvæ of the large cabbage white (Pieris Brassica), which when crushed give a disagreeable odour. This last property clearly shows why lizards reject this species as distasteful. Both caterpillar and butterfly possess a blood of a strong yellow colour and oily consistency, in which, however, I could not detect such a decided smell as is emitted by that of the Heliconince and Danaine."

I next made the experiment of placing before a lizard a caterpillar as much as possible like that of $E$. Facobace. Half grown larvæ of Bombyx Rubi likewisepossess golden yellow (but narrower)

${ }^{11}$ [It appears that the nauseous character of these last butterflies is to a certain extent retained after death, as I found that in an old collection which had been destroyed by mites, the least mutilated specimens were species of Danais and Euplea, genera which are known'to be distasteful when living, and to serve as models for mimicry. See Proc. Ent. Soc. 1877 , p. xii. R.M.] 
transverse rings on a dark ground, and they are much more hairy than those of E. Facobace. The lizard first applied its tongue to this caterpillar and then withdrew it, so that I believed it would also be avoided; nevertheless it was subsequently eaten. The caterpillars of Saturnia Carpini were similarly devoured in spite of their bristly hairs, and likewise cuspidate larvæ (Dicranura Vinula), notwithstanding their extraordinary appearanceand their forked caudal horn. ${ }^{12}$ These lizards were by no means epicures, but consumed large numbers of earth-worms, slugs, and great caterpillars, and once a specimen of the large and powerfully biting Orthopteron, Decticus Verucivorus. Creatures which possessed a strongly repugnant odour were, however, always rejected, this being the case with the strongly smelling beetle, Chrysomela Populi, as also with the stinking centipede, Iulus Terrestris, whilst the inodorous Lithobius Forficatus was greedily eaten. I will call particular attention to these last facts, because they favour the supposition that with rejected caterpillars a disgusting odouralthough perhaps not always perceptible by usis the cause of their being unpalatable.

Striking colours are of course only signals of distastefulness, and the experiment with Bombyx

12 [This bears out the view expressed in a previous note $I$, p. 290, that the grotesque attitude and caudal tentacles are more for protection against ichneumons than against larger foes. R.M.] 
$R u b i$ shows that the lizards were from the first prejudiced against such larvæ, the prejudice only being overcome on actually trying the specimen offered. A subsequent observation which I made after arriving at this conclusion, is most noteworthy. After the lizard had learnt by experience that there might be not only distasteful caterpillars (E. Facobace), but also palatable ones banded with black and yellow (B. Rubi), it sometimes tasted the Facobae larvæ, as if to convince itself that the insect was actually as it appeared to be, viz., unpalatable!

A striking appearance combined with a very perceptible and penetrating odour is occasionally to be met with, as in the caterpillar of the common Swallow-tail, Papilio Machaon. I have never seen a lizard make the slighest attempt to attack this species. I once placed two large specimens of this caterpillar in the lizard vivarium, where they remained for five days, and finally pupated unharmed on the side of the case.

I have recorded these experiments, although they do not thus far relate to Sphinx-caterpillars, with the markings of which we are here primarily concerned, because it appeared to me in the first place necessary to establish by my own experiments that signals of distastefulness did occur in caterpillars.

I now come to my unfortunately very meagre experience with Deilephila larvæ, with only two 
species of which have I been able to experiment, viz., D. Galii and Euphorbice.

The first of these was constantly rejected. Two large caterpillars, one of the black and the other of the yellow variety, were left for twelve hours in the lizard vivarium, without being either examined or touched. It thus appears that D. Galii is a distasteful morsel to lizards; and the habits of the caterpillar are quite in accordance with this, since it does not conceal itself, but rests fully exposed by day on a stem, so that it can scarcely escape being detected. It is almost as conspicuous as D. Euphorbice.

I was much surprised to find, however, that this last species was not rejected by lizards. On placing a large caterpillar, six to seven centimeters long, in the vivarium, the lizard immediately commenced to watch it, and as soon as it began to crawl about, seized it by the head, and, after shaking it violently, commenced to swalluw it. In spite of its vigorous twisting and turning, the insect gradually began to disappear, amidst repeated shakings; and in less than five minutes was completely swallowed. ${ }^{13}$ With regard to lizards, therefore, the prominent ring-spots of this larva are not effective as a means of alarm, nor are they considered as a sign of distastefulness.

13 These experiments, as already mentioned above, were not made with the common German lizard (Lacerta Stirpium), but with the large South European Lacerta Viridis. 
Unfortunately I have not hitherto been able to make any experiments with birds. It would be rash to conclude from the experience with lizards that ring-spots were of no biological value. There is scarcely any one means of protection which can render its possessor secure against all its foes. The venom of the most poisonous snakes does not protect them from the attack of the secretary bird (Serpentarius Secretarius) and serpent eagle (Spilornis Cheela); and the adder, as is well known, is devoured by hedgehogs without hesitation: It must therefore be admitted that many species which are protected by distastefulness, may possess certain foes against which this quality is of no avail. Thus, it cannot be said that brightly coloured caterpillars, which are not eaten by birds and lizards, are also spared by ichneumons. It is readily conceivable therefore, that the larva of $D$. Euphorbice may not be unpalatable to lizards, because they swallow it whole ; whilst it is perhaps distasteful to birds, because they must hack and tear in order to swallow it.

From these considerations it still appears most probable to me that $D$. Euphorbia, and the nearly allied D. Dahlii and Mauritanica, bear conspicuous ring-spots as signs of their being unpalatable to the majority of their foes. The fact that these species feed on poisonous Euphorbiacea, combined with their habit of exposing themselves openly by day, so as to be easily seen at a distance, may 
Studies in the Theory of. Descent.

perhaps give support to this view. As these insects are not protectively coloured, this habit would long ago have led to their extermination; instead of this, however, we find that in all situations favourable to their conditions of life they are among the commonest of the Sphingida.

Thus, D. Euphorbice occurs in large numbers both in South and North Germany (Berlin); and Dr. Staudinger informs me that in Sardinia the larvæ of $D$. Dahlii were brought to him by baskets full.

But if the conspicuous ring-spots (combined of course with the other bright colours) may be regarded as signals of distastefulness in many species of Deilephila, this by no means excludes the possibility that in some species these markings play another part, and are effective as a means of alarm. It even appears conceivable to me that in one and the same caterpillar they may play both parts against different foes, and it would certainly be of interest to confirm or refute this supposition by experiment.

In the light yellow variety of the caterpillar of $D$. Galii the ring-spots may serve as means of alarm, and still more so in that of D. Nicae, the resemblance of which to a snake has struck earlier observers. ${ }^{14}$

14 Thus, Boisduval states of this caterpillar, which in Provence lives on Euphorbia esula and allied species:- "Its resemblance to a serpent, and its brilliant colour, permit of its being 
The Origin of the Markings of Caterpillars. 343

In those species of Deilephila which conceal themselves by day, the ring-spots cannot be considered as signals of distastefulness, and they must therefore have some other meaning. As examples of this class may be mentioned $D$. $V$ espertilio, which is protectively coloured both in the young and in the adult stages; and likewise D. Hippophaës, in which this habit of concealment is associated with adaptive colouring. In the case of the first-named species, it appears possible that the numerous large ring-spots may serve to alarm small foes, but the truth of this supposition could only be decided by experiment. In $D$. Hippophaës, on the other hand, such an interpretation must be at once rejected, since most individuals possess but a single ring-spot, which shows no resemblance whatever to an eye.

I long sought in vain for the meaning of this ring-spot, the discovery of which would in this particular case be of the greatest value, because we have here obviously the commencement of the whole development of ring-spots before us-the initial stage from which the marking of all the other species of Deilephila has proceeded.

I believe that I have now found the correct answer to this riddle, but unfortunately at a period of the year when I am unable to prove it

easily discovered." This was written in 1843 , long before natural selection was thought of. 
experimentally. I consider that the ring-spots are crude imitations of the berries of the foodplant. The latter are orange-red, and exactly of the same colour as the spots; the agreement in colour between the latter and the berries is quite as close as that between the leaves and the general colouring of the caterpillar. I know of no species which more closely resembles the colour of the leaves of its food-plant, the dark upper side and light under side corresponding in the leaves and caterpillars. The colour of the Hippophae is not an ordinary green, but a greygreen, which shade also occurs, although certainly but rarely, in the larvæ. I may expressly state that I have repeatedly shown to people as many as six to eight of the large caterpillars on one buckthorn branch, without their being able at once to detect them. It is not therefore mere supposition, but a fact, that this species is protected by its general colouring. At first the orange-red spots appear rather to diminish this protection-at least when the insects are placed on young shoots bearing no berries. But since at the same time when the berries become red (end of July and the beginning of August) the caterpillars are in their last stage of development (i.e. possess red-spots), it appears extremely probable that these spots are vague representations of the berries. For the same reason that these caterpillars have acquired the habit of feeding only at dusk and during the 
morning twilight, or at night, and of concealing themselves by day, it must be advantageous for them to have the surface of their large bodies not only divided by white stripes, but also interrupted in yet another manner. How could this be better effected than by two spots which, in colour and position, represent the grouping of the red berries on the branches? When feeding, the insect always rests with the hind segments on a branch, the front segments only being more or less raised and held parallel to the leaves; the red spots thus always appear on the stem, where the berries are likewise situated. It might indeed be almost supposed that the small progress which the formation of secondary ring-spots on the other segments has made up to the present time, is explicable by the fact that such berry-like spots on other portions of the caterpillar would be rather injurious than useful.

It may, however, be asked how an imitation of red berries, which are eaten by birds just as much as other berries, can be advantageous to a caterpillar, since by this means it would rather attract the attention of its enemies?

Two answers can be given to this. In the first place, the berries are so numerous on every plant that there is but a very small chance of the smaller and less conspicuous berry-spots catching the eye of a bird before the true berries; and, secondly, the latter, although beginning to turn 
red when the caterpillars are feeding, do not completely ripen till the autumn, when the leaves are shed, and the yellowish-red clusters of berries can be seen at a distance. The caterpillar, however, pupates long before this time.

I have considered this case in such detail because it appears to me of special importance. It is the only instance which teaches us that the rows of ring-spots of the Deilephila larvæ proceed from one original pair - the only instance which permits of the whole course of development being traced to its origin. Were it possible to arrive at the causes of the formation of these spots, their original or primary significance would thereby be made clear.

I will now briefly summarise the results of the investigation of the biological value of the Deilephila ring-spots.

In the known species of the genus now existing these spots have different meanings.

In some species (certainly in Galii, and probably in Euphorbice and Mauritanica) the conspicuous ring-spots serve as signals of distastefulness for certain enemies (not for all).

In a second group of species they serve as a means of alarm, like the eye-spots of the Charocampa larvæ (Nicca? light form of Galii?).

Finally, in a third group, of which I can at present only cite Hippophaës, they act as an adaptive resemblance to a portion of a plant, 
The Origin of the Markings of Caterpillars. 347

and enhance the efficacy of the protective colouring.

5. Subordinate Markings.-If, from the foregoing considerations, it appears that the three chief elements of the Sphinx-markings-longitudinal and oblique stripes, and spot formations-are not purely morphological characters, but have a very decided significance with respect to their possessors, there should be no difficulty in referring the whole of the markings of the Sphingida to the action of natural selection, supposing that these three kinds of marking were the only ones which actually occurred.

In various species, however, there appear other patterns, which I have comprised under the term "subordinate markings," some of which I will select, for the purpose of showing the reasons which permit of their being thus designated.

I ascribe to this category, for example, that fine network of dark longitudinal streaks which often extends over the whole upper side of the caterpillar, and which is termed the "reticulation." This character is found chiefly in the adult larvæ of Charocampa, being most strongly pronounced in the brown varieties : it occurs also in Deilephila Vespertilio, Pterogon Enothera, and Sphinx Convolvuli. As far as I know, it is only associated with adaptive colours, and indeed occurs only in those caterpillars which rest periodically at the 
base of their food-plants among the dead leaves and branches. I do not consider this reticulation to be a distinct imitation, but only as one of the various means of breaking up the large uniform surface of the caterpillar so as to make it present inequalities, and thus render it less conspicuous. There can be no doubt as to the dependence of this character upon natural selection.

There is, however, a second group of markings, which must be referred to another origin. To this group, for instance, belong those light dots in Charocampa Porcellus and Elpenor which have been termed "dorsal spots." I know of no other explanation for these than that they are the necessary results of other new formations, and depend on correlation (Darwin), or, as I may express it, they are the result of the action of the law governing the organization of these species.

As long as we are confined to the mere supposition that the character in question may be the outward expression of an innate law of growth, it is permissible to attempt to show that a quite similar formation in another species depends upon such a law.

Many of the dark specimens of Sphinx Convolvuli show whitish dots on segments six to eleven, one being situated on the front edge of each of these segments, at the height of the completely vanished subdorsal line (Fig. 52). These spots vary much in size, lightness, and sharpness of 
definition. Now it might be difficult to attribute any biological significance to this character, but its origin becomes clear on examining light specimens in which the oblique white stripes are distinct on the sides and the subdorsal line is retained at least on the five or six anterior segments. It can then be seen that the spots are located at the points of intersection of the subdorsal and the oblique stripes (Fig. I6, P1. III.), and they can accordingly be explained by the tendency to the deposition of light pigment being twice as great in these positions as in other portions of the two systems of light lines. Light spots are thus formed when the lines which cross at these points are partially or completely extinct throughout their remaining course.

A marking is therefore produced in this case by a purely innate law of growth-by the superposition of two ancient characters now rudimentary. Many other unimportant details of marking must be regarded as having been produced in a similar manner, although it may not be possible to prove this with respect to every minute spot and stripe. The majority of "subordinate markings" depend on the commingling of inherited, but now meaningless, characters with newly acquired ones.

It would be quite erroneous to attribute to natural selection only those characters which can be demonstrated to still possess a biological value in the species possessing them. They may be 
equally due to heredity. Thus, it is quite possible that the faint and inconspicuous ring-spots of Deilephila Vespertilio are now valueless to the life of the species--they may be derived from an ancestral form, and have not been eliminated by natural selection simply because they are harmless. I only mention this as a hypothetical case.

In the case of markings of the second class, i.e. oblique stripes, a transference to later phyletic stages can be demonstrated, although the stripes thereby lose their original biological value. Thus, the Charocampa larvæ, when they were green throughout their whole life and adapted to the leaves, appear to have all possessed light oblique stripes in imitation of the leaf-ribs. All the species of the older type of colouring and marking, such as Charocampa Syriaca (Fig. 29) and Darapsa Charilus (Fig. 34), and also the light green young forms of C. Elpenor (Fig. 20), and Porcellus (Figs. 25 and 26), show these oblique stripes. In these last species the foliage imitation is abandoned at a later stage, and a dark brown, or blackish brown, ground-colour acquired. Nevertheless the oblique stripes do not disappear, but show themselves -in the fourth stage especially, and sometimes in the fifth-as distinct dirty yellow stripes, although not so sharply defined as in the earlier stages. These persistent stripes, in accordance with their small biological value, are very variable, since they are only useful in so far as they help to break 
up the large surface presented by the caterpillar, and are of no value as imitations of surrounding objects.

The oblique stripes of Sphinx Convolvuli offer a precisely similar case ; and it may be safely predicted that the young forms of this species would possess sharply defined light oblique stripes, since more or less distinct remnants of these markings occur in all the adult larvæ, and especially in the green form. The entire pattern of this caterpillar depends essentially on the commingling of characters persisting from an earlier period, i.e. of residues of the subdorsal and oblique stripes, both these markings being extraordinarily variable. The black reticulation was added to the groundcolour as a new means of adaptation, this character appearing only in the phyletically younger brown form, and being entirely absent, or only faintly indicated, in the older green variety. 
Objections to a Phyletic Vital Force.

IT has been shown in the previous section that the three elements composing the markings of the Sphinx-larvæ originally possessed a distinct significance with respect to the life of the species, and that they were by this means called into existence. It has likewise been shown, that in most of the species which possess these characters at the present time they still have a decided, although sometimes a different use, for their possessors, so that from this point of view no objection can be raised to their being considered as having arisen by natural selection.

On looking at the phenomenon as a whole, however, certain instances occur which appear quite irreconcilable with this view.

The most formidable objection is offered by the genus Deilephila. The row of ring-spots which nearly all the existing species have more or less developed, has arisen from a simple subdorsal line. It would not, therefore, be surprising if a species were discovered which possessed this line without 
any ring-spots as its only marking. If $D$. Hippophaës were thus marked, there would be no objection to the theoretica lassumption that this ${ }^{1}$ was the ancestor of the other species. It would then be said that ring-spots were first developed in a later species by natural selection, and that they had been transmitted to all succeeding and younger species.

Certain individuals of $D$. Hippophaës, however, possess small ring-spots, some of which are well developed on several segments. In this species the row of ring-spots is therefore comprised in the development. The remaining species, which are much younger phyletically than Hippophaës, could not have inherited their ring-spots from the latter, since this species itself only possesses them occasionally, and, so to speak, in a tentative manner. The spots would therefore appear to have arisen spontaneously in this species, and independently of those in the other species. But if this were the case, how should we be able to prove that in the other species also the ring-spots did not arise independently; and if, moreover, a large number of species showed the same character without its being referable to inheritance from a common ancestor, how could this be otherwise explained than as the result of a force innate in these species and producing similar variations? But this is nothing bnt Askenasy's "fixed direction of variation"-i.e., a phyletic vital force.

' Or some other extinct analogously-marked species. 
The only escape from this difficulty is perhaps to be found in proving that $D$. Hippophaës formerly possessed ring-spots, and that these have been subsequently either partially or completely lost, so that their occasional appearance in this species would therefore depend upon reversion. The ontogeny, however, teaches us that this is not the case, since the young caterpillar does not possess a greater number of more distinct ring-spots, but wants them altogether with the exception of a red spot on the eleventh segment, which is, however, much fainter than in the last stage.

This last-mentioned fact contains the solution of the problem. The premises from which this reasoning set out were all incorrect-the one red spot on the eleventh segment is likewise a ringspot, and indeed the most important one of all, being primary, or the first to come into existence. Now all specimens, without exception, possess this first ring-spot, which is useful, and has therefore been called forth by natural selection; it is not inherited, but newly acquired by this species; at least, if the explanation of these spots which I have previously offered is correct.

The primary pair of spots may have been transferred from this to later species by heredity; and since, in all segmented animals there is a tendency for the peculiarities of one segment to be repeated on the others, this repetition must have occurred with greater frequency and more completely in 


\section{The Origin of the Markings of Caterpillars. 355}

the later species-the more so if the process were favoured by natural selection, i.e. if the row of ring-spots which originated in this manner could in any way be turned to the use of the species.

In Hippophaës itself there must also be a tendency to the formation of secondary ring-spots, and indeed in a number of specimens we actually see series of such ring-spots, the latter being present in varying numbers, and in very different states of development. The fact that the ringspots have not become a constant and welldeveloped character, is simply explained by the circumstance that as such they would have endangered the existence of the species.

In this case there is therefore no necessity for assuming a phyletic vital force. The ring-spots of the genus Deilephila rather furnish us with an excellent explanation of a fact which might otherwise have been adduced in support of a phyletic vital force, viz., the strict uniformity in the development of larval markings.

Before I had been led to the discovery, by the study of the marking and development of Hippophaës, that the spots of the genus Deilephila originated on one segment only, from which they were transferred secondarily to the others, this astonishing regularity appeared to me an incomprehensible problem, which could only be solved by assuming a phyletic vital force. If it be attempted, for the ten species here considered, to construct a genea- 
logical tree based on the supposition that it is the rows of spots which have been inherited in cases where they occur, and not the mere tendency to their production by the transference of the one originally inherited primary spot to the remaining segments, the attempt will fail. The greater number of the species would have to be arranged in one row, since one species always bears a perfected form of marking, which appears in the young stages of the following species. But it is very improbable that nine different species, derived directly the one from the other, would contemporaneously survive. ${ }^{2}$ One species, $D$. Vespertilio, could not be inserted at all in the genealogical tree, since it wants one character which occurs in all the other species, viz., the caudal horn, which is absent even in the third stage, and must therefore have been lost at a very early period of the phyletic development, so that we may consider it to be on this account genetically allied to the oldest known form. But the markings of this larva pass through precisely the same stages of development as do those of the other species. Now if the ring-spots were inherited as such, the existence of a hornless species with ring-spots would be an insoluble riddle, and would favour the admission of parallel developmental series, which

2 [See Darwin's remarks on the struggle for life being most severe between individuals and varieties of the same species "Origin of Species," 6th ed. p, 59. R.M.] 
again could be scarcely otherwise explained than by a "fixed direction of variation." We have here one of that class of cases which the supporters of a phyletic vital force have already so often made use of in support of their view.

The explanation of such a case-i.e. its reference to known causes of species transformationis never easy, and is indeed impossible without a precise knowledge of the ontogeny of many species, as well as of the original significance of the characters in question. In the case of the Deilephila larvæ, however, such knowledge is still wanting. It is true that they present us with parallel developmental series, but these do not depend on an unknown phyletic force-the parallelism can be referred to the action of the imperfectly known laws of growth innate in segmented organisms. Because the characters of one segment have a tendency to repeat themselves on the others, from one parent-form possessing ring-spots on one segment only, there may have proceeded several developmental series, all of which developed rows of such spots independently of each other.

From these considerations we may venture to construct the following genealogical tree:- 
Possible genealogical-tree of the Genus Deilephila.

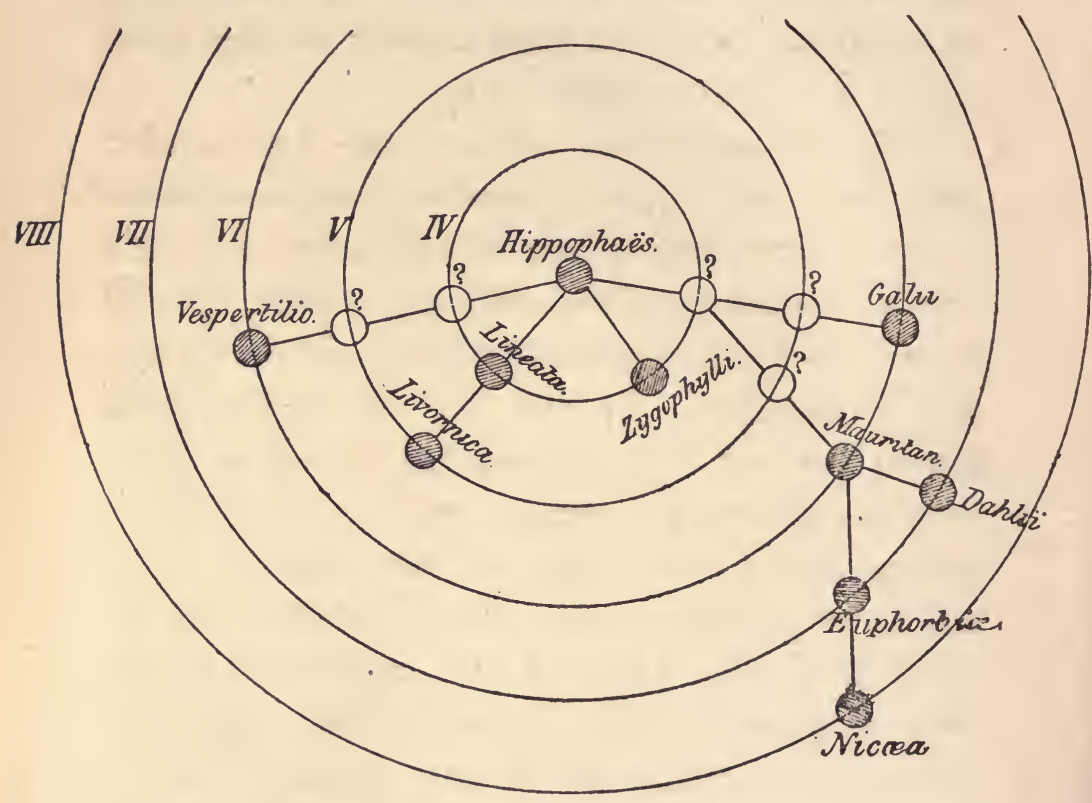

The circles indicate the phyletic stages IV.-VIII.; the eighth is only reached by Niccea, and is distinguished from the seventh chiefly by the ontogeny, in the third stage of which the seventh phyletic stage is reached, whilst in Euphorbice and Dahlii this stage is reached in the fourth ontogenetic stage. The phyletic stages indicated by queries are extinct, and only known through the ontogeny of existing species. It must be understood that this pedigree expresses only the ideal and not the actual relations of the species to one another. Thus, it is possible that Hippophaës is not the parent-form, but an unknown or extinct species, which must, however, have possessed the same marking, and so on. 
Four parallel series here proceed from the parent-form Hippophaës; there may have been five, or possibly only three, but the incomplete state of our knowledge of the ontogeny does not permit of any certain conclusion. For the point under consideration this is, however, quite immaterial. The distance from the central point (the parent-form) indicates the grade of phyletic development which the respective species have at present reached.

There is another case which is no less instructive, because it reveals, although in a somewhat different manner, the action of a law of growth innate in the organism itself, but which can nevertheless by no means be regarded as equivalent to a phyletic vital force. I refer to the coloured edges of the oblique stripes which occur in most of the species of the genus Sphinx. It has already been insisted upon in a previous section, that the mode in which this character originates negatives the assumption of a phyletic force, because these coloured edges are gradually built up out of irregularly scattered spots. There is no occasion for a "developmental force" to grope in the dark; if such a power exists, we should expect that it would add new characters to old ones with the precision of a master workman.

If, however, the coloured edges certainly depend on natural selection, this agency causing the scattered spots to coalesce and become linear, we 
have here the proof that such spots first arose in a precisely similar manner in several species, quite independently of one another - that, in fact, a " fixed direction of variation" in a certain sense exists.

In three species of Smerinthus-larvæ, red spots appear towards the end of the ontogeny; in $S$. Populi and Ocellatus in only a minority of individuals, and always separate (not coalescent), and in S. Tilice in a majority of specimens, the spots frequently becoming fused into one large, single, longish marking. These three species cannot have inherited the spots from a common ancestor, since they are absent in the younger ontogenetic stages, or occur only exceptionally, becoming larger and more numerous in the last stage; they obviously form a character which must be considered as a case of "anticipated development."

How is it then that three species vary independently of each other in an analogous manner? I know of no other answer to this question than that similar variations must necessarily arise from similar physical constitutions-or, otherwise expressed, the three species have inherited from an unknown parent species, devoid of spots, not this last character itself, but a physical constitution, having a tendency to the formation of red spots on the skin. ${ }^{3}$ The case offers many analogies to

' [Compare this with Darwin's remarks on "analogous variations," "Origin of Species," 6th ed., p. 125. R.M.] 
that of the colour varieties of Lacerta Muralis, to which Eimer ${ }^{4}$ briefly calls attention in his interesting communications on the blue lizard of the Faraglioni Rocks at Capri. The South Italian lizards, although having differently formed skulls, show the same brilliantly coloured varieties as those of North Italy; and Eimer believes that these parallel variations in widely separated localities, some of which have long been isolated, must be referred to a tendency towards fixed directions of variation innate in the constitution of the species.

I long ago insisted ${ }^{5}$ that it should not be forgotten that natural selection is, in the first place, dependent upon the variations which an organism offers to this agency, and that, although the number of possible variations may be very great for each species, yet this number is by no means to be considered as literally infinite. For every species there may be impossible variations. For this reason I am of opinion that the physical nature of each species is of no less importance in the

4 "Zoologische Studien auf Capri. II. Lacerta muralis cærula, ein Beitrag zur Darwin'schen Lehre." Leipzig, 1874 . [The subject of colour-variation in lizards has been much discussed in "Nature" since the publication of the abovementioned essay; see vol. xix., pp. 4, 53, 97, and 122, and vol. xx., pp. 290 and 480 . R M.]

- "Über die Berechtigung der Darwin'schen Theorie." Leipzig, I868. See also the previous essay "On the Seasonal Dimorphism of Butterflies," pp. I I2-I I6. 
production of new characters than natural selection, which must always, in the first place, operate upon the results of this physical nature, i.e. upon the variations presented, and can thus call new ones into existence.

It requires but a slight alteration of the definition to make out of this "restricted" or "limited variability," which is the necessary consequence of the physical nature of each species, a. "fixed direction of variation" in the sense of a phyletic vital force. Instead of-the Smerinthus-larvæ show a tendency to produce red spots on the skin, it is only necessary to say-these larvæ tend to produce red borders to the oblique stripes. The latter statement would, however, be incorrect, since the red borders first arose by the coalescence of red spots through the action of natural selection. It is not even correct to say that all the species of Smerinthus show this tendency to produce spots, since this character does not seem to occur either in S. Quercus or S. Tremula.

The distinction between the two modes of conception will become clear if we ask, as an example, whether those Charocampa-larvæ which do not at present possess eye-spots will subsequently acquire these markings, supposing that they maintain their existence on the earth for a sufficient period?

The supporters of a " fixed direction of variation "would answer this question in the affirmative. Ocelli constitute a character which occurs in nearly 
all the species of the group-they are the goal towards which the phyletic force is urging, and which must sooner or later be reached by each member of the group. On the other hand, I cannot express so decidedly my own opinion, viz., that such complicated characters as the manycoloured oblique stripes or eye-spots are never the results of purely internal forces, but always arise by the action of natural selection, i.e. by the combination of such minute and simple variations as may present themselves. It may be replied that the formation of eye-spots in those species which are at present devoid of them, cannot indeed be considered impossible, but that they would only appear if the constitution of these species had a tendency to give rise to the production of darker spots on the edge of the subdorsal line, and if, at the same time, the possession of eyespots would be of use to the caterpillar under its special conditions of life.

The condition of affairs would be quite different if we were simply concerned with the transference of a character from one segment on which it was already present, to the remaining segments. The transference would, in this case, result from causes purely innate in the organism - from the action of laws of equilibration or of growth (correlation), and the external conditions of life would play only a negative part, since they might prevent the complete reproduction of a character, such, for example, as 
eye-spots, on all the segments, in cases where it was disadvantageous to the species. The fact that our species of Charocampa have only faint indications, and not a completely-developed eye-spot, on the remaining segments, may perhaps be explained in this manner. It is conceivable that the two pairs of ocelli on the front segments are more effective as a means of alarm than if the insects were provided with two long rows of such markings; but nothing can be stated with certainty on this point until experiments have been made with caterpillars having rows of eye-spots.

The question raised above-whether the species of Charocampa at present devoid of eye-spots are to be expected to acquire this character in the course of their further phyletic developmentbrings with it another point, which cannot be here passed over.

If the utility of the four kinds of markings in their perfected form is demonstrated, their origination through natural selection is not, strictly speaking, thereby proved. It must also be shown that the first rudiments of these characters were also of use to their possessors. The question as to the utility of the " initial stages" of useful characters must here be set at rest.

In the case of markings such as longitudinal and oblique stripes, it is quite evident that the initial stages of these simple characters do not differ greatly from the perfected marking, but 
The Origin of the Markings of Caterpillars. 365

this is certainly not the case with eye- and ringspots. The most light is thrown upon this question by the latter, because a species which has remained at the initial stage of the formation of ring-spots here presents itself for examination, viz. Deilephila Hippophaës.

I have attempted to show that the orange-red spots, which, as a rule, adorn only the eleventh segment, enhance the adaptive colouring of this caterpillar by their resemblance to the berries of the sea-buckthorn, whilst the general surface resembles the leaves in colour. If this be admitted, the origination of these spots by natural selection offers no difficulty, since a smaller spot, or one of a fainter red, must also be of some use to its possessor.

This case is of importance, as showing that a " change of function" may occur in markings, just as it does in certain organs among the most diverse species of animals, in the course of phyletic development. The spots which in Hippophaës are imitations of red berries, in species which have further advanced phyletically play quite another part-they serve as means of alarm, or signals of distastefulness.

It appears to me very improbable, however, that the perfect ocelli of the Charocampa-larvæ have also undergone such a "functional change" (Dohrn). I rather believe that the first rudiments of these markings produced the same effect as that 
which they now exercise, viz., terror. We are certainly not so favourably circumstanced in this case in knowing a species which shows the initial steps of this character in its last stage of life; but in the initial steps which the second stage of certain species present, we see preserved the form under which the eye-spots first appeared in the phylogeny, and from this we are enabled to judge with some certainty of the effect which they must have produced at the time.

In the ontogeny of $C$. Elpenor and Porcellus we see that a small curvature of the subdorsal line first arises, the concavity of which becomes filled with darker green, and soon afterwards with black ; the upwardly curved piece of the subdorsal then becomes detached and more completely surrounded by black. The white fragment of the subdorsal which has become separated, in the next place broadens, and a black (dark) pupil appears in its centre.

Now the first rudiments of the eye-spot certainly appear very insignificant in a caterpillar two centimeters long, but we must not forget that in the ancestors of the existing Charocampa-larvæ this character appeared in the adult state. If we conceive the curvature of the white subdorsal with the underlying dark pigment to be correspondingly magnified, its importance as a means of alarm can scarcely be denied, particularly when we consider that this marking stands on the enlarged fourth seg- 
ment, which alone invests the caterpillar with a singular, and, to smaller foes, an alarming appearance. We know that in the case of those Charocampalarvæ which possess no eye-spots, the distension of this segment is employed against hostile attacks. (See the illustration of Darapsa Charilus, Pl. IV., Fig. 34.) Those markings which even only remotely resembled an eye must, in such a position, have increased the terrifying action. On these grounds I believe that it may be safely admitted, that this kind of marking possessed the same significance in its initial stages as it now does when fully perfected. No functional change has here taken place.

Among all the facts brought together in the first section I only know of one group of phenomena which at least permit of an attempt to refer them to a phyletic vital force. This is the occurrence of dark ground-colours in adult larvæ which are of light colours in their young condition. I have already attempted to show that in the Charocampa-larvæ this change of colour depends on a double adaptation, the young caterpillars being adapted to the green colour of the plant and the adults to the soil and dead leaves. This interpretation appears the more correct when we find the same process, viz. the gradual replacement of the original green by brown colours, among species of widely different genera, which, with the dark colouring, possess the necessarily 
correlated habit of hiding themselves by day when in the adult condition. This is the case with Sphinx Convolvuli, Deilephila Vespertilio, and Acherontia Atropos.

Thus far all has been easily explicable by natural selection; but when we also see a "tendency" to acquire a dark colour in the course of development, in those species which neither conceal themselves nor are adaptively coloured, but are very conspicuously marked-and if, further, it can be shown that these species, such for instance as Deilephila Galii, actually possess immunity from the attacks of foes, - - how can this tendency to the formation of a dark colour be otherwise explained than by the admission of a phyletic vital force urging the variations in this direction?

Nevertheless I believe that also on this point an appeal to unknown forces can be dispensed with. In the first place, dark ground-colours can be of use to a species otherwise than as means of adaptation. In D. Galii, as well as in D. Euphorbia, the light ring-spots appear rather at their brightest on the pitchy-black ground; and if this caterpillar must ( sit venia verbo!) become conspicuous, this purpose would be best attained by acquiring a dark ground-colour, such as that of D. Euphorbice.

The tendency, apparently common to all these Sphingida, to acquire a dark colour with increasing age, depends therefore on two quite distinct adap- 
The Origin of the Markings of Caterpillars. 369

tations-first, in species sought by enemies, on an adaptation to the colour of the soil; and secondly, in species rejected by foes, on the endeavour to produce the greatest possible contrast of colour.

Moreover, the supposition from which this last plea for a vital force set out is not universally correct, since there are species, such for instance as $D$. Nicaa, which never acquire a dark colour; and in $D$. Galii also, although all the individuals abandon the protective green of the young stages, they by no means all acquire a dark hue in exchange for this colour; many individuals in their light ochreous-yellow colouring rather strikingly resemble the snake-like caterpillar of $D$. Nicca. 


\section{VII.}

Phyletic Development of the Markings of the Sphingide: Summary and Conclusion.

IF, from the form possessed by many of the caterpillars of the Sphingida on their emergence from the egg, we may venture to draw a conclusion concerning the oldest phyletic stage, these larvæ were originally completely destitute of marking. The characteristic caudal horn must be older than the existing markings, since it is present in the younger stages (except in cases where it is altogether wanting), and is generally even larger than at a later age.

There is, however, further evidence that there were once Sphinx-larvæ without any markings. Such a species now exists. I do not mean the boring caterpillars of the Sesiida, ${ }^{1}$ which live in the dark, and are therefore colourless, but I refer to a

${ }^{1}$ [Mr. A. G. Butler has recently advanced the view that this family is not allied to the Sphingida, but is related on the one side to the Pyrales, and on the other to the Gelechiidla. See his paper "On the Natural Affinities of the Lepidopterous Family Ageriidce," Trans. Ent. Soc. 1878, p. I 2 I. R.M.] 
large larva (over six centimeters long) preserved in spirit in the Berlin Museum, ${ }^{2}$ which, from its form, belongs to the Smerinthus group. It possesses a caudal horn, and on the whole upper surface is covered with short and sparsely scattered bristles, such as occur in the Sesiida. The colour of this unknown insect appears to have been light green, although it now shows only a yellowish shade. Every trace of marking is absent, and it thus corresponds exactly with the youngest stages of the majority of the existing Sphinx-larvæ-even to the short bristles sparsely scattered over the whole upper surface of its body. We have therefore, so to speak, a living fossil before us, and it would be of great interest to ascertain its history.

All the data furnished by the developmental history go to show that of the three kinds of markings which occur in the Sphingida, viz., longitudinal and oblique stripes and spots, the first is the oldest. Among the species which are ornamented with oblique stripes or spots there are many which are longitudinally striped in their young stages, but the reverse case never occursyoung larvæ never show spots or oblique stripes when the adult is only striped longitudinally.

The first and oldest marking of the caterpillars of the Sphingida was therefore the longitudinal striping, or, more precisely speaking, the subdorsal,

${ }^{2}$ I am indebted to my esteemed colleague, Prof. Gestäcker, for the knowledge of this specimen. 
to which dorsal and spiracular lines may have been added. That this second stage of phyletic development has also been preserved in existing species has already been sufficiently shown; the greater portion of one group, the Macroglossina, has indeed remained at this stage of development.

From the biological value which must be attributed to this kind of marking, its origination by natural selection presents no difficulty. The first rudiments of striping must have been useful, since they must have broken up the large surface of the body of the caterpillar into several portions, and would thus have rendered it less conspicuous to its enemies.

Thus it is not difficult to perceive how a whole group of genera could have made shift with this low grade of marking up to the present time. Colour and marking are not the only means of offence and defence possessed by these insects ; and it is just such simply-marked larvæ as those of the Macroglossince which have the protective habit of feeding only at night, and of concealing themselves by day. Moreover, under certain conditions of life the longitudinal stripes may be a better means of protection, even for a Sphinx-larva, than any other marking; and all those species in which this pattern is retained at the present time live either among grasses or on Coniferce.

It cannot be properly said that the second form 
of marking-the oblique stripes-has been developed out of the first. If these had arisen by the transformation of the longitudinal stripes, the two forms could not exist side by side. This is the case, however, both in certain species in the adult state (Calymnia Panopus ${ }^{3}$ ), as well as in others during their young stages (most beautifully seen in Smerinthus Populi, Fig. 56). Various facts tend to show that the oblique stripes appeared in the phyletic development later than the longitudinal lines. In the first place they appear later than the latter in the ontogeny of certain species. This is the case with Charocampa Elpenor and Porcellus, in which, however, they certainly do not reach a high state of development. Then again, the longitudinal lines disappear completely in the course of the ontogeny, whilst the oblique stripes alone maintain their ground. Thus, the subdorsal line vanishes at a very early stage, with the exception of a small residue, ${ }^{4}$ in all native species of Smerinthus. I have already attempted to show that new characters are only acquired in the last stage, and that if still newer ones are then added, the former disappear from the last stage, and are transferred back to a younger one. Characters vanish therefore from a stage in the same order as they were acquired.

${ }^{3}$ Cat. Lep. East India Co., Pl. VIII,

${ }^{4}$ Such a residue is distinctly visible in S. Ocellatus; see Fig. 70, Pl. VII. 
Finally, among the genera with longitudinal stripes (e.g. Macroglossa) we know certain species which, when at an advanced age, possess oblique stripes (M. Fuciformis), although these slant in a direction opposite to those of most of the other larvæ of the Sphingida. These are, however, always species which differ from their allies in their mode of life, not feeding on grasses or low plants, but on large-leaved shrubs. If we were able to ascertain the ontogeny of these species, we should find that the oblique stripes appeared late in life, as has already been shown in the case of Pterogon Enothere.

If it be asked why the longitudinal lines were. first formed, and then the oblique stripes, it may be replied that the physical constitution of these caterpillars would be more easily able to give rise to simple longitudinal lines than to complicated oblique stripes crossing their segments. ${ }^{5}$ It may

- [The question here also suggests itself as to why the dorsal line should not have been the primary longitudinal stripe, seeing that such a marking is almost naturally produced in many caterpillars by the food in the alimentary canal ; or, in other words, why has not natural selection taken advantage of such an obvious means of producing a stripe in cases where it would have been advantageous? In answer to this I may state, that in large numbers of species the dorsal line has thus become utilized; but in the case of large caterpillars resting among foliage, it can be easily seen that light lateral (i.e. subdorsal) stripes, are more effective in breaking the homogeneity of the body than a dorsal line only slightly darker than the general ground-colour. Lateral lines are in fact visible from 
perhaps also be suggested that the oldest Sphingide lived entirely on low plants among grasses, and in the course of time gradually took to shrubs and trees. At the present time the majority of the Sphinx-larvæ still live on low plants, and but few on trees, such caterpillars generally belonging to certain special genera.

The character of oblique stripes becomes perfected by the addition of coloured edges, the latter, as is self-evident, having been added subsesequently.

The third chief constituent of the Sphinx-markings, i.e. the spots-whether perfect ocelli or only ring-spots-in two of the special genera here considered, arise on the subdorsal, where they are either deposited (Deilephila), or built up from a fragment of this line (Charocampa). That these markings can, however, also originate independently of the subdorsal, is shown by the ocellus of Pterogon Enothera, situated on the segment bearing the caudal horn. In this case, however, the ontogeny teaches us that the spot also succeeds the subdorsal, so that we can state generally that all these spot-markings are of later origin than the longitudinal striping.

two directions of space. If a caterpillar thus marked be placed on a twig, these lines are visible when we look at the creature's back or at either side. That the subdorsal are therefore the primary lines, as shown by Dr. Weismann's observations of the ontogeny of many of the Sphingida, is quite in harmony with the view of their having been produced by natural selection. R.M.] 
The question as to the relative ages of the oblique stripes and the spot-marking does not admit of a general answer. In some cases $(C$. Elpenor and Porcellus) the oblique stripes disappear when the ocelli reach complete development, and we may therefore venture to conclude that in these cases the former appeared earlier in the phylogeny. But it is very probable that oblique stripes arose independently at different periods, just as longitudinal lines occur irregularly in quite distinct families. It would be a great error if we were to ascribe the possession of oblique stripes solely to descent from a common ancestor. The oblique markings found on certain species of Macroglossa (M. Corythus from India) have not been inherited from a remote period, but have been independently acquired by this or by some recent ancestral species. They have nothing to do genetically with the oblique stripes which occur in some species of Charocampa (e.g. in C. Nessus, from India), or with those of the species of Smerinthus and Sphinx. They depend simply on analogous adaptation (Seidlitz ${ }^{6}$ ), i.e. on adaptation to an analogous environment.

The case is similar with the spot-markings. I have already shown that under certain conditions ring-spots may assume the exact appearance of

- "Die Darwin'sche Theorie. Elf Vorlesungen über die Entstehung der Thiere und Pflanzen durch Naturzüchtung." and ed., Leipzig, I875, p. 195. 
eye-spots by the formation of a nucleus in the " mirror," such as occurs occasionally in Deilephila Euphorbice (Fig. 43), more frequently in D. Galii, and as a rule in $D$. Vespertilio. Nevertheless, these markings arise in quite another manner to the eye-spots of the Charocampince, with which they conseqently have no genetic relation; the two genera became separated at a time when they neither possessed spot-markings. Further, in Pterogon Enothere we find a third kind of spotmarking, which is most closely allied to the ocelli of the Charocampa-larvæ, but is situated in quite another position, and must have originated in another manner, and consequently quite independently of these eye-spots.

It can also be readily understood why the first and second elements of the markings of the Sphingidee should be mutually exclusive, and not the second and third or the first and third.

A light longitudinal line cutting the oblique stripes, considerably diminishes that resemblance to a leaf towards which the latter have a tendency, and it is therefore only found in cases where an adaptive marking can be of no effect on account of the small size of the caterpillar, i.e. in quite young stages. (See, for instance, Fig. 56, the first stage of $S$. Populi.) At a later period of life the old marking must give way to the new, and we accordingly find that the subdorsal line vanishes from all the segments on which oblique stripes are situated, 
and is only retained on the anterior segments where the latter are wanting. In some few cases both elements of marking certainly occur together, such as in Calymnia Panopus and Macroglossa Corythus; but the oblique stripes are, under these circumstances, shorter, and do not extend above the subdorsal line, and in Darapsa Chorilus even become fused into the latter. ${ }^{7}$

In certain cases there may also be a special leaf structure imitated by the longitudinal lines, but on the whole the latter diminish the effect of the oblique stripes; and we accordingly find that not only has the subdorsal disappeared from those segments with oblique stripes, but that most larvæ with this last character are also without the otherwise broad spiracular and dorsal lines. This is the case with all the species of $S_{m e r i n t h u s}{ }^{8}$ known

' [In the following species, already mentioned in previous notes, the oblique stripes are bounded at their upper extremities by a conspicuous subdorsal line :-Acosmeryx Anceus, Cram.; Sphinx Cingulata, Fabr. ; Pachylia Ficus, Linn.; P. Syces, Hubn. In Pseudosphinx Cyrtolophia, Butl., the oblique white stripes, beautifully shaded with pink, run into the white pink-bordered dorsal line, so that when seen from above the markings present the appearance of the midrib and lateral veins of a leaf, and are probably specially adapted for this purpose. R.M.]

${ }^{8}$ [The dorsal line as well as the oblique stripes is present in the caterpillar of Smerinthus Tartarinovii, Ménét.; and in Ambulyx Gannascus, Stoll., the oblique stripes are bounded above by a subdorsal line, as in the species named in the preceding note. R.M.] 
to me, as well as with all the species of the genera Sphinx, Dolba, and Acherontia.

Oblique stripes and spot-markings are not, however, necessarily mutually exclusive in their action, and we also find these in certain cases united in the same larva, although certainly never in an equal state of perfection. Thus, Charocampa Nessus ${ }^{9}$ possesses strongly marked oblique stripes, but feebly developed ocelli; and, on the other hand, Cherocampa Elpenor shows strongly developed eye-spots, but the earlier oblique stripes are at most only present as faint traces. This is easily explained by the mode of life. These caterpillars-at least such of them as are perfectly known-do not live on plants with large, stronglyribbed leaves, and are even in the majority of individuals adapted to the colour of the soil; the oblique stripes have therefore in these cases only the significance of rudimentary formations.

That the first and third forms of markings also are not always mutually prejudicial in their action is shown by the case of Charocampa Tersa, in which the eye-spots certainly appear to possess some other significance than as a means of causing terror. In most of the Charocampa-larvæ the subdorsal line disappears in the course of the phylogeny, and it can be understood that the illusive appearance of the eye-spots would be

${ }^{9}$ Cat. Lep. East India Co., Pl. XI. 
more perfect if they did not stand upon a white line.

If we consider the small number of facts with which I have here been able to deal, the result of these investigations will not be deemed unsatisfactory. It has been possible to show that each of the three chief elements of the markings of the Sphingida have a biological significance, and their origin by means of natural selection has thus been made to appear probable. It has further been possible to show that the first rudiments of these markings must also have been of use; and it thus appears to me that their origin by means of natural selection has been proved to demonstration. Moreover, it has not been difficult to understand the displacement of the primary elements of the markings by secondary characters added at a later period, as likewise an essential effect of natural selection. Finally, it has been possible to explain also the subordinate or accessory elements of the markings, partly by the action of natural selection, and partly as the result of markings formerly present acting by correlation.

From the origin and gradual evolution of the markings of the Sphingida we may accordingly sketch the following picture :-

The oldest Sphinx-larvæ were without markings; they were probably protected only by adaptive colouring, and a large caudal horn, and by being armed with short bristles. 
The Origin of the Markings of Caterpillars. $38 \mathrm{I}$

Theit successors, through natural selection, became longitudinally striped ; they acquired a sub-. dorsal line extending from the horn to the head, as well as a spiracular, and sometimes also a dorsal, line. The caterpillars thus marked must have been best hidden on those plants in which an arrangement of parallel linear parts predominated; and we may venture to suppose that at this period most of the larvæ of the Sphingida lived on or among such plants (grasses).

At a later period oblique stripes were added to the longitudinal lines, the former (almost always) slanting across the seven hindmost segments from the back towards the feet in the direction of the caudal horn. Whether these stripes all arose simultaneously, or, as is more probable, whether only one at first appeared, which was then transferred to the other segments by correlation assisted by natural selection, cannot, at least from the facts available, at present be determined.

On the whole, as the oblique stripes became lengthened towards the back, the longitudinal lines disappeared, since they injured the deceptive effect of the stripes. In many species also there were formed dark or variegated coloured edges to the oblique stripes, in imitation of the shadow lines cast by the leaf-ribs.

Whilst one group of Sphingida (Sphinx, Smerinthus) were thus striving to make their external appearance approximate more and more to that of 
a ribbed leaf, others of the longitudinally striped species became developed in another manner.

Some of the latter lived indeed on bush-like leaved plants, but no oblique stripes were developed, because these would have been useless among the dense, narrow, and feebly-ribbed leaves of the food-plants. These caterpillars, from the earlier markings, simply retained the longitudinal lines, which, combined with a very close resemblance to the colour of the leaves, afforded them a high degree of protection against discovery. This protection would also have been enhanced if other parts of the food-plant, such as the berries (Hippophaës), were imitated in colour and position in such a manner that the large body of the caterpillar contrasted still less with its environment. In this way the first ring-spot probably arose in some species on only one-the penultimate segment.

As soon as this first pair of ring-spots had become an established character of the species, they had a tendency to become repeated on the other segments, advancing from the hind segments towards the front ones. Under certain conditions this repetition of the ring-spots might have been of great disadvantage to the species, and would therefore have been as far as possible prevented by natural selection (Hippophaës); in other cases, however, no disadvantage would have resulted-the caterpillar, well adapted to the colour of its foodplant, would not have been made more conspicuous 
The Origin of the Markings of Caterpillars. 383

by the small ring-spots, which might thus have become repeated on all the segments (Zygophylli). In cases like the two latter, striking colours must have been eliminated when inherited from an immediate ancestor; but on this point nothing can as yet be said with certainty.

In other cases the repetition of the ring-spots with strongly contrasted colours was neither prejudicial nor indifferent, but could be turned to the further advantage of the species. If a caterpillar fed on plants containing acrid juices (Euphorbiacea) which, by permeating its alimentary system, rendered it repulsive to other animals, the ring-spots commencing to appear (by repetition) would furnish an easy means for natural selection to adorn the species with brilliant colours, which would protect it from attack by acting as signals of distastefulness.

But if the dark spots stood on a light ground (Nicae), they would present the appearance of eyes, and cause their possessors to appear alarming to smaller foes.

From the developmental histories and biological data at present before us, it cannot with certainty be said which of these two functions of the ringspots was first acquired in the phylogeny, but we may perhaps suppose that their significance as a means of causing alarm was arrived at finally.

It may also be easily conceived that as the ringspots became more and more complicated, they 
would occasionally have played other parts, being fashioned once again in these stages into imitations of portions of plants, such as a row of berries or flower-buds. For this, however, there is as yet no positive evidence.

As the ring-spots became detached from the subdorsal line out of which they had arisen, the latter disappeared more and more completely from the last ontogenetic stage, and receded towards the younger stages of life of the caterpillar -it became historical. This disappearance of the subdorsal may also be explained by the fact that the original longitudinal stripe imitating the linear arrangement of leaves would become meaningless, even if it did not always diminish the effect of the ring-spots. But characters which have become worthless are known in the course of time to become rudimentary, and finally to disappear altogether. I do not believe that disuse alone causes such characters to vanish, although in the case of active organs it may have a large share in this suppression. With markings it cannot, however, be a question of use or disuse-nevertheless they gradually disappear as soon as they become meaningless. I consider this to be the effect of the arrest of the controlling action of natural selection upon these characters (suspension of the so-called "conservative adaptation," Seidlitz). Any variations may become of value if the character concerrued is met with in the necessary state of 
The Origin of the Markings of Caterpillars. 385

fluctuation. That this process of extinction does not proceed rapidly, but rather with extreme slowness, is seen in the ontogeny of several species of Deilephila, which retain the now meaningless subdorsal line through a whole series of stages of life.

In another group of Sphinx-larvæ with longitudinal stripes, an eye-spot became developed independently of the subdorsal line, in the position of the caudal horn, which has here vanished with the exception of a small knob-like swelling. This character-which we now see perfected in Pterogon Enotherc-undoubtedly serves as a means of causing terror; but whether the incipient stages possessed the same significance, cannot be decided in the isolated case offered by the one species of the genus Pterogon possessing this marking.

In a third group of longitudinally striped caterpillars, the younger genus Charocampa, eye-spots were developed directly from portions of the subdorsal line, at first only on the fourth and fifth segments. It can be here positively asserted that this character served as a means of alarm from its very commencement. It is certainly for this reason that we see the subdorsal line in the immediate neighbourhood of the spots disappear at an early stage, whilst it is retained on the other segments for a longer period. A portion of the younger (tropical) species of this group then developed similar, or nearly similar, ocelli on the remaining

C C 
segments by correlation; and it may now have occurred that in solitary cases the eye-spots acquired another significance (C. Tersa ?), becoming of use as a disguise by resembling berries or flower-buds. It is also conceivable that the eyespots may in other cases have been converted into a warning sign of distastefulness.

In all those larvæ which possessed purely terrifying markings, however, not only was the original protective colouring preserved, but in most of them this colour gradually became replaced by a better one (adaptation of the adult larva to the soil). The oblique stripes imitating the leaf-ribs also are by no means lost, but are almost always present, although but feebly developed, and often only temporarily.

The pattern formed by the oblique stripes may also be retained, even with perfect adaptation to the soil, and may be converted to a new use by losing its sharpness, and, instead of imitating definite parts of plants, may become transformed into an irregular and confused marking, and thus best serve to represent the complicated lights and shadows, stripes, spots, \&c., cast on the ground under low-growing plants from between the stems and dead leaves.

Just as in the case of ocellated species where caterpillars without eye-spots may retain and newly utilize their older markings, so larvæ havingoblique stripes with the most diversely coloured edges may 
show the same markings in allied (younger?) species, both in a rudimentary and in a transformed condition. These markings may thus contribute to the formation of a latticed or reticulated pattern. Even the oldest marking, the subdorsal line, may still play a part, since its remnants cause certain portions of the complicated pattern to appear more strongly marked ( $S$. Convolvuli). Finally, when an adaptation to a changing environment intersected by lights and shadows is required, new markings may be here added as in other cases, viz., dark streaks extending over the light surface of the whole caterpillar.

In concluding this essay, I may remark that, with respect to the wide and generally important question which gave rise to these investigations, a clearer and simpler result has been obtained than could have been expected, considering the complexity of the characters requiring to be traced to their causes, as well as our still highly imperfect knowledge of ontogenetic and biological facts.

For a long time I believed that it was not possible to trace all the forms of marking and their combinations to those causes which are known to produce transformation; I expected that there would be an inexplicable residue.

But this is not the case. Although it cannot yet be stated at first sight with certainty in every single instance how far any particular element of marking may have a biological value in the species 
possessing it, nevertheless it has been established that each of the elements of marking occurring in the larvæ of the Sphingida originally possessed a decided biological significance, which was produced by natural selection.

In the case of the three chief elements of the markings of the Sphingida, it can be further shown that not only the initial stages but also their ultimate perfection-the highest stages of their development, are of decided advantage to their possessors, and have a distinct biological value, so that the gradual development and improvement of these characters can be traced to the action of natural selection.

But although natural selection is the factor which has called into existence and perfected the three chief forms and certain of the subsidiary markings, in the repetition of the local character on the other segments, as well as in the formation of new elements of marking at the points of intersection of older characters now rudimentary, we can recognize a second factor which must be entirely innate in the organism, and which governs the uniformity of the bodily structure in such a manner that no part can become changed without exerting a certain action on the other parts-an innate law of growth (Darwin's " correlation ").

Only once during the whole course of the investigations was it for an instant doubtful whether a phyletic vital force did not make itself apparent, 
The Origin of the Markings of Caterpillars. 389

viz., in the red spots accompanying the oblique stripes in several Smerinthus-larvæ. Closer analysis, however, enabled us to perceive most distinctly the wide gulf that separates "analogous variation" from the mystic phyletic vital force. Nothing further remains therefore for the action of this force in respect to the marking and colouring of the Sphingida, since several even of the subordinate markings can be traced to their causes, only the "dorsal spots" of our two native species of Charocampa having been referred to correlation without decided proof. From the temporary inability to explain satisfactorily such an insignificant detail, no one will, however, infer the existence of such a cumbrous power as a phyletic vital force.

The final result to which these investigations have led us is therefore the following:-The action of a phyletic vital force cannot be recognized in the marking and colouring of the Sphingida; the origination and perfection of these characters depend entirely on the known factors of natural selection and correlation. 


\section{II.}

ON PHYLETIC PARALLELISM IN METAMORPHIC SPECIES.

\section{INTRODUCTION.}

IN the previous essay I attempted to trace a whole group of apparently "purely morphological" characters to the action of known factors of transformation, to explain them completely by these factors, and in this manner I endeavoured to exclude the operation of an internal power inciting change (phyletic vital force).

In this second study I have attempted to solve the problem as to whether such an innate inciting power can be shown to exist by comparing the forms of the two chief stages of metamorphic species, or whether such a force can be dispensed with.

Nobody has as yet apparently entertained the idea of testing this question by those species which appear in the two forms of larva and imago (insects), or, expressed in more general terms, by those species the individuals of which successively possess quite different forms (metamorphosis), or 
in which the different forms that occur are distributed among different individuals alternating with and proceeding from one another (alternation of generation). Nevertheless, it is precisely here that quite distinct form-relationships would be expected according as the development of the organic world depended on a phyletic vital force, or was simply the response of the specific organism to the action of the environment.

Assuming the first to be the case, there must have occurred, and must still occur, what I designate "phyletic parallelism," i.e. the two stages of metamorphic species must have undergone a precisely parallel development-every change in the butterfly must have been accompanied or followed by a change in the caterpillar, and the systematic groups of the butterflies must be also found in a precisely corresponding manner in a systematic grouping of the caterpillars. If species are able to fashion themselves into new forms by an innate power causing periodic change, this re-moulding cannot possibly affect only one single stage of development-such as the larva only-but would rather extend, either contemporaneously or successively, to all stages-larva, pupa, and imago: each stage would acquire a new form, and it might even be expected that each would change to the same extent. At least, it cannot be perceived why a purely internal force should influence the development of one stage more than that of 
another. The larvæ and imagines of two species must differ from one another to the same extent, and the same must hold good for the larvæ and imagines of two genera, families, and so forth. In brief, a larval system must completely coincide with the system based entirely on imaginal characters, or, what amounts to the same thing, the form-relationships of the larvæ must correspond exactly with the form-relationships of the imagines.

On the other hand, the condition of affairs must be quite different if an internal power causing phyletic remodelling does not exist, the transformation of species depending entirely on the action of the environment. In this case dissimilarities in the phyletic development of the different stages of life must be expected, since the temporary, and often widely deviating, conditions of life in the two stages can and must frequently influence the one stage whilst leaving the other unacted uponthe former can therefore undergo remodelling while the latter remains unchanged. ${ }^{1}$

"[Compare this with Darwin's "Origin of Species". (Ist. ed. p. 440), where it is stated that when an animal, during any part of its embryonic career, is active, and has to provide for itself, "the period of activity may come on earlier or later in life; but whenever it comes on, the adaptation of the larva to its conditions of life is just as perfect and beautiful as in the adult animal. From such special adaptations the similarity of the larvæ or active embryos of allied animals is sometimes much obscured." R.M.] 
Phyletic Parallelism in Metamorphic Species. 393

By this means there would arise an unequal difference between the two stages of two species. Thus, the butterflies, supposing these to have become changed, would bear a more remote formrelationship to each other than the caterpillars, and the differences between the former (imagines) would always be greater than that between the larvæ if the butterflies were, at several successive periods, affected by changing influences whilst the larvæ continued under the same conditions and accordingly remained unaltered. The two stages would not coincide in their phyletic developmentthe latter could not be expressed by parallel lines, and we should accordingly expect to find that there was by no means a complete congruity between the systems founded on the larval and imaginal characters respectively, but rather that the caterpillars frequently formed different systematic groups to the butterflies. ${ }^{2}$

Accordingly, the problem to be investigated was whether in those species which develope by means of metamorphosis, and of which the individual stages exist under very different conditions of life, a complete phyletic parallelism was to be found or not. This cannot be decided directly since we cannot see the phyletic development unfolded under our observation, but it can be

2 [For Fritz Müller's application of this principle to the case of certain groups of Brazilian butterflies see Appendix II. to this Part. R.M.] 
established indirectly by examining and comparing with each other the form-relationships of the two separate stages-by confronting the larval and imaginal systematic groups. If the phyletic development has been parallel and perfectly equal, so also must its end-results - the forms at present existing-stand at equal distances from one another; larval and imaginal systems must coincide and be congruent. If the course of the phyletic development has not been parallel, there must appear inequalities-incongruences between the two systems.

I am certain that systematists of the old school will read these lines wlth dismay. Do we not regard it as a considerable advance in taxonomy that we have generally ceased to classify species simply according to one or to some few characters, and that we now take into consideration not merely the last stage of the development (the imago), but likewise the widely divergent young stages (larva and pupa)? And now shall it not be investigated whether caterpillars and butterflies do not form quite distinct systems? In the case of new species of butterflies of doubtful systematic position was not always the first question:-what is the nature of the caterpillars? and did not this frequently throw light upon the relationships of the imago? Assuredly; and without any doubt we have been quite correct in taking the larval structure into consideration. But in so doing we 
should always keep in mind that there are two kinds of relationship-form- and blood-relationship-which might possibly not always coincide.

It has hitherto been tacitly assumed that the degree of relationship between the imagines is always the same as that between the larvæ, and if blood-relationship is spoken of this must naturally be the case, since the larva and the imago are the same individual. ' In all groups of animals we have not always the means of deciding strictly between form- and blood-relationship, and must accordingly frequently content ourselves by taking simply the form-relationship as the basis of our systems, although the latter may not always express the blood-relationship. But it is exactly in the case of metamorphic species that there is no necessity for, nor ought we to remain satisfied with, this mode of procedure, since we have here two kinds of form-relationship, that of the larvæ and that of the imagines, and, as I have just attempted to show, it is by no means self-evident that these always agree; there are indeed already a sufficient number of instances to show that such agreement does not generally exist.

This want of coincidence is strikingly shown in a group of animals widely remote from the Insecta, viz. the Hydromedusæ, the systematic arrangement of which is quite different according as this is based on the polypoid or on the medusoid generation. Thus, the medusoid family of the oceanic 
Hydrozoa springs from polypites belonging to quite different families, and in each of these polypoid families there are species which produce Meduse of another family.

Similarly, the larvæ of the Ophiuroidea (Pluteusform) among the Echinodermata are not the most closely related in form to those of the ordinary star-fishes, but rather to the larvæ of quite a distinct order, the sea-urchins.

I will not assert that in these two cases the dissimilarity in the form-relationship, or, as I may designate it, the incongruence of the morphological systems, must depend on an unequal rate of phyletic development in the two stages or generations, or that this incongruence can be completely explained by the admission of such an unequal rate of development: indeed it appears to me probable that, at least in the Ophiurea, quite another factor is concerned-that the form-relationship to the larvæ of the sea-urchins does not depend upon bloodrelationship, but on convergence (Oscar Schmidt), i.e. on adaptation to similar conditions of life. These two cases, however, show that unequal form-relationship of two stages may occur.

From such instances we certainly cannot infer off-hand that a phyletic force does not exist; it must first be investigated whether and to what extent such dissimilarities can be referred tounequal phyletic development and, should this be the case, whether deviations from a strict congruence of the 
morphological systems are not compatible with the admission of an internal transforming power. That a certain amount of influence is exerted by the environment on the course of the processes of development of the organic world, will however be acceded to by the defenders of the phyletic vital force. It must therefore be demonstrated that deviations from complete congruence occur, which, from their nature or magnitude, are incompatible with the admission of innate.powers, and, on the other hand, it must likewise be attempted to show that the departures from this congruence as well as the congruence itself can be explained without admitting a phyletic vital force.

In the following pages I shall attempt to solve this question for the order Lepidoptera, with the occasional assistance of two other orders of insects. Neither the Echinodermata nor the Hydromedusæ are at present adapted to such a critical examination; the number of species in these groups of which the development has been established with certainty is still too small, and their biological conditions are still to a great extent unknown. In both these respects they are far surpassed by the Lepidoptera. In this group we know a large number of species in the two chief stages of their development and likewise more or less exactly the conditions under which they exist during each of these phases. We are thus able to judge, at least to a certain extent, what changes in the conditions 
of life produce changes of structure. Neither in the number of known species of larvæ, nor in the intimate knowledge of their mode of life, can any of the remaining orders of insects compete with the Lepidoptera. There is no Dipterous or Hymenopterous genus in which ten or more species are so intimately known in the larval stage that they can be employed for the purposes of morphological comparison. Who is able to define the distinctions between the life-conditions of the larvæ of twenty different species of Culex or of Tipula? The caterpillars of closely allied species of Lepidoptera, on the other hand, frequently live on different plants, from which circumstance alone a certain difference in the life-conditions is brought about.

The chief question which the research had to reply to was the following:-Does there exist a complete phyletic parallelism among Lepidoptera or not? or, more precisely speaking:-Can we infer, from the form-relationships which at present exist between larvæ on the one hand and imagines on the other, an exactly parallel course of phyletic development in both stages; or do incongruences of form-relationship exist which point to unequal development?

Before I proceed to the solution of this question it is indispensable that one point should be cleared up which has not been hitherto touched upon, but which must be settled before the problem can be formally stated in general terms. Before 
it can be asked whether larvæ and imagines have undergone a precisely parallel development, we must know whether unequal development is possible-whether there does not exist such an intimate structural relationship between the two stages that every change in one of these must bring about a change in the other. Were this the case, every change in the butterfly would cause a correlative change in the caterpillar, and vice versâ, so that an inequality of form-relationship between the larvæ on one hand and the imagines on the other would be inconceivable-systems based on the characters of the caterpillars would completely coincide with those based on the characters of the butterflies and we should arrive at a false conclusion if we attributed the phyletically parallel development of the two stages to the existence of an internal phyletic force, whilst it was only the known factor, correlation, which caused the equality of the course of development.

For these reasons it must first be established that the larva and imago are not respectively fixed in form, and the whole of the first section will therefore be devoted to proving that the two stages change independently of one another. Conclusions as to the causes of change will then be drawn, and these will corroborate from another side a subsequent inquiry as to the presence or absence of complete congruence in the two morphological systems. The two questions the answers to which will be 
successively attempted are by no means identical, although closely related, since it is quite conceivable that the first may be answered by there being no precise correlation of form, or only an extremely small correlation, between the caterpillar and the imago, whilst, at the same time, it would not be thereby decided whether the phyletic development of the two stages had kept pace uniformly or not. A perfect congruence of morphological relationships could only take place if transformations resulted from an internal power instead of external influences. The question:Does there exist a fixed correlation of form between the two stages? must therefore be followed by another:-Do the form-relationships of the two stages coincide or not-has their phyletic development been uniform or not? 

WEISMANN, AUGUST

Studies in the theory of descent.

$$
\begin{gathered}
\text { QH } \\
366 \\
. W 43 \\
\text { v.1 }
\end{gathered}
$$


